\title{
THE ROLE OF TREE HEIGHT AND WOOD DENSITY FOR THE WATER USE, PRODUCTIVITY AND HYDRAULIC ARCHITECTURE OF TROPICAL TREES
}

\author{
Dissertation \\ zur Erlangung des mathematisch-naturwissenschaftlichen Doktorgrades \\ "Doctor rerum naturalium" \\ der Georg-August-Universität Göttingen
}

im Promotionsprogramm

Biodiversity, Ecology and Evolution

der Georg-August University School of Science (GAUSS)

vorgelegt von

Roman Mathias Link

aus Wiesbaden

Göttingen, 2020 


\section{Betreuungsausschuss:}

- Prof. Dr. Christoph Leuschner, Abteilung Pflanzenökologie und Ökosystemforschung, Universität Göttingen

- Prof. Dr. Bernhard Schuldt, Lehrstuhl für Ökophysiologie und Vegetationsökologie, Universität Würzburg

- Prof. Dr. Steven Jansen, Institut für Systematische Botanik und Ökologie, Universität Ulm

\section{Mitglieder der Prüfungskommission:}

- Referent: Prof. Dr. Christoph Leuschner, Abteilung Pflanzenökologie und Ökosystemforschung, Universität Göttingen

- Korreferent: Prof. Dr. Bernhard Schuldt, Lehrstuhl für Ökophysiologie und Vegetationsökologie, Universität Würzburg

- Weitere Mitglieder der Prüfungskommission

- Prof. Dr. Dirk Hölscher, Abteilung Waldbau und Waldökologie der Tropen, Universität Göttingen

- Prof. Dr. Holger Kreft, Abteilung Biodiversität, Makroökologie und Biogeographie, Universität Göttingen

- Prof. Dr. Hermann Behling, Abteilung Palynologie und Paläoökologie, Universität Göttingen

- Prof. Dr. Erwin Bergmeier, Abteilung Vegetationsanalyse und Phytodiversität, Universität Göttingen

Tag der mündlichen Prüfung: 19. Februar 2020 


\section{General abstract}

Tropical forests are the world's most productive terrestrial ecosystems and of central importance for global carbon and water cycles. Global climate projections predict increases in average temperature and an elevated frequency of extreme drought events throughout large parts of the tropics. In response to these changes, increases in mortality rates particularly among large trees have already been reported for many tropical forest ecosystems.

Hence, there is a need for better predictions of the performance of tropical forest trees under more frequent drought conditions, which the present work seeks to address a) by more accurately quantifying how much water plants use and b) by advancing the knowledge about plant traits and mechanisms that control plant water use, growth performance and drought responses. To achieve this, this study is separted two parts, the first of which aims at methodological improvements of water use and transpiration estimates, while the second part focuses on disentangling the relationship between tree height, wood density and wood anatomical properties, and quantifying their common effect on the productivity and water relations.

The backbone of this thesis is formed by data from a field study on five research sites situated on a rainfall gradient along the Pacific coastline of Costa Rica, which are complemented by additional results from a laboratory-based study of sap flux sensor performance and a large observational dataset from tropical forests in Indonesia.

In Part I, I first present accessory results from a laboratory-based calibration experiment based on 66 stems from five temperate diffuse-porous tree species. Three commonly applied sensor systems, thermal dissipation probes (TDP), heat field deformation (HFD) sensors, and heat ratio method (HRM) sensors, were validated against gravimetrically determined flow rates to compare them in terms of bias, precision and accuracy. Our results indicate a systematic underestimation of true sap flux density by on average $23-45 \%$ with the TDP method, and a relatively low precision (but lower bias) with HFD sensors. The best performance was observed for HRM sensors if restricted to low flow ranges. Based on the methods comparison, we conclude that the TDP and HFD methods require speciesspecific empirical calibration for optimal performance, and that for all methods there is a within-species variability in calibration relationships that puts a limit on accuracy.

In the light of these findings, I then discuss the outcome of a field study of sap flux measurements using the HFD method. In this work, we analyzed a dataset of sap flow measurements from 38 trees belonging to eight tropical dry forest tree species from Costa Rica. Based on a Bayesian hierarchical modelling approach, we developed a model for radial sap flux profiles that allowed to propagate model uncertainty when predicting the shape of HFD-based radial profiles onto new trees and new tree species, and describe how to integrate these model predictions with single-point sensor readings from other sensor systems in order to improve their accuracy. We found that tree height had a credible effect on both the shape of radial profiles and whole-tree water use, with larger trees having the bulk of flow closer to the bark and reaching higher transpiration rates. Compared to water use estimates based on radial profiles, estimates that assumed constant flow over the entire 
sapwood overestimated water use by $26 \%$ on average.

In Part II, I first show results from a dataset comprising trait averages from 99 tropical forest tree species from Sumatra and Sulawesi (Indonesia). In this study, we used structural equation models (SEM) to analyze the relationships between tree size, wood density, wood anatomical traits related to hydraulic efficiency, empirically determined sap flux density, biomass productivity and tree water use, and compared the results to simple bivariate associations. We found a strong correlation between water use and growth, which was completely explained by their common dependence on tree size and sap flux density. While wood hydraulic traits were closely associated with growth and water use, our model suggested that this relationship was mainly driven by a confounding size effect. After accounting for tree size, only a relatively small effect of wood properties remained that was mediated by sap flux density.

I then present a second SEM-based study that builds upon data from 201 tropical rainforest trees belonging to 40 species distributed along the rainfall gradient in Costa Rica. In this study, we found a strong dependence of biomass increment from canopy position and tree diameter, while the effects of wood density and wood hydraulic traits diminished after controlling for size effects. Notably, differences in growth along the rainfall gradient were completely explained by the effect of annual precipitation on canopy height. We further found trees belonging to species that are more affiliated to drier habitats to have smaller sapwood nonstructural carbohydrate concentrations and to be more common in the upper canopy.

Supplementary, unpublished results from an analysis of vulnerability curves measured from Costa Rican tropical rainforest trees indicate that the strong size effect in growth, water use and wood hydraulic trees surprisingly was mirrored by a size dependence in embolism resistance, with the highest embolism resistance in the largest and most fastgrowing species. In addition, we found embolism resistance to be strongly associated with stem sapwood properties, with a significantly higher embolism resistance for species with harder wood and lower vessel diameters.

In summary, the present work provides a set of methodological refinements to sap flow measurement methodology that has the potential to significantly improve the accuracy of tree level transpiration estimates. In addition, it adds to the growing body of evidence indicating that tree size and/or canopy position are important covariates that have to be controlled for when studying relationships between plant traits. In particular, we show that observed positive correlations of biomass increment and water use with wood properties can largely be attributed to a confounding size effect, which suggests that the functional importance of wood anatomical traits may often be overstated. 


\section{Publications presented in this work}

\section{Part I}

Chapter 3 Fuchs S, Leuschner C, Link RM, Coners H, Schuldt B. 2017. Calibration and comparison of thermal dissipation, heat ratio and heat field deformation sap flow probes for diffuse-porous trees. Agricultural and Forest Meteorology 244-245: 151161.

Chapter 4 Link RM, Fuchs S, Arias Aguilar D, Leuschner C, Castillo Ugalde M, Valverde Otarola JC, Schuldt B. In press. Tree height predicts the shape of radial sap flow profiles of Costa-Rican tropical dry forest tree species. Agricultural and Forest Meteorology.

\section{Part II}

Chapter 5 Kotowska M,Link RM, Röll A, Hertel D, Hölscher D, Leuschner C, Waite PA, Moser G, Tjoa A, Schuldt B. Submitted to Journal of Ecology. Disentangling the functional drivers of water use and productivity in tropical rainforest trees

Chapter 6 Link RM, Hartmann H, Arias Aguilar DA, Valverde Otarola JC, Castillo Ugalde M, Schuldt B. In preparation. Do wood anatomical traits predict the productivity of Costa Rican tropical forest trees?

\section{Additional work published during my doctorate}

\section{Peer reviewed publications}

Link RM, Schuldt B, Choat B, Jansen S, Cobb AR. 2018. Maximum-likelihood estimation of xylem vessel length distributions. Journal of Theoretical Biology 455: 329-341.

Waite P-A, Schuldt B, Link RM, Breidenbach N, Triadiati T, Hennings N, Saad A, Leuschner C. 2019. Soil moisture regime and palm height influence embolism resistance in oil palm. Tree Physiology 39: 1696-1712.

Li S, Li X, Link RM, Li R, Deng L, Schuldt B, Jiang X, Zhao R, Zheng J, Li S, et al. 2019. Influence of Cambial Age and Axial Height on the Spatial Patterns of Xylem Traits in Catalpa bungei, a Ring-Porous Tree Species Native to China. Forests 10: 662.

\section{Software}

Link RM. 2020. corrmorant: Flexible Correlation Matrices Based on ggplot2. $R$ package version 0.0.0.9002 (developmental version). URL: https://github.com/r-link/ corrmorant. 



\section{Contents}

1 Introduction 11

1.1 General introduction . . . . . . . . . . . . . . . . . . . 11

1.2 Key functional traits and their links to productivity and water relations . . 12

1.2 .1 Tree size . . . . . . . . . . . . . . . . . 12

1.2 .2 Wood density . . . . . . . . . . . . . . . . . 13

1.2 .3 Growth rates . . . . . . . . . . . . . . . . . . . . 14

1.3 Starving from hunger or parched with thirst? . . . . . . . . . . . 15

1.4 Environmental gradients as natural experiments . . . . . . . . . . . . 16

1.5 Disentangling causal relationships in complex ecological datasets . . . . . 16

1.6 Predicting tree water use and transpiration . . . . . . . . . . . . . 17

1.6.1 Sap flow measurements . . . . . . . . . . . . . . . . 17

1.6.2 Calibration studies . . . . . . . . . . . . . . . . . . 18

1.6.3 Scaling up to whole-tree water use . . . . . . . . . . . 18

1.7 Thesis structure and general objectives . . . . . . . . . . . . . . . . . 19

2 Methodology 33

2.1 Design of the field study in Costa Rica . . . . . . . . . . . . . . . . . 33

2.1 .1 Research area . . . . . . . . . . . . . . . . . 33

2.1 .2 Species selection $\ldots \ldots \ldots \ldots \ldots \ldots$

2.1 .3 Wood properties . . . . . . . . . . . . . . 36

2.1 .4 Tree size and growth rates . . . . . . . . . . . . . . . . 38

2.1.5 Sap flow measurements . . . . . . . . . . . . . . . . 38

2.1.6 Hydraulic measurements . . . . . . . . . . . . . . . . . . 39

2.2 External datasets . . . . . . . . . . . . . . . . . . . . . . . . . . 41

2.2 .1 Sap flow calibration study . . . . . . . . . . . . . . . 41

2.2.2 Tree productivity, water use and wood hydraulic properties of Indonesian tropical trees . . . . . . . . . . . . . . . . 4 42

Part I: Improving water use estimates based on sap flux probes

3 Calibration and comparison of thermal dissipation, heat ratio and heat field $\begin{array}{lr}\text { deformation sap flow probes for diffuse-porous trees } & \mathbf{4 9}\end{array}$

3.1 Abstract . . . . . . . . . . . . . . . . . . . . 49

3.2 Introduction . . . . . . . . . . . . . . . . . . 50

3.3 Material and methods . . . . . . . . . . . . . . . . . 52

3.3.1 Plant material, sample preparation and validation apparatus . . . 52

3.3.2 Thermal dissipation probes (TDP) . . . . . . . . . . . 53

3.3.3 Heat field deformation method (HFD) . . . . . . . . . . . . . 54

3.3 .4 Heat ratio method $(\mathrm{HRM}) \ldots \ldots \ldots . \ldots . \ldots 54$

3.3.5 Sensor installation, measurement procedure and gravimetric validation 55

3.3.6 Sapwood area determination and thermal diffusivity of fresh sapwood 56

3.3.7 Statistical analyses . . . . . . . . . . . . . . . . . 56 
3.4 Results . . . . . . . . . . . . . . . . . . . . . . 59

3.4.1 Sensor performance relative to the gravimetric reference . . . . . . 59

3.4.2 Calibration of TDP sensors . . . . . . . . . . . . . . 61

3.4.3 Calibration of HFD sensors . . . . . . . . . . . . . . . 62

3.5 Discussion . . . . . . . . . . . . . . . . . . . . . . 64

3.5.1 How accurate are sap flux probes? . . . . . . . . . . . . . . 64

3.5.2 Importance of between-stem variation in flux density . . . . . . . . 65

3.5.3 Calibrating TDP sensors . . . . . . . . . . . . . . 66

3.5.4 Calibrating the HFD sensor . . . . . . . . . . . . . . 67

3.5.5 Limitations of calibration experiments . . . . . . . . . . . 68

3.5.6 Conclusions . . . . . . . . . . . . . . . . . . . . . . . 69

Acknowledgements . . . . . . . . . . . . . . . . . . . . 69

Appendix A: Supplementary data . . . . . . . . . . . . . . . . . 70

Material and methods: supplementary equations . . . . . . . . . . 70

Supplementary figures . . . . . . . . . . . . . . . . . . 72

4 Tree height predicts the shape of radial sap flow profiles of Costa-Rican $\begin{array}{ll}\text { tropical dry forest tree species } & \mathbf{8 1}\end{array}$

4.1 Abstract . . . . . . . . . . . . . . . . . . . . 81

4.2 Introduction . . . . . . . . . . . . . . . . . . . . . . 82

4.3 Analytical framework . . . . . . . . . . . . . . . . . . 83

4.4 Material and methods . . . . . . . . . . . . . . . . . . . 85

4.4 .1 Study site . . . . . . . . . . . . . . . . 85

4.4 .2 Selection of experimental trees . . . . . . . . . . . . 85

4.4 .3 Sap flow measurements . . . . . . . . . . . . . . 8 86

4.4.4 Measurement of stand microclimate and soil moisture . . . . . . . 87

4.4.5 Modelling radial sap flux density profiles . . . . . . . . . . . . . . . 87

4.4.6 Estimates of total sap flow . . . . . . . . . . . . . . . 89

4.5 Results . . . . . . . . . . . . . . . . . . . . . . 90

4.5.1 Microclimatic and hydrologic conditions . . . . . . . . . . . . 90

4.5.2 Model of radial sap flow profiles . . . . . . . . . . . . . 90

4.5.3 Model comparison . . . . . . . . . . . . . . . . . . . . . 91

4.5.4 Parameter models . . . . . . . . . . . . . . . . . . . 92

4.5.5 Estimated tree water-use . . . . . . . . . . . . . . 92

4.6 Discussion . . . . . . . . . . . . . . . . . . . . . . . . 93

4.6.1 Modelling results . . . . . . . . . . . . . . . . . 93

4.6.2 Determinants of the shape of radial sap flow profiles . . . . . . . 96

4.6.3 Upscaled estimates of whole-tree water-use . . . . . . . . . . . . . . 97

4.6.4 Measuring radial profiles with HFD sensors . . . . . . . . . . . . . . 97

4.6.5 Temporal changes in radial profiles . . . . . . . . . . . . . . 98

4.6 .6 Conclusions . . . . . . . . . . . . . . . . . . . . . . . . 98

Acknowledgements . . . . . . . . . . . . . . . . . . . . . . . . 99

Supplementary material A: Supplementary methods . . . . . . . . . . . . . . 100

Model for radial profiles of sap flux density . . . . . . . . . . . . . 100

Model fitting . . . . . . . . . . . . . . . . . . . 103

Supplementary material B: Supplementary figures . . . . . . . . . . . . . . 105

Supplementary material C: Data package and model code on Github . . . . . . . 107

Part II: Effect of functional and structural traits on growth and water relations $\mathbf{1 1 5}$ 


\section{Disentangling the functional drivers of water use and productivity in tropical rainforest trees}

5.1 Abstract . . . . . . . . . . . . . . . . . . . . 117

5.2 Introduction . . . . . . . . . . . . . . . . . . . . . . 118

5.3 Materials and methods . . . . . . . . . . . . . . . . . . . . . . . 119

5.3 .1 Study sites . . . . . . . . . . . . . . . . . . . . 119

5.3.2 Tree morphological characteristics . . . . . . . . . . . . . . 121

5.3.3 Aboveground biomass and productivity . . . . . . . . . . . 121

5.3.4 Wood anatomical and derived hydraulic traits . . . . . . . . . . 122

5.3.5 Sap flux measurements and water use . . . . . . . . . . . . . . 122

5.3 .6 Statistical analyses . . . . . . . . . . . . . . . . . . . . 123

5.4 Results . . . . . . . . . . . . . . . . . . . . . . . . 124

5.4.1 Unadjusted relationships with wood anatomy and wood density . . . 124

5.4.2 Relationship between productivity and daily water use . . . . . . . . 124

5.4.3 Determinants of sap flux density and water use . . . . . . . . . . 125

5.4 .4 Determinants of plant productivity . . . . . . . . . . . . . 128

5.5 Discussion . . . . . . . . . . . . . . . . . . . . . . . . 129

5.5.1 Drivers of productivity-water use-relationships . . . . . . . . . 129

5.5.2 Wood anatomical traits outperform wood density as predictors of plant growth and water use . . . . . . . . . . . . . . . . . 130

5.5.3 The way forward from analyses of pairwise correlations . . . . . 131

5.5 .4 Conclusions . . . . . . . . . . . . . . . . . . . 131

Acknowledgments . . . . . . . . . . . . . . . . . . . . . . 132

Author contribution . . . . . . . . . . . . . . . . . . . 132

Supplementary material . . . . . . . . . . . . . . . . . . 133

6 Do wood anatomical traits predict the productivity of Costa Rican tropical forest trees?

6.1 Abstract . . . . . . . . . . . . . . . . . . . . . . . . . . . 149

6.2 Introduction . . . . . . . . . . . . . . . . . . . . 150

6.3 Material and methods . . . . . . . . . . . . . . . . . . 151

6.3.1 Research sites and species selection . . . . . . . . . . . . 151

6.3.2 Measurements of wood density, tree size and growth rates . . . . . 152

6.3.3 Wood anatomical analyses . . . . . . . . . . . . . . 153

6.3.4 Measurement of non-structural carbohydrates . . . . . . . . . . . 154

6.3.5 Water deficit affiliation . . . . . . . . . . . . . . . . . 154

6.3.6 Data analysis . . . . . . . . . . . . . . . . . . . . 154

6.4 Results . . . . . . . . . . . . . . . . . . . . . . . 158

6.4.1 Associations between wood anatomical traits and tree properties . . 158

6.4.2 Principal component analysis . . . . . . . . . . . . . . 158

6.4 .3 Piecewise structural equation model . . . . . . . . . . . . . 158

6.5 Discussion . . . . . . . . . . . . . . . . . . . . . . . . . 164

6.5.1 Determinants of plant growth . . . . . . . . . . . . . . 164

6.5.2 NSC, drought responses and wood anatomical traits along the rain-

fall gradient . . . . . . . . . . . . . . . . . 165

6.5.3 Influence of model choice . . . . . . . . . . . . . . . . 166

6.5 .4 Conclusions . . . . . . . . . . . . . . . . . . . 167

Acknowledgements . . . . . . . . . . . . . . . . . . 168

Author contributions . . . . . . . . . . . . . . . . . . . . 168 
Supplementary figures ． . . . . . . . . . . . . . . . . . . . . 169

Supplementary tables . . . . . . . . . . . . . . . . . . . 171

7 Synthesis $\quad 181$

7.1 Using sap flow probes to estimate whole tree water use and transpiration

rates . . . . . . . . . . . . . . . . . . . . . 181

7.1.1 How reliable are different sensor systems? . . . . . . . . . . . . . . . 181

7.1.2 Components of measurement uncertainty in sap flux density estimates 182

7.1.3 Incorporating radial profiles into upscaled water use estimates . . . . 184

7.2 Preliminary results of the hydraulic measurements on the Osa peninsula . . 184

7.2 .1 Fitted vulnerability curves . . . . . . . . . . . . . . . . 185

7.2.2 Relationship between vulnerability to embolism and tree properties . 186

7.3 Drivers of plant productivity and water relations in tropical forests . . . . . 191

7.3.1 Effects of tree size, wood density and wood anatomy . . . . . . . . 191

7.3.2 Water deficit affiliation as a predictor of drought resistance . . . . . 193

7.4 Concluding remarks . . . . . . . . . . . . . . . . . . . 193

$\begin{array}{ll}\text { List of Figures } & 201\end{array}$

$\begin{array}{ll}\text { List of Tables } & 203\end{array}$

$\begin{array}{ll}\text { Curriculum vitae } & 205\end{array}$

$\begin{array}{ll}\text { Acknowledgements } & 207\end{array}$

Declaration of originality and certificate of ownership 209 


\section{Introduction}

\subsection{General introduction}

Tropical forests are the world's most productive terrestrial ecosystems, contributing to around one third of metabolic activity on the Earth's land surface (Field et al. 1998; Roy et al. 2001; Malhi 2012) and forming the largest terrestrial carbon sink (Pan et al. 2011). They are estimated to make up $45 \%$ of the global forest cover (D'Annunzio et al. 2017), and house approximately $40 \%$ of the carbon stores in terrestrial biosphere (Meister et al. 2012). However, under a changing climate, tropical forests are predicted to be subjected to higher average temperatures and hence higher evaporative demand, as well as a higher frequency and intensity of extreme drought events (Fu et al. 2013; Joetzjer et al. 2013). Throughout many tropical forest regions both in Asia and South and Central America, these extreme events are exacerbated by the recurrent climate phenomenon of the El Niño-Southern Oscillation (ENSO), which in an irregular periodic pattern fosters extreme droughts, temperatures and rainfall events, and whose intensity and frequency may increase under a hotter climate (Cai et al. 2015).

There is clear evidence that already under the current climate conditions, tropical forest ecosystems are increasingly facing both drought-related declines in forest biomass productivity (Feeley et al. 2007; Zhao and Running 2010) and rises in tree mortality rates (Allen et al. 2010; Feldpausch et al. 2016; Brando et al. 2019). While the nature of the mechanisms that lead to tree death under drought are still the subject of lively debate (Hartmann 2015; Körner 2015; McDowell et al. 2018), some clear patterns emerge that link certain trait combinations to a disproportionately higher mortality risk (O'Brien et al. 2017), most notably: (i) taller trees face higher mortality rates, (ii) trees with higher wood density tend to be less susceptible to drought and (iii) fast growing trees tend to have higher mortality rates. Accordingly, drought-induced dieback does not affect all trees equally, and therefore has the potential to alter the species composition of tropical forest tree communities (Itoh et al. 2012; Esquivel-Muelbert et al. 2019). In addition, drought events can lead to fundamental changes in forest structure that can negatively affect the resilience of forests to further drought events, as the disproportionate loss of tall trees results in large canopy gaps that expose the understorey to higher light levels and temperatures (Slik 2004; Saatchi et al. 2013).

Ecophysiological studies play a key role for predictions of tropical forest behavior under a changing climate, as they deliver key components both for the parameterization and validation of process-based dynamic models and for the ground-truthing of remote-sensing based upscaling approaches. They can contribute to an improved understanding of changes in the structure, function and composition of tropical forests in response to climate change by (i) advancing the mechanistic understanding of the processes that lead to plant death under drought, (ii) investigating the link between these processes and aforementioned risk factors, and (iii) improving methods that generalize inferences from measurements on individual trees to the stand and ecosystem level. 
In the following, I will detail how the research presented in the scope of this dissertation intends to make contributions to all of these three aspects.

\subsection{Key functional traits and their links to productivity and water relations}

One central question of this work is whether functional traits are suitable predictors of the drought response of tropical trees. Hereby, a special emphasis is put on the network of relationships between functional traits and climate and their joint effect on plant water relations. As the design of the field study that forms the backbone of this work revolves around relationships between tree size, wood density and growth rates (cf. Section 2.1), the following section will discuss the current state of Tree Ecophysiology and Plant Hydraulics in the light of these properties.

\subsubsection{Tree size}

While trees have evolved a large stem length in order to outcompete other plants in a million-year struggle for light (King 1990; Falster and Westoby 2003), this competitive advantage comes at a large cost, as they have overcome a set of physical barriers in order to transport water from the primary uptake site in the roots all the way up to the leaves where it is needed for photosynthesis (Hartmann 2011). In order to transport water upwards, larger trees have to maintain steeper water potential gradients as they have to overcome both the greater gravitative potential associated with their height and the larger flow resistance posed by the longer flow path, pushing them closer to their hydraulic limits (Ryan and Yoder 1997; Koch et al. 2004; Ryan et al. 2006). Hydraulic optimality models (e.g. West et al. 1999; Anfodillo et al. 2006; Hölttä et al. 2011) predict that in order to make up for the pressure drop associated with a progressively longer flow path, the diameter of xylem vessels has to widen with flow path length, leading to larger average vessel sizes in the stems of taller trees (Anfodillo et al. 2006; Olson et al. 2014; Rosell et al. 2017). While the existence of direct causal link between vessel size and vulnerability to drought is still being debated (cf. Section 1.2.3), the repeatedly reported association between precipitation and vessel size (Machado et al. 2007; De Micco et al. 2008; Hacke et al. 2017) suggests the presence of a relationship and indicates possible consequences for tall, large vesseled trees. In either case, larger trees have an additional liability in conditions of insufficient water supply simply because of their higher absolute water use, which directly depends on tree size (Wullschleger et al. 1998; Meinzer et al. 2005; Horna et al. 2011). In addition to these internal constraints, the prominent canopy positions of larger trees expose them to higher levels of radiation, higher temperatures, lower relative humidities and higher velocities of air movement, all of which leads to an increase in evaporative demand that puts them under higher risk under drought conditions (Eamus et al. 2013; Stovall et al. 2019).

As a consequence of the aforementioned relationships, tree size is among the most important risk-factors for drought-induced mortality (O'Brien et al. 2017), and a decline in large trees in response to drought events has been reported across a large number of ecosystems (Slik 2004; Phillips et al. 2010b; Lindenmayer et al. 2012; Bennett et al. 2015; Grote et al. 2016; Olson et al. 2018; Stovall et al. 2019). 
Large trees make up a significant part of the carbon stocks of tropical forests (Bastin et al. 2015; Bastin et al. 2018; Fauset et al. 2015). In a global dataset, the largest 1\% of trees were found to make up around $50 \%$ of the total aboveground biomass (Lutz et al. 2018). In addition, larger trees possess higher rates of carbon assimilation that allow them actively fix larger amounts of carbon (Stephenson et al. 2014). Due to their prominent role in forest carbon cycles as well as their elevated drought sensitivity, the conservation of large trees has been singled out as a priority for maintaining ecosystem functions (Lutz et al. 2018).

\subsubsection{Wood density}

Wood density is closely related to many of the most relevant functions of woody tissues, namely mechanical support, water transport and the storage capacity, and has hence been termed an "integrator of wood properties" (Chave et al. 2009). In tropical trees, lower wood density is assumed to be associated with faster growth rates, lower survival rates and lower shade tolerance (King et al. 2006; Muller-Landau et al. 2006; Chao et al. 2008; Kraft et al. 2010; Wright et al. 2010; Philipson et al. 2014), and is hence indicative of a life-history strategies that prioritize fast growth and resource acquisition over longterm stability. While the overall association of low-density wood with higher mortality rates complicates the analysis of relationships between wood density and drought-induced mortality, there is ample evidence that light-wooded trees are especially prone to dieback during drought events (van Nieuwstadt 2002; Slik 2004; Phillips et al. 2010b; O'Brien et al. 2017).

A lower vulnerability to embolism for trees with higher wood density has been observed repeatedly (Hacke et al. 2001; Lens et al. 2011; Markesteijn et al. 2011; Christoffersen et al. 2016; Eller et al. 2018). High wood density is assumed to aid drought resistance by increasing the mechanical strength of the walls of the xylem conduits via its relationship to the ratio between wall thickness and conduit diameter, thus reducing the risk of implosion (Hacke et al. 2001; Lens et al. 2011). However, since wood density is an emergent property of wood traits resulting from the spatial arrangement of its components (Zieminska et al. 2013; Ziemińska et al. 2015), its effect on drought resistance can be assumed to be correlative rather than causal, and will only hold as long as there is a relationship between wood density and conduit wall thickness-to-span ratio (cf. Lens et al. 2011).

Given the lower relative investment of species with low wood density into construction costs (cf. King et al. 2006; van Gelder et al. 2006), it is not surprising that many studies find low wood density to be associated with higher growth rates (King et al. 2006; Rüger et al. 2012; Gibert et al. 2016; Falster et al. 2018; Fauset et al. 2019). In addition, in seasonally dry tropical forests, wood density has been found to be linked to a variety of wood-anatomical traits that themselves are linked to productivity, such as vessel density and the fraction of xylem area occupied by vessels (Hoeber et al. 2014; Hietz et al. 2016). However, a number of studies failed to establish similar relationships for humid tropical forests where drought normally is not limiting (Zhang and Cao 2009; Poorter et al. 2010; Fan et al. 2012; Schuldt et al. 2013; Kotowska et al. 2015), or found the relationship between wood density and growth to diminish above a certain size range (Francis et al. 2017).

A possible reason for the inconclusive evidence with regard to the relationship between wood density and growth is that many different combinations of wood anatomical traits with markedly different hydraulic properties can result in the same wood density 
(Ziemińska et al. 2013; Ziemińska et al. 2015), which explains the weak overall relationship between potential hydraulic conductivity and wood density found in global datasets (Zanne et al. 2010). In either case, the comparison of growth rates between studies is complicated by the large variety in measures of growth (cf. Gibert et al. 2016), which is of specific relevance for studies of wood density effects on growth rates as wood density directly enters the calculation of allometric biomass equations (Hietz et al. 2016).

\subsubsection{Growth rates}

It is well known that net primary productivity is globally correlated with tree mortality rates, though the mechanisms behind this pattern are debated (Stephenson et al. 2011). In past drought events in tropical forests, fast-growing pioneer tree species where disproportionately affected (Slik 2004; Phillips et al. 2009). As taller trees and trees with lighter wood both tend to have higher absolute growth rates (see previous sections), it is hard to separate which of these traits most closely corresponds to the drought sensitivity.

A highly conductive sapwood is widely considered a prerequisite for high productivity (Tyree 2003). In consequence, xylem hydraulic physiology has been termed the 'functional backbone of terrestrial plant productivity' (Brodribb 2009). Due to the link between productivity and xylem hydraulic efficiency, a possible explanation for a higher susceptibility to drought of fast-growing tree species lies in the suspected tradeoff between hydraulic efficiency and stability against hydraulic failure (Wheeler et al. 2005).

The major flow resistances water faces on its way through the xylem are the resistance posed by the xylem lumina and the resistance posed by the passage through inter-vessel pits (lumen and end wall resistance following the terminology in Wheeler et al. 2005). The lumen resistance can easily be approximated by the Hagen-Poiseuille Equation and scales with the $4^{\text {th }}$ power of its diameter (cf. Eq. (2.4)). The end wall resistance is harder to quantify as its contribution to the total flow resistance depends on pit characteristics and the vessel length distribution, but tends to make up around $50 \%$ of the total flow resistance (Sperry et al. 2005; Wheeler et al. 2005). The most straight-forward way for a plant to achieve a higher conductivity is therefore by increasing its vessel diameter and/or length. However, according to the pit-area hypothesis, a larger vessel surface area leads to a greater absolute area per vessel covered by inter-vessel pit membranes and hence more potential air seeding sites, resulting in a higher embolism risk (Wheeler et al. 2005; Hacke et al. 2006; Choat and Pittermann 2009; Christman et al. 2009). Accordingly, the dimensions of vessels in the xylem of a plant species represent a compromise between maximizing hydraulic conductivity (and hence potential carbon gain through photosynthesis) and minimizing the risk of hydraulic failure, which may explain the higher vulnerability of faster growing species. However, there is evidence that in addition to the mere surface area of a vessel, its embolism risk depends on a multitude of other quantities such as the number of inter-vessel pits per unit surface area, the average size of these pits and most importantly the pit membrane thickness (Choat et al. 2008; Lens et al. 2011; Tixier et al. 2014; Jansen et al. 2018), which puts the unconditional validity of the pit area hypothesis into question. This notion is supported by a recent analysis of a global dataset based on the Xylem Functional Traits Database (cf. Choat et al. 2012) by Gleason et al. (2016). Their results suggest that the global support for a tradeoff between xylem efficiency and safety against hydraulic failure is at best weak, with a total explained variance of only $5.3 \%$ for angiosperm and $8.6 \%$ for gymnosperm tree species, which is far from being sufficient to explain the relationship between productivity and vulnerability to drought. 
In any case, the positive relationship between vessel size and water availability both on a regional scale (Machado et al. 2007; De Micco et al. 2008; Hacke et al. 2017) and even between early- and latewood of single species (Eilmann et al. 2009) indicates the existence of at least a certain link between vulnerability to drought and wood structure - also if not mediated by a stability-efficiency tradeoff - which implies a possible link to productivity.

\subsection{Starving from hunger or parched with thirst?}

One of the central questions in the context of studies of plant drought mortality is the question what processes are causally responsible for the death of a tree in response to drought. In recent years, a large part of this debate has revolved around the mechanistic framework proposed by McDowell et al. (2008; 2011). These authors described a set of processes involved in drought-induced tree mortality, namely (i) the complete failure of the hydraulic pathway due to runaway embolism (hydraulic failure), (ii) a successive decline in plant health due to the depletion of nonstructural carbohydrate storage after stomatal closure (carbon starvation) and (iii) tissue damage due to mass infestations with herbivores facilitated by the weakened state of the plants (biotic agent demographics). The original publications focused in-depth on the interdependence between the different processes and concluded that while carbon starvation is likely a larger threat for isohydric plants that close their stomata early during a drought event and maintain large hydraulic safety margins, hydraulic failure is possibly more common in anisohydric plants. In either case, the processes are explicitly described as not mutually exclusive and said to most probably occur simultaneously in many cases; moreover, both are assumed to facilitate biotic agent outbreaks (McDowell et al. 2011).

However, many subsequent publications on that issue tried to weigh the evidence that one specific process is the main cause of plant death under drought, mostly with a specific focus on hydraulic failure and carbon starvation. This resulted in a body of studies implying that under many circumstances hydraulic failure is the more important of the two processes (Sevanto et al. 2014; Rowland et al. 2015a; Hartmann et al. 2018), while it has been put into question whether carbon starvation is likely to happen at all (Sala et al. 2010; Hartmann 2015). The interdependency between the processes is rarely addressed in experimental studies (Hartmann et al. 2018; but see O'Brien et al. 2014).

One of the most immediate potential links between nonstructural carbohydrate storage and xylem dysfunction is constituted by the process of embolism refilling (Zwieniecki and Holbrook 2009; Nardini et al. 2011). However, in the context of the identification of artifacts in commonly applied measurement methods in vulnerability curves (Choat et al. 2010; Wheeler et al. 2013; Martin-StPaul et al. 2014; Torres-Ruiz et al. 2014; TorresRuiz et al. 2017) the occurrence of frequent embolism- and refilling cycles was largely ruled out as a possible mechanistic link between the two processes (cf. Wheeler et al. 2013). Notwithstanding, this does not in general rule out a relationship between carbon starvation and hydraulic failure. Additional links are constituted e.g. by the disruption of xylem-phloem functioning during drought (Sala et al. 2010) and the structural investment invariably needed to produce new functional xylem (Trugman et al. 2018) and regain root function (Hagedorn et al. 2016) during drought recovery. Moreover, studies focusing on the role of nonstructural carbohydrate storage in plant drought responses (and finding inconclusive results) are often based on momentary data of an incomplete subset of all relevant nonstructural carbohydrate compounds, and mostly focus on one or few plant 
tissues (Hartmann and Trumbore 2016). Since nonstructural carbohydrate compounds perform a vast array of functions in the plant metabolism and are subjected to diel as well as annual cycles of supply and demand (Martínez-Vilalta et al. 2016; Hartmann and Trumbore 2016), conclusions drawn from point measurements are to be interpreted with care (Hartmann and Trumbore 2016).

Despite the controversy, there are certain lines of evidence that indicate that nonstructural carbohydrate storage and metabolisation do interact with plant drought responses: 1) there is experimental evidence that in response to xylem embolism metabolic pathways associated with starch depolymerization are activated and starch concentrations fall in xylem parenchyma cells (Salleo et al. 2009), while sucrose concentration rises in xylem conduits (Nardini et al. 2011); 2) vessel associated xylem parenchyma cells have extraordinarily high levels of aquaporin expression, whose activity patterns coincide with embolism (Secchi et al. 2017), 3) the analysis of year-ring datasets indicates that trees often do not die immediately after drought, but instead may be gradually weakened and die years later (Bigler et al. 2007), e.g. when exposed to pathogen outbreaks and/or successive drought events; and 4) general trends in nonstructural carbohydrate concentrations indicate an increase with tree size, drought and cold (all of which are of fundamental importance for the conductive system) that is consistent with an important role of nonstructural carbohydrates in maintaining hydraulic transport (Sala et al. 2012).

\subsection{Environmental gradients as natural experiments}

The change in plant community composition along environmental gradients reflects the adaptations of plant species to differences in environmental conditions (Whittaker 1967). Species distribution patterns in tropical forests suggest that the ranges of tropical forest species are predominantly shaped by drought sensitivity (Bongers et al. 1999; Engelbrecht et al. 2007; Brenes-Arguedas et al. 2009; Maharjan et al. 2011; Esquivel-Muelbert et al. 2017). For that reason, dry forest stands tend to be almost entirely devoid of wet forest species, while the ranges of dry-tolerant species often extend far into the ranges of humid forests, contributing to a higher species richness at more humid sites (Esquivel-Muelbert et al. 2017).

Due to the aforementioned environmental filtering, rainfall gradients can be considered akin to "natural experiments" (cf. Diamond 1986), as the species composition at each site along rainfall gradients represents the outcome of the selection for different degrees of drought intensity. Within the limits of what is achievable with purely observational approaches (Sagarin and Pauchard 2010), studies of differences in plant traits along rainfall gradients can therefore be used as a tool to identify trait combinations associated with drought resistance.

\subsection{Disentangling causal relationships in complex ecological datasets}

In observational studies in natural ecosystems, datasets tend to reflect a network of complex interrelations instead of a set of clear-cut one-to-one relationships. To this day many ecological studies tend to focus on pairwise bivariate associations between large sets of variables, often by inspecting correlation tables and without corrections for multiple testing 
and selectively reporting significant relationships. There is plenty of evidence that aforementioned practices are leading to inflated false discovery rates (Ioannidis 2005; Colquhoun 2014; Head et al. 2015). In the wake of studies indicating that a large fraction of published research findings cannot be reproduced under controlled replication settings (see e.g. Simmons et al. 2011), a debate about the fundament of statistical methodology has spun out in which has become heated enough to lead prominent calls to abandon the concept of statistical significance altogether (Wasserstein and Lazar 2016; Hurlbert et al. 2019; Wasserstein et al. 2019), and has been aptly summarized as "the Statistics Wars" (Mayo 2018).

While avoiding to get lost in the Garden of Forking Paths (Gelman and Loken 2013) in observational field studies is admittedly complicated, in this work I aim to take a more hypothesis-driven approach. In Chapter 5 and 6, a Structural Equation Modelling (SEM) approach is employed to test the validity of models built by sets of a-priori hypotheses about causal relationships between variables of interest. This approach has the advantage that it treats complex datasets in the form of multivariate networks of causal relationship (thus allowing to identify indirect effects and mediation), and that it provides tools to incorporate latent variables as representations of theoretical constructs (Grace 2006; Grace et al. 2010; Kline 2011; Grace et al. 2012).

One of the principal concepts behind structural equation modeling is to test whether a set of multivariate causal hypotheses is consistent with the observed data, which is a clear departure from the common practice of testing whether observed patterns in data deviate from a null hypothesis of no discernible relationship. Due to this shift of focus from null hypotheses to a-priori specified hypotheses, SEM approaches put a strong emphasis on theoretical knowledge about the analyzed systems (Grace and Bollen 2006). Of course, there are clear limits to what SEM can and cannot do (Bollen and Pearl 2013) most importantly, the degree to which a SEM really warrants causal inferences rests on the strength of the theoretical knowledge about the system at hand (Grace and Bollen 2006). In ecological field studies, the knowledge about the relationships of interest is often relatively vague, and observed patterns often consistent with different competing causal hypotheses.

In the present examples, models were constructed around sets of hypotheses either defined by the coauthors before the onset of the data analysis (Chapter 5) or stated in the project proposal (Chapter 6). Due to ambiguities in the translation of these hypotheses about theoretical constructs into relationships between manifest variables as well as complications due to unexpected patterns in the data, in both cases adjustments to the models were necessary that in the strict sense render the analysis exploratory rather than confirmatory (cf. Grace 2006). Notwithstanding, I am convinced that the manuscripts in Chapter 5 and 6 are indicative that a shift of focus in direction of a more hypothesis-driven approach may considerably advance the interpretation of complex ecological datasets.

\subsection{Predicting tree water use and transpiration}

\subsubsection{Sap flow measurements}

Transpiration from plant surfaces constitutes the largest fraction of total evapotranspiration in most terrestrial ecosystems (Schlesinger and Jasechko 2014). Due to their high evapotranspiration rates and their effect on hydrologic cycles and energy fluxes, forests 
exercise a key function in the global climate (Bonan 2008). For that reason, accurate estimates of forest transpiration rates are essential for our understanding of their role in a changing climate. While there are plenty of alternative methods to quantify transpiration rates (cf. Wilson et al. 2001; Wang and Dickinson 2012), a common method is to scale up from single tree water use estimates derived from sap flow measurements (Oishi et al. 2008; Wang and Dickinson 2012). Transpiration estimates based on sap flow have the advantage of preserving information about functional links between individual plants and their environment (Meinzer et al. 2001b; Wilson et al. 2001; Caylor and Dragoni 2009). Their focus on single trees makes them an interface between studies of individual plant water relations and stand and ecosystem level transpiration estimates.

The most common sap flow measurement methods are based on thermal methods which require installing a set of needles equipped with a heater and one or several thermocouples into the sapwood. The sap flux density at the point of sensor istallation is then estimated from the temperatures at the thermocouples based on empirical calibrations and/or assumptions based on the physics of heat conduction and convection (Vandegehuchte and Steppe 2013). Throughout the long history of thermometric sap flux measurement techniques (dating back well into the 1930s; cf. Huber 1932), a large set of different measurement methods with different sensor specifications and conformations, different modes of heating and different levels of sophistication were devised, three of which are discussed in-depth in Chapter 3.

\subsubsection{Calibration studies}

While the working principle of thermometric sap flow sensors is as simple as it is versatile, there still is ample room for improvement, as suggested by a host of studies indicating that the accuracy of most thermal methods is likely to benefit from species-specific recalibration (Bleby et al. 2004; de Oliveira Reis et al. 2006; Steppe et al. 2010; Sun et al. 2012; Niu et al. 2015), likely even for methods purportedly derived from physical principles (Vandegehuchte and Steppe 2012c). The main reason for the need for species-specific sensor calibration is that the wood of different species differs in its thermal properties because the thermal conductivity of sapwood depends on xylem structure and anatomy. Moreover, due to the fibrous structure of wood, heat transfer in the xylem is highly anisotropic, which contrasts with the assumptions behind many measurement methods (Vandegehuchte and Steppe 2012b).

As a consequence, the relationship between sensor readings and actual sap flow rates can be assumed to vary between species with different wood structure. In Chapter 3, evidence is provided that for several different methods, calibration parameters differ not only between species, but even between individuals within species.

\subsubsection{Scaling up to whole-tree water use}

Sap flux density is not distributed uniformly around the entire stem cross-section. It is long established that sap flux show a pronounced radial pattern (Edwards and Booker 1984; Čermák et al. 1992), usually with a stark decline from sap- to heartwood (Delzon et al. 2004). In addition, the occurrence of azimuthal patterns in sap flux density has been confirmed at least since Miller et al. (1980). While the latter are mostly assumed to average out over large enough sample sizes, the former are potentially a major source of error in upscaled water use estimates when sap flux density is only measured in the outermost 
few $\mathrm{cm}$ of sapwood and assumed to be constant over the entire sapwood depth (Caylor and Dragoni 2009; Reyes-Acosta and Lubczynski 2014; Zhang et al. 2015). Assuming sap flow to be constant across the entire sapwood depth has been associated with an overestimation of transpiration by up to $154 \%$ (Čermák and Nadezhdina 1998; Ford et al. 2004b). Notwithstanding the magnitude of potential errors, a recent study found that a majority of $58 \%$ out of 122 surveyed papers calculated tree water use based on the assumption of constant sap flux (Berdanier et al. 2016).

In Chapter 4, I build upon the approach of Caylor and Dragoni (2009) to mathematically decouple the radial sap flow profile from the time-dependent change in sap flow. I develop a Bayesian hierarchical model that allows to predict the shape of radial profiles measured with the Heat Field Deformation method based on easily measurable functional traits, and to propagate the uncertainty into water use predictions for new trees and new species. I further provide equations that allow to combine single-point sensor measurements with radial profiles measured on different trees to obtain water use estimates that take into account uncertainty and variability on different levels of hierarchicity.

\subsection{Thesis structure and general objectives}

The main focus of the work presented in this dissertation are different ways to improve our understanding of plant water relations in order to better understand and predict the mechanisms that promote changes in forest productivity and increases in tree mortality under a drier and hotter climate.

It is structured in two separate parts, the first of which aims at methodological improvements of water use estimates based on measurements obtained with thermal sap flow sensors by improved empirical calibrations (Chapter 3) and by more formally accounting for radial gradients in sap flux density during the upscaling end error propagation process (Chapter 4). The second part focuses on the causal relationships linking tree functional and structural traits to plant growth and water relations, drawing upon field studies from Indonesia (Chapter 5) and Costa Rica (Chapter 6). In addition, results from hydraulic measurements from the Costa Rican field sites that are as of yet unpublished are presented in the section 7.2 of the Synthesis chapter.

The main objectives of the present thesis are the following:

- Part I: Improving water use estimates based on sap flux probes

- to compare differences in the measurement accuracy of commonly used sap flow sensor systems and to improve their empirical calibrations,

- to develop a methodological framework for the prediction of radial sap flow profiles from structural and functional traits, and the propagation of the uncertainty in the estimated radial profile into whole-tree transpiration estimates;

- Part II: Effect of functional and structural traits on growth and water relations

- to study the effect of wood anatomy, wood density tree size on productivity, sap flow rates and tree water use in Indonesian tropical forest trees,

- to identify causal effects of wood anatomy, wood density and tree size on nonstructural carbohydrate storage, growth rates and drought adaptations of trees along a rainfall gradient in Costa Rica, 
- to assess the dependence of plant vulnerability to cavitation on wood anatomy, wood density and tree size.

The overarching motivation for this work was to test the following hypotheses, some aspects of which are addressed in all parts of this work besides Chapter 3:

(i) Larger trees have higher biomass productivity and water use resulting from their more conductive xylem both in stem and branch tissue which simultaneously makes them more prone to drought-induced embolism;

(ii) Trees with harder wood have slower biomass growth rates and lower hydraulic efficiency, but are more resistant against drought-induced embolism;

(iii) Wood anatomical traits are more closely related to productivity and water use than wood density.

\section{References}

Allen, C. D., A. K. Macalady, H. Chenchouni, D. Bachelet, N. McDowell, et al. (2010). "A global overview of drought and heat-induced tree mortality reveals emerging climate change risks for forests". In: Forest Ecology and Management 259.4, pp. 660-684. URL: https://linkinghub.elsevier.com/retrieve/pii/S037811270900615X.

Anfodillo, T., V. Carraro, M. Carrer, C. Fior, and S. Rossi (2006). "Convergent tapering of xylem conduits in different woody species". In: New Phytologist 169.2, pp. 279-290. URL: http://doi.wiley.com/10.1111/j.1469-8137.2005.01587.x.

Bastin, J.-F., N. Barbier, M. Réjou-Méchain, A. Fayolle, S. Gourlet-Fleury, et al. (2015). "Seeing Central African forests through their largest trees". In: Scientific Reports 5.1, p. 13156. URL: http://www.nature.com/articles/srep13156.

Bastin, J.-F., E. Rutishauser, J. R. Kellner, S. Saatchi, R. Pélissier, et al. (2018). "Pantropical prediction of forest structure from the largest trees". In: Global Ecology and Biogeography 27.11, pp. 1366-1383. URL: http://doi.wiley.com/10.1111/geb.12803.

Bennett, A. C., N. G. McDowell, C. D. Allen, and K. J. Anderson-Teixeira (2015). "Larger trees suffer most during drought in forests worldwide". In: Nature Plants 1.10, p. 15139. URL: https://www.nature.com/articles/nplants2015139.

Berdanier, A. B., C. F. Miniat, and J. S. Clark (2016). "Predictive models for radial sap flux variation in coniferous, diffuse-porous and ring-porous temperate trees". In: Tree Physiology 36.8. Ed. by N. Phillips, pp. 932-941. URL: https://academic.oup.com/ treephys/article-lookup/doi/10.1093/treephys/tpw027.

Bigler, C., D. G. Gavin, C. Gunning, and T. T. Veblen (2007). "Drought induces lagged tree mortality in a subalpine forest in the Rocky Mountains". In: Oikos 116.12, pp. 19831994. URL: http://doi.wiley.com/10.1111/j.2007.0030-1299.16034.x.

Bleby, T. M., S. S. O. Burgess, and M. A. Adams (2004). "A validation, comparison and error analysis of two heat-pulse methods for measuring sap flow in Eucalyptus marginata saplings". In: Functional Plant Biology 31.6, p. 645. URL: http://www.publish.csiro.au/ ?paper $=$ FP04013.

Bollen, K. A. and J. Pearl (2013). "Eight Myths About Causality and Structural Equation Models". In: Handbook of Causal Analysis for Social Research. Ed. by S. L. Morgan. Dordrecht: Springer Netherlands, pp. 301-328. URL: http://link.springer.com/10.1007/ 978-94-007-6094-3_15. 
Bonan, G. B. (2008). "Forests and Climate Change: Forcings, Feedbacks, and the Climate Benefits of Forests". In: Science 320.5882, pp. 1444-1449. URL: http://www.sciencemag. org/cgi/doi/10.1126/science.1155121.

Bongers, F., L. Poorter, R. Rompaey, and M. Parren (1999). "Distribution of twelve moist forest canopy tree species in Liberia and Côte d'Ivoire: response curves to a climatic gradient". In: Journal of Vegetation Science 10.3, pp. 371-382. URL: https://onlinelibrary. wiley.com/doi/abs/10.2307/3237066.

Brando, P. M., L. Paolucci, C. C. Ummenhofer, E. M. Ordway, H. Hartmann, et al. (2019). "Droughts, Wildfires, and Forest Carbon Cycling: A Pantropical Synthesis". In: Annual Review of Earth and Planetary Sciences 47.1, pp. 555-581. URL: https: //www.annualreviews.org/doi/10.1146/annurev-earth-082517-010235.

Brenes-Arguedas, T., P. D. Coley, and T. A. Kursar (2009). "Pests vs. drought as determinants of plant distribution along a tropical rainfall gradient". In: Ecology 90.7, pp. 1751-1761. URL: http://doi.wiley.com/10.1890/08-1271.1.

Brodribb, T. J. (2009). "Xylem hydraulic physiology: The functional backbone of terrestrial plant productivity". In: Plant Science 177.4, pp. 245-251. URL: https://linkinghub. elsevier.com/retrieve/pii/S0168945209001599.

Cai, W., A. Santoso, G. Wang, S.-W. Yeh, S.-I. An, et al. (2015). "ENSO and greenhouse warming". In: Nature Climate Change 5.9, pp. 849-859. URL: https://www.nature.com/ articles/nclimate2743.

Caylor, K. K. and D. Dragoni (2009). "Decoupling structural and environmental determinants of sap velocity: Part I. Methodological development". In: Agricultural and Forest Meteorology 149.3-4, pp. 559-569. URL: https://linkinghub.elsevier.com/retrieve/pii/ S0168192308002803.

Čermák, J., E. Cienciala, J. Kucera, and J.-E. Hallgren (1992). "Radial velocity profiles of water flow in trunks of Norway spruce and oak and the response of spruce to severing". In: Tree Physiology 10.4, pp. 367-380. URL: https://academic.oup.com/treephys/articlelookup/doi/10.1093/treephys/10.4.367.

Čermák, J. and N. Nadezhdina (1998). "Sapwood as the scaling parameter- defining according to xylem water content or radial pattern of sap flow?" In: Annales des Sciences Forestières 55.5, pp. 509-521. URL: http:// www . afs-journal .org / 10.1051/forest: 19980501.

Chao, K.-J., O. L. Phillips, E. Gloor, A. Monteagudo, A. Torres-Lezama, and R. V. Martínez (2008). "Growth and wood density predict tree mortality in Amazon forests". In: Journal of Ecology 96.2, pp. 281-292. URL: http://doi.wiley.com/10.1111/j.13652745.2007.01343.x.

Chave, J., D. Coomes, S. Jansen, S. L. Lewis, N. G. Swenson, and A. E. Zanne (2009). "Towards a worldwide wood economics spectrum". In: Ecology Letters 12.4, pp. 351-366. URL: http://doi.wiley.com/10.1111/j.1461-0248.2009.01285.x.

Choat, B., A. R. Cobb, and S. Jansen (2008). "Structure and function of bordered pits: new discoveries and impacts on whole-plant hydraulic function". In: New Phytologist 177.3, pp. 608-626. URL: http://doi.wiley.com/10.1111/j.1469-8137.2007.02317.x.

Choat, B., W. M. Drayton, C. Brodersen, M. A. Matthews, K. A. Shackel, H. Wada, and A. J. Mcelrone (2010). "Measurement of vulnerability to water stress-induced cavitation in grapevine: a comparison of four techniques applied to a long-vesseled species: Comparison of vulnerability curve technique in grapevine". In: Plant, Cell $\&$ Environment, no-no. URL: http://doi.wiley.com/10.1111/j.1365-3040.2010.02160.x. 
Choat, B., S. Jansen, T. J. Brodribb, H. Cochard, S. Delzon, et al. (2012). "Global convergence in the vulnerability of forests to drought". In: Nature 491.7426, pp. $752-755$. URL: https://www.nature.com/articles/nature11688.

Choat, B. and J. Pittermann (2009). "New insights into bordered pit structure and cavitation resistance in angiosperms and conifers". In: The New Phytologist 182.3, pp. 557560 .

Christman, M. A., J. S. Sperry, and F. R. Adler (2009). "Testing the 'rare pit' hypothesis for xylem cavitation resistance in three species of Acer". In: New Phytologist 182.3, pp. 664-674. URL: https://onlinelibrary.wiley.com/doi/abs/10.1111/j.1469-8137.2009. 02776.x.

Christoffersen, B. O., M. Gloor, S. Fauset, N. M. Fyllas, D. R. Galbraith, et al. (2016). "Linking hydraulic traits to tropical forest function in a size-structured and trait-driven model (TFS v.1-Hydro)". In: Geosci. Model Dev., p. 30.

Colquhoun, D. (2014). "An investigation of the false discovery rate and the misinterpretation of p-values". In: Royal Society Open Science 1.3, pp. 1-16. URL: http://rsos. royalsocietypublishing.org/cgi/doi/10.1098/rsos.140216.

D'Annunzio, R., E. Lindquist, and K. G. MacDicken (2017). Global forest land-use change from 1990 to 2010: an update to a global remote sensing survey of forests. Forest Resources Assessment Working Paper 187. Rome: Food and Agriculture Organization of the United Nations.

De Micco, V., G. Aronne, and P. Baas (2008). "Wood anatomy and hydraulic architecture of stems and twigs of some Mediterranean trees and shrubs along a mesic-xeric gradient". In: Trees 22.5, pp. 643-655. URL: http://link.springer.com/10.1007/s00468-008-0222-y. de Oliveira Reis, F., E. Campostrini, E. F. de Sousa, and M. G. e Silva (2006). "Sap flow in papaya plants: Laboratory calibrations and relationships with gas exchanges under field conditions". In: Scientia Horticulturae 110.3, pp. 254-259. URL: http:// www . sciencedirect.com/science/article/pii/S0304423806002883.

Delzon, S., M. Sartore, A. Granier, and D. Loustau (2004). "Radial profiles of sap flow with increasing tree size in maritime pine". In: Tree Physiology 24.11, pp. 1285-1293. URL: https://academic.oup.com/treephys/article-lookup/doi/10.1093/treephys/24.11.1285.

Diamond, J. M. (1986). "Overview: Laboratory experiments, field experiments, and natural experiments". In: Community Ecology. Ed. by J. M. Diamond and T. Case. New York, NY: Harper and Row, pp. 3-23. URL: http://users.wfu.edu/silmanmr/bio377/ assignments/Readings/ExperimentalDesign/Diamond.pdf.

Eamus, D., N. Boulain, J. Cleverly, and D. D. Breshears (2013). "Global change-type drought-induced tree mortality: Vapor pressure deficit is more important than temperature per se in causing decline in tree health". In: Ecology and Evolution 3.8, pp. 27112729. URL: https://arizona.pure. elsevier.com/en/publications / global-change- typedrought-induced-tree-mortality-vapor-pressure-.

Edwards, W. R. N. and R. E. Booker (1984). "Radial Variation in the Axial Conductivity of Populus and its Significance in Heat Pulse Velocity Measurement". In: Journal of Experimental Botany 35.4, pp. 551-561. URL: https://academic.oup.com/jxb/articlelookup/doi/10.1093/jxb/35.4.551.

Eilmann, B., R. Zweifel, N. Buchmann, P. Fonti, and A. Rigling (2009). "Drought-induced adaptation of the xylem in Scots pine and pubescent oak". In: Tree Physiology 29.8, pp. 1011-1020. URL: https://academic.oup.com/treephys/article-lookup/doi/10.1093/ treephys/tpp035.

Eller, C. B., F. d. V. Barros, P. R. L. Bittencourt, L. Rowland, M. Mencuccini, and R. S. Oliveira (2018). "Xylem hydraulic safety and construction costs determine tropical tree 
growth". In: Plant, Cell \& Environment 41.3, pp. 548-562. URL: https://onlinelibrary. wiley.com/doi/abs/10.1111/pce.13106.

Engelbrecht, B. M. J., L. S. Comita, R. Condit, T. A. Kursar, M. T. Tyree, B. L. Turner, and S. P. Hubbell (2007). "Drought sensitivity shapes species distribution patterns in tropical forests". In: Nature 447.7140, pp. 80-82. URL: https://www.nature.com/articles/ nature05747.

Esquivel-Muelbert, A., T. R. Baker, K. G. Dexter, S. L. Lewis, R. J. W. Brienen, et al. (2019). "Compositional response of Amazon forests to climate change". In: Global Change Biology 25.1, pp. 39-56. URL: https://onlinelibrary. wiley.com/doi/abs/10. $1111 / \mathrm{gcb} .14413$.

Esquivel-Muelbert, A., T. R. Baker, K. G. Dexter, S. L. Lewis, H. ter Steege, et al. (2017). "Seasonal drought limits tree species across the Neotropics". In: Ecography 40.5, pp. 618629. URL: https://onlinelibrary.wiley.com/doi/full/10.1111/ecog.01904.

Falster, D. S., R. A. Duursma, and R. G. FitzJohn (2018). "How functional traits influence plant growth and shade tolerance across the life cycle". In: Proceedings of the National Academy of Sciences 115.29, E6789-E6798. URL: http://www.pnas.org/lookup/doi/10. 1073/pnas.1714044115.

Falster, D. S. and M. Westoby (2003). "Plant height and evolutionary games". In: Trends in Ecology $\&$ Evolution 18.7, pp. 337-343. URL: http://www.sciencedirect.com/science/ article/pii/S0169534703000612.

Fan, Z.-X., S.-B. Zhang, G.-Y. Hao, J. Ferry Slik, and K.-F. Cao (2012). "Hydraulic conductivity traits predict growth rates and adult stature of 40 Asian tropical tree species better than wood density: Xylem traits and tree growth". In: Journal of Ecology 100.3, pp. 732-741. URL: http://doi.wiley.com/10.1111/j.1365-2745.2011.01939.x.

Fauset, S., M. Gloor, N. M. Fyllas, O. L. Phillips, G. P. Asner, et al. (2019). "IndividualBased Modeling of Amazon Forests Suggests That Climate Controls Productivity While Traits Control Demography". In: Frontiers in Earth Science 7, p. 83. URL: https://www. frontiersin.org/article/10.3389/feart.2019.00083/full.

Fauset, S., M. O. Johnson, M. Gloor, T. R. Baker, A. Monteagudo M., et al. (2015). "Hyperdominance in Amazonian forest carbon cycling". In: Nature Communications 6.1, p. 6857. URL: http://www.nature.com/articles/ncomms7857.

Feeley, K. J., S. Joseph Wright, M. N. Nur Supardi, A. R. Kassim, and S. J. Davies (2007). "Decelerating growth in tropical forest trees". In: Ecology Letters 10.6, pp. 461-469. URL: http://doi.wiley.com/10.1111/j.1461-0248.2007.01033.x.

Feldpausch, T. R., O. L. Phillips, R. J. W. Brienen, E. Gloor, J. Lloyd, et al. (2016). "Amazon forest response to repeated droughts". In: Global Biogeochemical Cycles 30.7, pp. 964-982. URL: http://doi.wiley.com/10.1002/2015GB005133.

Field, C. B., M. J. Behrenfeld, J. T. Randerson, and P. Falkowski (1998). "Primary Production of the Biosphere: Integrating Terrestrial and Oceanic Components". In: Science 281.5374, pp. 237-240. URL: https://science.sciencemag.org/content/281/5374/237.

Ford, C. R., M. A. McGuire, R. J. Mitchell, and R. O. Teskey (2004b). "Assessing variation in the radial profile of sap flux density in Pinus species and its effect on daily water use". In: Tree Physiology 24.3, pp. 241-249. URL: https://academic.oup.com/treephys/articlelookup/doi/10.1093/treephys/24.3.241.

Francis, E. J., H. C. Muller-Landau, S. J. Wright, M. D. Visser, Y. Iida, C. Fletcher, S. P. Hubbell, and A. R. Kassim (2017). "Quantifying the role of wood density in explaining interspecific variation in growth of tropical trees". In: Global Ecology and Biogeography 26.10, pp. 1078-1087. URL: http://doi.wiley.com/10.1111/geb.12604. 
Fu, R., L. Yin, W. Li, P. A. Arias, R. E. Dickinson, et al. (2013). "Increased dry-season length over southern Amazonia in recent decades and its implication for future climate projection". In: Proceedings of the National Academy of Sciences 110.45, pp. 1811018115. URL: http://www.pnas.org/cgi/doi/10.1073/pnas.1302584110.

Gelman, A. and E. Loken (2013). "The garden of forking paths: Why multiple comparisons can be a problem, even when there is no "fishing expedition" or "p-hacking" and the research hypothesis was posited ahead of time". In: Department of Statistic, Columbia University, New York, New York. URL: https://osf.io/n3axs/download.

Gibert, A., E. F. Gray, M. Westoby, I. J. Wright, and D. S. Falster (2016). "On the link between functional traits and growth rate: meta-analysis shows effects change with plant size, as predicted". In: Journal of Ecology 104.5. Ed. by S. Wilson, pp. 1488-1503. URL: http://doi.wiley.com/10.1111/1365-2745.12594.

Gleason, S. M., M. Westoby, S. Jansen, B. Choat, U. G. Hacke, et al. (2016). "Weak tradeoff between xylem safety and xylem-specific hydraulic efficiency across the world's woody plant species". In: New Phytologist 209.1, pp. 123-136. URL: https://nph.onlinelibrary. wiley.com/doi/abs/10.1111/nph.13646.

Grace, J. B. (2006). Structural Equation Modeling and Natural Systems. New York: Cambridge University Press.

Grace, J. B., T. M. Anderson, H. Olff, and S. M. Scheiner (2010). "On the specification of structural equation models for ecological systems". In: Ecological Monographs 80.1, pp. 67-87. URL: http://www.jstor.org/stable/27806874.

Grace, J. B. and K. A. Bollen (2006). The interface betwen theory and data in structural equation models. Open-File Report 1363, p. 33.

Grace, J. B., D. R. Schoolmaster, G. R. Guntenspergen, A. M. Little, B. R. Mitchell, K. M. Miller, and E. W. Schweiger (2012). "Guidelines for a graph-theoretic implementation of structural equation modeling". In: Ecosphere 3.8, pp. 1-44. URL: http://doi.wiley. com/10.1890/ES12-00048.1.

Grote, R., A. Gessler, R. Hommel, W. Poschenrieder, and E. Priesack (2016). "Importance of tree height and social position for drought-related stress on tree growth and mortality". In: Trees 30.5, pp. 1467-1482. URL: https://doi.org/10.1007/s00468-016-1446-x.

Hacke, U. G., J. S. Sperry, J. K. Wheeler, and L. Castro (2006). "Scaling of angiosperm xylem structure with safety and efficiency". In: Tree Physiology 26.6, pp. 689-701. URL: https://academic.oup.com/treephys/article-lookup/doi/10.1093/treephys/26.6.689.

Hacke, U. G., J. S. Sperry, W. T. Pockman, S. D. Davis, and K. A. McCulloh (2001). "Trends in wood density and structure are linked to prevention of xylem implosion by negative pressure". In: Oecologia 126.4, pp. 457-461. URL: http://link.springer.com/10. $1007 / \mathrm{s} 004420100628$.

Hacke, U. G., R. Spicer, S. G. Schreiber, and L. Plavcová (2017). "An ecophysiological and developmental perspective on variation in vessel diameter". In: Plant, Cell \& Environment 40.6, pp. 831-845. URL: https://www.onlinelibrary.wiley.com/doi/abs/10. $1111 /$ pce.12777.

Hagedorn, F., J. Joseph, M. Peter, J. Luster, K. Pritsch, et al. (2016). "Recovery of trees from drought depends on belowground sink control". In: Nature Plants 2.8, pp. 1-5. URL: https://www.nature.com/articles/nplants2016111.

Hartmann, H. (2015). "Carbon starvation during drought-induced tree mortality - are we chasing a myth?" In: Journal of Plant Hydraulics 2, e005. URL: https://hal.archivesouvertes.fr/hal-01230747.

Hartmann, H. (2011). "Will a 385 million year-struggle for light become a struggle for water and for carbon? - How trees may cope with more frequent climate change-type 
drought event". In: Global Change Biology 17.1, pp. 642-655. URL: http://doi.wiley. com/10.1111/j.1365-2486.2010.02248.x.

Hartmann, H., C. F. Moura, W. R. L. Anderegg, N. K. Ruehr, Y. Salmon, et al. (2018). "Research frontiers for improving our understanding of drought-induced tree and forest mortality". In: New Phytologist 218.1, pp. 15-28. URL: http://doi.wiley.com/10.1111/ nph.15048.

Hartmann, H. and S. Trumbore (2016). "Understanding the roles of nonstructural carbohydrates in forest trees - from what we can measure to what we want to know". In: New Phytologist 211.2, pp. 386-403. URL: http://doi.wiley.com/10.1111/nph.13955.

Head, M. L., L. Holman, R. Lanfear, A. T. Kahn, and M. D. Jennions (2015). "The Extent and Consequences of P-Hacking in Science". In: PLOS Biology 13.3, e1002106. URL: https://dx.plos.org/10.1371/journal.pbio.1002106.

Hietz, P., S. Rosner, U. Hietz-Seifert, and S. J. Wright (2016). "Wood traits related to size and life history of trees in a Panamanian rainforest". In: New Phytologist 213.1, pp. 170-180. URL: http://doi.wiley.com/10.1111/nph.14123.

Hoeber, S., C. Leuschner, L. Köhler, D. Arias-Aguilar, and B. Schuldt (2014). "The importance of hydraulic conductivity and wood density to growth performance in eight tree species from a tropical semi-dry climate". In: Forest Ecology and Management 330, pp. 126-136. URL: https://linkinghub.elsevier.com/retrieve/pii/S037811271400406X.

Hölttä, T., M. Mencuccini, and E. Nikinmaa (2011). "A carbon cost-gain model explains the observed patterns of xylem safety and efficiency". In: Plant, Cell \& Environment 34.11, pp. 1819-1834. URL: http://doi.wiley.com/10.1111/j.1365-3040.2011.02377.x.

Horna, V., B. Schuldt, S. Brix, and C. Leuschner (2011). "Environment and tree size controlling stem sap flux in a perhumid tropical forest of Central Sulawesi, Indonesia". In: Annals of Forest Science 68.5, pp. 1027-1038. URL: http://link.springer.com/10. 1007/s13595-011-0110-2.

Huber, B. (1932). "Beobachtung und Messung pflanzlicher Saftströme". In: Berichte der Deutschen Botanischen Gesellschaft 50, pp. 89-109.

Hurlbert, S. H., R. A. Levine, and J. Utts (2019). "Coup de Grâce for a Tough Old Bull: "Statistically Significant" Expires". In: The American Statistician 73.sup1, pp. 352-357. URL: https://www.tandfonline.com/doi/full/10.1080/00031305.2018.1543616.

Ioannidis, J. P. A. (2005). "Why Most Published Research Findings Are False". In: PLOS Medicine 2.8, e124. URL: https://journals.plos.org/plosmedicine/article?id=10.1371/ journal.pmed.0020124.

Itoh, A., S. Nanami, T. Harata, T. Ohkubo, S. Tan, L. Chong, S. J. Davies, and T. Yamakura (2012). "The Effect of Habitat Association and Edaphic Conditions on Tree Mortality during El Niño-induced Drought in a Bornean Dipterocarp Forest". In: Biotropica 44.5, pp. 606-617. URL: http://doi.wiley.com/10.1111/j.1744-7429.2012.00867.x.

Jansen, S., M. Klepsch, S. Li, M. Kotowska, S. Schiele, Y. Zhang, and H. Schenk (2018). "Challenges in understanding air-seeding in angiosperm xylem". In: Acta Horticulturae 1222, pp. 13-20. URL: https://www.actahort.org/books/1222/1222_3.htm.

Joetzjer, E., H. Douville, C. Delire, and P. Ciais (2013). "Present-day and future Amazonian precipitation in global climate models: CMIP5 versus CMIP3". In: Climate Dynamics 41, p. 2921. URL: https://ui.adsabs.harvard.edu/abs/2013ClDy...41.2921J/abstract.

King, D. A. (1990). "The Adaptive Significance of Tree Height". In: The American Naturalist 135.6, pp. 809-828. URL: https://www.journals.uchicago.edu/doi/abs/10.1086/ 285075 . 
King, D. A., S. J. Davies, S. Tan, and N. S. M. Noor (2006). "The role of wood density and stem support costs in the growth and mortality of tropical trees". In: Journal of Ecology 94.3, pp. 670-680. URL: http://doi.wiley.com/10.1111/j.1365-2745.2006.01112.x.

Kline, R. B. (2011). Principles and practice of structural equation modeling. 3rd ed. Methodology in the social sciences. OCLC: ocn636917444. New York: Guilford Press.

Koch, G. W., S. C. Sillett, G. M. Jennings, and S. D. Davis (2004). "The limits to tree height". In: Nature 428.6985, p. 851. URL: https: //www. nature.com/articles / nature02417.

Körner, C. (2015). "Paradigm shift in plant growth control". In: Current Opinion in Plant Biology 25, pp. 107-114. URL: http:/ / www. sciencedirect. com/science/article/ pii / S1369526615000540.

Kotowska, M. M., D. Hertel, Y. A. Rajab, H. Barus, and B. Schuldt (2015). "Patterns in hydraulic architecture from roots to branches in six tropical tree species from cacao agroforestry and their relation to wood density and stem growth". In: Frontiers in Plant Science 6. URL: https://www.frontiersin.org/articles/10.3389/fpls.2015.00191/full.

Kraft, N. J. B., M. R. Metz, R. S. Condit, and J. Chave (2010). "The relationship between wood density and mortality in a global tropical forest data set". In: New Phytologist 188.4, pp. 1124-1136. URL: http://doi.wiley.com/10.1111/j.1469-8137.2010.03444.x.

Lens, F., J. S. Sperry, M. A. Christman, B. Choat, D. Rabaey, and S. Jansen (2011). "Testing hypotheses that link wood anatomy to cavitation resistance and hydraulic conductivity in the genus Acer". In: New Phytologist 190.3, pp. 709-723. URL: http: //doi.wiley.com/10.1111/j.1469-8137.2010.03518.x.

Lindenmayer, D. B., W. F. Laurance, and J. F. Franklin (2012). "Global Decline in Large Old Trees". In: Science 338.6112, pp. 1305-1306. uRL: http://www.sciencemag.org/cgi/ doi/10.1126/science.1231070.

Lutz, J. A., T. J. Furniss, D. J. Johnson, S. J. Davies, D. Allen, et al. (2018). "Global importance of large-diameter trees". In: Global Ecology and Biogeography 27.7, pp. 849864. URL: http://doi.wiley.com/10.1111/geb.12747.

Machado, S. R., R. A. Rodella, V. Angyalossy, and C. R. Marcati (2007). "Structural variations in root and stem wood of Styrax (Styracaceae) from Brazilian forest and Cerrado". In: IAWA Journal 28.2, pp. 173-188. URL: https://brill.com/view/journals/ iawa/28/2/article-p173_5.xml.

Maharjan, S. K., L. Poorter, M. Holmgren, F. Bongers, J. J. Wieringa, and W. D. Hawthorne (2011). "Plant Functional Traits and the Distribution of West African Rain Forest Trees along the Rainfall Gradient: Functional Traits Affect Species Distribution". In: Biotropica 43.5, pp. 552-561. URL: http://doi.wiley.com/10.1111/j.17447429.2010.00747.x.

Malhi, Y. (2012). "The productivity, metabolism and carbon cycle of tropical forest vegetation". In: Journal of Applied Ecology, pp. 65-75. URL: https://besjournals.onlinelibrary. wiley.com/doi/abs/10.1111/j.1365-2745.2011.01916.x\%5C\%4010.1111/\%5C\%28ISSN\% 5C\%291365-2664.NovelEcosystemsintheAnthropocene.

Markesteijn, L., L. Poorter, F. Bongers, H. Paz, and L. Sack (2011). "Hydraulics and life history of tropical dry forest tree species: coordination of species' drought and shade tolerance". In: New Phytologist 191.2, pp. 480-495. URL: http://doi.wiley.com/10.1111/ j.1469-8137.2011.03708.x.

Martin-StPaul, N. K., D. Longepierre, R. Huc, S. Delzon, R. Burlett, R. Joffre, S. Rambal, and H. Cochard (2014). "How reliable are methods to assess xylem vulnerability to cavitation? The issue of 'open vessel' artifact in oaks". In: Tree Physiology 34.8, pp. 894- 
905. URL: https://academic.oup.com/treephys/article-lookup/doi/10.1093/treephys/ tpu059.

Martínez-Vilalta, J., A. Sala, D. Asensio, L. Galiano, G. Hoch, S. Palacio, F. I. Piper, and F. Lloret (2016). "Dynamics of non-structural carbohydrates in terrestrial plants: a global synthesis". In: Ecological Monographs 86.4, pp. 495-516. URL: http://doi.wiley. com/10.1002/ecm.1231.

Mayo, D. G. (2018). Statistical inference as severe testing: How to get beyond the Statistics Wars. Cambridge: Cambridge University Press.

McDowell, N. G., D. J. Beerling, D. D. Breshears, R. A. Fisher, K. F. Raffa, and M. Stitt (2011). "The interdependence of mechanisms underlying climate-driven vegetation mortality". In: Trends in Ecology 83 Evolution 26.10, pp. 523-532. URL: https: //linkinghub.elsevier.com/retrieve/pii/S0169534711001698.

McDowell, N., C. D. Allen, K. Anderson-Teixeira, P. Brando, R. Brienen, et al. (2018). "Drivers and mechanisms of tree mortality in moist tropical forests". In: New Phytologist 219.3, pp. 851-869. URL: https://nph.onlinelibrary.wiley.com/doi/abs/10.1111/nph. 15027.

McDowell, N., W. T. Pockman, C. D. Allen, D. D. Breshears, N. Cobb, et al. (2008). "Mechanisms of plant survival and mortality during drought: why do some plants survive while others succumb to drought?" In: New Phytologist 178.4, pp. 719-739. URL: http: //doi.wiley.com/10.1111/j.1469-8137.2008.02436.x.

Meinzer, F. C., B. J. Bond, J. M. Warren, and D. R. Woodruff (2005). "Does water transport scale universally with tree size?" In: Functional Ecology 19.4, pp. 558-565. URL: http://doi.wiley.com/10.1111/j.1365-2435.2005.01017.x.

Meinzer, F. C., M. J. Clearwater, and G. Goldstein (2001b). "Water transport in trees: current perspectives, new insights and some controversies". In: Environmental and Experimental Botany 45.3, pp. 239-262. URL: https://linkinghub.elsevier.com/retrieve/ pii/S0098847201000740.

Meister, K., M. S. Ashton, D. J. Craven, and H. Griscom (2012). "Carbon Dynamics of Tropical Forests". In: Managing Forest Carbon in a Changing Climate. Ed. by M. S. Ashton, M. L. Tyrrell, D. Spalding, and B. Gentry. Dordrecht: Springer Netherlands, pp. 51-76. URL: http://link.springer.com/10.1007/978-94-007-2232-3_18.

Miller, D. R., C. A. Vavrina, and T. W. Christensen (1980). "Measurement of Sap Flow and Transpiration in Ring-porous Oaks Using a Heat Puise Velocity Technique". In: Forest Science 26.3, pp. 485-494. URL: https://academic.oup.com/forestscience/article/ $26 / 3 / 485 / 4788710$.

Muller-Landau, H. C., R. S. Condit, J. Chave, S. C. Thomas, S. A. Bohlman, et al. (2006). "Testing metabolic ecology theory for allometric scaling of tree size, growth and mortality in tropical forests". In: Ecology Letters 9.5, pp. 575-588. URL: http://doi. wiley.com/10.1111/j.1461-0248.2006.00904.x.

Nardini, A., M. A. Lo Gullo, and S. Salleo (2011). "Refilling embolized xylem conduits: Is it a matter of phloem unloading?" In: Plant Science 180.4, pp. 604-611. URL: https: //linkinghub.elsevier.com/retrieve/pii/S0168945211000045.

Niu, F., A. Röll, A. Hardanto, A. Meijide, M. Köhler, Hendrayanto, and D. Hölscher (2015). "Oil palm water use: calibration of a sap flux method and a field measurement scheme". In: Tree Physiology 35.5, pp. 563-573. URL: https://academic.oup.com/treephys/articlelookup/doi/10.1093/treephys/tpv013.

O'Brien, M. J., B. M. J. Engelbrecht, J. Joswig, G. Pereyra, B. Schuldt, et al. (2017). "A synthesis of tree functional traits related to drought-induced mortality in forests across 
climatic zones". In: Journal of Applied Ecology 54.6. Ed. by J. Firn, pp. 1669-1686. URL: http://doi.wiley.com/10.1111/1365-2664.12874.

O'Brien, M. J., S. Leuzinger, C. D. Philipson, J. Tay, and A. Hector (2014). "Drought survival of tropical tree seedlings enhanced by non-structural carbohydrate levels". In: Nature Climate Change 4.8, pp. 710-714. URL: http://www. nature.com/articles / nclimate2281.

Oishi, A. C., R. Oren, and P. C. Stoy (2008). "Estimating components of forest evapotranspiration: A footprint approach for scaling sap flux measurements". In: Agricultural and Forest Meteorology 148.11, pp. 1719-1732. URL: https://linkinghub.elsevier.com/ retrieve/pii/S0168192308001810.

Olson, M. E., T. Anfodillo, J. A. Rosell, G. Petit, A. Crivellaro, et al. (2014). "Universal hydraulics of the flowering plants: vessel diameter scales with stem length across angiosperm lineages, habits and climates". In: Ecology Letters 17.8. Ed. by B. Enquist, pp. 988-997. URL: http://doi.wiley.com/10.1111/ele.12302.

Olson, M. E., D. Soriano, J. A. Rosell, T. Anfodillo, M. J. Donoghue, et al. (2018). "Plant height and hydraulic vulnerability to drought and cold". In: Proceedings of the National Academy of Sciences 115.29, pp. 7551-7556. URL: http://www.pnas.org/lookup/doi/ $10.1073 /$ pnas. 1721728115 .

Pan, Y., R. A. Birdsey, J. Fang, R. Houghton, P. E. Kauppi, et al. (2011). "A Large and Persistent Carbon Sink in the World's Forests". In: Science 333.6045, pp. 988-993. URL: https://science.sciencemag.org/content/333/6045/988.

Philipson, C. D., D. H. Dent, M. J. O'Brien, J. Chamagne, D. Dzulkifli, et al. (2014). "A trait-based trade-off between growth and mortality: evidence from 15 tropical tree species using size-specific relative growth rates". In: Ecology and Evolution 4.18, pp. $3675-3688$.

Phillips, O. L., L. E. O. C. Aragao, S. L. Lewis, J. B. Fisher, J. Lloyd, et al. (2009). "Drought Sensitivity of the Amazon Rainforest". In: Science 323.5919, pp. 1344-1347. URL: http://www.sciencemag.org/cgi/doi/10.1126/science.1164033.

Phillips, O. L., G. van der Heijden, S. L. Lewis, G. López-González, L. E. O. C. Aragão, et al. (2010b). "Drought-mortality relationships for tropical forests". In: New Phytologist 187.3, pp. 631-646. URL: http://doi.wiley.com/10.1111/j.1469-8137.2010.03359.x.

Poorter, L., I. McDonald, A. Alarcón, E. Fichtler, J.-C. Licona, et al. (2010). "The importance of wood traits and hydraulic conductance for the performance and life history strategies of 42 rainforest tree species". In: New Phytologist 185.2, pp. 481-492. URL: http://doi.wiley.com/10.1111/j.1469-8137.2009.03092.x.

Reyes-Acosta, J. L. and M. W. Lubczynski (2014). "Optimization of dry-season sap flow measurements in an oak semi-arid open woodland in Spain". In: Ecohydrology 7.2, pp. 258-277. URL: http://doi.wiley.com/10.1002/eco.1339.

Rosell, J. A., M. E. Olson, and T. Anfodillo (2017). "Scaling of Xylem Vessel Diameter with Plant Size: Causes, Predictions, and Outstanding Questions". In: Current Forestry Reports 3.1, pp. 46-59. URL: http://link.springer.com/10.1007/s40725-017-0049-0.

Rowland, L., A. C. L. da Costa, D. R. Galbraith, R. S. Oliveira, O. J. Binks, et al. (2015a). "Death from drought in tropical forests is triggered by hydraulics not carbon starvation". In: Nature 528.7580, pp. 119-122.

Roy, J., H. A. Mooney, and B. Saugier (2001). Terrestrial Global Productivity. Elsevier.

Rüger, N., C. Wirth, S. J. Wright, and R. Condit (2012). "Functional traits explain light and size response of growth rates in tropical tree species". In: Ecology 93.12, pp. 26262636. URL: http://doi.wiley.com/10.1890/12-0622.1. 
Ryan, M. G., N. Phillips, and B. J. Bond (2006). "The hydraulic limitation hypothesis revisited". In: Plant, Cell and Environment 29.3, pp. 367-381. URL: http://doi.wiley. com/10.1111/j.1365-3040.2005.01478.x.

Ryan, M. G. and B. J. Yoder (1997). "Hydraulic Limits to Tree Height and Tree Growth". In: BioScience 47.4, pp. 235-242. URL: https://www.jstor.org/stable/1313077.

Saatchi, S., S. Asefi-Najafabady, Y. Malhi, L. E. O. C. Aragao, L. O. Anderson, R. B. Myneni, and R. Nemani (2013). "Persistent effects of a severe drought on Amazonian forest canopy". In: Proceedings of the National Academy of Sciences 110.2, pp. 565-570. URL: http://www.pnas.org/cgi/doi/10.1073/pnas.1204651110.

Sagarin, R. and A. Pauchard (2010). "Observational approaches in ecology open new ground in a changing world". In: Frontiers in Ecology and the Environment 8.7, pp. 379386. URL: https://esajournals.onlinelibrary.wiley.com/doi/abs/10.1890/090001.

Sala, A., D. R. Woodruff, and F. C. Meinzer (2012). "Carbon dynamics in trees: feast or famine?" In: Tree Physiology 32.6, pp. 764-775. URL: https://academic.oup.com/ treephys/article-lookup/doi/10.1093/treephys/tpr143.

Sala, A., F. Piper, and G. Hoch (2010). "Physiological mechanisms of drought-induced tree mortality are far from being resolved". In: New Phytologist 186, pp. 274-281. URL: https://nph.onlinelibrary.wiley.com/doi/abs/10.1111/j.1469-8137.2009.03167.x\%5C\% 4010.1002/\%5C\%28ISSN\%5C\%291469-8137\%5C\%28CAT\%5C\%29VirtualIssues\%5C\% 28VI\%5C\%29VirtualSpecialIssuetomarkthe200thVolumeofNewPhytologist.

Salleo, S., P. Trifilò, S. Esposito, A. Nardini, and M. A. L. Gullo (2009). "Starch-to-sugar conversion in wood parenchyma of field-growing Laurus nobilis plants: a component of the signal pathway for embolism repair?" In: Functional Plant Biology 36.9, pp. 815825. URL: https://www.publish.csiro.au/fp/FP09103.

Schlesinger, W. H. and S. Jasechko (2014). "Transpiration in the global water cycle". In: Agricultural and Forest Meteorology 189-190, pp. 115-117. URL: https://linkinghub. elsevier.com/retrieve/pii/S0168192314000203.

Schuldt, B., C. Leuschner, N. Brock, and V. Horna (2013). "Changes in wood density, wood anatomy and hydraulic properties of the xylem along the root-to-shoot flow path in tropical rainforest trees". In: Tree Physiology 33.2, pp. 161-174. URL: https://academic. oup.com/treephys/article-lookup/doi/10.1093/treephys/tps122.

Secchi, F., C. Pagliarani, and M. A. Zwieniecki (2017). "The functional role of xylem parenchyma cells and aquaporins during recovery from severe water stress". In: Plant, Cell \& Environment 40.6, pp. 858-871. URL: https://onlinelibrary.wiley.com/doi/abs/ $10.1111 /$ pce. 12831 .

Sevanto, S., N. G. Mcdowell, L. T. Dickman, R. Pangle, and W. T. Pockman (2014). "How do trees die? A test of the hydraulic failure and carbon starvation hypotheses". In: Plant, Cell \& Environment 37.1, pp. 153-161. URL: http://doi.wiley.com/10.1111/pce.12141.

Simmons, J. P., L. D. Nelson, and U. Simonsohn (2011). "False-Positive Psychology: Undisclosed Flexibility in Data Collection and Analysis Allows Presenting Anything as Significant". In: Psychological Science 22.11, pp. 1359-1366. URL: http://journals.sagepub. com/doi/10.1177/0956797611417632.

Slik, J. W. F. (2004). "El Niño droughts and their effects on tree species composition and diversity in tropical rain forests". In: Oecologia 141.1, pp. 114-120. URL: http: //link.springer.com/10.1007/s00442-004-1635-y.

Sperry, J. S., U. G. Hacke, and J. K. Wheeler (2005). "Comparative analysis of end wall resistivity in xylem conduits". In: Plant, Cell and Environment 28.4, pp. 456-465. URL: http://doi.wiley.com/10.1111/j.1365-3040.2005.01287.x. 
Stephenson, N. L., A. J. Das, R. Condit, S. E. Russo, P. J. Baker, et al. (2014). "Rate of tree carbon accumulation increases continuously with tree size". In: Nature 507.7490, pp. 90-93. URL: https://www.nature.com/articles/nature12914.

Stephenson, N. L., P. J. van Mantgem, A. G. Bunn, H. Bruner, M. E. Harmon, K. B. O'Connell, D. L. Urban, and J. F. Franklin (2011). "Causes and implications of the correlation between forest productivity and tree mortality rates". In: Ecological Monographs 81.4, pp. 527-555. URL: http://doi.wiley.com/10.1890/10-1077.1.

Steppe, K., D. J. De Pauw, T. M. Doody, and R. O. Teskey (2010). "A comparison of sap flux density using thermal dissipation, heat pulse velocity and heat field deformation methods". In: Agricultural and Forest Meteorology 150.7-8, pp. 1046-1056. URL: https: //linkinghub.elsevier.com/retrieve/pii/S0168192310001000.

Stovall, A. E. L., H. Shugart, and X. Yang (2019). "Tree height explains mortality risk during an intense drought". In: Nature Communications 10.1, p. 4385. URL: http:// www.nature.com/articles/s41467-019-12380-6.

Sun, H., D. P. Aubrey, and R. O. Teskey (2012). "A simple calibration improved the accuracy of the thermal dissipation technique for sap flow measurements in juvenile trees of six species". In: Trees 26.2, pp. 631-640. URL: http://link. springer.com/10. 1007/s00468-011-0631-1.

Tixier, A., S. Herbette, S. Jansen, M. Capron, P. Tordjeman, H. Cochard, and E. Badel (2014). "Modelling the mechanical behaviour of pit membranes in bordered pits with respect to cavitation resistance in angiosperms". In: Annals of Botany 114.2, pp. 325334. URL: https://academic.oup.com/aob/article-lookup/doi/10.1093/aob/mcu109.

Torres-Ruiz, J. M., H. Cochard, B. Choat, S. Jansen, R. López, et al. (2017). "Xylem resistance to embolism: presenting a simple diagnostic test for the open vessel artefact". In: New Phytologist 215.1, pp. 489-499. URL: https://nph.onlinelibrary.wiley.com/doi/ abs/10.1111/nph.14589.

Torres-Ruiz, J. M., H. Cochard, S. Mayr, B. Beikircher, A. Diaz-Espejo, C. M. RodriguezDominguez, E. Badel, and J. E. Fernández (2014). "Vulnerability to cavitation in Olea europaea current-year shoots: further evidence of an open-vessel artifact associated with centrifuge and air-injection techniques". In: Physiologia Plantarum 152.3, pp. 465-474. URL: http://doi.wiley.com/10.1111/ppl.12185.

Trugman, A. T., M. Detto, M. K. Bartlett, D. Medvigy, W. R. L. Anderegg, C. Schwalm, B. Schaffer, and S. W. Pacala (2018). "Tree carbon allocation explains forest droughtkill and recovery patterns". In: Ecology Letters 21.10, pp. 1552-1560. URL: https:// onlinelibrary.wiley.com/doi/abs/10.1111/ele.13136.

Tyree, M. T. (2003). "Hydraulic limits on tree performance: transpiration, carbon gain and growth of trees". In: Trees 17, pp. 95-100.

van Gelder, H. A., L. Poorter, and F. J. Sterck (2006). "Wood mechanics, allometry, and life-history variation in a tropical rain forest tree community". In: New Phytologist 171.2, pp. 367-378. URL: http://doi.wiley.com/10.1111/j.1469-8137.2006.01757.x.

van Nieuwstadt, M. G. L. (2002). "Trial by fire: postfire development of a tropical dipterocarp forest". OCLC: 907013963. PhD thesis. Utrecht, Netherlands: Universiteit Utrecht.

Vandegehuchte, M. W. and K. Steppe (2012b). "Use of the correct heat conductionconvection equation as basis for heat-pulse sap flow methods in anisotropic wood". In: Journal of Experimental Botany 63.8, pp. 2833-2839. URL: https://academic.oup.com/ jxb/article-lookup/doi/10.1093/jxb/ers041.

- (2012c). "Interpreting the Heat Field Deformation method: Erroneous use of thermal diffusivity and improved correlation between temperature ratio and sap flux density". 
In: Agricultural and Forest Meteorology 162-163, pp. 91-97. URL: https://linkinghub. elsevier.com/retrieve/pii/S0168192312001438.

Vandegehuchte, M. and K. Steppe (2013). "Sap-flux density measurement methods: working principles and applicability". In: Functional Plant Biology 40.3, pp. 213-223. URL: http://dx.doi.org/10.1071/FP12233.

Wang, K. and R. E. Dickinson (2012). "A review of global terrestrial evapotranspiration: Observation, modeling, climatology, and climatic variability". In: Reviews of Geophysics 50.2. URL: http://doi.wiley.com/10.1029/2011RG000373.

Wasserstein, R. L. and N. A. Lazar (2016). "The ASA's Statement on $p$-Values: Context, Process, and Purpose". In: The American Statistician 70.2, pp. 129-133. URL: https: //www.tandfonline.com/doi/full/10.1080/00031305.2016.1154108.

Wasserstein, R. L., A. L. Schirm, and N. A. Lazar (2019). "Moving to a World Beyond " $p<0.05 "$ ". In: The American Statistician 73.sup1, pp. 1-19. URL: https://www. tandfonline.com/doi/full/10.1080/00031305.2019.1583913.

West, G. B., J. H. Brown, and B. J. Enquist (1999). "A general model for the structure and allometry of plant vascular systems". In: Nature 400.6745, pp. 664-667. URL: http: //www.nature.com/articles/23251.

Wheeler, J. K., B. A. Huggett, A. N. Tofte, F. E. Rockwell, and N. M. Holbrook (2013). "Cutting xylem under tension or supersaturated with gas can generate PLC and the appearance of rapid recovery from embolism: Sampling induced embolism". In: Plant, Cell $\&$ Environment 36, pp. 1938-1949. URL: http://doi.wiley.com/10.1111/pce.12139.

Wheeler, J. K., J. S. Sperry, U. G. Hacke, and N. Hoang (2005). "Inter-vessel pitting and cavitation in woody Rosaceae and other vesselled plants: a basis for a safety versus efficiency trade-off in xylem transport". In: Plant, Cell and Environment 28.6, pp. 800812. URL: http://doi.wiley.com/10.1111/j.1365-3040.2005.01330.x.

Whittaker, R. H. (1967). "Gradient Analysis of Vegetation". In: Biological Reviews 42.2, pp. 207-264. URL: https://onlinelibrary.wiley.com/doi/abs/10.1111/j.1469-185X.1967. tb01419.x.

Wilson, K. B., P. J. Hanson, P. J. Mulholland, D. D. Baldocchi, and S. D. Wullschleger (2001). "A comparison of methods for determining forest evapotranspiration and its components: sap-flow, soil water budget, eddy covariance and catchment water balance". In: Agricultural and Forest Meteorology 106.2, pp. 153-168. URL: https://linkinghub. elsevier.com/retrieve/pii/S0168192300001994.

Wright, S. J., K. Kitajima, N. J. B. Kraft, P. B. Reich, I. J. Wright, et al. (2010). "Functional traits and the growth-mortality trade-off in tropical trees". In: Ecology 91.12, pp. 3664-3674. URL: http://www.jstor.org/stable/29779549.

Wullschleger, S. D., F. C. Meinzer, and R. A. Vertessy (1998). "A review of whole-plant water use studies in trees". In: Tree Physiology 18.8-9, pp. 499-512. URL: https:// academic.oup.com/treephys/article/18/8-9/499/1632547.

Zanne, A. E., M. Westoby, D. S. Falster, D. D. Ackerly, S. R. Loarie, S. E. J. Arnold, and D. A. Coomes (2010). "Angiosperm wood structure: Global patterns in vessel anatomy and their relation to wood density and potential conductivity". In: American Journal of Botany 97.2, pp. 207-215. URL: http://doi.wiley.com/10.3732/ajb.0900178.

Zhang, J.-G., Q.-Y. He, W.-Y. Shi, K. Otsuki, N. Yamanaka, and S. Du (2015). "Radial variations in xylem sap flow and their effect on whole-tree water use estimates". In: Hydrological Processes 29.24, pp. 4993-5002. uRL: http://doi.wiley.com/10.1002/hyp. 10465.

Zhang, J.-L. and K.-F. Cao (2009). "Stem hydraulics mediates leaf water status, carbon gain, nutrient use efficiencies and plant growth rates across dipterocarp species". In: 
Functional Ecology 23.4, pp. 658-667. URL: http://doi.wiley.com/10.1111/j.13652435.2009.01552.x.

Zhao, M. and S. W. Running (2010). "Drought-Induced Reduction in Global Terrestrial Net Primary Production from 2000 Through 2009". In: Science 329.5994, pp. 940-943. URL: http://www.sciencemag.org/cgi/doi/10.1126/science.1192666.

Ziemińska, K., D. W. Butler, S. M. Gleason, I. J. Wright, and M. Westoby (2013). "Fibre wall and lumen fractions drive wood density variation across 24 Australian angiosperms". In: AoB PLANTS 5. URL: https://academic.oup.com/aobpla/article/doi/10.1093/ aobpla/plt046/163348.

Ziemińska, K., M. Westoby, and I. J. Wright (2015). "Broad Anatomical Variation within a Narrow Wood Density Range - A Study of Twig Wood across 69 Australian Angiosperms". In: PLOS ONE 10.4. Ed. by S. Delzon, e0124892. URL: https://dx.plos.org/ 10.1371/journal.pone.0124892.

Zwieniecki, M. A. and N. M. Holbrook (2009). "Confronting Maxwell's demon: biophysics of xylem embolism repair". In: Trends in Plant Science 14.10, pp. 530-534. URL: https: //linkinghub.elsevier.com/retrieve/pii/S1360138509001812. 


\section{Methodology}

\subsection{Design of the field study in Costa Rica}

\subsubsection{Research area}

The five research sites of the field study in Costa Rica are situated alongside a precipitation gradient stretching over the Pacific coastline of Costa Rica (cf. Figure 2.1). From the northwestern Guanacaste region to the Osa peninsula in the southernmost part of the country, the mean annual precipitation increases about threefold, accompanied by a stark reduction in rainfall seasonality. The changes in environmental conditions along the gradient are mirrored by a drastic shift in the dominating vegetation type, from seasonally dry forest stands dominated by deciduous, drought-adapted species in the north to evergreen humid tropical rainforest vegetation in the south.

The five research sites considered in this work form part of a plot network maintained by the School of Forestry Engineering of the Instituto Tecnológico de Costa Rica (ITCR), which kindly permitted their use for our study.

\subsubsection{Site descriptions}

The northernmost site is situated on the premises of the Estación Experimental Forestal Horizontes (EEFH), which forms part of the to the Área de Conservación de Guanacaste in the cantón Liberia in the Guanacaste province of Costa Rica. The climate in Horizontes is characterized by an almost rain-free dry season of 5-6 months (December-May). The long-term mean annual temperature is $25^{\circ} \mathrm{C}$, while the annual precipitation recorded at the nearby Santa Rosa climate station ranges from 880 to $3030 \mathrm{~mm}$ with a 30 -year average of $1765 \mathrm{~mm}$ (Instituto Meteorológico de Costa Rica 2015; Werden et al. 2018b). The site comprises ten secondary forest plots $(60 \times 60 \mathrm{~m})$ in different states of succession at elevations of about $60-100 \mathrm{~m}$ a.s.l.. The vegetation is constituted by relatively open tropical dry forest stands dominated by deciduous trees. The plots are situated on former pasture land which was abandoned between 21 and 40 years before the begin of the measurement campaign in 2015 (Reyes Cordero 2012). Inside the sample plots, the vegetation is formed by a mosaic of relatively young secondary forest trees and occasional large emergent trees that were left uncut by farmers as shading trees for livestock, especially Hymenaea courbaril, which is known to produce fruits that are readily eaten by cattle (M. Castillo Ugalde, personal communication). As a part of studies performed by the ITCR, all trees with a diameter at breast height $>5 \mathrm{~cm}$ were censused twice (in 2012 and 2013). The soils in the research area are predominantly made up by Inceptisols and Vertisols (Alfaro et al. 2001; Reyes Cordero 2012).

Miramar, the next site on the precipitation gradient, is situated in the cantón Montes de Oro of the Puntarenas province. As at the EEFH site, the dominant vegetation type is tropical dry forest, although with a slightly shorter dry period of four months, a somewhat 

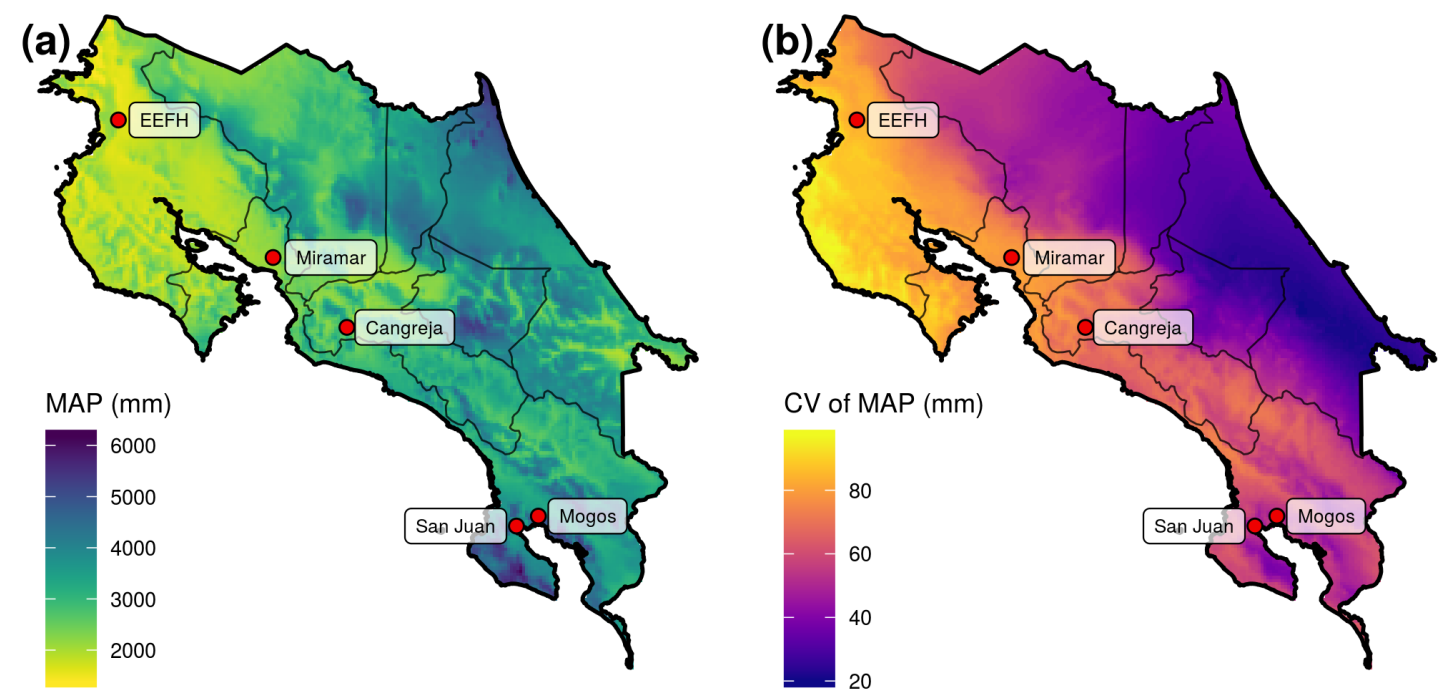

Figure 2.1: Map of the research are showing the five research sites overlaid over data from the CHELSA climatologies (Karger et al. 2017). (a) estimated mean annual precipitation from 1979 to 2013 and (b) coefficient of variation of the monthly average precipitation in the same period as a measure of seasonality (cf. BIOCLIM15 in Hijmans et al. 2005).

higher annual precipitation of 2000 - $4000 \mathrm{~mm}$ and mean annual temperatures between 24 and $30{ }^{\circ} \mathrm{C}$ (Zamora Ávila 2010). The soils are classified as Ultisols and Alfisols (Zamora Ávila 2010). In Miramar, there are 8 plots of $50 \times 50 \mathrm{~m}$ (situated at about $60-80 \mathrm{~m}$ a.s.l.) in which census data are available for all trees with $\mathrm{DBH}>10 \mathrm{~cm}$ for the years 2011 and 2013.

La Cangreja is situated in the cantón Puriscal (San José province). The region is considerably more humid than the two aforementioned sites, facing annual precipitations of over 4000 mm (Jiménez 1999; Guzmán Q and Vega S 2015), with a long-term annual mean temperature around $25^{\circ} \mathrm{C}$ (Acosta Vargas 2012) and predominantly humid conditions also during the dry period between December and April. The vegetation is formed by primary humid tropical forest on nutrient-poor soils situated in a terrain with a complex topography and steep slopes (Jiménez 1999). Occasionally, the floristic composition is enriched by the occurrence of dry forest tree species such as Hymenaea courbaril. The plots (seven plots of variable shape and areas of $1.000-2.500 \mathrm{~m}^{2}$ ) are situated at about 370-470 m a.s.l.. In these plots, all trees $>10 \mathrm{~cm}$ DBH were censused in 1998, 1999 and 2011 (Acosta Vargas 1998; Acosta Vargas 2012).

The remaining two sites, Los Mogos and San Juan, are both situated on the Osa Peninsula (Cantón Osa, Puntarenas province) and do not differ much in their site conditions. The climate on the peninsula is hyper-humid with a mean annual temperature of $27^{\circ} \mathrm{C}$ and average precipitations of around $5500 \mathrm{~mm}$. A dry season of variable length occurs between December and April (Sanchez Azofeifa et al. 2002), lasting between 0 and 5 months (Vílchez and Rocha 2004). The vegetation in Los Mogos is constituted by slightly degraded primary humid tropical forest which was subjected to an experimental forestal intervention in 1992, when limited amounts of wood were extracted. The permanent plots $(100 \times 100 \mathrm{~m})$ have been monitored repeatedly since 1990 and were censused 10 times in irregular intervals between 1990 and 2010. In San Juan, the vegetation consists of degraded primary humid tropical forest which was subjected to an experimental forestal intervention in 2005, when timber from fallen trees was extracted as a part of a forest 
Table 2.1: Stand characteristics and average climate conditions during the study interval. Given are coordinates, elevation, average stem density and basal area at the time of the last census, approximate canopy height (80th percentile of tree heights), mean annual precipitation, mean annual temperature, average relative humidity, and daytime (6:00 - 18:00) vapor pressure deficit including standard deviations (cf. Chapter 6).

\begin{tabular}{|c|c|c|c|c|c|c|c|c|c|}
\hline Site & Coordinates & $\begin{array}{c}\text { Elevation } \\
\text { (m a.s.l) }\end{array}$ & $\begin{array}{l}\text { Stem density } \\
\left(\mathrm{n} \mathrm{ha}^{-1}\right)\end{array}$ & $\begin{array}{c}\text { Basal area } \\
\left(\mathrm{m}^{2} \mathrm{ha}^{-1}\right)\end{array}$ & $\begin{array}{l}\text { Canopy hgt } \\
\text { (m) }\end{array}$ & $\begin{array}{l}\text { MAP } \\
(\mathrm{mm})\end{array}$ & $\begin{array}{l}\text { MAT } \\
\left({ }^{\circ} \mathrm{C}\right)\end{array}$ & $\begin{array}{c}\text { Rel. humidity } \\
(\%)\end{array}$ & $\begin{array}{c}\text { daily VPD } \\
\text { (kPa) }\end{array}$ \\
\hline EEFH & $10.711837^{\circ} \mathrm{N}$ & 97 & 493.9 & 20.9 & 16.4 & 987 & $26.9 \pm 3.9$ & $78.0 \pm 16.1$ & $1.31 \pm 0.94$ \\
\hline Miramar & $\begin{array}{l}85.550981^{\circ} \mathrm{E} \\
10.040557^{\circ} \mathrm{N}\end{array}$ & 58 & 365.3 & 30.0 & 20.4 & 2455 & $28.0 \pm 4.9$ & $83.7 \pm 17.9$ & $1.47 \pm 1.13$ \\
\hline & $84.748973^{\circ} \mathrm{E}$ & & & & & & & & \\
\hline Cangreja & $\begin{array}{r}9.699548^{\circ} \mathrm{N} \\
84.366278^{\circ} \mathrm{E}\end{array}$ & 468 & 552.2 & 40.1 & 34.1 & 5384 & $26.0 \pm 4.1$ & $91.4 \pm 17.0$ & $0.89 \pm 0.88$ \\
\hline Mogos & $\begin{array}{r}8.778120^{\circ} \mathrm{N} \\
83.373702^{\circ} \mathrm{E}\end{array}$ & 55 & 570.4 & 26.2 & 31.7 & 4208 & $27.5 \pm 4.3$ & $83.6 \pm 15.5$ & $1.25 \pm 1.09$ \\
\hline San Juan & $\begin{array}{r}8.729797^{\circ} \mathrm{N} \\
83.487431^{\circ} \mathrm{E}\end{array}$ & 219 & 524.5 & 28.4 & 34.7 & 4627 & $26.7 \pm 3.8$ & $88.2 \pm 11.4$ & $0.84 \pm 0.71$ \\
\hline
\end{tabular}

management experiment. All trees with DBH > $10 \mathrm{~cm}$ were censused in 2005 and 2007 in four $50 \times 50 \mathrm{~m}$ plots.

The stand characteristics and the observed average climate conditions during the study interval from 2015-2018 are summarized in Table 2.1.

\subsubsection{Effects of the ENSO phenomenon in 2015/16}

While in the wake of the El Niño/Southern Oscillation (ENSO) phenomenon in 2015/16, all five research sites were subjected to unusually dry conditions, the drought event was disproportionately severe in the seasonally dry regions in north-western Costa Rica and resulted in the lowest annual precipitations ever recorded for the Guanacaste area (Instituto Meteorológico de Costa Rica 2015; Werden et al. 2018a). The extreme conditions in that year led to a largely delayed onset of the rainy season in both 2015 and 2016 and resulted in a visibly increased mortality of pioneer trees both in the dry and humid forest plots (M. Castillo Ugalde, personal observation). Accordingly, a signal of this drought event will likely be present in all measurements performed in this and the following years.

\subsubsection{Species selection}

At each of the five research sites, eight experimental tree species were selected based on a stratified sampling scheme with the aim to cover large gradients in wood density and tree height at maturity. To achieve this, the species present at each site were pre-stratified by their abundance based on species lists from the ITCR. The 30 most common tree species at each site were pre-selected and ranked by their average tree diameter at breast height as a proxy for tree height, as prior height measurements were not available for all sites. Then, wood density data were extracted from the Global Wood Density Database (Zanne et al. 2009; Chave et al. 2009). If no wood density information was available on species level, genus or family level averages were used. A final set of eight tree species per site was subsequently selected out of the pre-selected sample of species aiming to cover the broadest possible gradients in both $\mathrm{DBH} /$ height and wood density. Additional information about species properties with the potential to interfere with the measurements was also taken 

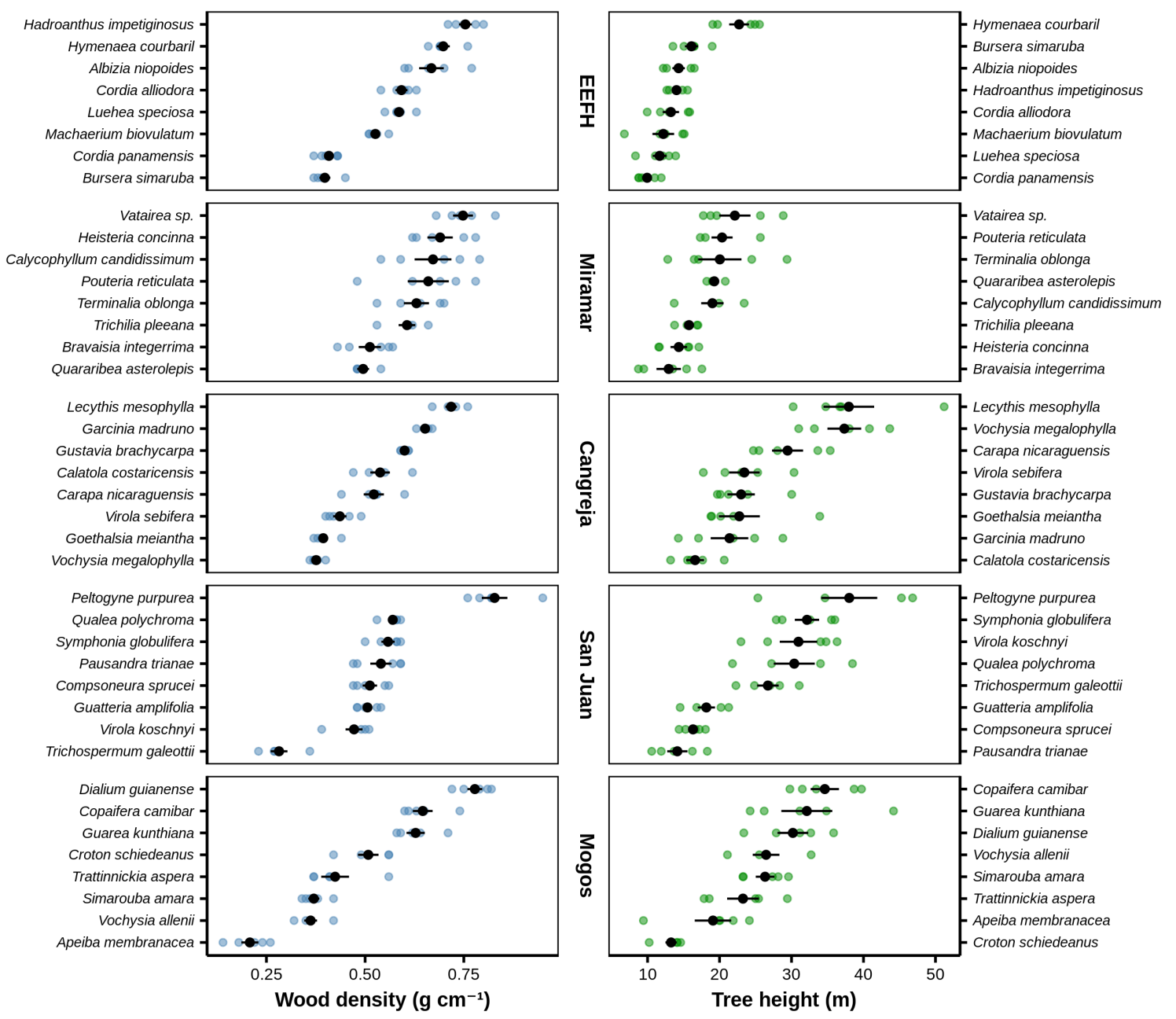

Figure 2.2: Gradients in wood density (left) and tree height (right) of the selected species at the five research sites. Shown are the observed values (colored) with the corresponding means and standard errors (black).

into account for the species selection; e.g., species with an abundant production of latex had to be excluded to avoid interference with hydraulic measurements. After deciding for a final set of 40 species, five experimental trees per species were chosen from the 50th to 100th percentile of the diameter distribution to ensure the sampling of mature tree individuals, resulting a total of 200 trees.

As visible in Figure 2.2, the final species selection covered broad gradients in both focal variables at all sites, as far as the conditions at each site permitted. However, the large difference in average height between dry and humid tropical forests constrained the maximum height on the dryer end of the rainfall gradient (cf. Moles et al. 2009).

\subsubsection{Wood properties}

\subsubsection{Wood sampling and wood density estimates}

During the initial field campaign in 2015, two sapwood samples of a length of approx. 5-7 $\mathrm{cm}$ were taken from all trees in a height of $1 \mathrm{~m}$ above ground level with a $5 \mathrm{~mm}$ increment corer (Mora, Sweden) to analyze wood properties. One of the two sapwood samples was 
subsequently used to determine the wood density of the sapwood (WD, $\mathrm{g} \mathrm{cm}_{-3}$ ) as the oven-dry weight divided by the green volume. Prior to weighing, wood samples were dried for at least $48 \mathrm{~h}$ at $105^{\circ} \mathrm{C}$ within two days after collection. Wet volume was calculated from fresh length and average diameter (based on two measurements each on both ends) measured with a caliper assuming a perfectly cylindrical shape.

\subsubsection{Wood anatomical traits}

The other of the two sapwood samples was placed in $70 \%$ alcohol solution immediately after collection and transported to the University of Göttingen, Germany, for further processing. Transverse sections with an area of $145.5 \pm 54.1 \mathrm{~mm}^{2}$ (mean \pm standard deviation) and containing 1386.4 vessels on average (range: 173-7557) were cut with a sliding microtome (G.S.L.1; Schenkung Dapples, Zurich, Switzerland) and digitized at $100 \times$ magnification using a stereo-microscope with an automatic stage and an integrated digital camera (SteREOV20; Carl Zeiss MicroImaging GmbH, Göttingen, Germany). The microscopic images were processed with Adobe Photoshop CS6 (v.13.0.1; Adobe Systems Inc., San Jose, CA, USA) and ImageJ (Schneider et al. 2012), using the particle analysis function to estimate vessel lumen area $\left(A_{\text {lumen }} ; \mu \mathrm{m}^{2}\right)$, vessel density $\left(\mathrm{VD} ; \mathrm{n} \mathrm{mm^{-2 }}\right)$ and major and minor vessel radius $(a$ and $b ; \mu \mathrm{m})$. The latter were used to estimate the equivalent vessel diameter $(D ; \mu \mathrm{m})$ according to White $(1991)$ as

$$
D=\left(\frac{32(a b)^{3}}{a^{2}+b^{2}}\right)^{1 / 4}
$$

This quantity was then used to calculate the hydraulically weighted average vessel diameter $\left(D_{h}, \mu \mathrm{m}\right)$ based on Sperry et al. (1994).

$$
D_{h}=\frac{\sum D^{5}}{\sum D^{4}}
$$

Relative vessel lumen area $\left(\% A_{\text {lumen }} ; \%\right)$ was calculated as the sum of the areas of all vessels in a cross-section divided by the corresponding xylem area $A_{x y l e m}$ according to

$$
\% A_{\text {lumen }}=100 \frac{\sum A_{\text {lumen }}}{A_{\text {xylem }}}
$$

The measured vessel diameters were used to calculate the xylem-area specific potential conductivity $\left(K_{p} ; \mathrm{kg} \mathrm{m}^{-1} \mathrm{MPa}^{-1} \mathrm{~s}^{-1}\right)$ according to the Hagen-Poiseuille equation as

$$
K_{p}=\frac{\pi \rho \sum D^{4}}{128 \eta A_{x y l e m}}
$$

where $\eta$ is the viscosity and $\rho$ the density of water $\left(\eta=1.002 \cdot 10^{-9} \mathrm{MPa}\right.$ and $\rho=$ $998.2 \mathrm{~kg} \mathrm{~m}^{-3}$ at $20^{\circ} \mathrm{C}$, respectively). 


\subsubsection{Sapwood nonstructural carbohydrate content}

After drying, the wood cores used for wood density estimation were sent to the Max Planck Institute for Biogeochemistry in Jena to analyze glucose, fructose, sucrose, starch and overall nonstructural carbohydrate (NSC) content. Concentrations were measured using High Performance Liquid Chromatography-Pulsed Amperometric Detection (cf. Landhäusser et al. 2018) on an alcoholic extract of soluble sugars as well as an hydrolized starch extract (see Section 6.3.4 for details).

\subsubsection{Tree size and growth rates}

To track changes in tree diameter, all 200 experimental trees were equipped with D1 dendrometer bands (UMS GmbH, Munich, Germany) between May and August 2015, and re-measured in 2-month intervals until March/April 2018. In addition, the height of the experimental trees was determined using a Vertex IV Hypsometer with Transponder T3 (Haglöf, Längsele, Sweden) during the initial measurement campaign in 2015 (cf. Figure $2.2)$.

Based on the tree diameter, height and wood density measurements, we calculated aboveground biomass (AGB) estimates with the improved pantropical allometric equations provided by Chave et al. (2014) using R package BIOMASS v. 2.1.1 (Réjou-Méchain et al. 2017). Simple approximations to the absolute annual diameter, basal area and aboveground biomass growth rates were estimated for each tree based on the slope of a regression of these variables versus time in years. Analogously, relative growth rates were estimated as the linear regression slope of log-transformed diameter/basal area/AGB versus time.

\subsubsection{Sap flow measurements}

The sap flow measurements were performed in four measurement campaigns of 5-7 days each between Oct. and Nov. 2015 at the EEFH, the northernmost site on the gradient. Sap flux density was measured on all 40 experimental trees at the research site using the heat field deformation (HFD) method (Nadezhdina et al. 1998; Nadezhdina et al. 2012; Nadezhdina 2018) with a commercial sensor stem (HFD100, ICT International Pty Ltd., Armidale, Australia). A detailed description of the sap flow data collection and processing is provided in Section 4.4.3.

The HFD method allows to measure radial gradients in sap flux density with a high spatial resolution without having to install several sensors per tree or manually changing sensor positions (Nadezhdina et al. 1998; Nadezhdina et al. 2012). However, the relatively high price of the commercial sensor systems and their high energy use make their application on a larger scale impracticable. In addition, there is evidence that the physical derivation of the methods used to convert HFD readings to sap flux estimates rests on faulty assumptions, which may limit measurement accuracy without prior empirical calibration on species level (Vandegehuchte and Steppe 2012c). This is evidenced by an underestimation of gravimetrically measured sap flux densities with the HFD method by up to $60 \%$ (Steppe et al. 2010), as well as the large within-species variability identified in Chapter 3 of this work.

Accordingly, while HFD sensor systems are arguably the only readily available tool to capture radial sap flux profiles with a satisfying spatial resolution, logistical and technical 
limitations reduce their usefulness for large-scale measurements of absolute water transport. For that reason, the analysis in Chapter 4 is centered on methods that allow to generalize from measurements of radial profiles based on small subsamples of trees equipped with HFD sensors onto a larger sample of trees equipped with conventional single-point sensors. Subsequently, methods are proposed that allow to scale up to whole-tree transpiration while accurately propagating the uncertainty in the radial profile estimates.

\subsubsection{Hydraulic measurements}

\subsubsection{Sample collection}

The samples for the hydraulic measurements were collected during two field campaigns in 2016 and 2017 at the wo sites on the Osa peninsula (Mogos and San Juan). For 30 trees belonging to 10 evergreen tropical rainforest tree species, at least three straight canopy branches of a length of approximately $1.7 \mathrm{~m}$ were sampled with a handsaw using tree climbing equipment. The species number had to be limited to 10 out of the 16 experimental species in San Juan and Mogos to avoid a) species with maximum vessel lengths above 1 $\mathrm{m}, \mathrm{b})$ species with small canopies and irregular growth patterns that impeded sampling several straight segments with a length of more than $1 \mathrm{~m}$ and c) pioneer species with very low wood density (e.g. Apeiba membranacea) which do not provide the structural stability necessary for tree climbing.

On the forest floor, at least two samples with straight sections of $1 \mathrm{~m}$ were selected, marked at the position intended for measurement and cleared of all side branches. The remaining samples were cut back in the same form and stored for approximate measurements of maximum vessel length. The samples were then wrapped in towels soaked in water and enclosed in large plastic sheets until repackaging in the field lab. All leaves from branches attached downstream of the basipetal end of the sample were collected in plastic bags. In addition, a branch section of approximately $10 \mathrm{~cm}$ was sampled from all trees used for vulnerability curve measurements to be used for the determination of branch nonstructural carbohydrate contents.

\subsubsection{Sample preparation for hydraulic measurements}

In the field laboratory, the ends of the samples intended for Cavitron measurement were recut to a length of $1.5 \mathrm{~m}$ on the same day, tightly wrapped in absorbent cloths soaked in a sodium-silver-chloride complex solution (Katadyn Micropur, Wallisellen, Switzerland) and then covered in cling wrap to avoid rot and infection. Packages of three to four samples were then rolled together in blankets soaked in Micropur solution, and packed into tight packages in heavy-duty plastic bags, sealed with adhesive tape and stored under refrigeration (cf. Delzon et al. 2010). The sample packages were subsequently fit into 20 $\mathrm{cm}$ diameter plastic tubes and shipped to the Caviplace phenotyping platform (Genebois, University of Bordeaux, Pessac, France) with priority shipping after returning from the field.

\subsubsection{Estimates of maximum vessel length}

The acropetal ends of the samples for maximum vessel length were connected to a reservoir containing air at an elevated pressure of 0.1 MPa above ambient pressure (generated with 
a syringe) and consecutively recut under water using a tree pruner in $2-3 \mathrm{~cm}$ segments to record the maximum length at which air is able to escape on the bottom end of the sample through an open vessel (Ewers and Fisher 1989). These values were then used to validate whether the approximate maximum vessel length of the samples is below $1 \mathrm{~m}$, a prerequisite for successful measurement in the applied centrifuge.

\subsubsection{Measurement of vulnerability curves}

Before the vulnerability curve measurements, the samples were recut under water to a length of $1 \mathrm{~m}$ and debarked on both ends over a length of several $\mathrm{cm}$ to avoid artifacts related to the leakage of resin, latex or mucilage from the bark. Following the flowcentrifugation (Cavitron) method (Cochard et al. 2013), vulnerability curves where then determined as the relationship between the specific conductivity $K_{\text {obs }}$ of the sample $(\mathrm{kg}$ $\left.\mathrm{m}^{-1} \mathrm{MPa}^{-1} \mathrm{~s}^{-1}\right)$ and the negative pressure $\Psi(\mathrm{MPa})$ generated by the centripetal force of the centrifuge rotor. The measurements were performed with a purpose-built Cavitron with a $1 \mathrm{~m}$ rotor (Cavi1000; DGMeca, 255 Gradignan, France) designed in order to avoid vessel-length related measurement artifacts (Choat et al. 2010; Torres-Ruiz et al. 2014; Martin-StPaul et al. 2014) in long-vesseled species (Lobo et al. 2018; Charrier et al. 2018).

Preliminary estimates of the vulnerability curve parameters were obtained for each sample by fitting simple nonlinear regression models using the $\mathrm{nls}($ ) function in $\mathrm{R} v$. 3.6.1 ( $\mathrm{R}$ Core Team 2019). To achieve this, the relative loss of hydraulic conductivity was described using a reparameterized formulation of the survivor function of the Weibull distribution scaled by the sample-specific maximum conductivity $K_{\max }$ :

$$
K_{\text {obs }} \sim \operatorname{Normal}\left(K_{\text {max }} \cdot \exp \left(\log (0.5) \cdot\left(\frac{\Psi}{\Psi_{50}}\right)^{k}\right), \sigma\right)
$$

where $\Psi_{50}$ is the pressure associated with $50 \%$ loss of conductivity, $k$ is the shape parameter of the Weibull distribution and $\sigma$ is the residual standard deviation. Fitting vulnerability curves on the conductivity scale instead of the common practice of rescaling the data to percent loss conductivity has the advantage that $K_{\max }$ can be treated as an unknown quantity estimated from the data instead of arbitrarily fixing it at its maximum value (Ogle et al. 2009), which has the potential to result in biased parameter estimates.

Using the estimated $K_{\max }$, the observed and predicted conductivity values can easily be scaled to the PLC scale using the following equation:

$$
P L C=100 \cdot\left(1-\frac{K}{K_{\max }}\right)
$$

The reparameterization of the survivor function given in Eq. (2.5) of the Weibull distribution differs from the reparameterization in Ogle et al. (2009) insofar as the initial shape parameter $k$ is retained instead of replacing it by a slope at $\Psi_{50}$. The reason for this decision is the much higher mechanistic value of $k$ compared to a local value of the slope at an arbitrary position in the curve: The shape parameter $k$ can be used to formally test hypotheses about the general shape of the curve, as values of $k \leq 1$ correspond to r-shaped and values of $k>1$ to s-shaped curves. 


\subsubsection{Leaf traits and branch nonstructural carbohydrates}

For all branch samples used for vulnerability curve measurements, all distal leaves where scanned and oven-dried at $70^{\circ} \mathrm{C}$ for at least $48 \mathrm{~h}$ at the laboratory in Costa Rica to determine the total leaf area $\left(A_{L_{\text {Total }}}, \mathrm{m}^{2}\right)$, specific leaf area $\left(S L A, \mathrm{~cm}^{2} \mathrm{~g}^{-1}\right)$ and the Huber value (i.e. the ratio between sapwood area and leaf area). After drying, the samples were shipped to Germany and used for an analysis of leaf carbon and nitrogen content $\left(\mathrm{g} \mathrm{kg}^{-1}\right)$ as well as stable isotope ratios $\left(\delta^{13} \mathrm{C}\right.$ and $\delta^{15} \mathrm{~N}, \%$ ) .

The samples for branch nonstructural carbohydrate content were debarked and heated for $1 \mathrm{~min}$ in a microwave at $700 \mathrm{~W}$ to deactivate all present enzymes on the day of collection, and then oven-dried at $70^{\circ} \mathrm{C}$ upon return to the laboratory. The samples were subsequently sent to the Max Planck Institute for Biogeochemistry in Jena for an analysis of glucose, fructose, sucrose and starch concentrations using the same protocol as in case of the stem samples (cf. Section 2.1.3.3, 6.3.4).

\subsection{External datasets}

Chapters 3 and 5 are based on data from datasets which were collected outside the framework of the field study in Costa Rica. The following section is meant to provide an overview of the two accessory datasets and the rationale for their inclusion in this work, whereas the data sources and methodology are discussed in more detail in the corresponding chapters.

\subsubsection{Sap flow calibration study}

Chapter 3 entails a comparison of the measurement accuracy of three different thermometric sap flow measurement methods. To achieve this, excised stem segments of five diffuse-porous temperate forest species (Fagus sylvatica, Tilia cordata, Acer pseudoplatanus, Acer campestre and Populus nigra) were connected to water vessels and subjected to negative pressure to induce flow. Each stem was equipped with a set of sap flow probes, and the sensor readings were validated against sap flux densities computed from gravimetrically determined flow rates. The compared sensor types were thermal dissipation probes (TDP) (Granier 1985; Granier and Gross 1987), heat ratio method (HRM) sensors (Burgess et al. 2001) and heat field deformation (HFD) sensors (Nadezhdina et al. 1998; Nadezhdina et al. 2012; Nadezhdina 2018).

In addition to the out-of-the-box performance using the calibration equations proposed by the authors of the method, new calibration equations were set up for the TDP and HFD method based on nonlinear mixed models using R package nlme (Pinheiro et al. 2015) in order to test for variability in calibration parameters between species and stems.

The inclusion of Chapter 3 into this work is motivated by its central importance for Chapter 4: The outcome of our calibration study - and specifically its corroboration of the hypothesis by Vandegehuchte and Steppe (2012c) that HFD probes strongly benefit from species specific calibration (cf. Section 2.1.5) - led to our decision to focus on modelling the shape radial sap flow profiles instead of comparing absolute values of water use. In doing so, in Chapter 4 we propose a method that allows to combine the main advantage of HFD sensors, namely their high radial resolution, with the advantages of single-point sensor systems, i.e. their generally lower price, higher accuracy in point measurements of sap flux density and lower energy use. 


\subsubsection{Tree productivity, water use and wood hydraulic properties of Indonesian tropical trees}

In Chapter 5, we analyze observational data from 99 Southeast Asian tropical rainforest tree species. Based on species level averages from a total of 265 individual trees from two study sites on the islands of Sumatra and Sulawesi, this study aims to identify the mechanistic linkages between sap flux density, plant water use, growth rates, wood density, wood anatomical traits, and tree size.

To achieve this, we used standardized major axis regressions based $\mathrm{R}$ package smatr (Warton et al. 2012) to analyze pairwise bivariate associations between aforementioned variables, and contrasted their output with a more principled, hypothesis-driven approach based on structural equation models fitted with the lavaan package (Rosseel 2012). We thereby illustrate that focusing on pairs of variables one-at-a-time instead of properly accounting for the complex interrelationships in ecological datasets can result in fundamentally different and potentially flawed interpretations.

This study is uniquely relevant in the context of the present work as it a) establishes the structural equation modelling framework that it shares with Chapter 6 and b) as an applied example of upscaled sap flow estimates, it represents a link between the methodological work on sap flow methods in Chapter 3 and 4 and the broad ecosystem perspective of Chapter 6.

\section{References}

Acosta Vargas, L. G. (1998). "Análisis de la composición florística y estructura para la vegetación del piso basal de la Zona Protectora la Cangreja, Mastatal de Puriscal". Tésis de Bachillerato. Cartago, Costa Rica: Instituto Tecnológico de Costa Rica.

- (2012). "Análisis silvigénico de los bosques húmedos tropicales del Parque Nacional La Cangreja, Pácifico Central de Costa Rica". Tesis de Licenciatura. Cartago, Costa Rica: Instituto Tecnológico de Costa Rica.

Alfaro, E. A., A. Alvarado, and A. Chaverri (2001). "Cambios edáficos asociados a tres etapas sucesionales de bosque tropical seco en Guanacaste, Costa Rica". In: Agronomía Costarricense 25.1, pp. 7-19.

Burgess, S. S. O., M. A. Adams, N. C. Turner, C. R. Beverly, C. K. Ong, A. A. H. Khan, and T. M. Bleby (2001). "An improved heat pulse method to measure low and reverse rates of sap flow in woody plants". In: Tree Physiology 21.9, pp. 589-598. URL: https://academic.oup.com/treephys/article-lookup/doi/10.1093/treephys/21.9.589.

Charrier, G., S. Delzon, J.-C. Domec, L. Zhang, C. E. L. Delmas, et al. (2018). "Drought will not leave your glass empty: Low risk of hydraulic failure revealed by long-term drought observations in world's top wine regions". In: Science Advances 4.1, eaao6969.

Chave, J., D. Coomes, S. Jansen, S. L. Lewis, N. G. Swenson, and A. E. Zanne (2009). "Towards a worldwide wood economics spectrum". In: Ecology Letters 12.4, pp. 351-366. URL: http://doi.wiley.com/10.1111/j.1461-0248.2009.01285.x.

Chave, J., M. Réjou-Méchain, A. Búrquez, E. Chidumayo, M. S. Colgan, et al. (2014). "Improved allometric models to estimate the aboveground biomass of tropical trees". In: Global Change Biology 20.10, pp. 3177-3190. URL: https://onlinelibrary.wiley.com/ doi/abs/10.1111/gcb.12629. 
Choat, B., W. M. Drayton, C. Brodersen, M. A. Matthews, K. A. Shackel, H. Wada, and A. J. Mcelrone (2010). "Measurement of vulnerability to water stress-induced cavitation in grapevine: a comparison of four techniques applied to a long-vesseled species: Comparison of vulnerability curve technique in grapevine". In: Plant, Cell \& Environment, no-no. URL: http://doi.wiley.com/10.1111/j.1365-3040.2010.02160.x.

Cochard, H., E. Badel, S. Herbette, S. Delzon, B. Choat, and S. Jansen (2013). "Methods for measuring plant vulnerability to cavitation: a critical review". In: Journal of Experimental Botany 64.15, pp. 4779-4791. URL: https://academic.oup.com/jxb/articlelookup/doi/10.1093/jxb/ert193.

Delzon, S., C. Doute, A. Sala, and H. Cochard (2010). "Mechanism of water-stress induced cavitation in conifers: bordered pit structure and function support the hypothesis of seal capillary-seeding". In: Plant, Cell \& Environment 33.12, pp. 2101-2111. URL: https: //www.ncbi.nlm.nih.gov/pmc/articles/PMC3003904/.

Ewers, F. W. and J. B. Fisher (1989). "Techniques for measuring vessel lengths and diameters in stems of woody plants". In: American Journal of Botany 76.5, pp. 645-656. URL: http://doi.wiley.com/10.1002/j.1537-2197.1989.tb11360.x.

Granier, A. (1985). "Une nouvelle méthode pour la mesure du flux de sève brute dans le tronc des arbres". In: Annales des Sciences Forestières 42.2, pp. 193-200. URL: http: //www.afs-journal.org/10.1051/forest:19850204.

Granier, A. and P. Gross (1987). "Mesure du flux de sève brute dans le tronc du Douglas par une nouvelle méthode thermique". In: Annales des Sciences Forestières 44.1, pp. 114. URL: http://dx.doi.org/10.1051/forest:19870101.

Guzmán Q, J. A. and H. Vega S (2015). "Is forest cover conserved and restored by protected areas?: The case of two wild protected areas in the Central Pacific of Costa Rica". In: Revista de Biología Tropical 63.3, pp. 579-590. URL: https://revistas.ucr.ac.cr/index. $\mathrm{php} / \mathrm{rbt} /$ article/view/15814.

Hijmans, R. J., S. E. Cameron, J. L. Parra, P. G. Jones, and A. Jarvis (2005). "Very high resolution interpolated climate surfaces for global land areas". In: International Journal of Climatology 25.15, pp. 1965-1978. URL: http://doi.wiley.com/10.1002/joc.1276.

Instituto Meteorológico de Costa Rica (2015). Boletin Del ENOS No. 82. URL: https: //www.imn.ac.cr/documents/10179/28160/\%5C\%23\%5C\%2082.

Jiménez, Q. (1999). Importancia biológica de la zona protectora La Cangreja. Propuesta para el manjejo de la zona protectora La Cangreja. Tech. rep. Santiago de Puriscal, Costa Rica.

Karger, D. N., O. Conrad, J. Böhner, T. Kawohl, H. Kreft, et al. (2017). "Climatologies at high resolution for the earth's land surface areas". In: Scientific Data 4, p. 170122. URL: http://www.nature.com/articles/sdata2017122.

Landhäusser, S. M., P. S. Chow, L. T. Dickman, M. E. Furze, I. Kuhlman, et al. (2018). "Standardized protocols and procedures can precisely and accurately quantify nonstructural carbohydrates". In: Tree Physiology 38.12, pp. 1764-1778. URL: https:// academic.oup.com/treephys/article/38/12/1764/5146736.

Lobo, A., J. M. Torres-Ruiz, R. Burlett, C. Lemaire, C. Parise, et al. (2018). "Assessing inter- and intraspecific variability of xylem vulnerability to embolism in oaks". In: Forest Ecology and Management 424, pp. 53-61. URL: https://linkinghub.elsevier.com/ retrieve/pii/S0378112717320327.

Martin-StPaul, N. K., D. Longepierre, R. Huc, S. Delzon, R. Burlett, R. Joffre, S. Rambal, and H. Cochard (2014). "How reliable are methods to assess xylem vulnerability to cavitation? The issue of 'open vessel' artifact in oaks". In: Tree Physiology 34.8, pp. 894- 
905. URL: https://academic.oup.com/treephys/article-lookup/doi/10.1093/treephys/ tpu059.

Moles, A. T., D. I. Warton, L. Warman, N. G. Swenson, S. W. Laffan, et al. (2009). "Global patterns in plant height". In: Journal of Ecology 97, pp. 923-932. URL: https: / / besjournals.onlinelibrary.wiley.com/doi/abs/10.1111/j.1365-2745.2009.01526.x\% 5C\%4010.1111/\%5C\%28ISSN\%5C\%291365-2745.GLOBWA.

Nadezhdina, N. (2018). "Revisiting the Heat Field Deformation (HFD) method for measuring sap flow". In: iForest - Biogeosciences and Forestry 11.1, pp. 118-130. URL: http: //www.sisef.it/iforest/?doi=ifor2381-011.

Nadezhdina, N., J. Čermák, and V. Nadezhdin (1998). "Heat field deformation method for sap flow measurements". In: Measuring sap flow in intact plants. Proceedings of 4th International Workshop, Židlochovice, Czech Republic, IUFRO Publ. Brno, Czech Republic: Mendel University, pp. 72-92.

Nadezhdina, N., M. W. Vandegehuchte, and K. Steppe (2012). "Sap flux density measurements based on the heat field deformation method". In: Trees 26.5, pp. 1439-1448. URL: http://link.springer.com/10.1007/s00468-012-0718-3.

Ogle, K., J. J. Barber, C. Willson, and B. Thompson (2009). "Hierarchical statistical modeling of xylem vulnerability to cavitation: Methods". In: New Phytologist 182.2, pp. 541-554. URL: http://doi.wiley.com/10.1111/j.1469-8137.2008.02760.x.

Pinheiro, J., D. Bates, S. DebRoy, D. Sarkar, and R Core Team (2015). nlme: Linear and Nonlinear Mixed Effects Models. R Package Version 3. URL: https://CRAN.Rproject.org $/$ package $=$ nlme.

R Core Team (2019). R: A Language and Environment for Statistical Computing. Vienna, Austria: R Foundation for Statistical Computing. URL: https://www.R-project.org/.

Réjou-Méchain, M., A. Tanguy, C. Piponiot, J. Chave, and B. Hérault (2017). "BIOMASS: an $\mathrm{R}$ package for estimating above-ground biomass and its uncertainty in tropical forests". In: Methods in Ecology and Evolution 8.9. Ed. by S. Goslee, pp. 1163-1167. URL: http://doi.wiley.com/10.1111/2041-210X.12753.

Reyes Cordero, D. (2012). "Análisis de los procesos de restauración pasiva para un bosque seco tropical en la Estación Experimental Forestal Horizontes, Guanacaste, Costa Rica". Thesis. URL: http://copa.acguanacaste.ac.cr:8080/handle/11606/887.

Rosseel, Y. (2012). "lavaan : An R Package for Structural Equation Modeling". In: Journal of Statistical Software 48.2. URL: http://www.jstatsoft.org/v48/i02/.

Sanchez Azofeifa, G. A., B. Rivard, J. Calvo, and I. Moorthy (2002). "Dynamics of Tropical Deforestation Around National Parks: Remote Sensing of Forest Change on the Osa Peninsula of Costa Rica". In: Mountain Research and Development 22.4, pp. 352-358. URL: http://www.bioone.org/doi/abs/10.1659/0276-4741.

Sperry, J. S., K. L. Nichols, J. E. M. Sullivan, and S. E. Eastlack (1994). "Xylem Embolism in Ring-Porous, Diffuse-Porous, and Coniferous Trees of Northern Utah and Interior Alaska". In: Ecology 75.6, pp. 1736-1752. URL: http://doi.wiley.com/10.2307/1939633.

Steppe, K., D. J. De Pauw, T. M. Doody, and R. O. Teskey (2010). "A comparison of sap flux density using thermal dissipation, heat pulse velocity and heat field deformation methods". In: Agricultural and Forest Meteorology 150.7-8, pp. 1046-1056. URL: https: //linkinghub.elsevier.com/retrieve/pii/S0168192310001000.

Torres-Ruiz, J. M., H. Cochard, S. Mayr, B. Beikircher, A. Diaz-Espejo, C. M. RodriguezDominguez, E. Badel, and J. E. Fernández (2014). "Vulnerability to cavitation in Olea europaea current-year shoots: further evidence of an open-vessel artifact associated with centrifuge and air-injection techniques". In: Physiologia Plantarum 152.3, pp. 465-474. URL: http://doi.wiley.com/10.1111/ppl.12185. 
Vandegehuchte, M. W. and K. Steppe (2012c). "Interpreting the Heat Field Deformation method: Erroneous use of thermal diffusivity and improved correlation between temperature ratio and sap flux density". In: Agricultural and Forest Meteorology 162-163, pp. 91-97. URL: https://linkinghub.elsevier.com/retrieve/pii/S0168192312001438.

Vílchez, B. and O. Rocha (2004). "Fenología y biología reproductiva del nazareno (Peltogyne purpurea Pittier) en un bosque intervenido de la Península de Osa, Costa Rica, América Central". In: Kurú: Revista Forestal 1.1, p. 14.

Warton, D. I., R. A. Duursma, D. S. Falster, and S. Taskinen (2012). "smatr 3- an R package for estimation and inference about allometric lines". In: Methods in Ecology and Evolution 3.2, pp. 257-259. URL: https://besjournals.onlinelibrary.wiley.com/doi/ abs/10.1111/j.2041-210X.2011.00153.x.

Werden, L. K., P. Alvarado J., S. Zarges, E. Calderón M., E. M. Schilling, M. Gutiérrez L., and J. S. Powers (2018a). "Using soil amendments and plant functional traits to select native tropical dry forest species for the restoration of degraded Vertisols". In: Journal of Applied Ecology 55.2. Ed. by M. Nuñez, pp. 1019-1028. URL: http://doi.wiley.com/ 10.1111/1365-2664.12998.

Werden, L. K., B. G. Waring, C. M. Smith-Martin, and J. S. Powers (2018b). "Tropical dry forest trees and lianas differ in leaf economic spectrum traits but have overlapping water-use strategies". In: Tree Physiology 38.4, pp. 517-530. URL: https://academic.oup. com/treephys/article/38/4/517/4566185.

White, F. (1991). Viscous Fluid Flow. New York: McGraw-Hill.

Zamora Ávila, M. (2010). "Caracterización de la flora y estructura de un bosque transicional húmedo a seco, Miramar, Puntarenas Costa Rica". Tesis de Licenciatura. Cartago, Costa Rica: Instituto Tecnológico de Costa Rica.

Zanne, A. E., G. Lopez-Gonzalez, D. A. Coomes, J. Ilic, S. Jansen, et al. (2009). Data from: Towards a worldwide wood economics spectrum. URL: http://dx.doi.org/10.5061/ dryad.234. 

Part I: Improving water use estimates based on sap flux probes 



\title{
3 Calibration and comparison of thermal dissipation, heat ratio and heat field deformation sap flow probes for diffuse-porous trees
}

\author{
Sebastian Fuchs, Christoph Leuschner, Roman Link, Heinz Coners, Bernhard \\ Schuldt \\ Plant Ecology, Albrecht von Haller Institute for Plant Sciences, University of Goettingen, \\ Untere Karspüle 2, 37073 Goettingen, Germany
}

\subsection{Abstract}

Sap flow probes are routinely used in forest and horticulture hydrology for estimating tree water use. This requires unbiased measurements when upscaling from tree to stand level, but accuracy and comparability of different thermometric methods have been questioned. Three sap flow measuring techniques were compared against gravimetric flow measurement in cut stem segments: 'Granier-type' thermal dissipation probes (TDP; three different sensor types), the heat field deformation method (HFD), and the heat ratio method (HRM). For the empirical methods (TDP and HFD), new calibration parameters were estimated using a nonlinear hierarchical modelling approach. 66 stem segments from five temperate, diffuse-porous tree species (9-16 cm stem diameter, $100 \mathrm{~cm}$ stem length) were exposed to a wide range of flux densities by applying subatmospheric pressure $(-50$ to $-650 \mathrm{hPa})$ analogous to natural flow conditions in the field. All TDP probes underestimated flux density by $23-45 \%$ when calculated with Granier's original calibration parameters, with the deviation increasing with flux rate. The accuracy was significantly improved by estimating new calibration parameters, especially for probes differing from Granier's original sensor design. Species-specific parameters further improved accuracy, although the species differences might partially be explained by variation in the observed ranges of sap flux. The HFD sensor overestimated gravimetric flow by $11 \%$; empirical calibration did not improve its accuracy compared to the manufacturer's equation. At low to medium flow rates, the HRM system achieved higher accuracy than the other probes ( $0.8 \%$ underestimation), while performing poorly at high flux rates under our measurement settings (energy input of $25 \mathrm{~J}$ ). Both for TDP and HFD sensors, we observed a surprisingly large variability in calibration parameters between different stems of the same species. We conclude that (i) TDP and HFD sensors require species-specific calibration to measure sap flux with high accuracy, (ii) the original Granier equation cannot be used for TDP probes with deviating design, and (iii), at low to medium flow rates, the highest accuracy can be achieved with HRM sensors. Our results help to increase the accuracy of tree sap flow measurements with thermal dissipation probes, and to assess various levels of errors related to the differ- 
ent thermometric methods. This is important when synthesizing forest transpiration data on regional and global scales.

Keywords: Error sources, Gravimetric flow determination, Sap flux density, Sap velocity, Transpiration, Water use

Published in: Agricultural and Forest Meteorology (2017) 244-245: 151-161

\subsection{Introduction}

In the face of a warming climate with more frequent drought exposure in summer, precise information on the water consumption of trees and forests is of fundamental importance for biological, forestry, agricultural, and horticultural research. A variety of sap flow techniques are routinely used in tree ecophysiology for estimating whole-tree transpiration and extrapolating water loss to the stand and catchment level, and for optimizing irrigation management. Most techniques install sensors in the trunk using heat as a tracer for sap movement in the xylem because the stem is the 'bottleneck' in the water flow path long the soil plant atmosphere continuum. The earliest attempts of thermometric sap flow measurement in stems date back to the 1930s, when Huber (1932) used the travelling time of an externally induced heat pulse to a certain point downstream as a measure for sap velocity (see also Marshall 1958). On this basis, the widely used 'compensation heat pulse method' (CHPM) was developed (Swanson 1962; Swanson and Whitfield 1981). This method has the disadvantage that reverse flow and low or very high flux densities cannot be measured because a temperature equilibrium between upstream and downstream probe does not establish under those conditions (Bleby et al. 2004; Vandegehuchte and Steppe 2013). Another heat pulse method, the heat ratio method (HRM), was developed by Burgess et al. (2001) as a modification of the CHPM method, capable of measuring reverse flow and low flux densities. Instead of directly measuring the travelling time of a heat pulse, the temperature ratio of two equidistant sensors alongside a heater after a certain amount of time is used to calculate sap velocities.

Simultaneously, constant heating methods were developed which relate sap flow to the amount of dissipated thermal energy from a constantly heated source rather than to the velocity of a heat pulse. First attempts by Vieweg and Ziegler (1960) did not result in quantitative measurements of sap flow because they did neither entail empirical calibration nor calculations based on the physics of heat transfer. A simple but budget-friendly and therefore still widely used constant heating method (TDP, 'thermal dissipation probe') was developed by Granier (1985), who empirically related the dissipation of heat from a single heated probe to sap flux density. The latest iteration of constant heating techniques is the heat field deformation (HFD) method (Nadezhdina et al. 1998; Nadezhdina et al. 2012). Changes in the heat field around a linear heater are recorded by three measuring probes with multiple thermocouples along the radial profile and are then related to sap flux density in the xylem. By now, empirical calibrations of HFD measurements are still missing and the method so far has primarily been used for the investigation of radial variation in sap flux density.

To employ sap flow measurements for extrapolating transpiration rate to the stand level, high measurement accuracy is needed (Mitchell et al. 2009; Steppe et al. 2010). Several studies have tested the accuracy of different sensor systems by comparison to gravimetrically measured flow rate, typically using potted plants or excised stem or branch segments. The HRM system was tested in a potted plant experiment (Bleby et al. 2004) and directly 
compared to the older CHPM system. While both methods were found to achieve a high accuracy when estimating sap flow at medium flow rates, HRM showed a better performance at low flow rates. For high sap flow rates in highly conductive roots, however, Bleby et al. (2008) reported strong limitations of the HRM method. Steppe et al. (2010) tested CHPM, HFD and TDP sensors simultaneously on cut stems of the diffuse-porous tree species Fagus grandifolia and found underestimations of flux densities by 35\%, 46\% or $60 \%$, respectively. So far, no other study has tested the accuracy of the HFD method against an independent reference, but Vandegehuchte and Steppe (2012c) reviewed the equation given by Nadezhdina et al. $(1998 ; 2012)$ and concluded that some of its variables are physically misinterpreted, e.g. the use of thermal diffusivity and sapwood depth. In consequence, they argued that this method should be considered merely empirical, as there is no valid physical justification for the linear relationship between measured HFD temperature difference ratios and sap flux density proposed by Nadezhdina et al. (1998; 2012). Instead, based on the results of a 3D-Finite Element Model simulation, Vandegehuchte and Steppe (2012c) provide evidence for a nonlinear relationship between sensor temperature ratio and sap flux density and suggest to describe it with second-order polynomials with 2-4 parameters. While several authors performed experimental validations of the TDP method (Granier 1985; Granier and Gross 1987; Cabibel et al. 1991), there have been no analogous studies of the relationship between the HFD temperature ratio and sap flux density so far.

The TDP method has been tested in various experiments on a wide range of species including ring- and diffuse-porous trees, and has repeatedly been found to underestimate sap flux density by 6-90\% (de Oliveira Reis et al. 2006; Taneda and Sperry 2008; Bush et al. 2010; Hultine et al. 2010; Steppe et al. 2010; Renninger and Schäfer 2012; Sun et al. 2012). Possible reasons for these systematic errors are deviations from the original sensor design (Lu et al. 2004), species-specific differences in wood properties (Lu et al. 2004; Vandegehuchte and Steppe 2013), differences in radial sap flux density profiles (Clearwater et al. 1999; Bush et al. 2010) and wound effects (Wullschleger et al. 2011). Very steep radial sap flux density gradients are often found in ring-porous species, which can result in large parts of the sensors being located in non-conducting tissue. Consequently, the calculated flux rates often vary widely, and flux may be underestimated by up to $90 \%$ (Bush et al. 2010), even when the 'Clearwater-correction' for sensors exceeding the sapwood depth is applied (Clearwater et al. 1999). Because of simplicity and cost-efficiency, TDP sensors are often custom-made, with the sensors partly deviating in shape and size from the original sensor design described by Granier (1985). This is also true for some commercially available TDP sensors (e.g., UP GmbH, Germany and Dynamax Inc., USA) which differ in geometry or heating power from the original (Lu et al. 2004), thus demanding for a test as to whether these altered systems need recalibration (Granier 1996; Lu et al. 2004). Moreover, the original assumption of Granier (1985) that his calibration parameters are species-independent has been questioned by several studies (de Oliveira Reis et al. 2006; Taneda and Sperry 2008; Bush et al. 2010) and reviews (Lu et al. 2004; Vandegehuchte and Steppe 2013).

The main objective of this study was to compare the accuracy of three commonly used sap flow sensor systems (TDP, HFD and HRM) against gravimetrically measured water flow in cut stem segments. The approach of Steppe et al. (2010) was extended by including the improved HRM instead of the CHPM technique, by applying vacuum to simulate a wide range of sap flux densities comparable to natural flow conditions in the field, and by increasing the species number to five common temperate diffuse-porous broad-leaved tree species. The match between gravimetrically and thermometrically determined flux density 
was assessed using a set of evaluation statistics that quantify precision, bias and overall accuracy of the measurements. We conducted a series of calibration experiments both for three different commercially available and custom-made sensor designs of the most widely distributed TDP method and one commercially available design of HFD sensors. As the equations used to calculate sap flux from HRM measurements are directly derived from the physics of heat dissipation (Burgess et al. 2001), we did not perform an independent empirical calibration for this method. We used non-linear mixed models to obtain stem-independent estimates of the calibration parameters and their uncertainty and simultaneously tested the hypotheses that the empirically estimated calibration parameters differ from the original parameters given by Granier (1985), and that there are speciesspecific differences in calibration parameters. For the HFD method, we analogously tested the hypotheses that the measured temperature ratio does not linearly depend on sap flux density after controlling for stem-specific covariates, and that calibration parameters differ between species. Based on the output of our models, we additionally were able to quantify the between-stem variability in calibration parameters, which is of crucial importance for the development of uncertainty budgets for these sap flux methods.

\subsection{Material and methods}

\subsubsection{Plant material, sample preparation and validation apparatus}

Validation experiments were carried out with stem segments from five temperate broad leaved tree species with diffuse-porous sapwood, Fagus sylvatica L. (FS), Tilia cordata L. (TC), Acer pseudoplatanus L. (AP), Acer campestre L. (AC) and Populus nigra L. (PN). Fagus, Tilia and Acer tree individuals were selected in a limestone beech forest near Göttingen (Göttinger Wald at 190-380 m a.s.l.; 51 35 N, $9^{\circ} 59$ E; mean annual precipitation (MAP) 650-700 mm, mean annual temperature (MAT) $7.0-8.5^{\circ} \mathrm{C}$ ), and Populus tree individuals harvested in a young poplar plantation on limestone close to Erfurt $(189 \mathrm{~m}$ a.s.l.; $51^{\circ} 02 \mathrm{~N}, 10^{\circ} 47 \mathrm{E}$; $549 \mathrm{~mm}$ MAP, $9.4^{\circ} \mathrm{C}$ MAT; Schmidt-Walter et al. 2014).

For each tree individual, 2-5 segments of $1.4 \mathrm{~m}$ length and 8.6-16 $\mathrm{cm}$ diameter were cut with a chainsaw. Only straight and branch- and knotless stem segments were selected. Both segment ends were wrapped with wet sponge cloths and sealed with cling film immediately after cutting. Subsequently, stems were stored in large plastic tubes to prevent dehydration and used for the flow measurements within 4 days. Directly before measurement, stem segments were re-cut to $1 \mathrm{~m}$ length with a high-precision circular saw blade and the bark was removed. The acropetal end of the segment was connected to a vacuum system using rubber adapters and reducers of variable size from a waste pipe system. The basipetal end was submerged into a container (diameter $450 \mathrm{~mm}$, height $370 \mathrm{~mm}$, Aricon Typ SB-42, Solingen, Germany) filled with degassed and demineralized water containing $10 \mathrm{mM} \mathrm{KCl}$ and $1 \mathrm{mM} \mathrm{CaCl}_{2}$, which was placed on an electric balance (DE35K0.5D, KERN \& Sohn GmbH, Balingen, Germany). Balance and TDP data were stored with a CR1000 data logger equipped with an AM16/32 multiplexer (Campbell Scientific Inc., Logan, UT, USA). The HFD sensors were logged with a smart logger system (ICT International, Armidale, Australia), while the HRM sensors were stand-alone systems with internal data storage (SFM1, ICT International, Armidale, Australia). 
Table 3.1: Detailed specifications of the three compared TDP sensor designs.

\begin{tabular}{lllll}
\hline Description & Unit & $\mathrm{TDP}_{\mathrm{UP}}$ & $\mathrm{TDP}_{\text {long }}$ & $\mathrm{TDP}_{\text {short }}$ \\
\hline Length of heating element & $\mathrm{mm}$ & 20 & 24 & 12 \\
Size of aluminium sleeve & $\mathrm{mm}$ & $24 \times 2$ & $26 \times 2$ & $13 \times 2$ \\
Resistance of heating element & $\Omega$ & 29.1 & 13.9 & 6.95 \\
Power supply & $\mathrm{A}$ & 0.083 & 0.120 & 0.120 \\
Power consumption & $\mathrm{W}$ & 0.20047 & 0.20016 & 0.10008 \\
Average $\Delta T_{\max }$ values & ${ }^{\circ} \mathrm{C}$ & 11.15 & 9.84 & 7.82 \\
\hline
\end{tabular}

\subsubsection{Thermal dissipation probes (TDP)}

The TDP method developed by Granier $(1985 ; 1987)$ consists of two needles in aluminium sleeves that are radially inserted into the sapwood and connected with a copper-constantan thermocouple. One needle is constantly heated, while the other one is placed upstream in a distance of ca. $10 \mathrm{~cm}$ as a reference temperature sensor. The temperature difference $(\Delta T)$ between the needles decreases with increasing heat dissipation from the heated needle as sap flux density increases. According to Granier $(1985 ; 1987)$, sap flux density $u\left(\mathrm{~m}^{3} \mathrm{~m}^{-2}\right.$ $\mathrm{s}^{-1}$ ) can be empirically determined from the measured temperature difference using the following relationship:

$$
u=a \cdot\left(\frac{\Delta T_{\max }-\Delta T}{\Delta T}\right)
$$

where $\Delta T$ is the measured temperature difference and $\Delta T_{\max }$ the maximum temperature difference between the needles recorded at zero flux. The parameters $a$ and $b$ were determined experimentally by Granier (Granier 1985; Granier and Gross 1987) using five tree species (Pseutotsuga menziesii, Pinus nigra, Quercus robur, Castanea sativa, Prunus malus), and calibrating against columns filled with synthetic fibre and sawdust as:

$$
a=118.99 \times 10^{-6} \mathrm{~m}^{3} \mathrm{~m}^{-2} \mathrm{~s}^{-1}, \quad b=1.231
$$

Since in the past Granier's calibration parameters were applied to sensors differing in geometry and/or heating power, we used three different sensor designs with variable specifications and heater length (Table 3.1). TDP ${ }_{\text {UP }}$ are commercially available sensors (SFS2 Typ M, UP GmbH, Ibbenbüren, Germany), and both $\mathrm{TDP}_{\text {long }}$ and $\mathrm{TDP}_{\text {short }}$ are custommade sensors of variable length (manufactured by the Uniwerkstätten Kassel, Kassel, Germany).

The sapwood depth (for determination see Chapter 3.3.6, for exemplary images see Figure S4 in the supplementary material) always exceeded the sensor length of the TDP sensors in four of the five tree species. For F. sylvatica, however, the sap wood depth was partly shorter than the sensor length. As the difference between sensor length and sap wood depth never exceeded $2 \mathrm{~mm}$, we considered this inconsistency to be negligible and did not apply the Clearwater-correction for sensors that are partly installed in non-conducting tissue (Clearwater et al. 1999). 


\subsubsection{Heat field deformation method (HFD)}

The HFD method (Nadezhdina et al. 1998; Nadezhdina et al. 2012) relates sap flow to the deformation of a heat field around a continuously heated needle surrounded by three sensor needles. We used the commercially available HFD50 sensor (ICT International Pty Ltd., Armidale, Australia), which uses needles with a diameter of $1.6 \mathrm{~mm}$ and a length of 62 $\mathrm{mm}$, and contains 8 thermocouple junctions spaced $5 \mathrm{~mm}$ apart. The heater is $82 \mathrm{~mm}$ long to avoid influence of non-heated sap on the deepest points of measurement. Changes in the heat field are characterized by the ratio of symmetric $\left(\Delta T_{s y m}\right.$, top to bottom needle) to asymmetric temperature differences $\left(\Delta T_{a s}\right.$, tangential to bottom needle), which increases the system's sensitivity to a wider range of flux densities, because $\Delta T_{\text {sym }}$ mainly responds to low flux densities and enables the distinction of forward and reverse flows, while $\Delta T_{a s}$ nearly linearly responds to medium and high sap flux densities (Nadezhdina et al. 1998; Nadezhdina et al. 2012). According to Nadezhdina et al. (1998; 2012), sap flux density $u$ can be calculated from the ratio of temperature differences, the geometry of needle spacing (i.e. the axial and tangential needle distances $Z_{a x}$ and $Z_{t g}$ ), the thermal diffusivity of the sapwood $(D)$, and sapwood depth $\left(L_{s w}\right)$ as:

$$
u=D \cdot \frac{z_{a x}}{z_{t g}-L_{s w}}\left(\frac{H+\Delta T_{s y m}-\Delta T_{a s}}{\Delta T_{a s}}\right) \quad\left(\mathrm{m}^{3} \mathrm{~m}^{-2} \mathrm{~s}^{-1}\right)
$$

with $H$ standing for the absolute value of the term $\Delta T_{s y m}-\Delta T_{a s}$ under conditions of zero flow. To compare the different sensor systems, we calculated sap flux density according to the original Eq. (3.3) using the Sap Flow Tool software (v1.4, ICT International Pty Ltd., Armidale, Australia).

Additionally, we examined the relationship between HFD ratio (bracket-term in Eq. (3.3)) and sap flux density in order to conduct an empirical calibration as recommended by Vandegehuchte and Steppe (2012c). In our experiment, we calculated sap flux density as the weighted average of all measurement points within the cross-sectional area of conducting sapwood. The sapwood area of a trunk was divided into concentric annuli delimited by the midpoints between measurement points, and the point estimates of sap flux density were weighted according to the amount of conducting sapwood in the corresponding annulus assuming a perfectly circular stem.

\subsubsection{Heat ratio method (HRM)}

HRM is a heat pulse method that consists of a central heater needle and two equidistant temperature sensor probes placed upstream and downstream (Burgess et al. 2001). The velocity of the heat pulse $\left(V_{h}\right.$, in $\left.\mathrm{m} \mathrm{s}^{-1}\right)$ can be calculated from the temperature ratio between the two sensor probes, the thermal diffusivity of the sapwood ( $D$, for derivation of this variable see Supplementary material) and the distance $\mathrm{x}$ between the heater and the sensor probes (based on Marshall 1958) as:

$$
V_{h}=\frac{D}{x} \ln \left(\frac{\Delta T_{\text {downstream }}}{\Delta T_{\text {upstream }}}\right) \quad\left(\mathrm{m} \mathrm{s}^{-1}\right)
$$

The temperature ratio $\left(\Delta T_{\text {downstream }} / \Delta T_{\text {upstream }}\right)$ is somewhat variable during the first $60 \mathrm{~s}$ after application of the heat pulse, but achieves a constant value thereafter. Thus, 
$\mathrm{V}$ h was calculated by averaging over the 40 measurements taken between 60 and $100 \mathrm{~s}$ after heat pulse application. Heat pulse velocity $\left(V_{h}\right)$ was converted into sap flux density (u) using the following equation (Burgess et al. 2001, rearranged):

$$
u=\frac{\rho_{b}}{\rho_{s}}\left(m_{c}+\frac{c_{w}}{c_{s}}\right) \cdot V_{h} \quad\left(\mathrm{~m}^{3} \mathrm{~m}^{-2} \mathrm{~s}^{-1}\right)
$$

where $\rho_{b}$ basic density of the dry sapwood (i.e. dry weight divided by the green volume), $\rho_{s}$ the density of the sap (assumed to be the density of water), $m_{c}$ the water content of fresh sapwood, $c_{w}$ the specific heat capacity of the dry wood matrix $\left(1200 \mathrm{~J} \mathrm{~kg}^{-1} \mathrm{~K}^{-1}\right.$ at $20{ }^{\circ} \mathrm{C}$; Becker and Edwards 1999) and $c_{s}$ the specific heat capacity of the sap (assumed to be that of water, $4186 \mathrm{~J} \mathrm{~kg}^{-1} \mathrm{~K}^{-1}$ at $20{ }^{\circ} \mathrm{C}$; Becker and Edwards 1999). Unlike Burgess et al. (2001) and others, we express the resulting variable as sap flux density instead of a velocity of sap movement. Although both variables mathematically appear to have the same unit, it has been pointed out that the cancellation of $\mathrm{m}^{2}$ is physically incorrect (e.g., Steppe et al. 2010; Vandegehuchte and Steppe 2013).

We used a commercially available HRM sensor system (SFM1, ICT International Pty Ltd., Armidale, Australia), which consists of two thermocouples spaced $15 \mathrm{~mm}$ apart and positioned at $5 \mathrm{~mm}$ and $20 \mathrm{~mm}$ depth behind the cambium. The data were analyzed with the Sap Flow Tool software (v1.4, ICT International Pty Ltd., Armidale, Australia). The sapwood area was divided into concentric annuli delimited by the midpoints between the measurement points. The point estimates of sap flux density were weighted according to the amount of conducting sapwood in the respective annulus assuming a perfectly circular stem. Average sap flux density was calculated as the weighted average of both measuring points. The time interval between heat pulses was set to $10 \mathrm{~min}$ and the heat pulse energy to $25 \mathrm{~J}$ to keep the maximum temperature rise at the sensor probes within the recommended margin of $0.7-1.5{ }^{\circ} \mathrm{C}$ in order to avoid additional heat-induced damage to the tissue adjacent to the heater (Burgess and Downey 2014). In our study, no wound responses were observed due to the short measurement periods. Thus, the wound diameter varied only slightly between the stem segments $(1.6-1.7 \mathrm{~mm})$ and corresponded closely to the size of the drilled holes. Nevertheless, wound diameters were quantified for all HRM installations from the scans of the dyed cross-sections (see chapter below) and appropriate wound correction factors according to Burgess et al. (2001) were applied to the HRM data. Since the HRM method is known to be less reliable at high flux densities $83 \times 10^{-6} \mathrm{~m}^{3} \mathrm{~m}^{-2}$ $\mathrm{s}^{-1}$ (Bleby et al. 2008), observations with flux densities above this threshold were excluded from the assessment of measurement accuracy.

\subsubsection{Sensor installation, measurement procedure and gravimetric validation}

To account for circumferential variation in sapwood depth, each three HRM and TDP sensors were operated in parallel with the sensors positioned at angles of $120^{\circ}$ to each other at the same height of the stem. The data of the three sensors were subsequently averaged. In case of the HFD system, it was not possible to install more than one sensor per stem segment due to the length of the needles and the resulting thermal interference. For the HRM and TDP installations, we checked for thermal independence of the sensors in all runs by consecutively switching single heaters on and off.

HFD and HRM sensor installation holes were drilled with drilling templates supplied by the manufacturer. Polystyrene slices of variable sizes were used as spacers in order to position 
the first measurement point $5 \mathrm{~mm}$ below the cambium. For installing the TDP sensors, the bark was carefully removed and holes were drilled corresponding to the length of the aluminium sleeves. Sleeves were inserted to line up precisely with the outer boundary of the sapwood. Before the insertion into the installed sleeves, all sensor needles/heaters were coated in silicon grease. The shafts of the installed sensors were tightened with sealing mass (Terostat IX, Henkel, Düsseldorf, Germany) for maximum thermal insulation.

The TDP and HFD methods require a period of stable zero flux to enable calculation of sap flux density. After flushing and prior to the measurements, we recorded baseline temperature values for $8-10 \mathrm{~h}$ under conditions of zero suction at a constant air temperature of $20{ }^{\circ} \mathrm{C}\left( \pm 0.5^{\circ} \mathrm{C}\right)$.

Subsequent to the zero flux periods, the suction applied to the stem segments was increased in $50 \mathrm{hPa}$ steps to $-650 \mathrm{hPa}$, starting at $-50 \mathrm{hPa}$, with every suction level being maintained for $1 \mathrm{~h}$. To account for time lags in the sensor reading, data from the first 15 min were discarded in each pressure level (Figure 3.2 and Figure S2).

Gravimetric sap flux density was calculated by dividing water flow (volume per time) by the sapwood area (see Section 3.3.6) at the respective accuracy of gravimetric records due to evaporation and "Archimedes error" caused by buoyancy are given in the Supplementary material.

\subsubsection{Sapwood area determination and thermal diffusivity of fresh sapwood}

After each flow experiment, sapwood area was visualized with a safranin solution $(0.1 \%)$ by soaking the dye solution through the conducting sapwood at a subatmospheric pressure of $-500 \mathrm{hPa}$. After drying for $24 \mathrm{~h}$, cross-sections at the heater positions of all sensors were cut with a circular saw, scanned with $600 \mathrm{dpi}$ and the scans processed with the software ImageJ (NIH, USA, http://rsbweb.nih.gov/ij/).

Both for the HRM and HFD method, thermal diffusivity of fresh sapwood $(D)$ needs to be estimated in order to calculate sap flux density (Swanson 1983; Burgess et al. 2001; for derivation of $D$ see Supplementary material). Three fresh sapwood samples per species were taken directly after the sap flow measurements in order to determine fresh weight, volume (using Archimedes' principle) and oven-dried weight $\left(120 \mathrm{~h}\right.$ at $\left.70{ }^{\circ} \mathrm{C}\right)$. We obtained $\mathrm{D}$ values of $2.99 \times 10^{3}, 2.739 \times 10^{3}$ and $2.849 \times 10^{3} \mathrm{~cm}^{2} \mathrm{~s}^{-1}$ for the wood of F. sylvatica, T. cordata and A. pseudoplatanus, respectively.

\subsubsection{Statistical analyses}

\subsubsection{Empirical calibration of TDP sensors}

As the dataset used for calibration is based on repeated measurements on the same experimental units (i.e. stems), individual observations, i.e. averaged data from one pressure level, cannot be considered independent. We therefore analyzed the relation between sensor readings and gravimetrically determined sap flux density with nonlinear mixed models using the nlme() function of the nlme package (Pinheiro et al. 2015) of $\mathrm{R} v 3.2 .2$ ( $\mathrm{R}$ Core Team, 2015) to account for both pseudoreplication in the repeated sap flow measurements and the between-stem variability in flow characteristics. As the different sensor designs varied considerably in various parameters, we decided to analyze their data in three separate models. On the observation level, our models had the form 


$$
u_{i j}=a_{j} \cdot K_{i j}^{b_{j}}+\epsilon_{i j}
$$

where $u_{i j}$ is the observed gravimetric sap flux density, $K_{i j}$ the term $\left(\Delta T_{\max } \Delta T\right) / \Delta T$ averaged over the three TDP sensors installed in a given stem segment, $a_{j}$ and $b_{j}$ the stem-specific calibration parameters, and $\epsilon_{i j}$ an error term for observation $i$ and stem $j$.

On the stem level, we assume $a_{j}$ and $b_{j}$ to be normally distributed around the speciesspecific means $a_{\text {spec }}$ and $b_{\text {spec }}$ with the standard deviations $S D_{R E_{a}}$ and $S D_{R E_{b}}$ for the stems of the five species:

$$
\begin{gathered}
a_{j} \sim N\left(a_{\text {spec }}, S D_{R E_{a}}\right) \\
b_{j} \sim N\left(b_{\text {spec }}, S D_{R E_{b}}\right)
\end{gathered}
$$

As the dataset displayed a considerable heteroscedasticity with large species-specific differences in error variance, we allowed the residual standard deviation to vary between species:

$$
\epsilon_{i j} \sim N\left(0, R S D_{\text {spec }}\right)
$$

Additionally, we fitted a simplified model that replaced the species-specific $a_{\text {spec }}$ and $b_{\text {spec }}$ by the overall averages $a_{\text {mean }}$ and $b_{\text {mean }}$, thus attributing all species-specific variability in the calibration parameters to the stem-specific random effects. Also in these models, we decided to keep species-specific error variances to avoid distorted parameter estimates due to the high heteroscedasticity. The model assumptions were checked visually by inspecting plots of the residuals. The hypothesis that the parameters $a$ and $b$ have species-specific values was tested with likelihood ratio tests (LRT) against reduced null models which each set the species-specific differences of one of those parameters to zero. LRT were performed using maximum likelihood (ML) estimation. In order to test whether the estimated values of $a$ and $b$ differed significantly from the estimates of Granier (1985), we expressed these parameters as a difference from Granier's original estimates in models refitted with restricted maximum likelihood (REML), and used Wald $z$-tests to test the hypothesis that the difference is significantly different from zero.

\subsubsection{Empirical calibration of HFD sensors}

Due to the amount of available data, it was unrealistic to fit a 4- or 5-parametric nonlinear mixed model using the polynomial expressions for sap flux density proposed by Vandegehuchte and Steppe (2012c). In order to account for a possibly curvilinear relationship between sap flux density $u$ and the area-weighted average HFD ratio (symmetric to asymmetric temperature differences), while keeping the number of estimated parameters at a reasonable minimum, we decided to model it with nlme using a power law analogous to Eq. (3.6).

$$
u_{i j}=c_{j} \cdot H F D_{i j}^{d_{j}}+\epsilon_{i j}
$$


Analogous to Eq. (3.7) and (3.8), $c_{j}$ and $d_{j}$ were assumed to be normally distributed with species-specific means $c_{\text {spec }}$ and $d_{\text {spec }}$ and common standard deviations $S D_{R E_{c}}$ and $S D_{R E_{d}}$.

Additionally, we fitted a simplified model that attributed all species differences to the stemspecific random effects for $c$ and $d$. Again, considerable heterogeneity of variance made it necessary to use a species-specific error variance $R S D_{\text {spec }}^{2}$ (cf. Eq. (3.9)). As a physical basis for the equation of Nadezhdina et al. (2012) is lacking (cf. Eq. (3.3)), we decided to account for possible sources of variance on the species and stem level (e.g., thermal conductivity and sapwood depth) by the fixed species effects and stem level random effects for $c$.

To test for species differences in $\mathrm{c}$ and $\mathrm{d}$, we again used likelihood ratio tests against reduced null models. Additionally, the null hypothesis that $d$ is equal to 1 (i.e. the relationship between $u$ and HFD ratio is linear on stem level, as assumed by Nadezhdina et al. 2012) was tested by reparameterizing $d$ as a difference to 1 and performing a Wald $z$-test against the null hypothesis that this difference is zero.

\subsubsection{Evaluation statistics}

The performance of the different sap flux measurement methods was compared by a set of different evaluation statistics that quantify precision, bias and overall accuracy. To measure the precision of the estimates, we calculated the Pearson correlation coefficient $r$ between gravimetrically observed and estimated sap flux density. In order to facilitate comparison with the assessment of Steppe et al. (2010), we expressed the amount of bias as a percentage of over- or under-estimation derived from the slope of a regression line through observed and measured values. However, to avoid mathematical inconsistencies, we regressed observed on measured values instead of measured on observed values (Piñeiro et al. 2008). As measures of overall accuracy, we calculated the root mean square error (RMSE) and its (scale-independent) coefficient of variation (CV RMSE), which is more meaningful for comparisons between species due to their differences in the range of observed sap flux densities. Additionally, we expressed the amount of explained variation in the observed flux densities as Lave's Pseudo- $R^{2}$ (Lave 1970).

For the different types of TDP sensors, the evaluation statistics mentioned above were calculated using both the original calibration parameters of Granier (1985) and the parameters estimated by our models. Likewise, for the HFD method, the evaluation statistics were calculated for both the original equation of Nadezhdina et al. (2012) and our empirical calibration equations. As the evaluation statistics provided in this study were calculated from the dataset which was used for model fitting, they can be expected to overestimate the accuracy of sap flow predictions from our own models compared to predictions based on literature values of calibration parameters. We tried to reduce this bias by working with the marginal predictions of our mixed models (i.e., using generalizations of our model predictions to 'average stems' instead of stem-specific predictions). However, we acknowledge that, if feasible, it is preferable to evaluate the measurement accuracy with an independent dataset. 
TDPuP

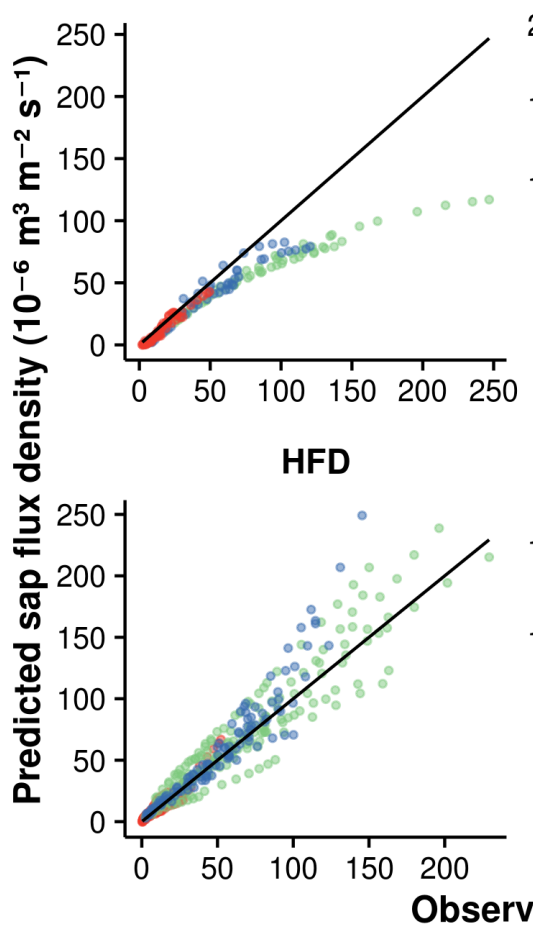

TDP long
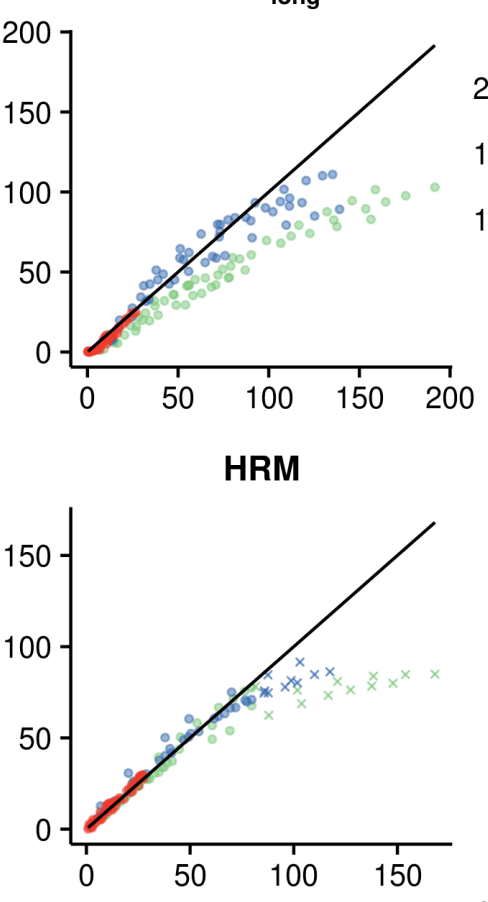

TDP $_{\text {short }}$

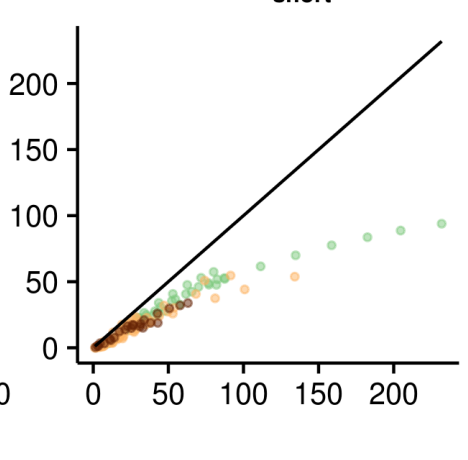

Figure 3.1: Plot of predicted versus gravimetrically determined sap flux density for the five sensor types and five tree species. Each dot represents the aggregated data from a single pressure level in one stem segment (averaged over 45 min of measurement). In case of the HRM system, all data points with sap flux density $>83 \times 10^{-6} \mathrm{~m}^{3} \mathrm{~m}^{-2} \mathrm{~s}^{-1}$ ) were marked by crosses and excluded from further analyses (see Section 3.3.4).

\subsection{Results}

\subsubsection{Sensor performance relative to the gravimetric reference}

Gravimetrically determined flux density and flux densities predicted from sensor readings were highly correlated for all five sensor systems $(r=0.94-0.99$; Figure 3.1, Table 3.2). The stepwise increase in flow rate in the calibration experiments is well mirrored in all measuring systems, though with different time lags relative to the gravimetric reference measurement (Figure 3.2). In all systems, the time lag was largest at low flow rates (small applied suction); it was much larger in the HFD and TDP systems than in the HRM system. To account for this time lag, we excluded all data from the first $15 \mathrm{~min}$ of a suction level from further analyses. The best agreement with the gravimetric reference data was found for the HRM system with less than $1 \%$ systematic bias when high flux values $\left(83 \times 10^{-6} \mathrm{~m}^{3} \mathrm{~m}^{-2} \mathrm{~s}^{-1}\right)$ were excluded from the analysis as suggested by Bleby et al. (2008). A slight, but notable bias in relation to the gravimetric reference was found for the HFD system (11\% overestimation), while the deviation was much larger for all tested TDP systems when calculated with the original calibration equation $(23-45 \%$ underestimation, depending on sensor length). Also in terms of evaluation statistics that penalize both bias and lack of precision, the HRM system performed better than the other methods (RMSE and Pseudo- $R^{2}$ in Table 3.2).

Throughout all TDP experiments, the relationship between sensor data and gravimetric 


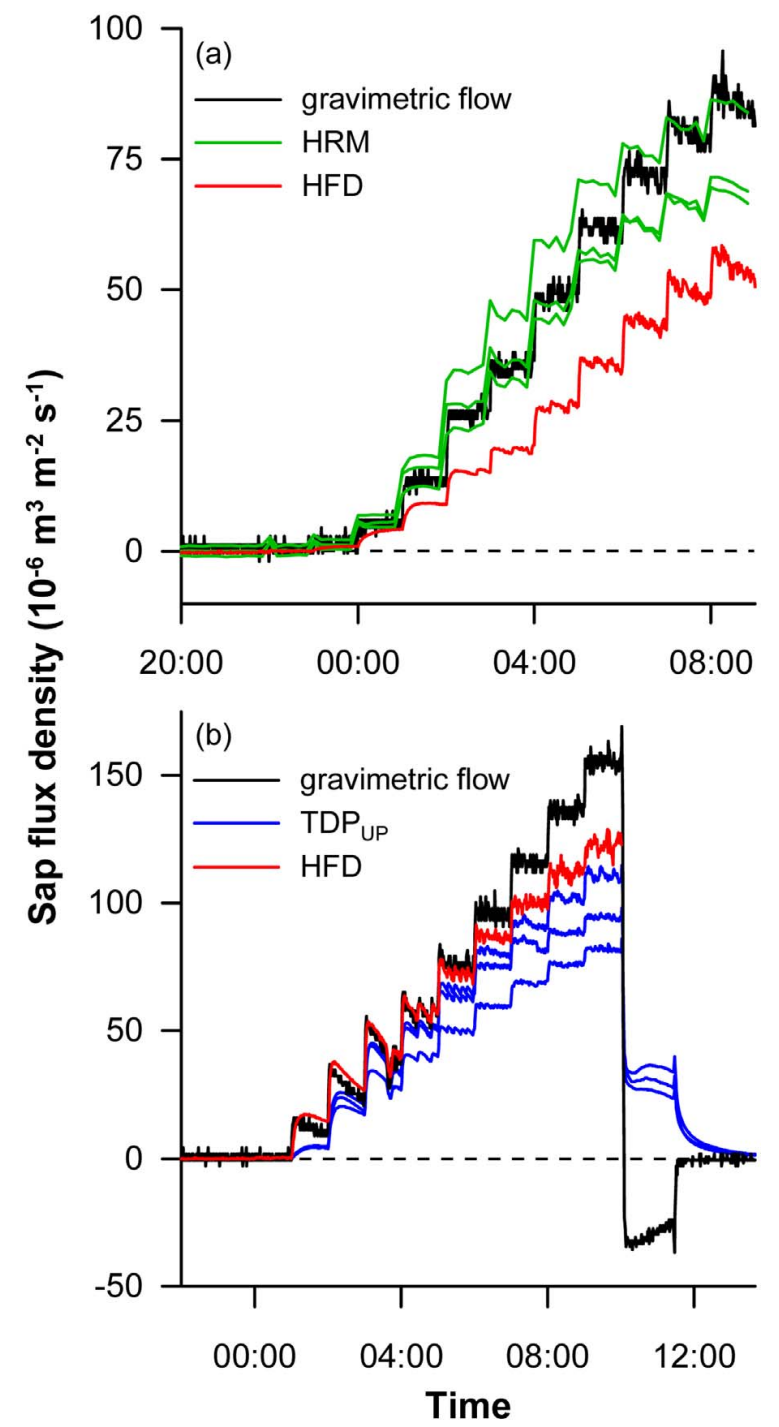

Figure 3.2: Typical result of a flow experiment with stepwise change of applied suction to cut stem segments of Tilia cordata (a) and Fagus sylvatica (b). Black lines show the gravimetrically determined flux density, coloured lines the flux derived from the output of single sensors as calculated with the original equations given by manufacturers. Please note that TDP sensors cannot distinguish between positive and negative flows; for that reason the reverse flow generated at the end of the experiment (right side of graph b) is recorded as positive flow. 
Table 3.2: Comparison of the accuracy of the five tested sensor systems measured as relative deviation from the gravimetric data. Given are evaluation statistics for precision (Pearson correlation coefficient, $r$ ), bias (percentage deviation of the slope of the linear regression between sensor and gravimetric data from the 1:1 line, Perc. deviation) and overall accuracy (root mean square error, RMSE; normalized root mean square error, CV RMSE; and Lave's Pseudo $R^{2}$ ).

\begin{tabular}{|c|c|c|c|c|c|}
\hline Sensor type & RMSE & CV RMSE & Correlation & Pseudo $r^{2}$ & Perc. deviation \\
\hline \multicolumn{6}{|c|}{ Accuracy of sensor systems with original calibrations } \\
\hline $\mathrm{TDP}_{\mathrm{UP}}$ & 25.46 & 0.49 & 0.96 & 0.71 & -31.71 \\
\hline $\mathrm{TDP}_{\text {long }}$ & 22.17 & 0.43 & 0.94 & 0.76 & -23.31 \\
\hline $\mathrm{TDP}_{\text {short }}$ & 26.68 & 0.68 & 0.96 & 0.52 & -45.00 \\
\hline HFD & 14.76 & 0.33 & 0.95 & 0.88 & 11.65 \\
\hline HRM & 3.56 & 0.13 & 0.99 & 0.97 & -0.84 \\
\hline \multicolumn{6}{|c|}{ Accuracy of TDP and HFD sensors with new calibrations across all species } \\
\hline $\mathrm{TDP}_{\mathrm{UP}}$ & 15.45 & 0.28 & 0.98 & 0.92 & -15.08 \\
\hline $\mathrm{TDP}_{\text {long }}$ & 13.88 & 0.28 & 0.95 & 0.90 & -7.87 \\
\hline $\mathrm{TDP}_{\text {short }}$ & 7.80 & 0.22 & 0.96 & 0.90 & -0.69 \\
\hline HFD & 22.57 & 0.55 & 0.87 & 0.57 & 19.33 \\
\hline \multicolumn{6}{|c|}{ Accuracy of TDP and HFD sensors with new calibrations for single species } \\
\hline $\mathrm{TDP}_{\mathrm{UP}}$ & 6.44 & 0.12 & 0.99 & 0.92 & -2.69 \\
\hline $\mathrm{TDP}_{\text {long }}$ & 8.48 & 0.17 & 0.98 & 0.98 & 0.09 \\
\hline $\mathrm{TDP}_{\text {short }}$ & 7.73 & 0.22 & 0.96 & 0.96 & -1.31 \\
\hline HFD & 12.65 & 0.31 & 0.97 & 0.82 & 12.40 \\
\hline
\end{tabular}

data was non-linear, which lead to increased deviations at higher sap flux densities.

The accuracy of the three TDP sensor types was greatly improved when specific calibration parameters derived from our experiments were used for calculation (Table 3.2). This was not true in case of the HFD system, where the use of empirical calibration equations improved precision but simultaneously increased bias. Nevertheless, the inclusion of species-specific calibration parameters increased accuracy considerably in all cases compared to calibrations that pooled over species (Table 3.2).

\subsubsection{Calibration of TDP sensors}

Plotting the term $\Delta T_{\max } / \Delta T-1$ ('flow index $K$ ') against the gravimetric flow data revealed high variation between different stems of the same species and also between the five species (Figure 3.3). The between-stem standard deviation of the parameters $a$ and $b\left(S D_{R E_{a}}\right.$ and $\left(S D_{R E_{a}}\right)$ was high (ca. $20-50 \%$ of the mean parameter estimates) among the stems of the same species and also for models that pooled data across all species, whereas the residual standard deviation, and accordingly the fraction of the unexplained variance that cannot be attributed to between-stem and species differences, was relatively low (Table 3.3). This suggests that the TDP systems are capable of monitoring temporal variation in flux density in a consistent manner, but the measured sap flux values are highly dependent on intra- and interspecific variation of sapwood properties.

The parameters $a$ and $b$ differed significantly $(\mathrm{P}<0.001)$ between the three species in the systems with longer heating elements $\left(\mathrm{TDP}_{\mathrm{UP}}\right.$ and $\mathrm{TDP}_{\text {long }}, 20$ and $24 \mathrm{~mm}$; Table 3.3). In case of the $\mathrm{TDP}_{\text {short }}$ system with $12 \mathrm{~mm}$-long heating elements, no species-specific 


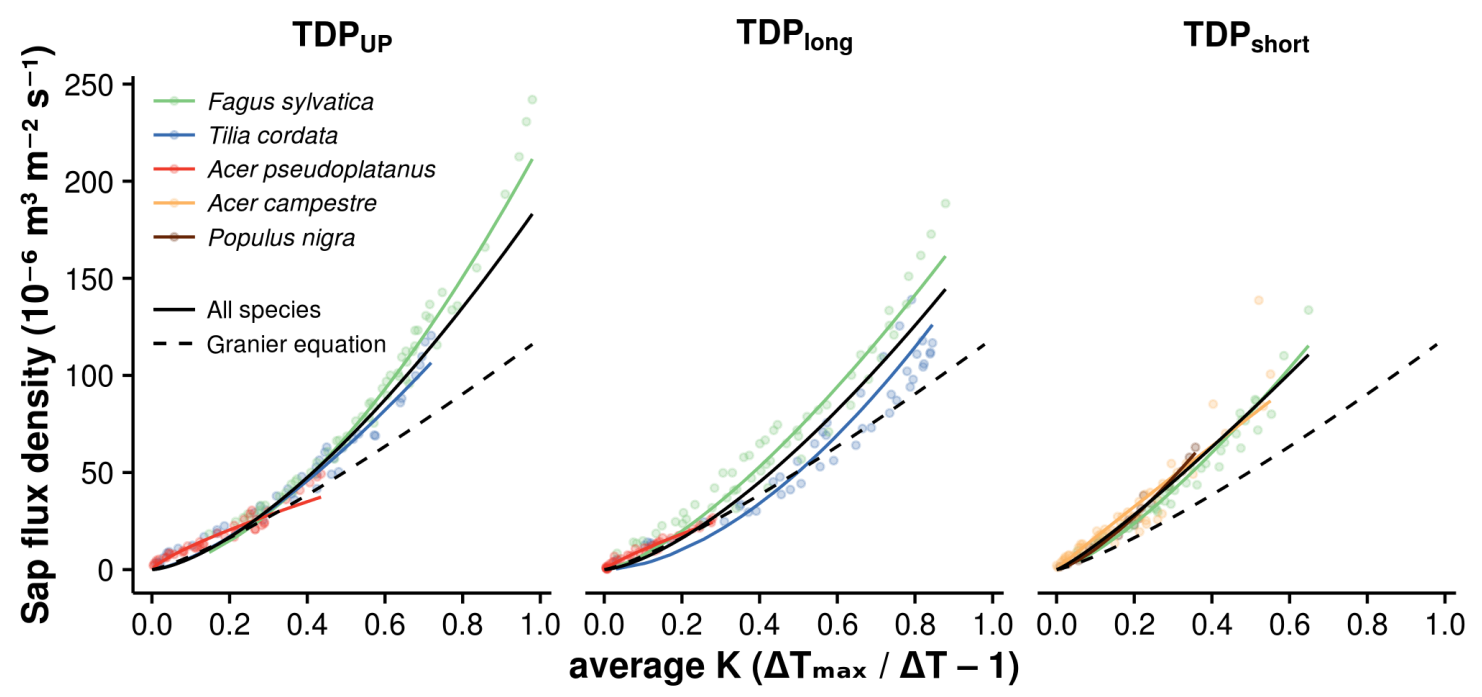

Figure 3.3: Plot of the gravimetrically determined sap flux density versus sap flow index $K$ $\left(\Delta T_{\max } / \Delta T-1\right)$ determined for the three types of TDP sensors. $K$ values are the average of 3 sensors per stem to account for sapwood variation along the stem circumference. Solid lines display marginal (i.e. stem-independent) predictions of non-linear mixed effects models (for the five species in different colours, for the pooled data set in black), dashed lines depict the relationship from the original equation given by Granier (1985) for comparison.

differences in the parameter $a(\mathrm{P}=0.301)$ and only slight differences in $b(\mathrm{P}=0.014)$ could be detected. While the parameter estimates of the TDP $\mathrm{UP}_{\text {and }} \mathrm{TDP}_{\text {long }}$ systems where in a rather similar range both when estimating on species level and when pooling data across species, at least one of the parameters deviated significantly from the original value in Granier (1985) in all cases (Table 3.3). The estimated calibration parameters for the system with short heaters deviated considerably from the other systems, while the parameter b of the short system was notably closer to Granier's original value (Table 3.3).

\subsubsection{Calibration of HFD sensors}

Similar to TDP sensors, we found high between-species and between-stem variation, as is visible in the plot of gravimetric sap flux density versus HFD ratio in Figure 3.4 and highly significant species differences in the estimates of the parameters $c$ and $d$ (Table 3.4). Corresponding to the visible between-stem variation, we found high random effect standard deviations for the parameter estimates on the stem level (Table 3.4) that amounted to between $13.2 \%$ and $36.6 \%$ of the estimated values. In contrast, the relatively low residual standard deviation of the models indicates that consecutive measurements within stems were highly consistent. On the level of single stems, the parameter d (which defines the curvature of the power function) was scattered above and below one for all species, leading to very high stem-level variability in measured values at higher flux densities. For both the models with and without species-specific parameters, d was significantly different from 1 , in contradiction to the assumption of a linear relationship from Nadezhdina et al. (2012). 
Table 3.3: Results of the non-linear mixed effects models for the TDP sensors with and without species differences in parameters. Given are the number of observations $(n)$ and stems $\left(n_{\text {stem }}\right)$, estimates of the parameters a and $\mathrm{b} \pm$ corresponding standard errors, P-values for the tests of the null hypotheses that the parameters do not differ from the original values of Granier (1985) $\left(P\left(a=a_{\text {Granier }}\right)\right.$, Wald $z$-test $)$ and that the species differences are equal to zero $(P \mathrm{P}(a$ equal $)$, LRT, only for models with species effects), random effects standard deviations $\left(S D_{R E}\right)$ for $a$ and $b$ and residual SD (estimated on species level). P-values below 0.05 are highlighted in bold font. AP: Acer pseudoplatanus; FS: Fagus sylvatica, TC: Tilia cordata.

\begin{tabular}{|c|c|c|c|c|c|c|c|c|c|c|}
\hline Species & $\mathbf{n}\left(\mathbf{n}_{\text {stem }}\right)$ & $a \pm \mathrm{SE}$ & $P\left(a=a_{\text {Granier }}\right)$ & $P(a$ equal $)$ & $b \pm \mathrm{SE}$ & $\mathbf{P}\left(b=b_{\text {Granier }}\right)$ & $\mathbf{P}(b$ equal $)$ & $\mathrm{SD}_{\mathrm{RE}} a$ & $\mathrm{SD}_{\mathrm{RE}} b$ & Residual SD \\
\hline \multicolumn{11}{|l|}{$\mathrm{TDP}_{\mathrm{UP}}$} \\
\hline AP & $44(5)$ & $73.09 \pm 11.92$ & $* * *$ & & $0.796 \pm 0.104$ & $* * *$ & & 24.89 & 0.217 & 1.32 \\
\hline FS & $61(7)$ & $217.31 \pm 10.37$ & $* * *$ & $<0.001$ & $1.662 \pm 0.091$ & $* * *$ & $<0.001$ & 24.89 & 0.217 & 3.08 \\
\hline $\mathrm{TC}$ & $43(5)$ & $171.01 \pm 13.91$ & $* * *$ & & $1.430 \pm 0.118$ & n.s. & & 24.89 & 0.217 & 3.01 \\
\hline All & 148 (17) & $159.70 \pm 16.36$ & $*$ & & $1.329 \pm 0.109$ & n.s. & & 66.06 & 0.433 & $\begin{array}{c}1.30(\mathrm{AP}) 3.03(\mathrm{FS}) \\
2.97(\mathrm{TC})\end{array}$ \\
\hline \multicolumn{11}{|l|}{$\mathrm{TDP}_{\text {long }}$} \\
\hline $\mathrm{AP}$ & $44(4)$ & $67.00 \pm 10.87$ & $* * *$ & & $0.812 \pm 0.103$ & $* * *$ & & 17.84 & 0.184 & 1.19 \\
\hline FS & $53(6)$ & $194.73 \pm 08.30$ & $* * *$ & $<0.001$ & $1.417 \pm 0.080$ & $*$ & $<0.001$ & 17.84 & 0.184 & 2.23 \\
\hline $\mathrm{TC}$ & $45(5)$ & $163.94 \pm 09.12$ & $* * *$ & & $1.705 \pm 0.103$ & $* * *$ & & 17.84 & 0.184 & 2.86 \\
\hline All & $142(15)$ & $150.31 \pm 13.76$ & $*$ & & $1.343 \pm 0.100$ & n.s. & & 51.76 & 0.375 & $\begin{array}{c}1.20(\mathrm{AP}) 2.24(\mathrm{FS}) \\
2.89(\mathrm{TC})\end{array}$ \\
\hline \multicolumn{11}{|l|}{$\mathrm{TDP}_{\text {short }}$} \\
\hline $\mathrm{AC}$ & $54(7)$ & $156.27 \pm 27.18$ & n.s. & & $0.979 \pm 0.083$ & $* *$ & & 69.85 & 0.200 & 2.80 \\
\hline FS & $41(5)$ & $205.55 \pm 32.17$ & $* *$ & 0.301 & $1.342 \pm 0.096$ & n.s. & 0.014 & 69.85 & 0.200 & 2.51 \\
\hline PN & $21(3)$ & $222.49 \pm 52.32$ & n.s. & & $1.301 \pm 0.151$ & n.s. & & 69.85 & 0.200 & 2.72 \\
\hline All & $116(15)$ & $182.94 \pm 19.78$ & $* *$ & & $1.162 \pm 0.072$ & n.s. & & 71.62 & 0.254 & $\begin{array}{c}2.68(\mathrm{AC}) 2.48(\mathrm{FS}) \\
2.70(\mathrm{PN})\end{array}$ \\
\hline
\end{tabular}

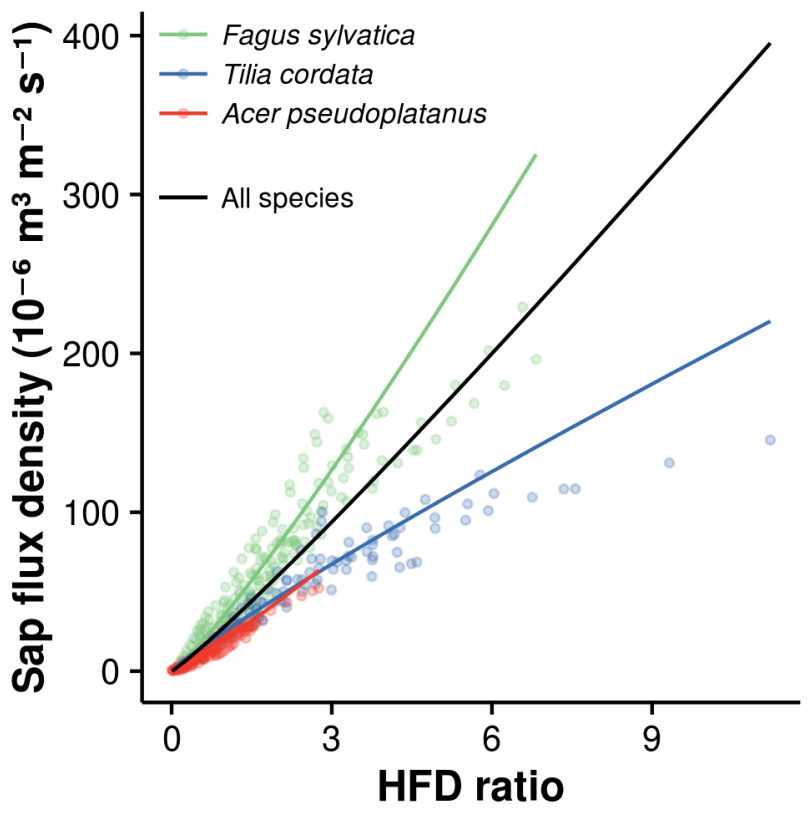

Figure 3.4: Plot of the gravimetrically determined sap flux density versus HFD ratio $((H+$ $\left.\left.\Delta T_{\text {sym }}\right) / T_{a s}-1\right)$. Solid lines display marginal (i.e. stem-independent) predictions of non-linear mixed effects models (for the five species in different colours, for the pooled data set in black). 
Table 3.4: Results of the non-linear mixed effects models for the HFD sensors with and without species differences in parameters. Given are the estimates of the parameters $c$ and $d \pm$ corresponding standard errors, P-values for the tests of the null hypotheses that $\mathrm{d}$ is equal to 1 , i.e. sap flux scales linearly with the HFD ratio $(P(d=1)$, Wald $z$-test $)$ and that the species differences are equal to zero $(P(c$ equal $)$, LRT, only for model with species effects), random effects standard deviations $\left(S D_{R E}\right)$ for $c$ and $d$ and residual SD (estimated on species level). AP: Acer pseudoplatanus; FS: Fagus sylvatica; TC: Tilia cordata.

\begin{tabular}{cccccccccc}
\hline Species & $\mathbf{n}\left(\mathbf{n}_{\text {stem }}\right)$ & $\boldsymbol{c} \pm \mathbf{S E}$ & $\boldsymbol{P}(\boldsymbol{c}$ equal $)$ & $\boldsymbol{d} \pm \mathbf{S E}$ & $\boldsymbol{P}(\boldsymbol{d}=\mathbf{1})$ & $\boldsymbol{P}(\boldsymbol{d}$ equal $)$ & $\mathbf{S D}_{\mathrm{RE}} \boldsymbol{c}$ & $\mathbf{S D}_{\mathrm{RE}} \boldsymbol{d}$ & Residual SD \\
\hline AP & $162(15)$ & $19.98 \pm 1.85$ & & $1.138 \pm 0.044$ & 0.002 & & 7.12 & 0.151 & 0.86 \\
FS & $187(21)$ & $35.92 \pm 1.57$ & $<0.001$ & $1.147 \pm 0.034$ & $<0.001$ & $<0.001$ & 7.12 & 0.151 & 1.31 \\
TC & $107(12)$ & $25.11 \pm 2.10$ & & $0.898 \pm 0.046$ & 0.027 & & 7.12 & 0.151 & 1.91 \\
All & $456(48)$ & $28.34 \pm 1.51$ & & $1.090 \pm 0.029$ & 0.002 & 10.36 & 0.195 & $0.84(\mathrm{AP}) 1.29(\mathrm{FS}) 1.88(\mathrm{TC})$ \\
\hline
\end{tabular}

\subsection{Discussion}

\subsubsection{How accurate are sap flux probes?}

The present study is the first to directly assess the performance of TDP, HFD and HRM sensors in comparison to a gravimetric reference method applied to cut stems of different tree species. We used subatmospheric pressure to simulate natural flow conditions and stem segments of comparable size to the smallest individuals measured in the field. Our results confirm the principal applicability of all three methods for qualitative sap flow measurements in diffuse-porous, temperate tree species, as the output of all sensor types showed strong correlation with sap flux density. However, we cannot confirm the systematic underestimation of sap flux rates by TDP, HFD and CHPM systems found by Steppe et al. (2010) in F. grandifolia, neither for $F$. sylvatica nor for the densities was very similar. In our study, only the TDP method revealed similar flux underestimation at medium to high flux densities for all sensor types tested. Systematic underestimation of flow by the TDP method which increases with increasing sap flux density was also found in other calibration experiments, e.g. Taneda and Sperry (2008) on Quercus gambelii (ring-porous) and Acer grandidentatum (diffuse-porous), de Oliveira Reis et al. (2006) on papaya plants, and Cabibel et al. (1991) on Malus domestica, Q. robur, C. sativa and PVC columns filled with synthetic fibres. Although the percentage error was highest for the TDP method, it has to be kept in mind that data points at high flux densities have a high leverage on this statistic which is derived from a linear regression function forced through the origin. Thus, the non-linear pattern observed for TDP might cause our measure of bias to disproportionally penalize this method in comparison to HFD and HRM, which showed a less pronounced non-linear deviation.

The HFD method has been validated only once so far (Steppe et al. 2010). The underestimation of $46 \%$ found by these authors clearly differs from our results ( $11 \%$ overestimation). Beside the fact that Steppe et al. (2010) investigated a different tree species (F. grandifolia), another explanation is plausible. The calculation of sap flux density according to Nadezhdina et al. (1998; 2012) introduces thermal diffusivity as multiplicator and sapwood depth as divisor in the equation. Our data show a thermal diffusivity of $2.99 \times 10^{-3}$ $\mathrm{cm}^{2} \mathrm{~s}^{-1}$ for F. sylvatica wood, whereas Steppe et al. (2010) assumed the thermal diffusivity of $F$. grandifolia to be $2.5 \times 10^{-3} \mathrm{~cm}^{2} \mathrm{~s}^{-1}$ (literature value, Marshall 1958). In addition, the sapwood depth in the sample of Steppe et al. (2010) was on average twice as large as in our study ( $57.3 \mathrm{~mm}$ versus $27.2 \mathrm{~mm}$, respectively). These differences alone can explain most of the observed discrepancy. In accordance with other publications assessing 
the accuracy of the HRM method (Burgess et al. 2000; Burgess et al. 2001; Bleby et al. 2004; Bleby et al. 2008), our results confirm both a high accuracy of the method at low flux densities and its limitation at high flux densities $\left(>83 \times 10^{-6} \mathrm{~m}^{3} \mathrm{~m}^{-2} \mathrm{~s}^{-1}\right)$, Already Marshall (1958) suggested that the logarithmic relationship between heat pulse velocity and the ratio of temperature increases only applies for $\Delta T_{\text {downstream }} / \Delta T_{\text {upstream }}$ ratios $<$ 20 (corresponding to sap flux densities of $124 \times 10^{-6} \mathrm{~m}^{3} \mathrm{~m}^{-2} \mathrm{~s}^{-1}$ ).

The large majority of published studies on sap flux in mature temperate trees reported flux densities $<110 \times 10^{-6} \mathrm{~m}^{3} \mathrm{~m}^{-2} \mathrm{~s}^{-1}$ (Lu et al. 2004). A field study by Gebauer et al. (2012) on the same tree species and using identical TDP long sensors reported sap flux density maxima of around $\left.95 \times 10^{-6} \mathrm{~m}^{3} \mathrm{~m}^{-2} \mathrm{~s}^{-1}\right)($ recalculated with the species-specific calibration coefficients for the $\mathrm{TDP}_{\text {long }}$ system of this study). Steppe et al. (2010) reported maxima of ca. $140 \times 10^{-6} \mathrm{~m}^{3} \mathrm{~m}^{-2} \mathrm{~s}^{-1}$ in a $F$. grandifolia tree, when applying correction factors obtained by calibration against a cut-stem experiment. It appears that HRM systems deliver reliable data mostly in the low-flux range, which limits the applicability of the system in measuring tasks with mature trees. This should apply at least for heat pulse energy levels of $25 \mathrm{~J}$ (or less), as used in this study. We have no information on the system's accuracy under higher energy input, which is an option to accommodate higher flux rates at the cost of increased tissue damage and consequently wounding reaction (Burgess and Downey 2014).

\subsubsection{Importance of between-stem variation in flux density}

Repeated flow measurements on the same stem were highly consistent across all systems. This is illustrated by the low residual standard deviations of all models which only amounted to a small fraction of the observed range of sap flux (Tables 3.3 and 3.4). In contrast, our models identified large between-stem variability in calibration parameters, indicating a strong dependence of sap flux measurements on species- and stemspecific variables such as differences in sapwood morphology and anatomy. Especially the between-stem portion of the variability in calibration parameters is of utmost importance as it represents a highly important source of uncertainty in sap flux measurement systems which cannot easily be controlled for even when species-specific calibrations are available. Additionally, an important consequence of the high stem-level variability is that calibrations which do not consider the pseudoreplication within stems by accounting for the hierarchical nature of the data will invariably underestimate the standard errors of estimates of calibration parameters. Anatomical properties that directly influence thermal conduction and convection (wood density, water content, vessel size and distribution, tissue irregularities like reaction wood and frequency of knots) are likely to differ greatly between stem segments, representing an important source of uncertainty when attempting to extrapolate to larger stem samples or to scale up to stand level. While inconsistencies in sensor installation (e.g. variable drilling accuracy, thermal insulation, or bark properties) certainly contributed to the large observed variability in calibration parameters, the variation between stems that remained after averaging over three separately installed sensors for the HRM and TDP systems provide an estimate for the magnitude of above-mentioned sources of variability. The HRM method, the only approach founded on a sound mechanistic basis with respect to the physics of heat dissipation, includes thermal diffusivity as a parameter in the conduction-convection equation. This variable was estimated separately for each species in our study, and the results of the HRM measurements accordingly show only small species differences in flux density. We assume that estimating thermal diffusivity on the individual tree level might further improve the measurement accuracy in field 
studies that make use of the HRM system. As estimates of thermal diffusivity can easily be obtained from short fresh wood samples with limited labour demand, this approach could be a viable route for controlling part of the observed between-stem variability.

Although our data show the between-stem variability to be highest for the HFD method, this result has to be interpreted with care, as for this method we cannot disentangle between-stem variability and variation between sensors mounted on the same stem. Due to technical reasons, we could install only one HFD sensor per stem, while for the TDP and HRM systems we effectively averaged out part of the variability as three sensors were operated in parallel on each stem, likely leading to an overestimation of the between-stem variability in the HFD data.

\subsubsection{Calibrating TDP sensors}

In the past 30 years, TDP sensors have frequently been used in most biomes on boreal, temperate, semi-arid and tropical forest tree species with different wood properties (e.g. Gebauer et al. 2012; Horna et al. 2011; Grossiord et al. 2013; Klein et al. 2014). Consequently, Granier's original power function parameters for the TDP system have been subject to several re-calibration efforts in the past to address apparent inconsistencies in certain species and cope with altered sensor designs. Estimates of the parameter a range from $119 \times 10^{-6}$ (Granier 1985) over $134 \times 10^{-6}$ (oil palm frond; Niu et al. 2015) and 137 $\times 10^{-6}$ (temperate tree species; Cabibel et al. 1991) up to $702 \times 10^{-6}$ (conifers; Lundblad et al. 2001), $1531 \times 10^{-6}$ (tropical papaya plants; de Oliveira Reis et al. 2006) or even $58,100 \times 10^{-6}$ (ring-porous temperate tree species; Bush et al. 2010), which illustrates the impossibility of applying universal parameters for all woody species. Based on a simulation model, Wullschleger et al. (2011) demonstrated the strong dependence of heat dissipation patterns of TDP sensors on wood properties. With our study, we corroborate their findings by identifying significant differences in calibration parameters even between temperate tree species with similar wood properties.

Thus, our results provide strong evidence against the hypothesis that the original calibration parameters given by Granier (1985) are universally applicable to different species and can accommodate different sensor designs. This also has to be considered when employing commercially available Granier-type sensors, such as those available from UP GmbH.

However, care is needed when interpreting the observed differences in species-specific calibration parameters in our study. Two facts may complicate the direct comparison of calibrations between species: (1) induced flux ranges in the experiments differed largely between species (from ca. 20 to $240 \times 10^{-6} \mathrm{~m}^{3} \mathrm{~m}^{-2} \mathrm{~s}^{-1}$ ) due to species differences in hydraulic conductivity. Especially in case of $A$. pseudoplatanus the maximum induced flow rates were substantially lower than in the other species. (2) TDP sensor readings clearly deviated from the assumed power-law relationship at small flux densities (low suction levels), i.e. the sensors' response (increase of the $K$-value) was too low in relation to the increase in sap flow (Figure 3.3). This indicates a reduced sensitivity of the TDP systems in this flux range, likely related to the longer time lag before reaching stable measurements at lower pressures (cf. Figure 3.2). A power-law is not flexible enough to describe the observed data pattern at low flux densities perfectly, which in consequence may have resulted in lower estimates of the parameter $\mathrm{b}$ in the case of Acer ( $<1$ in all cases), the species with the lowest range of induced flow rates. Our models might therefore exaggerate species differences in parameter $b$ to accommodate the deviations from the power law model observed for lower flow rates. In any case, our evaluation statistics suggest 
that in situations when it is not practicable to perform independent empirical calibrations for all analyzed species, pooling over a set of species with similar wood properties to obtain sensor-specific calibration parameters can result in a substantial improvement in accuracy compared to the use of Granier's original equation (Table 3.2). However, the observed deviations from a power law are in accordance with the model predictions by Hölttä et al. (2015), demonstrating that the relationship between $K$ and actual flux density is dependent on the range of flow rates examined.

As expected, the TDP sensor with short heating element $(12 \mathrm{~mm})$ showed the strongest deviation from Granier (1985) original parameter estimates because heating power and probe geometry were altered. In contrast to our findings, several authors calibrated different types of Granier sensors with shorter length (10 and $15 \mathrm{~mm}$ sensors; Braun and Schmid 1999; James et al. 2002; Lu et al. 2004) and reported validity of Granier's original calibration equation. According to Lu et al. (2004), James et al. (2002) adjusted the power input of the shorter probes to keep $\Delta T_{\max }$ in the same temperature range as in case of the original probes. In case of our short TDP sensors, heating power was reduced by $50 \%$, because we used a non-adjustable constant current source. This resulted in reduced $\Delta T_{\max }$ values (see Table 3.1 ), even though the surface of the probe was approximately $50 \%$ smaller than in case of the $\mathrm{TDP}_{\text {long }}$ system. This may explain the greater underestimation of flux by this sensor type compared to the longer probes, and illustrates the need of independent empirical calibration if there are changes in sensor design.

\subsubsection{Calibrating the HFD sensor}

The assumption of a non-linear relationship between sap flux density and HFD ratio was confirmed by our data, although the curvature was not as distinct as predicted by Vandegehuchte and Steppe (2012c). The observed highly significant species differences in the calibration parameters suggest that a species-independent empirical calibration is not possible with this sensor.

The original flux calculation according to Nadezhdina et al. (1998; 2012) achieved a comparable accuracy as our empirically-based species-specific calibration using the HFD ratio, and performed distinctly better than our empirically-based calibration with all species pooled. This indicates that the inclusion of thermal diffusivity on the species level and sap wood depth on the stem level suggested by Nadezhdina et al. (2012) does improve measurement accuracy, even though it lacks a physical justification (Vandegehuchte and Steppe 2012c).

Interpreted as a purely empirical method with species-specific calibration parameters, the HFD sensors performed worse than the other methods in terms of all accuracy indicators, what, however, can partly be attributed to the inability to exclude within-stem variation, as only one sensor could be installed per stem. In addition, the HFD ratio is not defined for $\Delta T_{a s}=0$, leading to implausibly high HFD ratios when $\Delta T_{a s}$ becomes very small; this occurred in some of our experiments at very high flux densities. This raises the more general question whether the HFD ratio is an appropriate proxy for sap flux density.

We can confirm the statement of Vandegehuchte and Steppe (2012c) that quantitative measures of sap flux density with the HFD method are only reliable after a species-specific empirical calibration. However, our calibration experiments indicate that HFD measurements are consistent at the level of single stems. In addition, the observed relationship was only moderately non-linear for the observed species, indicating that the HFD method 
with the original calculations (Nadezhdina et al. 2012) is a valid tool for the study of radial flux patterns.

\subsubsection{Limitations of calibration experiments}

The contradicting results of published calibration experiments for TDP sensors may partly be explained by the use of different species and sensor designs, but could also be a consequence of contrasting experimental conditions. The setup of most cut-stem calibration experiments used positive pressure to generate water flow through stem segments (Granier 1985; Granier and Gross 1987; Cabibel et al. 1991; Braun and Schmid 1999; de Oliveira Reis et al. 2006; Steppe et al. 2010). Some authors even do not give details on the driving force of flux in their experiments (e.g. James et al. 2002). Besides this study, only a few authors used vacuum to generate flow (Taneda and Sperry 2008; Hultine et al. 2010; Bush et al. 2010). Remarkably, all calibration experiments which applied subatmospheric pressure reported marked flow underestimation compared to gravimetrically determined flow rates, whereas all experiments with cut stems that confirmed Granier's calibration parameters used positive pressure.

Application of positive or subatmospheric pressure may affect the thermal conductivity in the vicinity of the sensor in different ways. Possible installation errors that cannot be completely avoided lead to either water leakage (during measurements with positive pressure) or small amounts of air being soaked in (during measurements with subatmospheric pressure). Water leakage may artificially decrease sensor temperatures through evaporative cooling on the stem surface, whereas dryer wood and an increased level of embolism in the surrounding wound may increase thermal insulation (less heat conduction), and result in reduced sap flux close to the sensor (less heat convection). This may have opposing effects on $\Delta T$ depending on the validation setup. An underestimation of fluxes in vacuum systems and also for in vivo measurements in living trees seems likely in comparison to validation setups applying positive pressure. This puts calibration parameters derived under positive pressure including those conducted by Granier (1985) into question, as they reflect more artificial conditions. In accordance with this, we are not aware of any study reporting overestimation of sap flow in field experiments with Granier (1985) original equation, while underestimation has often been suspected in such in vivo experiments (e.g., Köcher et al. 2009).

Although a cut-stem experiment has advantages like exact flow determination and a broad range of inducible fluxes, the experimental conditions deviate from nature, e.g. through the occurrence of open vessels in short segments, which may alter hydraulic conductivity selectively for single vessels. Furthermore, we might have fostered artificial xylem embolism formation during segment preparation by cutting the segments in air. Although this could substantively alter the conductivity and thermal diffusivity of the segments (e.g., Schenk et al. 2013), their xylem was relaxed before cutting, and at least $20 \mathrm{~cm}$ were dismissed at both ends of the segments in order to cope with this potential source of errors. Despite this shortcoming of cut-stem experiments, we could confirm that the depth of the conductive sapwood of our stem segments visualized by dye injection corresponds to in vivo field experiments (e.g., Gebauer et al. 2012). Another limitation of cut-stem experiments might be that water is provided to the entire stem surface, which might lead to different radial sap flow profiles compared with intact trees. A setup with potted plants or large, weighable lysimeters (e.g., Bleby et al. 2004; Green and Romero 2012) may keep the system closer to natural conditions, but the range of stem diameters and the accuracy 
of flow determination are limited.

\subsubsection{Conclusions}

Despite more than 80 years of development history and several important methodological innovations in the last decades, the measuring accuracy of the different sap flow probe types is not yet fully satisfying, limiting the comparability and complicating the synthesis of sap flow data measured with different thermometric methods (e.g., Poyatos et al. 2016). Our calibration experiments on five temperate tree species with similar sapwood anatomy suggest that for measurements in low to intermediate sap flux ranges, the highest accuracy can be achieved with the HRM technique, which has the advantage that it does not require calibration on species level. Further, our data show that species-specific calibration has the potential to improve the accuracy of constant heating methods (TDP and HFD) significantly. When species-specific calibrations are not available in TDP studies, it may still be possible to achieve major improvements in accuracy by pooling across species with similar wood properties. Due to the constraints of our design it is difficult to directly compare the accuracy of the HFD measurements to the other methods as within-stem variability could not be averaged out, but our HFD measurements were consistent on the stem level, which suggests the validity of this method for relative comparisons of radial profiles. Our results support earlier conclusions that many estimates of forest stand transpiration derived through upscaling of TDP measurements must represent underestimates of true water consumption. Furthermore, our study suggests that a great fraction of the uncertainty in sap flow estimates can be attributed to high between-stem variability in the calibration parameters. This has important implications both for the uncertainty budget of measurements on individual tree level and for the error propagation in studies that scale up to stand or ecosystem level. However, evaluations of measurement accuracy must also consider possible shortcomings in the reference measuring technique itself, i.e. gravimetric flow determination in cut stems as the most widely used approach. Comparisons between sap flow measurements and flow estimates derived from modern imaging techniques such as NMR would be welcome. Future calibration experiments should (1) examine systematic differences in calibration parameters between tree species with similar and with contrasting xylem anatomy, (2) address the extent of intraspecific variation in these parameters for stems of similar diameter and age, and (3) better define the trustworthy ranges of flow measurement for the different measurement techniques.

\section{Acknowledgements}

We thank Volker Meng from the Forest Botanical Garden of Göttingen University for permission to sample F. sylvatica trees, and Ernst Kreysern from the Reyershausen forest department for permission to extract F. sylvatica, Acer platanoides and T. cordata tree individuals. Constructive and helpful comments from three anonymous reviewers helped to improve the manuscript. 


\section{Appendix A: Supplementary data}

\section{Material and methods: supplementary equations}

\section{Thermal diffusivity of fresh sapwood}

Both the HRM and HFD method require the thermal diffusivity of fresh sapwood $(D)$ for calculating sap flux density (Swanson 1983; Burgess et al. 2001). D is calculated using equation S1:

$$
D=\frac{K_{g w}}{\rho c} \quad\left(m^{2} s^{-1}\right)
$$

where $K_{g w}$ is the thermal conductivity, $\rho$ is the density and $c$ the specific heat capacity of fresh sapwood. The thermal conductivity is calculated with equation S2:

$$
K_{g w}=K_{s}\left(m_{c} \frac{\rho_{b}}{\rho_{s}}\right)+\left(0.04182\left(21-20\left(1-\frac{\rho_{b}+m_{c}}{1000}\right)\right)\right) \cdot\left(1-m_{c} \frac{\rho_{b}}{\rho_{s}}\right)
$$

where $K_{s}$ is the thermal conductivity of water $\left(5.984 \cdot 10^{1} \mathrm{~J} \mathrm{~m}^{1} s^{1} \check{\mathrm{r}} C^{1}\right.$ at $\left.20{ }^{\circ} \mathrm{C}\right), m_{c}$ the water content of sapwood, $\rho_{b}$ the basic density of dry sapwood (dry weight per green volume) and $\rho_{s}$ the density of sap (water). Finally, the density and specific heat capacity is estimated from the expression:

$$
\rho_{c}=\frac{w_{d} c_{w}+c_{s}\left(w_{f}-w_{d}\right)}{V}
$$

where $w_{f}$ is the fresh weight and $w_{d}$ the oven-dried weight of the sample, $c_{s}$ and $c_{w}$ the specific heat capacity of sap (water) and the dry wood matrix (cf. Becker and Edwards 1999), and $V$ the volume of the sample.

\section{Equations and assumptions underlying the gravimetric measurement of water flow during the calibration experiments}

A lid with a circular aperture for the stem segment on top of the vat prevented high and variable evaporation rates. The remaining evaporation was recorded for 24 hours and an adequate correction was applied to the gravimetric data (Eq. S5). The volume of the stem below the water surface adds up to the gravimetric measurements (Archimedes principle). Since the water level in the vat is changing, accordingly the amount of displaced water changes as well. A volumetric correction for evaporation and for the "Archimedes error" as a function of the changes in water level in the vat was applied to the gravimetric data afterwards:

Flow rate F:

$$
F=\left(M_{t_{1}}-\left(M_{t_{2}}-E-C\right)\right) \cdot\left(t_{2}-t_{1}\right)^{-1} \quad\left(m^{3} s^{-1}\right)
$$

Correction term for evaporation loss under the experimental conditions: 


$$
E=3.0757 \cdot 10^{-9} \quad\left(m^{3} s^{-1}\right)
$$

Correction term for the amount of water $\mathrm{C}$ displaced by the submerged part of the stem:

$$
C=\frac{M_{t_{1}}-M_{t_{2}}}{a_{s}+a_{w}} \cdot a_{s} \cdot\left(t_{2}-t_{1}\right)^{-1} \quad\left(m^{3} s^{-1}\right)
$$

where $t_{1}-t_{2}$ is the considered measurement period, $M$ the weight of the vat plus water (balance data), $a_{s}$ the cross-sectional area (including bark) of the submerged stem part, and $a_{w}$ the open surface area of the water in the vat. For the submerged stem part, a cylindrical shape was assumed for simplicity. 


\section{Supplementary figures}

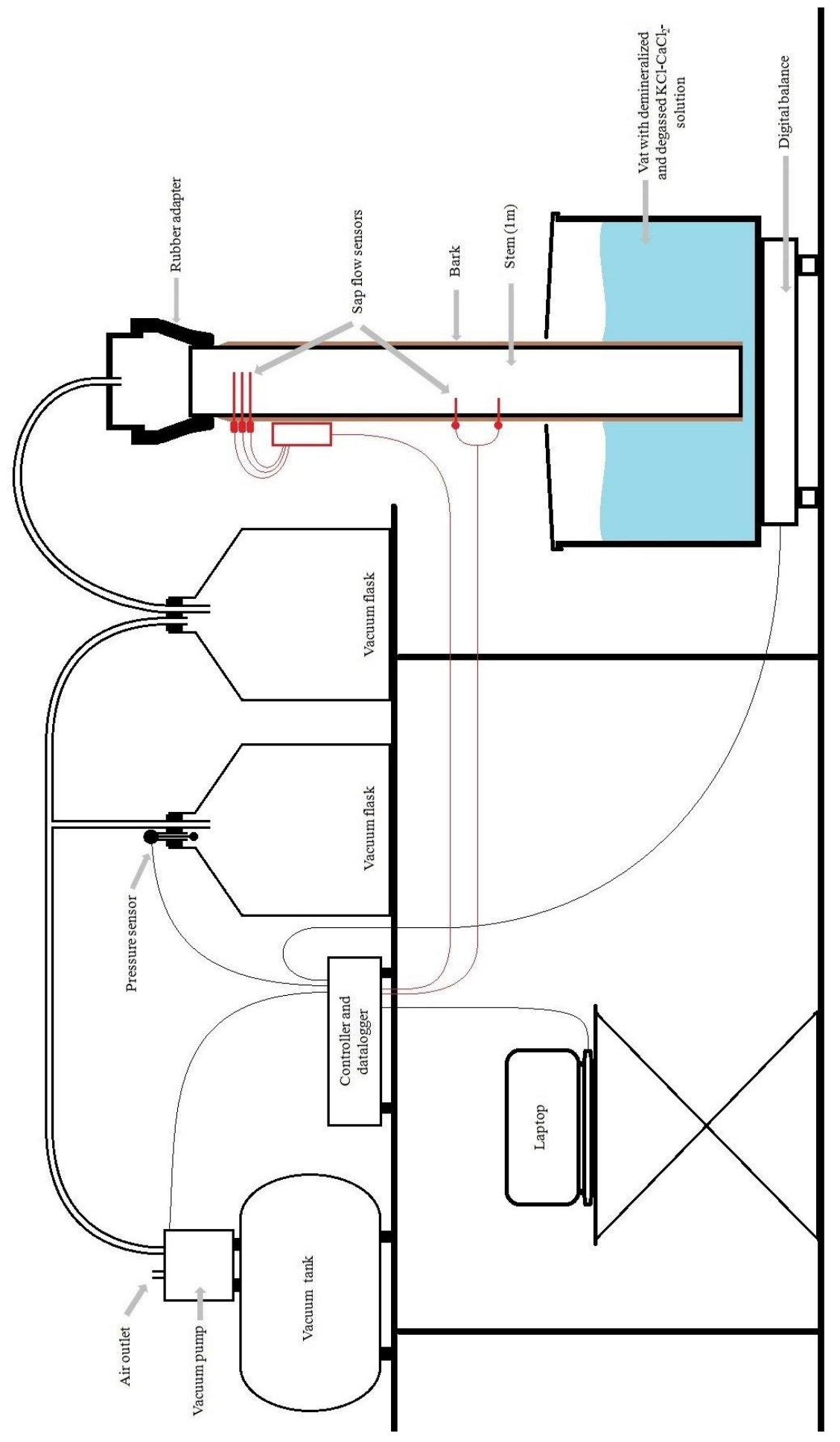

Figure S1 Laboratory set-up for calibrating sap flow sensors against gravimetrically determined flow. 


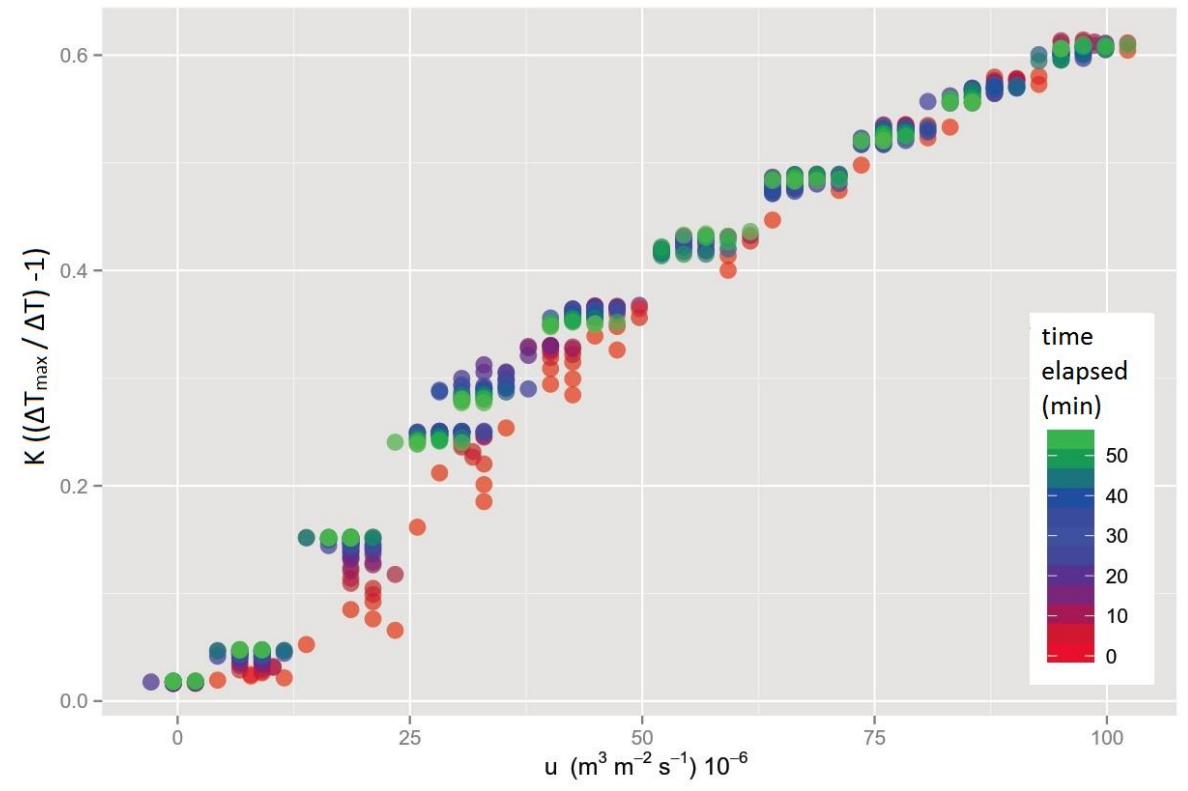

Figure S2 Gravimetrically determined sap flux density $(u)$ versus sap flux index $(K)$ averaged from a set-up of $3 \mathrm{TDP}_{\mathrm{UP}}$ sensors mounted on a Fagus sylvatica stem. The colour gradient displays the time lag (in min) of the sensor response recorded in the 60 min-measuring periods of each pressure level (red dots are measurements taken directly after a pressure level change). 

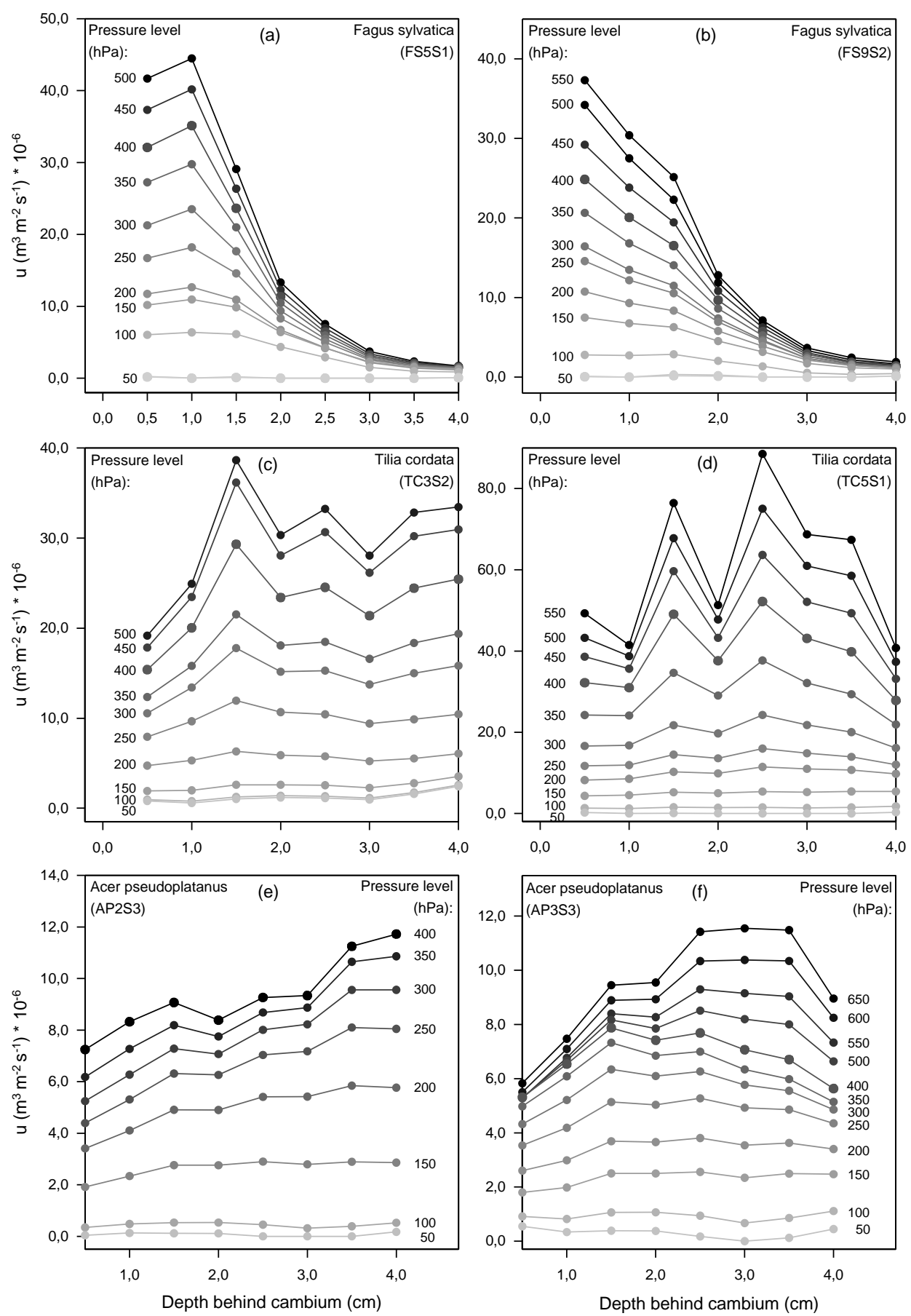

Figure S3 Radial variation in sap flux density $(u)$ measured with a HFD sensor in six exemplary stem segments of Fagus sylvatica (a, b), Tilia cordata (c, d) and Acer pseudoplatanus (e, f). The different lines depict the effect of an increase in applied subatmospheric pressure on sensor output (pressure values: absolute difference to ambient pressure). The colour gradient from grey to black displays the suction gradient. 

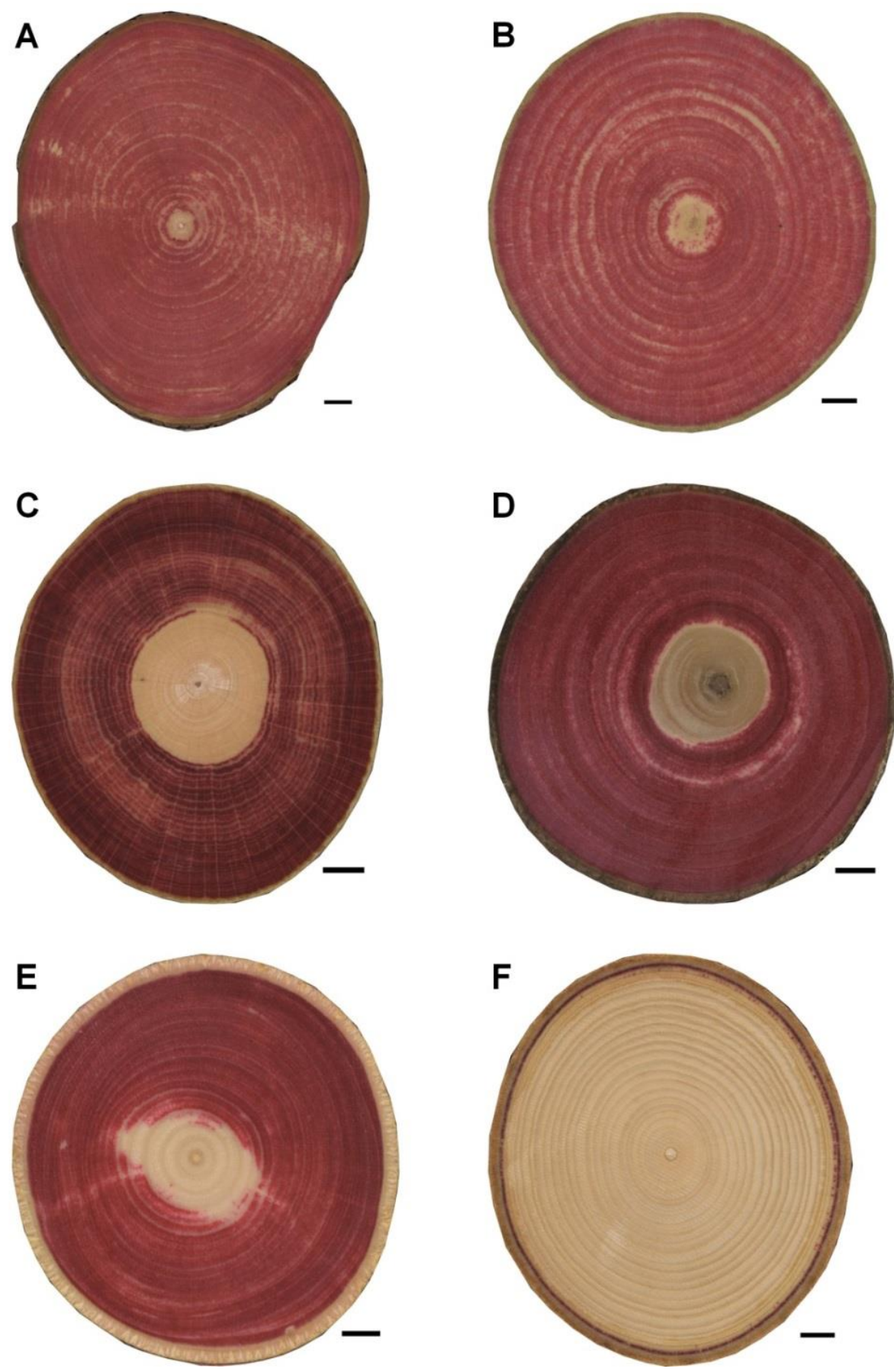

Figure S4 Exemplary images of representative stem cross-sections dyed with safranin for visualization of the conductive sapwood area for the five investigated diffuse-porous broadleaved tree species. For comparison, the conductive sapwood area of the ring-porous tree species $F$. excelsior is additionally given. The scale bar represents a length of $1 \mathrm{~cm}$. A: Acer campestre; B: Acer pseudoplatanus; C: Fagus sylvatica; D: Populus nigra; E: Tilia cordata; F: Fraxinus excelsior. 


\section{References}

Becker, P. and W. R. N. Edwards (1999). "Corrected heat capacity of wood for sap flow calculations". In: Tree Physiology 19.11, pp. 767-768. uRL: https://academic.oup.com/ treephys/article/19/11/767/1671685.

Bleby, T. M., S. S. O. Burgess, and M. A. Adams (2004). "A validation, comparison and error analysis of two heat-pulse methods for measuring sap flow in Eucalyptus marginata saplings". In: Functional Plant Biology 31.6, p. 645. URL: http://www.publish.csiro.au/ ?paper $=$ FP04013.

Bleby, T., A. McElrone, and S. Burgess (2008). "Limitations of the HRM: great at low flow rates, but not yet up to speed". In: 7th International Workshop on Sap Flow: Book of Abstracts. Seville, Spain: International Society of Horticultural Sciences.

Braun, P. and J. Schmid (1999). "Sap flow measurements in grapevines (Vitis vinifera $>/ i>$ L.) 2. Granier measurements". In: Plant and Soil 215, pp. 47-55.

Burgess, S. S. O., M. A. Adams, N. C. Turner, C. R. Beverly, C. K. Ong, A. A. H. Khan, and T. M. Bleby (2001). "An improved heat pulse method to measure low and reverse rates of sap flow in woody plants". In: Tree Physiology 21.9, pp. 589-598. URL: https://academic.oup.com/treephys/article-lookup/doi/10.1093/treephys/21.9.589.

Burgess, S. S. O., M. A. Adams, and T. M. Bleby (2000). "Measurement of sap flow in roots of woody plants: a commentary". In: Tree Physiology 20.13, pp. 909-913. URL: https://academic.oup.com/treephys/article/20/13/909/1663461.

Burgess, S. S. O. and A. Downey (2014). SFM1 Sap Flow Meter Manual. URL: http: //\%20www.ictinternational.com/content/uploads/2014/03/SFM1-complete-manual1. pdf.

Bush, S. E., K. R. Hultine, J. S. Sperry, and J. R. Ehleringer (2010). "Calibration of thermal dissipation sap flow probes for ring- and diffuse-porous trees". In: Tree Physiology 30.12, pp. 1545-1554. URL: https://academic.oup.com/treephys/article-lookup/doi/10. 1093/treephys/tpq096.

Cabibel, B., F. Do, and J. Horoyan (1991). "Mesures thermiques des flux de sève dans les troncs et les racines et fonctionnement hydrique des arbres. I. Analyse théorique des erreurs sur la mesure des flux et validation des mesures en présence de gradients thermiques extérieurs". In: Agronomie 11.8, pp. 669-678. URL: http://dx.doi.org/10. 1051/agro:19910804.

Clearwater, M. J., F. C. Meinzer, J. L. Andrade, G. Goldstein, and N. M. Holbrook (1999). "Potential errors in measurement of nonuniform sap flow using heat dissipation probes". In: Tree Physiology 19.10, pp. 681-687. URL: https://academic.oup.com/treephys / article-lookup/doi/10.1093/treephys/19.10.681.

de Oliveira Reis, F., E. Campostrini, E. F. de Sousa, and M. G. e Silva (2006). "Sap flow in papaya plants: Laboratory calibrations and relationships with gas exchanges under field conditions". In: Scientia Horticulturae 110.3, pp. 254-259. URL: http:// www. sciencedirect.com/science/article/pii/S0304423806002883.

Gebauer, T., V. Horna, and C. Leuschner (2012). "Canopy transpiration of pure and mixed forest stands with variable abundance of European beech". In: Journal of Hydrology 442443, pp. 2-14. URL: https://linkinghub.elsevier.com/retrieve/pii/S0022169412002065.

Granier, A. (1996). "Sap flow measurements using the radial flowmeter technique". In: INRA-Unité d'Ecophysiologie Forestiére, Champenoux, France.

- (1985). "Une nouvelle méthode pour la mesure du flux de sève brute dans le tronc des arbres". In: Annales des Sciences Forestières 42.2, pp. 193-200. URL: http://www.afsjournal.org/10.1051/forest:19850204. 
Granier, A. and P. Gross (1987). "Mesure du flux de sève brute dans le tronc du Douglas par une nouvelle méthode thermique". In: Annales des Sciences Forestières 44.1, pp. 114. URL: http://dx.doi.org/10.1051/forest:19870101.

Green, S. and R. Romero (2012). "Can we improve heat-pulse to measure low and reverse flow?" In: Acta Horticulturae 951, pp. 19-29. URL: https://www.actahort.org/books/ 951/951_1.htm.

Grossiord, C., A. Granier, A. Gessler, M. Pollastrini, and D. Bonal (2013). "The influence of tree species mixture on ecosystem-level carbon accumulation and water use in a mixed boreal plantation". In: Forest Ecology and Management 298, pp. 82-92. URL: https://linkinghub.elsevier.com/retrieve/pii/S0378112713001308.

Hölttä, T., T. Linkosalo, A. Riikonen, S. Sevanto, and E. Nikinmaa (2015). "An analysis of Granier sap flow method, its sensitivity to heat storage and a new approach to improve its time dynamics". In: Agricultural and Forest Meteorology 211-212, pp. 2-12. URL: http://www.sciencedirect.com/science/article/pii/S0168192315001471.

Horna, V., B. Schuldt, S. Brix, and C. Leuschner (2011). "Environment and tree size controlling stem sap flux in a perhumid tropical forest of Central Sulawesi, Indonesia". In: Annals of Forest Science 68.5, pp. 1027-1038. URL: http://link.springer.com/10. 1007/s13595-011-0110-2.

Huber, B. (1932). "Beobachtung und Messung pflanzlicher Saftströme". In: Berichte der Deutschen Botanischen Gesellschaft 50, pp. 89-109.

Hultine, K. R., P. L. Nagler, K. Morino, S. E. Bush, K. G. Burtch, P. E. Dennison, E. P. Glenn, and J. R. Ehleringer (2010). "Sap flux-scaled transpiration by tamarisk (Tamarix spp.) before, during and after episodic defoliation by the saltcedar leaf beetle (Diorhabda carinulata)". In: Agricultural and Forest Meteorology 150.11, pp. 1467-1475. URL: http://www.sciencedirect.com/science/article/pii/S016819231000198X.

James, S. A., M. J. Clearwater, F. C. Meinzer, and G. Goldstein (2002). "Heat dissipation sensors of variable length for the measurement of sap flow in trees with deep sapwood". In: Tree Physiology 22.4, pp. 277-283. URL: https://academic.oup.com/treephys/articlelookup/doi/10.1093/treephys/22.4.277.

Klein, T., E. Rotenberg, E. Cohen-Hilaleh, N. Raz-Yaseef, F. Tatarinov, et al. (2014). "Quantifying transpirable soil water and its relations to tree water use dynamics in a water-limited pine forest". In: Ecohydrology 7.2, pp. 409-419. URL: https://onlinelibrary. wiley.com/doi/abs/10.1002/eco.1360.

Köcher, P., T. Gebauer, V. Horna, and C. Leuschner (2009). "Leaf water status and stem xylem flux in relation to soil drought in five temperate broad-leaved tree species with contrasting water use strategies". In: Annals of Forest Science 66.1, pp. 101-101. URL: http://link.springer.com/10.1051/forest/2008076.

Lave, C. A. (1970). "The Demand for Urban Mass Transportation". In: The Review of Economics and Statistics 52.3, pp. 320-323. URL: https://www.jstor.org/stable/ 1926301.

Lu, P., L. Urban, and Z. Ping (2004). "Granier's Thermal Dissipation Probe (TDP) Method for Measuring Sap Flow in Trees: Theory and Practice". In: Acta Botanica Sinica 46.6, pp. 631-646.

Lundblad, M., F. Lagergren, and A. Lindroth (2001). "Evaluation of heat balance and heat dissipation methods for sapflow measurements in pine and spruce". In: Annals of Forest Science 58.6, pp. 625-638. uRL: http://dx.doi.org/10.1051/forest:2001150.

Marshall, D. C. (1958). "Measurement of Sap Flow in Conifers by Heat Transport". In: Plant Physiology 33.6, pp. 385-396. URL: https://www.ncbi.nlm.nih.gov/pmc/articles/ PMC541111/. 
Mitchell, P. J., E. Veneklaas, H. Lambers, and S. S. O. Burgess (2009). "Partitioning of evapotranspiration in a semi-arid eucalypt woodland in south-western Australia". In: Agricultural and Forest Meteorology 149.1, pp. 25-37. URL: http://www.sciencedirect. com/science/article/pii/S0168192308002050.

Nadezhdina, N., J. Čermák, and V. Nadezhdin (1998). "Heat field deformation method for sap flow measurements". In: Measuring sap flow in intact plants. Proceedings of 4th International Workshop, Židlochovice, Czech Republic, IUFRO Publ. Brno, Czech Republic: Mendel University, pp. 72-92.

Nadezhdina, N., M. W. Vandegehuchte, and K. Steppe (2012). "Sap flux density measurements based on the heat field deformation method". In: Trees 26.5, pp. 1439-1448. URL: http://link.springer.com/10.1007/s00468-012-0718-3.

Niu, F., A. Röll, A. Hardanto, A. Meijide, M. Köhler, Hendrayanto, and D. Hölscher (2015). "Oil palm water use: calibration of a sap flux method and a field measurement scheme". In: Tree Physiology 35.5, pp. 563-573. URL: https://academic.oup.com/treephys/articlelookup/doi/10.1093/treephys/tpv013.

Piñeiro, G., S. Perelman, J. P. Guerschman, and J. M. Paruelo (2008). "How to evaluate models: Observed vs. predicted or predicted vs. observed?" In: Ecological Modelling 216.3, pp. 316-322. URL: http:// www. sciencedirect.com/science/article/pii / S0304380008002305.

Pinheiro, J., D. Bates, S. DebRoy, D. Sarkar, and R Core Team (2015). nlme: Linear and Nonlinear Mixed Effects Models. $R$ Package Version 3. URL: https://CRAN.Rproject.org $/$ package $=$ nlme.

Poyatos, R., V. Granda, R. Molowny-Horas, M. Mencuccini, K. Steppe, and J. MartínezVilalta (2016). "SAPFLUXNET: towards a global database of sap flow measurements". In: Tree Physiology 36.12, pp. 1449-1455. URL: https://academic.oup.com/treephys/ article/36/12/1449/2571314.

Renninger, H. J. and K. V. R. Schäfer (2012). "Comparison of Tissue Heat Balance- and Thermal Dissipation-Derived Sap Flow Measurements in Ring-Porous Oaks and a Pine". In: Frontiers in Plant Science 3. URL: http://journal.frontiersin.org/article/10.3389/ fpls.2012.00103/abstract.

Schenk, H., S. Espino, A. Mendez, and A. McElrone (2013). "Limitations in the hydraulic pathway: Effects of xylem embolisms on sap velocity and flow". In: Acta Horticulturae 991, pp. 323-332. URL: https://www.actahort.org/books/991/991_40.htm.

Schmidt-Walter, P., F. Richter, M. Herbst, B. Schuldt, and N. P. Lamersdorf (2014). "Transpiration and water use strategies of a young and a full-grown short rotation coppice differing in canopy cover and leaf area". In: Agricultural and Forest Meteorology 195-196, pp. 165-178. URL: http://www.sciencedirect.com/science/article/pii/ S0168192314001233.

Steppe, K., D. J. De Pauw, T. M. Doody, and R. O. Teskey (2010). "A comparison of sap flux density using thermal dissipation, heat pulse velocity and heat field deformation methods". In: Agricultural and Forest Meteorology 150.7-8, pp. 1046-1056. URL: https: //linkinghub.elsevier.com/retrieve/pii/S0168192310001000.

Sun, H., D. P. Aubrey, and R. O. Teskey (2012). "A simple calibration improved the accuracy of the thermal dissipation technique for sap flow measurements in juvenile trees of six species". In: Trees 26.2, pp. 631-640. URL: http://link. springer.com/10. 1007/s00468-011-0631-1.

Swanson, R. H. and D. W. A. Whitfield (1981). "A Numerical Analysis of Heat Pulse Velocity: Theory and Practice". In: Journal of Experimental Botany 32.1, pp. 221-239. URL: https://academic.oup.com/jxb/article/32/1/221/746052. 
Swanson, R. (1983). "Numerical and experimental analyses of implanted-probe heat pulse velocity theory (PhD Thesis)". PhD thesis. Alberta: University of Alberta.

Swanson, R. H. (1962). "instrument for detecting sap movement in woody plants". In:

Taneda, H. and J. S. Sperry (2008). "A case-study of water transport in co-occurring ringversus diffuse-porous trees: contrasts in water-status, conducting capacity, cavitation and vessel refilling". In: Tree Physiology 28.11, pp. 1641-1651. URL: https://academic. oup.com/treephys/article-lookup/doi/10.1093/treephys/28.11.1641.

Vandegehuchte, M. W. and K. Steppe (2012c). "Interpreting the Heat Field Deformation method: Erroneous use of thermal diffusivity and improved correlation between temperature ratio and sap flux density". In: Agricultural and Forest Meteorology 162-163, pp. 91-97. URL: https://linkinghub.elsevier.com/retrieve/pii/S0168192312001438.

Vandegehuchte, M. and K. Steppe (2013). "Sap-flux density measurement methods: working principles and applicability". In: Functional Plant Biology 40.3, pp. 213-223. URL: http://dx.doi.org/10.1071/FP12233.

Vieweg, G. and H. Ziegler (1960). "Thermoelektrische Registrierung der Geschwindigkeit des Transpirationsstromes". In: Berichte der deutschen botanischen Gesellschaft 73, pp. 221-226.

Wullschleger, S. D., K. W. Childs, A. W. King, and P. J. Hanson (2011). "A model of heat transfer in sapwood and implications for sap flux density measurements using thermal dissipation probes". In: Tree Physiology 31.6, pp. 669-679. URL: https://academic.oup. com/treephys/article-lookup/doi/10.1093/treephys/tpr051. 



\title{
4 Tree height predicts the shape of radial sap flow profiles of Costa-Rican tropical dry forest tree species
}

\author{
Roman M. Link ${ }^{1,2}$, Sebastian Fuchs ${ }^{2}$, Dagoberto Arias Aguilar ${ }^{3}$, Christoph \\ Leuschner $^{2}$, Marvin Castillo Ugalde $^{3}$, Juan Carlos Valverde Otarola ${ }^{3}$, Bern- \\ hard Schuldt ${ }^{1,2}$ \\ ${ }^{1}$ University of Würzburg, Julius-von-Sachs-Institute of Biological Sciences, Chair of Eco- \\ physiology and Vegetation Ecology, Julius-von-Sachs-Platz 3, 97082 Würzburg, Germany \\ ${ }^{2}$ Plant Ecology and Ecosystems Research, Albrecht von Haller Institute for Plant Sciences, \\ University of Goettingen, Untere Karspüle 2, 37073 Göttingen, Germany \\ ${ }^{3}$ Instituto Tecnológico de Costa Rica, Escuela de Ingeniería Forestal, Apartado Postal 159 \\ 7050, Cartago, Costa Rica
}

\subsection{Abstract}

Sap flow measurements are a crucial tool for studies of plant water relations, but upscaling to tree or stand transpiration requires accounting for the radial distribution of sap flow across the stem. Because radial sap flow profiles cannot be measured with single-point measuring methods, predicting their shape based on easier to measure structural or functional traits is a potential route to cost-efficiently improve water-use estimates. We used heat field deformation (HFD) sensors to measure sap flux density at different sapwood depths on 38 trees of eight tropical tree species in secondary dry forest patches in northwest Costa Rica. Based on a Bayesian hierarchical modeling framework, we developed a flexible model for radial profiles that expresses the average profile depth and the spread of the profile around this depth as functions of tree height, wood density and stem growth rate, while allowing for random tree and species effects. From the model output, we scale up to approximate whole-tree daily water use (DWU). Our model revealed pronounced tree height effects, with taller trees having narrower sap flow profiles peaking closer to the cambium. While it explained $96 \%$ of the variance in the dataset, large fractions were attributed to random species and tree individual effects. Including functional traits as predictors improved the accuracy of predictions considerably both for new trees and new species. DWU responded positively to tree height, but not to annual stem increment and wood density. Extrapolating the average sap flux in the outermost $2 \mathrm{~cm}$ over the entire sapwood area overestimated DWU on average by $26 \%$ compared to estimates based on radial profiles. Our model provides a starting point for future studies aiming to improve landscape-scale water-use estimates integrating single-point sap flow measurements and radial profiles from a subset of trees.

Keywords: Sap flow, water-use, radial profile, heat field deformation, hierarchical Bayes, dry forest 
Published in: Agricultural and Forest Meteorology (2020) in press

\subsection{Introduction}

Accurate estimates of stand-level transpiration are indispensable for an improved understanding of water fluxes in terrestrial ecosystems, which in turn is required to predict the response of forests to changing precipitation regimes (Schlesinger and Jasechko 2014). A common way of estimating stand-level transpiration is by scaling up predictions of wholetree water-use of individual trees that are based on measurement with thermal sap flux probes placed into the conductive part of the sapwood (Oishi et al. 2008; Wang and Dickinson 2012). While transpiration estimates based on water-use estimates of individual trees have the advantage of preserving information on functional links between plants and their environment (Meinzer et al. 2001b; Wilson et al. 2001; Caylor and Dragoni 2009), uncertainties regarding the spatial distribution of sap flux in the stem can result in large inaccuracies when scaling up to tree- and stand-level (Hatton et al. 1995; Ford et al. 2004b; Oishi et al. 2008; Reyes-Acosta and Lubczynski 2013).

It has long been known that sap flux is highly variable across the sapwood area, both in radial (Edwards and Booker 1984; Čermák et al. 1992) and azimuthal direction (Miller et al. 1980). In recent years, radial gradients in sap flux density (in the following, radial profiles) have received special attention, as many commonly used sap flux probes only measure the sap flux density in the outermost few centimeters of the sapwood, which potentially leads to large errors in whole-tree water-use estimates when assuming uniform flux across the sapwood in the presence of pronounced radial changes (Caylor and Dragoni 2009; Reyes-Acosta and Lubczynski 2014; Zhang et al. 2015). As sap flux density tends to decline with increasing distance from the cambium (Delzon et al. 2004), ignoring radial variation when scaling up to whole-tree water-use has been found to lead to an overestimation of tree water-use by up to $154 \%$ (Čermák and Nadezhdina 1998; Ford et al. 2004b).

Notwithstanding the obvious importance of accounting for radial gradients when scaling up sap flux density measurements to estimates of tree water-use, a literature survey by Berdanier et al. (2016) found that a majority of $58 \%$ of a sample of 122 papers published between 2013 and 2015 assumed constant sap flux density throughout the sapwood, while $27 \%$ of the papers used a simple correction based on weighted means in different annuli and only $15 \%$ used continuous radial profile models. We concur with the notion of these authors that there is a need for transferrable models that enable to account for radial profiles in the absence of species- or site-specific radial sap flux measurements. This is especially true when studying tree water-use in tropical forests, where the determination of species-specific radial profiles may often not be feasible due to the high species diversity.

The shape of radial gradients in sap flux density has been linked to a multitude of explanations, such as ontogenetic changes in wood anatomy related to sapwood maturation and aging (Spicer and Gartner 2001), anatomical differences between conifers, ring-porous and diffuse-porous trees (Berdanier et al. 2016), connection with roots situated in different soil layers (Nadezhdina et al. 2007) and even small-scale differences between early- and latewood tracheids in conifers (Fan et al. 2018). As a consequence, radial profiles may differ considerably between species, even in the same habitat (Gebauer et al. 2008). It has further been shown in some instances that the shape of radial profiles can be linked to other tree traits, e.g. tree size (Delzon et al. 2004; Zhang et al. 2018) and wood anatomical 
traits (Guyot et al. 2015; Zhao et al. 2018). This indicates that when measuring radial profiles for all present species is not feasible, a promising way to reduce the uncertainty in upscaled estimates of tree water-use is to identify surrogate traits that predict their shape.

In this study, we use a dataset of daily averages of sap flux measurements performed with the heat field deformation method (Nadezhdina et al. 1998; Nadezhdina et al. 2012; Nadezhdina et al. 2018) to model the radial sap flux profiles of 38 trees belonging to eight Costa-Rican tropical dry forest species using a Bayesian hierarchical modelling framework. We hereby follow the approach of Caylor and Dragoni (2009), who proposed to separate sap flux measurements into a time-dependent component describing the response of stem conductance to environmental conditions and a time-invariant component describing the relative spatial distribution of sap flux density in the tree. In this work, we focus on the time-invariant component of sap flux, extending upon the hierarchical modelling approach of Berdanier et al. (2016) by expressing the parameters determining the shape of the radial sap flux profiles as functions of a set of structural and functional traits.

We hypothesize that (i) the parameters governing the shape of the radial profiles can be predicted by wood density, tree height and radial growth rate, and (ii) there are credible differences in the relative shape of radial profiles between trees of the same species. We further use the predicted radial profiles to obtain estimates of whole-tree water-use for each tree with the propagated uncertainty from our model, and investigate their relationship with a set of predictor variables. We then compare these estimates of whole-tree water-use against simple water-use estimates based on the average sap flux density in the outermost $2 \mathrm{~cm}$ of sapwood to test the hypothesis that (iii) single-sensor methods that assume constant sap flux density across the sapwood depth consistently overestimate tree water-use compared to methods based on radial profiles.

\subsection{Analytical framework}

When upscaling from sap flux density measurements to whole-tree water-use, the instantaneous whole-tree sap flow $F_{s}(t)$ at a time $t$ can be described as the product of the average sap flux density $\overline{v_{s}}(t)$ at that time $t$ and the sapwood area $A_{s}$ :

$$
F_{s}(t)=\overline{v_{s}}(t) A_{s}
$$

Under the simplifying assumption of a homogeneous radial sap flux profile (i.e., no azimuthal variation in sap flux density) and expressing the sap flux profile with regard to a relative radial coordinate $r$ describing the distance from the cambium relative to the radius $R$ of the tree, it is possible to compute the average sap flux density by integrating over the radial profile, yielding the following expression for $F_{s}(t)$ (Caylor and Dragoni 2009; Berdanier et al. 2016):

$$
F_{s}(t)=2 \pi R^{2} \int_{0}^{1}(1-r) v_{s}(r ; t) \mathrm{d} r
$$

In this study, we follow the framework of Caylor and Dragoni (2009), who proposed to decompose the instantaneous sap flux density $v_{s}(r ; t)$ at any point $r$ in the radial profile 
a) $\quad \mu$ fixed at 0.3

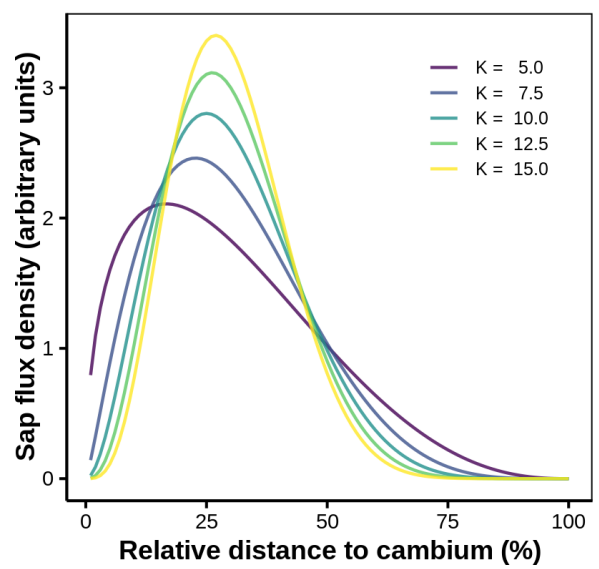

b) $\mathrm{K}$ fixed at 10

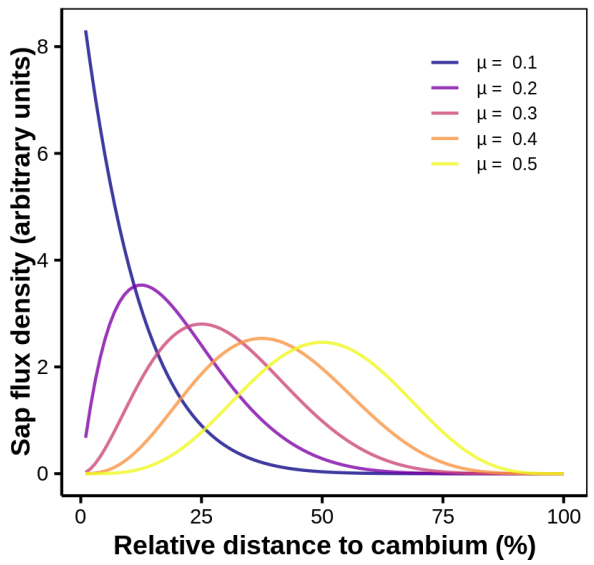

Figure 4.1: Illustration of the possible shapes of radial sap flux density profiles that can be taken by the reparameterized Beta distribution in Eq. 4 when a) changing the concentration parameter $K$, while the average profile depth $\mu$ is held constant at $0.3, \mathbf{b}$ ) changing $\mu$, while $K$ is held constant at 10 .

into a product of a time-invariant component $\rho_{s}(r)$ describing the radial sap flux profile and a time-dependent component $c_{s}(t)$ describing stem conductance:

$$
v_{s}(r ; t)=\rho_{s}(r) c_{s}(t)
$$

Like Caylor and Dragoni (2009), we describe the radial component based on the probability density function of a beta distribution, but express it based on the (biologically more interpretable) relative distance $r$ from the cambium instead of a relative distance from the tree center. In addition, we reparameterize it with its expected value $\mu=\alpha /(\alpha+\beta)$ and a concentration parameter $K=\alpha+\beta$ instead of the commonly used shape parameters $\alpha$ and $\beta$ (cf. Ferrari and Cribari-Neto 2004):

$$
\rho_{s}(r \mid \mu, K)=\frac{r^{\mu K-1}(1-r)^{(1-\mu) K-1}}{\mathrm{~B}(\mu K,(1-\mu) K)},
$$

where $\mathrm{B}(a, b)$ is the beta function. This reparameterization has the advantage that it results in biologically directly interpretable parameters describing the 'average profile depth' $\mu$ (weighted average of relative distance of the cambium weighted by the sap flux density at that position) and the concentration $K$ showing how narrowly the profile is centered around $\mu$. The possible radial profile shapes that can be described by Eq. (4.4) are illustrated in Figure 4.1; it can be seen that larger values of $\mu$ move the bulk of sap flow away from the cambium, while larger values of $K$ center the profile more strongly around $\mu$.

Inserting Eq. (4.3) into Eq. (4.2) yields

$$
F_{s}(t)=2 \pi R^{2} c_{s}(t) \int_{0}^{1}(1-r) \rho_{s}(r) \mathrm{d} r
$$

which has a simple closed form solution for the Beta distribution, as the integral in Eq. (4.5) is equal to $1-\mu$, yielding the following expression for the whole-tree sap flow $F_{s}(t)$ (cf. Caylor and Dragoni 2009): 


$$
F_{s}(t)=\overline{\rho_{s}} c_{s}(t) A_{s}=2 \pi R^{2}(1-\mu) c_{s}(t)
$$

Accordingly, under the given assumptions, the entire influence of the shape of the radial profile on the whole-tree water use can be expressed based on the average profile depth $\mu$, which can be directly estimated from the data when expressing the radial profile according to Eq. (4.4).

\subsection{Material and methods}

\subsubsection{Study site}

The sap flow measurements were performed on eight tropical dry forest tree species at the Estación Experimental Forestal Horizontes (EEFH) in the Guanacaste area in northwestern Costa Rica $\left(10.718^{\circ} \mathrm{N}, 85.594^{\circ} \mathrm{W}\right)$ during the rainy season of 2015 . The climate in the region is characterized by a pronounced annual pattern in precipitation with an almost rain-free dry season that lasts from December until May. The mean annual temperature is $25{ }^{\circ} \mathrm{C}$, and annual precipitation at the nearby Santa Rosa climate station ranges from 880 to $3030 \mathrm{~mm}$ with a 30-year average of $1765 \mathrm{~mm}$ (Instituto Meteorológico de Costa Rica 2015; Werden et al. 2018b). The measured trees are situated in permanent sample plots managed by the School of Forestry Engineering of the Instituto Tecnológico de Costa Rica that were established in 2012. The vegetation in the sample plots consists of secondary forests on former pastures that were abandoned between 21 and 40 years before the measurement campaign in 2015 (Reyes Cordero 2012). The trees in the sample plots belong to mostly deciduous tropical dry forest species and constitute a mosaic of relatively young secondary forest trees interspersed by large emergent trees that were left uncut by farmers as shading trees for livestock (mostly Hymenaea courbaril). The soils of the plots are Inceptisols and Vertisols (Alfaro et al. 2001; Reyes Cordero 2012).

\subsubsection{Selection of experimental trees}

Out of the species present in the permanent sample plots, eight species were selected to represent a gradient in wood density $(W D)$ and tree height at maturity. To achieve this, the 30 most common species were stratified by average wood density and diameter at breast height $(D B H)$ as a proxy for tree height, and eight species representing gradients in both variables were selected taking into account species-specific information such as the presence of abundant latex or resins that interfere with hydraulic measurements. Of each of these species, five individuals were sampled from the 50th to 100th percentile of the diameter distribution to ensure selecting mature individuals.

All experimental trees were equipped with dendrometer bands (UMS GmbH, München, Germany) in August 2015 to measure $D B H$ and radial growth rates. Annual stem increment $(A S I)$ was determined as the slope of the regression line of $D B H$ against time using a dataset of bimonthly growth measurements from August 2015 until October 2017. The height $H$ of the experimental trees was determined in November 2015 using a Vertex IV Hypsometer with Transponder T3 (Haglöf, Längsele, Sweden). WD of the sapwood was measured from 5-7 cm long samples taken with a $5.15 \mathrm{~mm}$ increment corer (Haglöf, Långsele, Sweden) as the oven-dry weight (dried at $105{ }^{\circ} \mathrm{C}$ ) divided by the wet volume. 
Table 4.1: The tree species studied, ordered by median wood density. Given are the number of observed trees $(\mathrm{n})$, and the median and range (minimum - maximum) of wood density (WD), tree height, diameter at breast height $(\mathrm{DBH})$ and annual stem increment (ASI).

\begin{tabular}{|c|c|c|c|c|c|}
\hline Species & Family & WD $\left(\mathrm{g} \mathrm{cm}^{-3}\right)$ & Height (m) & DBH (cm) & $\operatorname{ASI}\left(\mathbf{m m ~ y r}^{-1}\right)$ \\
\hline Bursera simaruba (L.) Sarg. & Burseraceae & $0.39(0.37-0.45)$ & $16.5(15.1-19.0)$ & $50.8(33.2-73.6)$ & $6.7(3.0-13.6)$ \\
\hline $\begin{array}{l}\text { Cordia panamensis L. Riley } \\
\text { Machaerium biovulatum }\end{array}$ & Cordiaceae & $0.40(0.37-0.43)$ & $11.0(9.6-14.6)$ & $18.3(17.8-33.8)$ & $3.5(0.9-5.4)$ \\
\hline Micheli & Fabaceae & $0.52(0.51-0.56)$ & $12.5(6.8-15.1)$ & $15.4(14.8-18.4)$ & $3.6(1.1-14.1)$ \\
\hline $\begin{array}{l}\text { Luehea speciosa (Willd.) } \\
\text { Cordia alliodora (Ruiz \& }\end{array}$ & Malvaceae & $0.58(0.55-0.63)$ & $12.1(8.3-13.9)$ & $22.2(21.9-26.5)$ & $0.3(-0.2-8.4)$ \\
\hline $\begin{array}{l}\text { Pav.) Oken } \\
\text { Albizia niopoides (Benth.) }\end{array}$ & Cordiaceae & $0.59(0.54-0.63)$ & $14.4(11.8-16.6)$ & $19.1(15.0-29.2)$ & $2.8(1.0-5.6)$ \\
\hline Burkart & Fabaceae & $0.66(0.60-0.77)$ & $14.2(12.2-16.5)$ & $26.3(21.0-36.6)$ & $3.5(2.1-11.1)$ \\
\hline Hymenaea courbaril L. & Fabaceae & $0.69(0.66-0.76)$ & $24.3(19.1-25.6)$ & $76.2(52.6-91.5)$ & $3.4(0.8-4.3)$ \\
\hline (Mart. Ex DC.) Mattos & Bignoniaceae & $0.75(0.71-0.80)$ & $14.0(12.7-15.6)$ & $27.4(23.1-34.8)$ & $9.4(7.0-13.2)$ \\
\hline
\end{tabular}

The volume was estimated from length and four diameter measurements with a caliper (two at each end along a coordinate plane). A list of the sampled species with the averages of $H, D B H$ and $W D$ is provided in Table 4.1.

\subsubsection{Sap flow measurements}

Measurements of radial patterns in sap flux density were performed with the heat field deformation (HFD) method (Nadezhdina et al. 1998; Nadezhdina et al. 2012; Nadezhdina 2018) using a commercially available sensor type (HFD100, ICT International Pty Ltd., Armidale, Australia). During each of four subsequent measurement campaigns of 5-7 days each in October and November 2015, HFD sensors were installed on ten experimental trees. The measurements from two of the trees had to be discarded because of sensor/battery malfunctions, resulting in a final dataset with observations from 38 trees.

To install the sensors, the bark was partially removed and four holes were drilled in predefined distances using a drilling template. Then, stainless steel sleeves were inserted into the holes, and the sensors were coated in silicone grease and introduced into the sleeves. Polystyrene spacers of adequate sizes were used to ensure that the first measurement point was situated exactly $5 \mathrm{~mm}$ below the cambium in all stems. Each sensor was connected to a 60 Ah battery, and programmed to log sensor temperatures at eight different depths (in 1 -cm steps from $0.5 \mathrm{~cm}$ to $7.5 \mathrm{~cm}$ below the cambium) in intervals of $10 \mathrm{~min}$. To ensure thermal insulation of the sensors, the stem sections containing the sensors were completely covered with insulating mats made of open-cell foam coated with a reflective aluminum layer.

The measured temperature differences between the sensors were used to calculate estimates of sap flow per section $\left(S F S, \mathrm{~cm}^{3} \mathrm{~cm}^{-1} \mathrm{~s}^{-1}\right)$ according to Nadezhdina et al. (1998; 2012) using the Sap Flow Tool software (v1.4, ICT International Pty Ltd., Armidale, Australia), assuming a nominal thermal diffusivity of sapwood of $2.5 \times 10^{-3} \mathrm{~cm}^{-2} \mathrm{~s}^{-1}$ (Marshall 1958). The dataset was then aggregated by calculating daily averages of estimated $S F S$ for all complete measurement days.

The HFD method has recently been criticized due to flaws in the mechanistic derivation of the equation used to calculate sap flux density (Vandegehuchte and Steppe 2012c), a 
possible underestimation of flux densities of up to $60 \%$ (Steppe et al. 2010) and due to the large inter- and intraspecific variability in calibration parameters in empirical calibrations (Fuchs et al. 2017). The thermal properties of the wood of the studied tropical dry forest species are likely to deviate considerably from the properties of temperate species the method has been tested on. For that reason, absolute values of sap flux density of tropical species measured with HFD method should be treated with care unless species-specific calibration data are available. However, relative differences in the radial patterns of sap flux density should not be affected by the above-mentioned problems as long as the withinstem calibration relationship is approximately linear and there are no radial changes in thermal diffusivity. In either case, due to the unanswered question whether $S F D$ can be calculated by dividing $S F S$ by the sapwood depth (Vandegehuchte and Steppe 2012c), we decided to base our model on the raw $S F S$ values.

\subsubsection{Measurement of stand microclimate and soil moisture}

To track environmental variables relevant for sap flow, we measured vertical gradients in microclimatic variables at three different subsites throughout the entire measurement interval in October and November 2016. To achieve this, we used ropes fixed at high canopy branches to install small loggers (iButton Hygrochrom ${ }^{\mathrm{TM}}$, Dallas Semiconductor, Dallas, TX) in different heights and recorded air temperature $(T)$ and relative air humidity $(R H)$ in 10-min intervals. The first measurement point was situated at breast height (1.3 $\mathrm{m}$ ); the following points were installed in $5-\mathrm{m}$ intervals from $5 \mathrm{~m}$ height to the canopy level (20 m in two subsites, $15 \mathrm{~m}$ in a third subsite). The resulting measurements of $T$ and $R H$ were used to calculate the air vapor pressure deficit $(V P D)$ based on Equation (11) in Allen et al. (1998). In addition, during each of the four campaigns, soil samples were taken at $10 \mathrm{~cm}$ soil depth to measure gravimetric soil water content in all nine subplots of the five sample plots.

\subsubsection{Modelling radial sap flux density profiles}

The measured radial sap flux profiles were modeled in a Bayesian hierarchical modeling framework based on the Stan probabilistic programming language (Carpenter et al. 2017) accessed through R v. 3.5.2 (R Core Team 2019) using rstan v. 2.18.2 (Stan Development Team 2018). The observational unit in our model were daily averages of the raw $S F S$ values. The shape of the radial profile was described with the density function of the Beta distribution $\left(\rho_{s}\right.$; see Eq. (4.4) multiplied with an arbitrary multiplicative constant $c$ adjusting $\rho_{s}$ to the observed absolute values of $S F S$ (see Section 4.4.6 for the relationship between $c$ and $c_{s}(t)$ ). The observed $S F S$ values were assumed to be distributed normally around the expected value. The parameters $\mu$ and $K$ were expressed as functions of the predictor variables $H, W D$ and $A S I$, using a logit and a natural log link, respectively, and allowed to vary randomly between trees and species. The multiplicative parameter $c$ was allowed to vary randomly between trees and measurement days within trees, but not assigned a parameter regression, as the absolute value of $S F S$ does not have a mechanistic explanation (see above). The random tree and species effects $\boldsymbol{v}$ and $\boldsymbol{w}$ were described with a multivariate normal distribution, while the random day effects $\boldsymbol{u}$ were assumed to be drawn from a normal distribution. For an observation $i$ on day $j$ belonging to tree $k$ of species $l$, the model could be expressed as: 


$$
\begin{gathered}
\widehat{S F S}_{i j k l}=c_{j k} \cdot \rho_{s}\left(r_{i j k l} \mid \mu_{k l}, K_{k l}\right)=c_{j k} \cdot \frac{r^{\mu_{k l} K_{k l}-1}(1-r)^{\left(1-\mu_{k l}\right) K_{k l}-1}}{\mathrm{~B}\left(\mu_{k l} L_{k l},\left(1-\mu_{k l}\right) K_{k l}\right)} \\
S F S_{i j k l} \sim \operatorname{Normal}\left(\widehat{S F S}_{i j k l}, \sigma\right) \\
\log \left(K_{k l}\right)=\beta_{K_{0}}+\beta_{K_{1}} W D_{k l}+\beta_{K_{2}} h_{k l}+\beta_{K_{3}} A S I_{k l}+v_{K_{k}}+w_{k_{l}} \\
\operatorname{logit}\left(\mu_{k l}\right)=\beta_{\mu_{0}}+\beta_{\mu_{1}} W D_{k l}+\beta_{\mu_{2}} h_{k l}+\beta_{\mu_{3}} A S I_{k l}+v_{\mu_{k}}+w_{\mu_{l}} \\
\log \left(c_{j k}\right)=c_{0}+u_{j k}+v_{c_{k}} \\
\boldsymbol{v}_{k} \sim \operatorname{MVN}\left(\mathbf{0}, \boldsymbol{\Sigma}_{v}\right) \\
\boldsymbol{w}_{l} \sim \operatorname{MVN}\left(\mathbf{0}, \boldsymbol{\Sigma}_{w}\right) \\
u_{j k} \sim \operatorname{Normal}\left(0, \tau_{u}\right)
\end{gathered}
$$

where $\sigma$ is the residual standard error, $\beta_{\mu_{0 \ldots 3}}$ and $\beta_{K_{0 . \ldots 3}}$ are the parameters of the tree level regressions of $\mu$ and $K$ against $H, W D$ and $A G R$, and $\boldsymbol{\Sigma}_{v}, \boldsymbol{\Sigma}_{w}$ and $\tau_{u}$ are the covariance matrices/standard deviation of the random effects. In addition to the full model described above, we fitted two simplified models, both of which did not include fixed effects in the parameter regressions for $\mu$ and $K$, and one of which additionally assumed $\mu$ and $K$ to be constant between trees belonging to the same species.

All parameters in the model were assigned weakly informative priors (Gelman 2006; Gelman et al. 2008). MCMC (Markov Chain Monte Carlo) sampling was performed using Hamiltonian Monte Carlo via Stan's No-U-Turn-Sampler (Hoffman and Gelman 2014) using 4 chains with 10,000 iterations each and a burn-in of 5,000 samples. To describe the variance explained on different levels in the hierarchy of the model, we calculated the Bayesian $\mathrm{R}^{2}$ proposed by Gelman et al. (2018) extended to a multi-level modeling approach analogously to Nakagawa and Schielzeth (2013) for each of the parameter regressions, and additionally calculated a pseudo- $\mathrm{R}^{2}$ as a measure of model fit. Model performance was compared between the three alternative model formulations by calculating goodness-of-fit statistics from model predictions to assess precision (correlation between observed and predicted values), trueness (mean signed deviation), and overall accuracy (root mean square error and pseudo- $\mathrm{R}^{2}$ ) when using the model to predict sap flow per section for new measurement days, new trees and new tree species.

A detailed description of our model including details on transformations, prior specification, model fitting and inspection, calculation of explained variance and goodness-of-fit statistics is given in Supplementary Material A. 


\subsubsection{Estimates of total sap flow}

According to the authors that introduced the HFD method, dividing sap flow per section by the sapwood depth $\left(L_{S W}\right)$ results in an estimate $v^{\prime}$ of sap flux density (Nadezhdina et al. 1998; Nadezhdina et al. 2012).

$$
v^{\prime}=\frac{S F S}{L_{S W}}
$$

While there is sufficient evidence that the correlation of this quantity with gravimetrically measured sap flow density is only empirical (Vandegehuchte and Steppe 2012c; Fuchs et al. 2017), we estimated $v^{\prime}$ from our sap flux profiles to illustrate how to use our model output to calculate tree water-use.

If the equality in Eq. (4.15) holds and $v^{\prime}$ is indeed an estimate of sap flux density, the multiplicative constant $c$ in our model equation (Eq. (4.7)) can be converted to an estimate of stem conductance by dividing it by $L_{S W}$. If this is the case, the average water-use of a tree can be estimated by

$$
F_{s}=2 \pi R^{2}\left(1-\mu_{j k}\right) \frac{c_{k}}{L_{S W_{k}}},
$$

where $c_{k}$ is the tree-level prediction of $c$ (i.e., without day-level random effects). As sapwood depth was not measured, it was estimated from the model as the depth up to which $90 \%$ of flow takes place using the quantile function of the beta distribution with the estimated parameters of the radial profile. We then assessed how the log-transformed posterior mean of tree $D W U$ responded to $W D, H$ and $A G R$ using simple linear mixed effects models with random species effects (Bates et al. 2015) with p-values from Wald $z$-tests with Satterthwaite's correction (Kuznetsova et al. 2017). As a species-specific calibration of the HFD sensors was not possible, the outcome of these calculations has to be interpreted with care.

To assess how much our radial profile-based estimates of tree water-use differ from singlesensor measurements with a sensor with a typical sensor length of $2 \mathrm{~cm}$, we calculated a naive estimate of tree water-use assuming sap flux density to be constant across the sapwood area. We calculated the average sap flux density over a subset of the radial profile ranging from depth $a$ to depth $b$ as

$$
\bar{v}_{s_{\text {naive }}}=\frac{1}{b-a} \int_{a / R}^{b / R} S F S(r) \mathrm{d} r \frac{1}{L_{S W}} .
$$

We then used Eq. (4.1) to calculate the approximate tree water-use based on the average sap flux density in the outermost $2 \mathrm{~cm}$, and calculated the ratio of this quantity to the tree water-use based on radial profiles as

$$
\text { Water use ratio }=\frac{F_{s_{\text {naive }}}}{F_{s}}=\frac{V_{s_{\text {naive }}} A_{s}}{F_{s}}
$$

to be able to quantify the degree of over-estimation of single-point measurements with short sensors relative to measurements based on radial sap flux profiles. Based on the propagated MCMC uncertainty of our model, we then tested whether this computed quantity was credibly different from one (i.e., whether both estimates were not equivalent). 

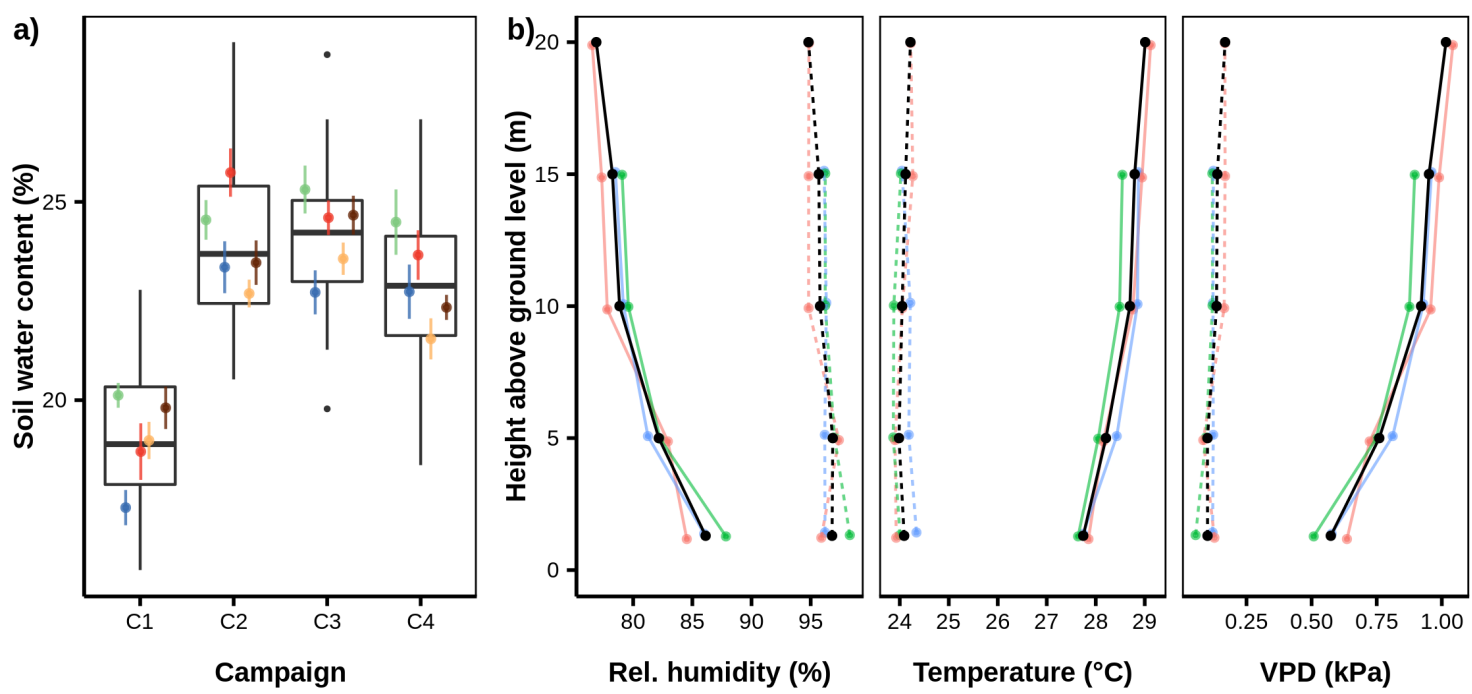

Figure 4.2: a) Gravimetric soil water content during the four measurement campaigns. Boxplots show median, inner-quartile range, minimum, and maximum values. Colored: averages \pm standard errors for the five sample plots. b) Vertical changes in relative air humidity, temperature, and vapor pressure deficit averaged over the entire measurement period. Solid: daytime average (6:00 a.m. $-6: 00$ p.m.); dashed: nighttime average (6:00 p.m. - 6:00 a.m.); black: overall averages; colored: averages for the three subsites.

\subsection{Results}

\subsubsection{Microclimatic and hydrologic conditions}

According to the soil moisture measurements, gravimetric soil water content was on a lower level during the first campaign (mean \pm standard error: $19.0 \pm 0.3 \%$ ) and increased to comparable, somewhat higher values between $23.0 \pm 0.3 \%$ and $24.2 \pm 0.3 \%$ during the following three campaigns (Figure 4.2a).

The vertical stand microclimate measurement campaign revealed a pronounced increase in evaporative demand with height in the stand during the daytime hours (6:00 am to 6:00 $\mathrm{pm}$ ), when $R H$ declined by $10.7 \%$ from the forest floor at $1.3 \mathrm{~m}$ to the uppermost canopy at $20 \mathrm{~m}$ (from $86.1 \pm 0.1 \%$ to $76.9 \pm 0.1 \%$ ), related to an increase in $\mathrm{T}$ by $1.3^{\circ} \mathrm{C}$ (from $27.74 \pm 0.03{ }^{\circ} \mathrm{C}$ to $29.01 \pm 0.04^{\circ} \mathrm{C}$ ). This resulted in a by $77.1 \%$ higher VPD than on the forest floor. During nighttime (6:00 pm to 6:00 am), on the other hand, vertical gradients were neither observed in $\mathrm{T}\left(\sim 24{ }^{\circ} \mathrm{C}\right.$ in all heights) nor $R H(\sim 95 \%$ in all heights; Figure $4.2 \mathrm{~b})$.

\subsubsection{Model of radial sap flow profiles}

The predictions of our model described the observed radial patterns in $S F S$ very well for the large majority of trees (Figure B.1). In total, the day-specific predictions of the full model explained $96 \%$ of the variance in the observed SFS. A plot of the radial profiles predicted by the full model is shown in Figure 3 (for tree-level plots, see Figure B. 2 in the supplementary material).

All parameters in the model had a value of $\widehat{R}$ well below 1.1 (average $\widehat{R}: 1.00007$, maximum $\widehat{R}: 1.00180)$, which indicates that the chains had fully converged after the burn-in period 

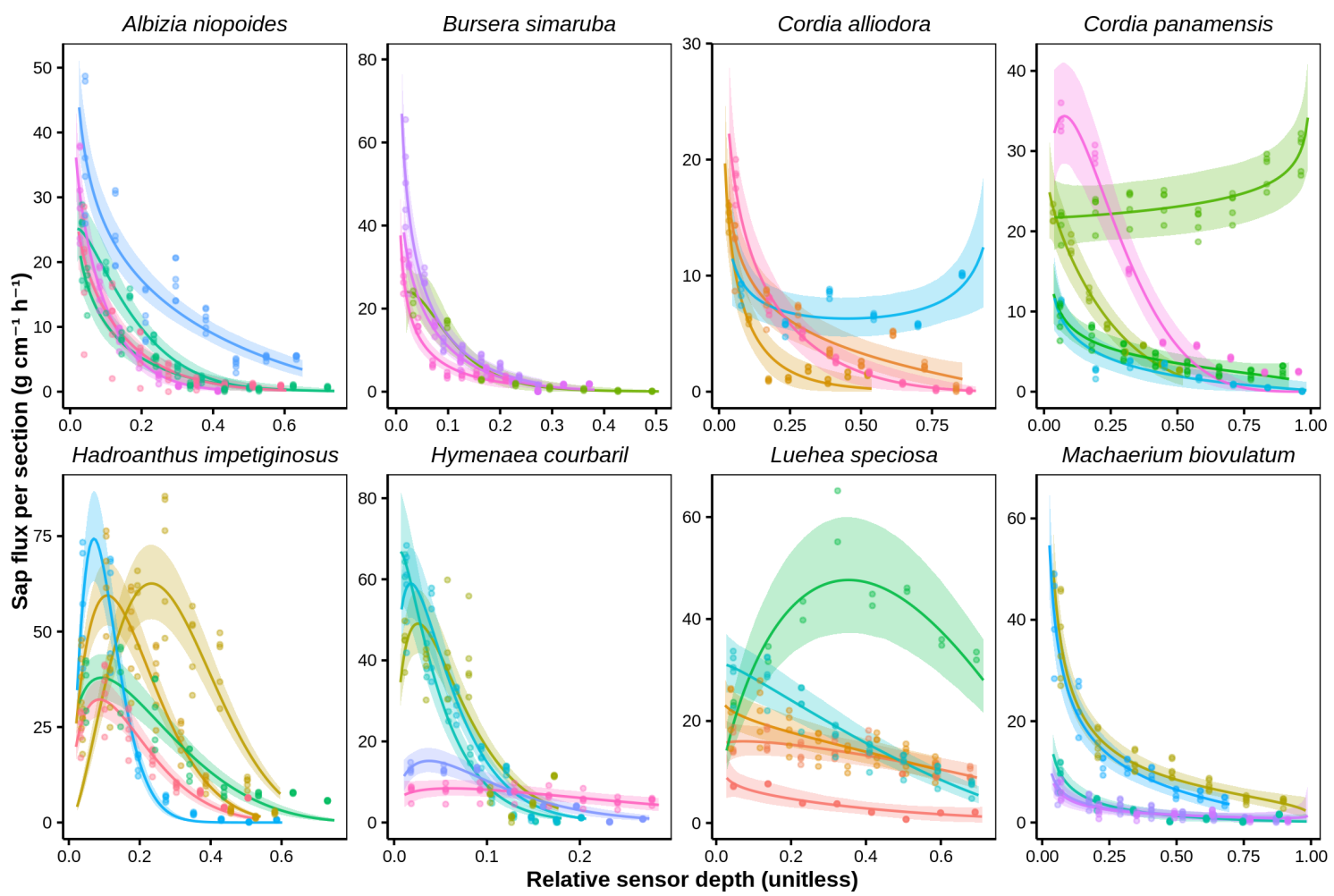

Figure 4.3: Predicted radial sap flow profiles based on the full model. Shown are the observed daily averages of sap flow per section versus sensor depth relative to the stem radius overlaid with the stem-level predictions for all stems with their $95 \%$ credible intervals (colors indicate the different stems). For tree-level plots of model predictions, see Figure B.2.

of 5,000 iterations. The effective sample size was 17,097 on average, and did not reach less than $20 \%$ of the total sample size except for three parameters associated with the covariance matrices of the random effects and less than $10 \%$ for none of the parameters.

\subsubsection{Model comparison}

The accuracy of the predictions of the three different models is shown in Table 4.2. The predictions of the model with average profile depth $\mu$ and concentration parameter $K$ fixed on the species level performed worst in precision (Corr.) and overall accuracy (RMSE, pseudo- $\mathrm{R}^{2}$ ) on all three levels of predictions, and only scored best in trueness (lowest MSD) for the day-level predictions. The average predictions for new days by both the tree-level models with and without parameter regressions performed almost identically in terms of bias, precision and overall accuracy. However, when generalizing to new trees and new species, the model that incorporated information about tree size, wood density and growth achieved a much better fit, with the average predictions for new trees explaining $69.0 \%$ and the predictions for new species still explaining $66.6 \%$ of the variance in the dataset compared to $62.1 \%$ and $55.1 \%$, respectively, for the model without parameter regressions. While it is notable that the models had a tendency to underpredict the true values (negative MSD), this is likely partially an artefact caused by smoothing out the curvature of the predicted profiles when marginalizing over a large set of possible parameter values. 
Table 4.2: Predictive accuracy of the three fitted models on three levels of generalization (average predictions for new measurement days, new trees and new tree species). Model A: constant radial profile within species, no parameter regressions; Model B: tree effects, but no parameter regressions; Model C: full model. Given are the root mean square error (RMSE), mean squared deviation (MSD), Pearson correlation between observed and predicted values (Corr.) and explained variance (pseudo- $\left.\mathrm{R}^{2}\right)$.

\begin{tabular}{llccccc}
\hline Level & Model & MAE & RMSE & Bias & Corr. & pseudo-R \\
\hline New day & Model A & 3.977 & 6.517 & -0.024 & 0.888 & 0.786 \\
& Model B & 2.346 & 4.041 & -0.139 & 0.959 & 0.919 \\
\multirow{3}{*}{ New tree } & Model C & 2.351 & 4.049 & -0.125 & 0.958 & 0.918 \\
& Model A & - & - & - & - & - \\
& Model B & 5.325 & 10.409 & -0.879 & 0.716 & 0.621 \\
\multirow{2}{*}{ New species } & Model C & 4.88 & 9.187 & -0.551 & 0.784 & 0.69 \\
& Model A & 6.046 & 10.804 & -2.122 & 0.671 & 0.508 \\
& Model B & 6.221 & 11.664 & -1.665 & 0.638 & 0.551 \\
& Model C & 5.158 & 9.32 & -0.885 & 0.772 & 0.666 \\
\hline
\end{tabular}

\subsubsection{Parameter models}

The predictor variables explained a considerable part of the variance in both the estimated concentration parameter $K$ and the expected relative profile depth $\mu$. On the scale of the linear predictor, the fixed effects for $H, W D$ and $A S I$ explained $46.3 \%$ of the variance in the average profile depth $\mu$, while only $6.7 \%$ of the variance was explained by random species and $47.0 \%$ by random tree differences. For the concentration parameter $K$, on the scale of the linear predictor, $43.2 \%$ of the variance was explained by the fixed effects, while species-level random effects explained $27.0 \%$ and random tree effects $29.8 \%$ of the variance, respectively.

Partial residual plots displaying the response of the estimated parameters to each of the predictor variables while controlling for the effect of other predictors are provided in Figure 4.4. While the effect of wood density and stem increment was not credibly different from zero neither for average profile depth nor for the concentration parameter (Figure 4.4, Table 4.3), both parameters responded strongly to tree height, with radial profiles reaching up to a lower relative depth and being more concentrated around their expected value for higher trees (Figure 4.4, Table 4.3).

\subsubsection{Estimated tree water-use}

While there was considerable within-species variability in the estimated daily water-use $(D W U)$, clear species patterns were visible (Figure 4.5a), with species averages of $D W U$ spanning more than one order of magnitude. While the approximate $D W U$ did not respond significantly to wood density and stem increment, there was a strong positive association with tree height $(\mathrm{t}=56.98$, edf $=33.5, \mathrm{p}<0.001$; cf. Figure $4.5 \mathrm{~b}-\mathrm{d})$. On average, estimates of $D W U$ based on short sensors were $26 \%$ higher than the radialprofile-based estimates used as a baseline, with a range of $-41 \%$ to $+113 \%$. Credible underpredictions only occurred for two trees with strongly hump-shaped radial profiles (cf. Figure 4.6). The average $D W U$ predictions from short sensors were credibly larger than the profile-based predictions for all but one species (Handroanthus impetiginosus). 

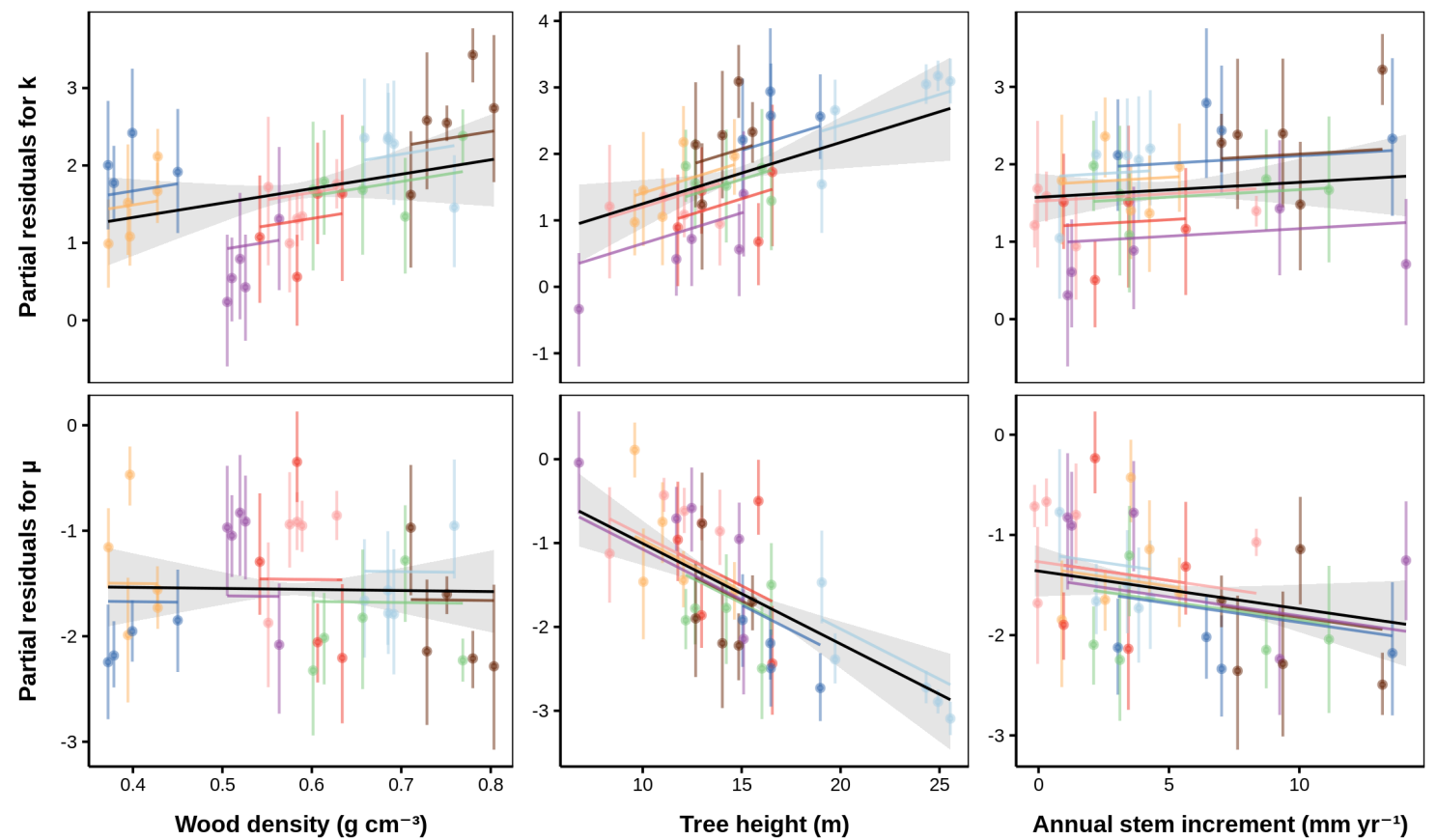

Albizia niopoides

- Cordia alliodora

Annual stem increment $\left(\mathrm{mm} \mathrm{yr}^{-1}\right)$

Luehea speciosa

Machaerium biovulatum

Figure 4.4: Partial residual plots for the stem-level regressions of the estimated parameters. Shown are the predicted responses of the estimated concentration parameter $K$ and the expected depth of the profile $\mu$ (with $95 \%$ credible intervals) to wood density, tree height and annual stem increment, when keeping the other predictors at their average values. For both parameters, only the tree height effect was credibly different from zero (see Table 4.3).

\subsection{Discussion}

\subsubsection{Modelling results}

Our results indicate that our model was well able to capture the shape of the observed radial sap flux profiles, with the day-wise predictions of the full model explaining a total of $96.0 \%$ of the variance in sap flow per section. However, a large part of the variance in the dataset was associated with sources of random variability acting on higher levels in the hierarchy of the data, resulting in considerably larger uncertainty when predicting to new trees and new species. Due to differences in the scale of the response, we cannot directly compare our model fit to the model of Berdanier et al. (2016), to our knowledge the only other authors who modeled radial sap flow profile based on Bayesian hierarchical models. However, Figure B.1 suggests at least a similar fit to that of those authors (cf. Figure 4.1a-d in Berdanier et al. 2016). The better performance of the models that allowed for within-species variation in the parameters describing the shape of the radial profile indicates the magnitude of the observed intraspecific differences, and questions the assumption of Caylor and Dragoni (2009) that the relative radial component of sap flux density should be approximately constant within species. In either case, it should be noted that the exact amount of between-tree variability cannot be determined from our data, as we only could install one HFD sensor per tree due to technical limitations, which makes it impossible to separate between-stem and azimuthal variation. A sizeable part of the observed within-species differences in radial profile parameters could therefore actually 

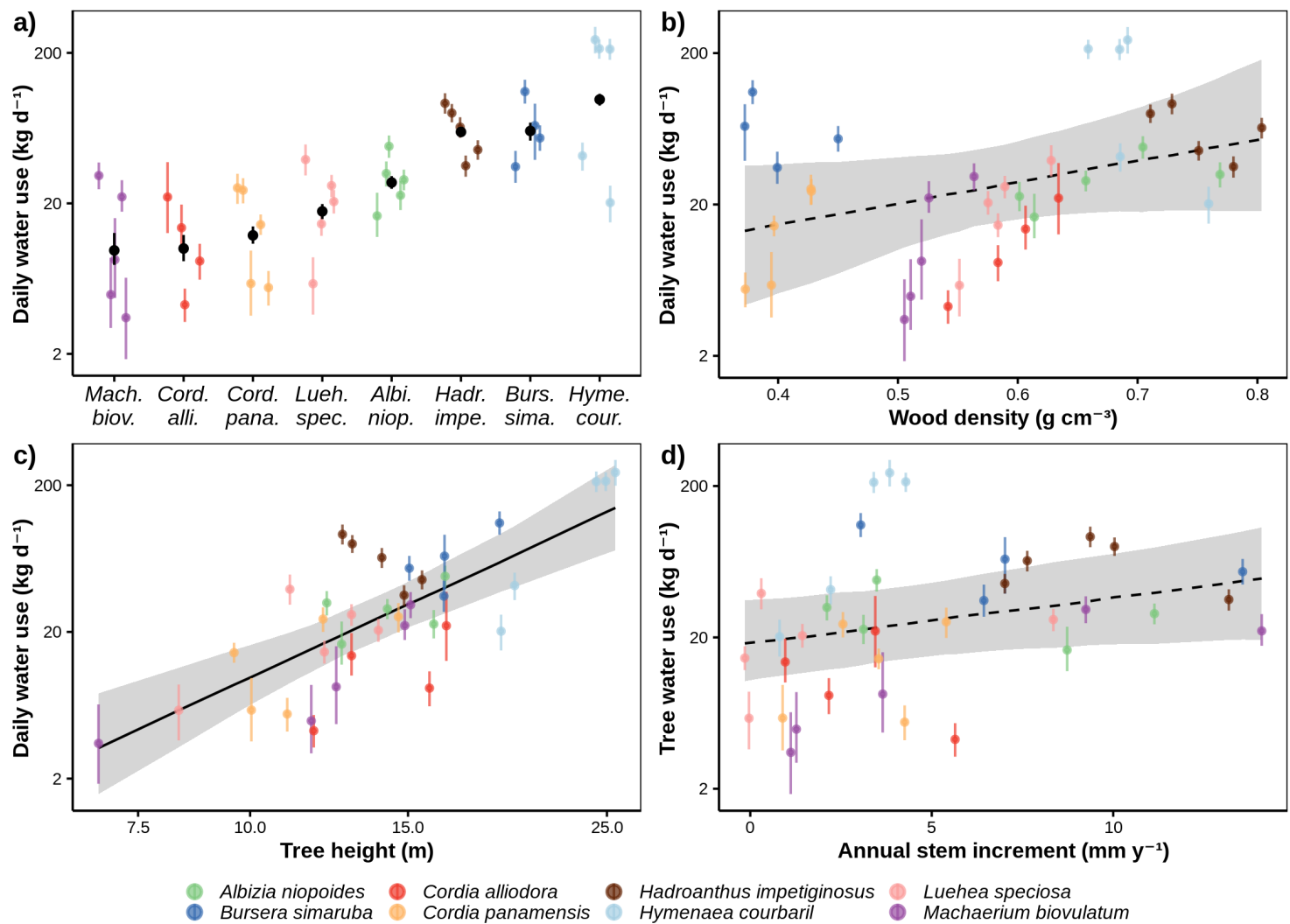

Figure 4.5: Estimated daily water-use (posterior mean $\pm 95 \%$ CI on a $\log _{10}$ scale) vs. a) species, b) wood density, c) tree height and $\mathbf{d}$ ) annual stem increment. Regression lines in b)-d) from mixed effects models with random species effects based on the posterior mean predictions with bootstrapped $95 \%$ confidence bounds.

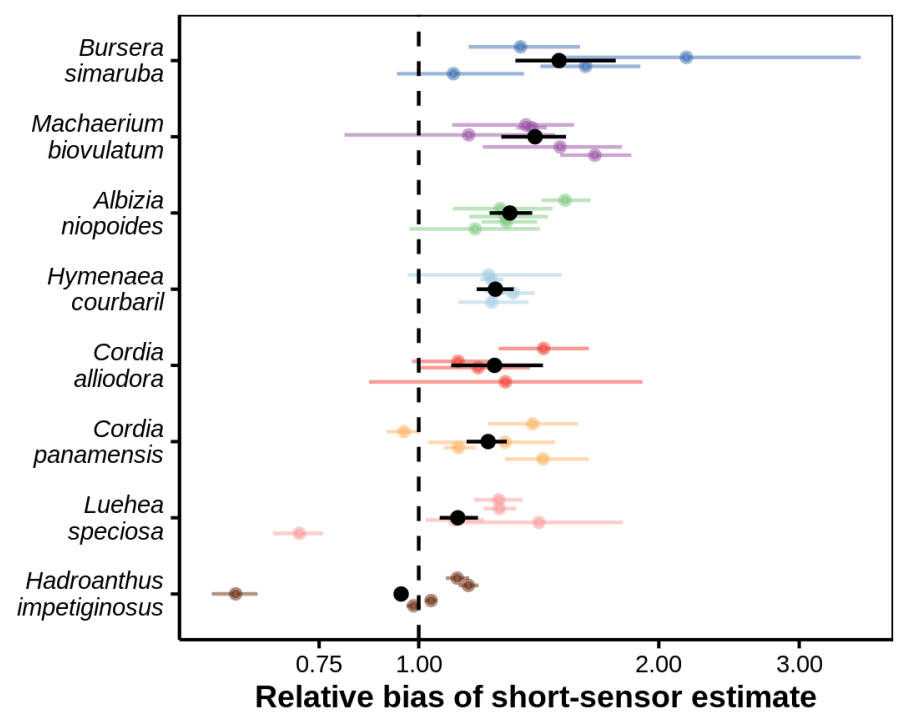

Figure 4.6: Ratio of the predicted daily water-use estimated by assuming the value measured in the outermost $2 \mathrm{~cm}$ of the sapwood to be constant across the entire sapwood depth and the estimates based on radial profiles with their propagated MCMC-based 95\% credible intervals (black: species average $\pm 95 \% \mathrm{CI}$ ). Values greater than one indicate overprediction relative to the profile-based estimates, values smaller than one indicate underprediction. 
Table 4.3: Summary of MCMC output. Shown are the posterior mean \pm MCMC standard error, the standard deviation of the MCMC samples, the $2.5 \%, 25 \%, 50 \%, 75 \%$ and $97.5 \%$ quantiles of the posterior sample, the effective sample size $\mathrm{n} \_$eff and thê $\mathrm{R}$ statistic for all model parameters. Italic: Quantiles of the parameters whose $95 \%$ credible intervals include zero.

\begin{tabular}{|c|c|c|c|c|c|c|c|c|c|}
\hline Parameter & Mean \pm SE & SD & $2.5 \%$ & $25 \%$ & $50 \%$ & $75 \%$ & $97.5 \%$ & $\mathbf{n}_{\text {eff }}$ & $\hat{\mathbf{R}}$ \\
\hline$\beta_{\mu}$ : Intercept & $-1.557 \pm 0.000$ & 0.029 & -1.613 & -1.576 & -1.557 & -1.538 & -1.499 & & \\
\hline$\beta_{\mu}: \mathrm{WD}$ & $-0.002 \pm 0.001$ & & -0.230 & .071 & 0.000 & 0.071 & 0.212 & & 1.0006 \\
\hline${ }_{\mu}: \mathrm{H}$ & $-0.491 \pm 0.0$ & 0.108 & -0.714 & -0.559 & -0.488 & -0.420 & -0.286 & .5 & 1.0001 \\
\hline$\beta_{\mu}:$ ASI & $-0.133 \pm 0.0$ & & -0.327 & -0.202 & -0.133 & -0.066 & 0.072 & & 04 \\
\hline $\mathrm{K}$ : Interc & & & 1.570 & 1.640 & 1.676 & 1.711 & & & \\
\hline $\mathrm{K}: \mathrm{WD}$ & $0.207 \pm 0$ & & -0.12 & 0.100 & 0.207 & 0.317 & & & 002 \\
\hline к: Н & & & & 0.288 & 382 & 476 & & & 003 \\
\hline $\mathrm{K}:$ ASI & & & & -0.085 & & & & & \\
\hline & & & & & & & & & \\
\hline & & & & & & & & & \\
\hline u & 0.17 & & 0.157 & 0.168 & 0.174 & 0.180 & 0.193 & 102028 & 002 \\
\hline$\tau_{\mathrm{v}}: \mu$ & & & & 0.545 & & & & & \\
\hline$\tau_{\mathrm{v}}: \mathrm{K}$ & & & & & & & & & \\
\hline$\tau_{\mathrm{v}}: \mathrm{c}_{0}$ & 0.73 & & & 0.681 & & 0.771 & & & 999 \\
\hline$\tau_{\mathrm{w}}: \mu$ & 0.1 & & & & & 0.277 & & & 1.0005 \\
\hline$\tau_{\mathrm{w}}: \mathrm{K}$ & 0.4 & & & 369 & 456 & 0.546 & & 3.9 & 0001 \\
\hline$\Omega_{\mathrm{v}}: \operatorname{cor}($ & -0.72 & 0.1 & -0.900 & -0.818 & -0.749 & -0.658 & -0.399 & 552 & 0004 \\
\hline $\left.\mathrm{c}_{0}\right)$ & $0.649 \pm 0.002$ & & 0.388 & 0.589 & 0.666 & 0.729 & & & 1.0009 \\
\hline$\Omega_{\mathrm{v}}: \operatorname{co}$ & $-0.724 \pm 0.002$ & & -0.900 & -0.818 & -0.749 & -0.658 & -0.399 & 5520.7 & 1.0004 \\
\hline , K) & -0.12 & & -0.762 & -0.412 & -0.148 & 0.142 & 0.650 & 6968.7 & 1.0000 \\
\hline A & $0.563 \pm 0.002$ & 0.319 & 0.181 & 0.353 & 0.491 & 0.684 & 1.374 & 20700.0 & 0.9999 \\
\hline
\end{tabular}

result from within-stem variability along the azimuthal dimension, which is known to significantly affect sap flow estimates (Reyes-Acosta and Lubczynski 2014; Molina et al. 2016).

In contrast to Berdanier et al. (2016) who reported a poor performance of models based on relative depth, we were able to model sap flux with good accuracy based on relative distance from the cambium using a reparameterized beta distribution. While the shape of radial profiles certainly can be described with models based on absolute depth with equal accuracy as with our model, models based on relative depth have a number of clear advantages. Working with relative depth ensures that the function for the radial component of sap flux integrates to one over the tree radius without further corrections, which facilitates the decomposition of the sap flux signal into a radial and time-varying component. Moreover, due to our reparameterization (cf. Figure 4.1), the average profile depth is directly estimated as a model parameter, which greatly simplifies integrating over the cross-section of a tree to estimate whole-tree water-use. In addition, in experimental model runs with different equations for the radial profile, we found the beta-based model to achieve similar accuracy while having much better convergence properties in our case than the reparameterized gamma probability density function that performed best in the study of Berdanier et al. (2016) (results not shown). 


\subsubsection{Determinants of the shape of radial sap flow profiles}

The pronounced intraspecific variability in the shapes of the observed radial profiles is evident from the data at first glance (compare Figure 4.3). While up to a certain degree this might be a masked effect of azimuthal variation (see above), the highly different shapes of the curves make it likely that between-tree variability plays a significant role. Our variance decomposition of the parameter regressions indicates that also after including functional traits as regressors, random tree effects still explained $47.0 \%$ of the variance in the average relative profile depth $\mu$ and $29.3 \%$ of the variance in the concentration parameter $K$. In contrast, especially for $\mu$, the contribution of random species differences to the total variance was comparatively low (cf. Figure 4.1 for the interpretation of the parameters).

As the predictor variables tree height, wood density and growth rate vary considerably between species (cf. Table 4.1), a certain part of the interspecific variability was likely explained by the fixed effects, thus shrinking the variance of the random species component. This is illustrated by the better performance of the model that included parameter regressions when marginalizing out random species- and tree-effects (Table 4.2). Nonetheless, the outcome of our study underlines the need to account for within-species differences in radial profiles in order to reliably propagate uncertainty when scaling up water-use estimates.

The radial profiles of the observed species can be grouped into three types: a) species with consistently monotonously declining profiles (Albizia niopoides, Bursera simaruba and Machaerium biovulatum), b) species with predominantly hump-shaped profiles (Hymenaea courbaril, Handroanthus impetiginosus) and c) species without clear patterns and with large intraspecific variability in profiles (Cordia alliodora, Cordia panamensis and Luehea speciosa). Notably, while the species in the first group share few common traits, the second group comprises the two most hard-wooded species in the dataset (Table 4.1), and the third consists only of small early-successional species. The fact that in the latter group some individuals were found to have the maximum of sap flux density close to the center of the trunk is not surprising, as due to their small size their wood was likely conductive over the entire cross-section.

In our model, the only predictor that had a credible effect on the parameters of the radial profiles was tree height. For taller trees, the bulk of flow occurred closer to the cambium (i.e., lower average profile depth $\mu$ ) and the profile was more narrowly centered around its average value (i.e. higher concentration parameter $K$; cf. Figure 4.1). This is in accordance with the results of Zhang et al. (2018), who found tree height to be a major driver of the shape of radial profiles of trees in a Chinese subtropical evergreen forest, and described hump-shaped profiles for lower canopy species, while upper canopy species tended to have a maximum of flow close to the cambium. A similar pattern was also reported by Delzon et al. (2004), who found steeper radial profiles for trees with larger diameters. The large height effect on the shape of the radial profile likely reflects the fact that the relative fraction of sapwood in the cross-sectional area of a tree tends to decrease with tree size, a pattern that has repeatedly been described for Neotropical seasonally-dry forest species (Meinzer et al. 2005; Reyes-García et al. 2012). This may be exacerbated by the fact that in order to make up for the longer flow path, taller trees need wider vessels (Ryan and Yoder 1997; Ryan et al. 2006; Olson et al. 2018), which can be expected to increase the contribution of the outermost xylem layers to total water transport. 


\subsubsection{Upscaled estimates of whole-tree water-use}

The approximate estimates of tree daily water-use differed considerably between species, and were positively associated with tree height. The higher water-use observed in tall trees is in line with theoretical expectations based on allometric scaling models (West et al. 1999; Enquist 2002; Meinzer et al. 2005) and is likely related to an increased transpirational demand (Horna et al. 2011). This is corroborated by our microclimatic measurements, which indicated $V P D$ during daytime to be on average $77.1 \%$ higher in tree crowns at a height of $20 \mathrm{~m}$ than at the position of the sensors close to the forest floor (Figure 4.2b). Similar vertical microclimatic patterns have been observed in Paleotropical perhumid forests, where VPD doubled from the forest floor to the uppermost canopy (Schuldt et al. 2011). While increased rainfall after the first measurement campaign led to increased soil water content in the following campaigns (Figure 4.2a), the estimated average sap flux densities during a measurement campaign were not associated with the soil water content and did not change systematically between campaigns (Figure B.3). This indicates that soil water supply did not limit tree transpiration during the measurement interval.

Our results further highlight the importance of accounting for radial profiles to obtain correct estimates of whole-tree daily water use. We found single-point estimates of wateruse based on the average flux density over the first $2 \mathrm{~cm}$ of the profile to overestimate tree water-use by on average $26.0 \%$ compared to water-use estimates based on radial profiles, with a large variability in the ratio both within and between species. As our own measurements of radial profiles are limited by the maximum measurement depth of $7.5 \mathrm{~cm}$ permitted by the installed sensor system, it is possible that the actual amount of bias is even larger. While it has often been reported that ignoring radial variation most likely leads to an overestimation of sap flow (Nadezhdina et al. 2002; Reyes-Acosta and Lubczynski 2014; Zhang et al. 2015), many transpiration estimates are still based on uncorrected single-point measurements (see review in Berdanier et al. 2016). Our results show that, in addition to the overall positive bias of on average $26 \%$ resulting from the use of short-sensor probes, ignoring radial gradients in sap flux density induces a species-specific bias depending on the prevailing shapes of radial profiles that may obscure comparisons of water-use between trees of different species.

\subsubsection{Measuring radial profiles with HFD sensors}

The heat field deformation method for sap flow measurement has the advantage of being able to continuously monitor the radial distribution of sap flux density with a single sensor installation at high temporal and spatial resolution (Nadezhdina et al. 2012; Nadezhdina et al. 2018). The availability of commercial stand-alone HFD sensor systems makes the application of the method relatively easy. However, it has repeatedly been reported that the HFD method is likely to result in biased estimates without species-specific calibration (Vandegehuchte and Steppe 2012c; Steppe et al. 2010; Fuchs et al. 2017), which can hardly be accomplished in species-rich tropical forests (cf. Section 4.4.3). Additionally, commercial HFD probes are comparatively costly, and their use in remote sites is complicated by the relatively high energy use. Notwithstanding these limitations, the high radial resolution of HFD sensors makes them a valuable tool for studies that scale up water-use, especially when using the framework of Caylor and Dragoni (2009) to decompose sap flow into a radial component and an overall stem conductance. In this setting, HFD sensors can be used to track radial profiles for a subsample of trees, which can then be used to more accurately estimate the water-use of a larger sample of trees equipped with more 
economical single-point sensors, e.g. thermal dissipation probes (TDP, Granier (1985)) or heat-ratio-method (HRM, Burgess et al. 2001) sensors by applying a correction as detailed by Eq. 11-15 in Caylor and Dragoni (2009). Examples for the use of HFD sensors in conjunction with TDP sensors can be found in Poyatos et al. (2007), Reyes-Acosta and Lubczynski (2013), Reyes-Acosta and Lubczynski (2014) and Pinto et al. (2014), while Fan et al. (2018) show the parallel use of HFD and HRM sensors in a laboratory setting. However, none of these studies explicitly adopted the aforementioned framework.

\subsubsection{Temporal changes in radial profiles}

While our model operates under the simplifying assumption that the radial component of sap flow is time-invariant, it should be mentioned that there is substantial evidence that this is not always the case. Radial sap flow profiles have been reported to change both diurnally (Ford et al. 2004a; Fiora and Cescatti 2006; Poyatos et al. 2007; HernandezSantana et al. 2016) and seasonally (Ford et al. 2004a; Fiora and Cescatti 2006; Nadezhdina et al. 2007; Poyatos et al. 2007; Chiu et al. 2016), with suspected links to soil water content (Ford et al. 2004a; Nadezhdina et al. 2007), light availability (Fiora and Cescatti 2006) and stomatal conductance (Hernandez-Santana et al. 2016).

When scaling up sap flux density measurements to tree level water-use, aggregating data as daily averages is a simple procedure to at least reduce the effect of diurnal changes in the profile. Dealing with seasonal changes in radial profiles is considerably more complicated, as they can only be detected with long-term monitoring settings and averaging them out to avoid biased estimates of tree transpiration is difficult. However, Chiu et al. (2016) found the magnitude of seasonal changes in both radial profiles and azimuthal gradients in sap flux density to be much smaller than seasonal tree-to-tree variation, which indicates that to improve up-scaled water-use estimates with limited resources, it may be more beneficial to increase the number of trees equipped with easier-to-operate single-point sensors.

\subsubsection{Conclusions}

In this study, we have demonstrated how measurements of sap flux per xylem section measured with the heat field deformation method can be used to estimate radial gradients in sap flux density using a Bayesian hierarchical modeling approach. Extending on the framework of Caylor and Dragoni (2009), we have shown how the output of these models can be integrated with sap flux measurements of single-probe sensors to obtain more accurate estimates of tree water-use, and how to improve model predictions onto additional species by incorporating functional traits as predictors of the shape of radial sap flow profiles. Building upon the model code provided in the digital supplement, it is possible to predict radial profiles for new trees with similar wood properties. In addition, our model lends itself to extension e.g. by including observations covering a wider range of tree functional types, by incorporating a submodel for azimuthal flow variation, by using more adequate predictor variables or by allowing the parameters of radial profiles to vary as a function of time. 


\section{Acknowledgements}

This study was financed by the German Research Foundation (DFG, SCHU 2935/1-1). We gratefully acknowledge the logistic support of Milena Gutiérrez, the Área de Conservación Guanacaste and the staff of the Estación Experimental Forestal Horizontes. 


\section{Supplementary material A: Supplementary methods}

\section{Model for radial profiles of sap flux density}

\section{Model structure}

In order to model the measured radial sap flux profiles while simultaneously treating the parameters determining their shape as a function of tree height and wood density, we used nonlinear mixed models in a Bayesian hierarchical modeling framework. The models were written in the Stan probabilistic programming language (Carpenter et al. 2017) accessed through R v. 3.5.2 (R Core Team 2018) using rstan v. 2.18.2 (Stan Development Team 2018).

The radial sap flow profiles were modeled based on daily averages of the raw sap flux per section $(S F S)$ values, using only data from complete measurement days covering a full 24 hours of $S F S$ measurements tracked in 10 min intervals. On the first stage of the model, the shape of the radial profile was described with the density function of the Beta distribution $\left(\rho_{s}\right.$; see Eq. (4.4) in the main text) multiplied with an arbitrary multiplicative constant $c$ adjusting $\rho_{s}$ to the observed absolute values of $S F S$. The expected sap flux per section $\left(\widehat{S F S}_{i j k l}\right)$ for observation $i$ on day $j$ belonging to tree $k$ of species $l$ was described as follows:

$$
\widehat{S F S}_{i j k l}=c_{j k} \cdot \rho_{s}\left(r_{i j k l} \mid \mu_{k l}, K_{k l}\right)=c_{j k} \cdot \frac{r^{\mu_{k l} K_{k l}-1}(1-r)^{\left(1-\mu_{k l}\right) K_{k l}-1}}{\mathrm{~B}\left(\mu_{k l} L_{k l},\left(1-\mu_{k l}\right) K_{k l}\right)}
$$

where $r$ is the relative depth (distance from the cambium divided by radius of the woody stem), $\mu$ is the 'average profile depth' (expected value of the Beta distribution used to model the shape of the profile) and $K$ is a concentration parameter that increases as the profile becomes increasingly centered around $\mu$.

The observed sap flow per section was assumed to be normally distributed around its expected value with standard deviation $\sigma$.

$$
S F S_{i j k l} \sim \operatorname{Normal}\left(\widehat{S F S}_{i j k l}, \sigma\right)
$$

On the second stage of the model, we assigned regression equations to the three parameters $c, \mu$ and $K$. As $c$ and $K$ are constrained to be positive, their parameter level regressions were expressed on a natural log scale, while $\mu$, which is strictly bounded between 0 and 1 , was modelled with a logit link. $\log (K)$ and $\operatorname{logit}(\mu)$ were expressed as linear functions of wood density $W D$, tree height $h$ and annual stem increment $A S I$, and assigned tree and species level random effects ( $v$ and $w$, respectively). Prior to analysis, the predictor variables were scaled and centered to reduce the correlation in their regression parameters.

$$
\log \left(K_{k l}\right)=\beta_{K_{0}}+\beta_{K_{1}} W D_{k l}+\beta_{K_{2}} h_{k l}+\beta_{K_{3}} A S I_{k l}+v_{K_{k}}+w_{K_{l}}=\boldsymbol{X} \beta_{K}+v_{K_{k}}+w_{K_{l}}
$$

$$
\operatorname{logit}\left(\mu_{k l}\right)=\beta_{\mu_{0}}+\beta_{\mu_{1}} W D_{k l}+\beta_{\mu_{2}} h_{k l}+\beta_{\mu_{3}} A S I_{k l}+v_{\mu_{k}}+w_{\mu_{l}}=\boldsymbol{X} \boldsymbol{\beta}_{\mu}+v_{\mu_{k}}+w_{\mu_{l}}
$$


where $\boldsymbol{X}$ is a $k \times 4$ model matrix containing one intercept column and three columns with the predictor variables, and $\beta_{k}$ and $\beta_{\lambda}$ are the corresponding parameter vectors for the tree level regressions.

As we were not primarily interested in the measured absolute values of unscaled $S F S$, we did not assign fixed effects to the regression for the multiplicative parameter $c$. Instead, we expressed it in terms of it average value $c_{0}$ and allowed it to vary randomly between trees $\left(v_{c_{k}}\right)$ and measurement days within trees $\left(u_{j k}\right)$ :

$$
\log \left(c_{j k}\right)=c_{0}+u_{j k}+v_{c_{k}}
$$

The random effects for measurement days were included to account for recognizable systematic deviations from the measurements of particular days from the overall average profile of that tree.

To account for correlations between the parameters $\mu, K$ and $c$, we described the treeand species-level random effects with multivariate normal distributions:

$$
\begin{gathered}
\boldsymbol{v}_{k} \sim \operatorname{MVN}\left(\mathbf{0}, \Sigma_{v}\right) \\
\boldsymbol{w}_{l} \sim \operatorname{MVN}\left(\mathbf{0}, \Sigma_{w}\right),
\end{gathered}
$$

where $\boldsymbol{v}_{k}$ and $\boldsymbol{w}_{l}$ are vectors containing the tree and species specific random effects for tree $k$ and species $l$, respectively, and $\Sigma_{v}$ and $\Sigma_{w}$ are the corresponding covariance matrices.

Analogously, the day level random effects $u$ were assumed to be drawn from a normal distribution with a mean of 0 and a standard deviation $\tau_{u}$.

$$
u_{j k} \sim \operatorname{Normal}\left(0, \tau_{u}\right)
$$

In addition to the full model described by Eqn. A.1-A.8, we fitted two reduced models, both of which did not include fixed effects in the parameter regressions for $\mu$ and $K$, and one of which additionally assumed $\mu$ and $K$ to be constant between trees belonging to the same species.

\section{Transformations}

In order to aid convergence, several transformations was performed on the data and estimated parameters: First, we scaled the response variable (observed sap flux per section) by dividing it by its standard deviation.

Additionally, we performed a QR decomposition on the design matrix $\boldsymbol{X}$ and estimated the regression coefficients $\boldsymbol{\theta}_{K}$ and $\boldsymbol{\theta}_{\mu}$ on the resulting (orthogonal) matrix $\boldsymbol{Q}^{*}$ instead of fitting the model directly on $\boldsymbol{X}$, thus reducing the correlation in the estimated parameters and largely speeding up convergence (Stan Development Team 2017, Ch. 8.2., 26.6). The resulting parameter estimates were then back-transformed to parameters corresponding to the original design matrix. 
We used the non-centered parameterization (Betancourt and Girolami 2015) to more efficiently sample the random effects, i.e. samples were taken from a standard normal distribution and multiplied with their scales in a second step to shift the data's correlation with the parameters to the hyperparameters (Stan Development Team 2017, Ch. 26.6).

Additionally, we performed a Cholesky decomposition on the correlation matrices $\Omega_{\text {tree }}$ and $\Omega_{\text {spec }}$ and afterwards defined priors for the corresponding Cholesky factors instead of directly definining priors on the correlation matrices to speed up model convergence (see below).

\section{Priors}

Following the philosophy of Gelman and Shalizi (2013), we conceptualize prior distributions as a testable part of the model, essentially acting like a regularization device. We therefore assigned all parameters weakly informative priors strong enough to constrain their estimates to a reasonable range of the parameter space, but sufficiently weak to avoid distorting the parameter estimates.

The fixed effect parameter meter vectors $\boldsymbol{\theta}_{K}$ and $\boldsymbol{\theta}_{\mu}$ as well as the intercept $c_{0}$ of the multiplicative parameter $c$ were assigned Cauchy priors with a location of 0 and a scale of 10 (cf. Gelman et al. 2008).

$$
\boldsymbol{\beta}_{K} \sim \text { Cauchy }(0,10) \quad \boldsymbol{\beta}_{\mu} \sim \text { Cauchy }(0,10) \quad c_{0} \sim \text { Cauchy }(0,10)
$$

Unlike e.g. the normal distribution, the Cauchy distribution has a non-zero slope all along

its tails. Accordingly, Cauchy priors have the advantage that while placing the bulk of probability mass at low parameter values (in the given example, $50 \%$ between -10 and 10 , and $93.6 \%$ between -100 and 100), they still allow for occasional high values, which makes them a good choice for weakly informative priors.

Based on the same reasoning, all variance parameters in the model were assigned halfCauchy priors (cf. Gelman 2006).

The residual standard deviation $\sigma$ was assigned a half-Cauchy prior with a location of 0 and a scale of 2 .

$$
\sigma \sim \text { half Cauchy }(0,2)
$$

To assign priors for the random effects covariance matrices $\boldsymbol{\Sigma}_{v}$ and $\boldsymbol{\Sigma}_{w}$, they were decomposed into a correlation matrix $\boldsymbol{\Omega}$ and a vector of standard deviations $\boldsymbol{\tau}$ (see Stan Development Team 2017, Ch. 8.13), making use of the following equality:

$$
\boldsymbol{\Sigma}=\operatorname{diag}(\boldsymbol{\tau}) \boldsymbol{\Omega} \operatorname{diag}(\boldsymbol{\tau})
$$

The resulting scale vectors $\boldsymbol{\tau}_{v}$ and $\boldsymbol{\tau}_{w}$ as well as the standard deviation of the random day effects $\tau_{u}$ were assigned hierarchical half-Cauchy priors with a common scale parameter drawn from a uniform distribution (Gelman 2006).

$$
\tau_{v} \sim \text { half Cauchy }(0, A)
$$




$$
\begin{gathered}
\boldsymbol{\tau}_{w} \sim \text { half Cauchy }(0, A) \\
\tau_{u} \sim \operatorname{half} \text { Cauchy }(0, A) \\
A \sim \operatorname{Uniform}(0,10)
\end{gathered}
$$

The corresponding correlation matrices $\boldsymbol{\Omega}_{v}$ and $\boldsymbol{\Omega}_{w}$ were described with a LKJ prior (Lewandowski et al. 2009) with $\eta=1.5$, which puts moderately increased weight on the identity matrix:

$$
\boldsymbol{\Omega}_{v} \sim \operatorname{LKJ}(2.5) \quad \boldsymbol{\Omega}_{w} \sim \operatorname{LKJ}(2.5)
$$

To aid convergence, this prior was placed on the Cholesky factor of the correlation matrix

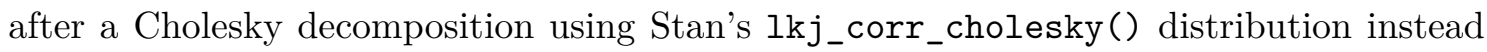
of directly sampling from a LKJ distribution (Stan Development Team 2017, Ch. 8.13, Ch. 59.1-2).

\section{Model fitting}

As the specified model was to complex to converge when starting from Stan's default random starting values, we first fitted a simplified version of the model with $\mathrm{R}$ package nlme (Pinheiro et al. 2017). The maximum likelihood estimates of the model were then transformed to the scale of the final model, and starting values were randomly sampled from a uniform distribution within $\pm 10 \%$ of the maximum likelihood estimates.

MCMC Sampling was performed with Hamiltonian Monte Carlo sampling via Stan's NoU-Turn-Sampler (Hoffman and Gelman 2014) using 4 chains with 10000 iterations each for all three models with the sampling settings adapt_delta $=0.999$, max_treedepth $=15$, stepsize $=0.01$. For each chain, we discarded a burn-in interval of 5000 samples to ensure convergence for all model parameters. Convergence was assessed based on the potential scale reduction factor for split chains $\hat{R}$ and visually by inspection of trace plots of the most relevant model parameters. Model evaluation was performed by visual and formal posterior predictive checks (Gelman et al. 2014).

\section{Explained variance on different levels in the model}

To estimate the relative contribution of fixed effects, species level random effects and tree level random effects in our full model on the estimated parameter values of $\mu$ and $k$, we performed a variance partitioning on the scale of the linear predictor for these parameters. Our calculation was based on the Bayesian R-squared proposed by Gelman et al. (2018), extended to a multilevel model analogously to Nakagawa and Schielzeth (2013). The fraction of explained variance for parameter $\theta$ was calculated as the posterior mean of the fraction of the variance of the fixed effects $\tau_{f_{\theta}}^{2}=\operatorname{var}\left(\mathbf{X} \beta_{\theta}\right)$ divided by the sum of all variance components of that parameter: 


$$
R_{\theta}^{2}=\mathrm{E}\left(\frac{\tau_{f_{\theta}}^{2}}{\tau_{f_{\theta}}^{2}+\tau_{w \theta}^{2}+\tau_{v \theta}^{2}}\right)
$$

The contributions of the variance components $\tau_{w \theta}^{2}$ and $\tau_{w \theta}^{2}$ to the total variance in $\theta$ were calculated equivalently. In addition, we used an equivalent decomposition of the variance in the response to calculate a pseudo-R-squared for the day-level and average day predictions for each tree (compare Gelman et al. 2018).

\section{Model comparison}

To compare the predictive performance of the three competing models, we sampled from the posterior predictive distribution $p\left(S F S_{\text {pred }} \mid S F S_{\text {obs }}\right)$ on different levels in the hierarchy in the model:

$$
p\left(S F S_{\text {pred }} \mid S F S_{\text {obs }}\right)=\int_{\boldsymbol{\theta}} p\left(S F S_{\text {pred }} \mid S F S_{o b s}, \boldsymbol{\theta}\right) p\left(\boldsymbol{\theta} \mid S F S_{o b s}\right) \mathrm{d} \boldsymbol{\theta}
$$

where $S F S_{\text {pred }}$ is the predicted and $S F S_{\text {obs }}$ the observed sap flow, and $\boldsymbol{\theta}$ are the model parameters. We integrated over all possible values of a subset of the parameters in the model while retaining others at their predicted values to obtain the posterior predictive distributions for a) new sampling days, b) new trees and c) new species (maintaining the tree level effects of $c_{0}$ at their predicted values to maintain the scale of the predictions). We then assessed how well the observed data were fitted by the posterior means of the predictive distributions using a set of accuracy statistics (see following table) that quantify precision (correlation between observed and predicted values), trueness (mean signed deviation), and overall accuracy (root mean square error and pseudo- $R^{2}$ ):

\begin{tabular}{llll}
\hline Statistic & Equation & Description & Interpretation \\
\hline Correlation & & Pearson correlation & Indicator of \\
& $\frac{\mathrm{E}\left(\left(y-\mu_{y}\right)\left(\hat{y}-\mu_{\hat{y}}\right)\right)}{\sigma_{y} \sigma_{\hat{y}}}$ & between observed & and precision \\
& & &
\end{tabular}

MSD

$$
\mathrm{E}(y-\hat{y})
$$

RMSE

$$
\sqrt{\mathrm{E}\left((y-\hat{y})^{2}\right)}
$$

pseudo-R ${ }^{2}$

$$
\mathrm{E}\left(\frac{\sigma_{\hat{y}}}{\sigma_{\hat{y}}+\sigma_{y-\hat{y}}}\right)
$$

Expected value of the difference between observed and predicted values Square root of expectation of the square differences between observed and predicted values Approximate explained variance by the model
Indicator of trueness

Indicator of overall accuracy

Indicator of overall accuracy 


\section{Supplementary material B: Supplementary figures}

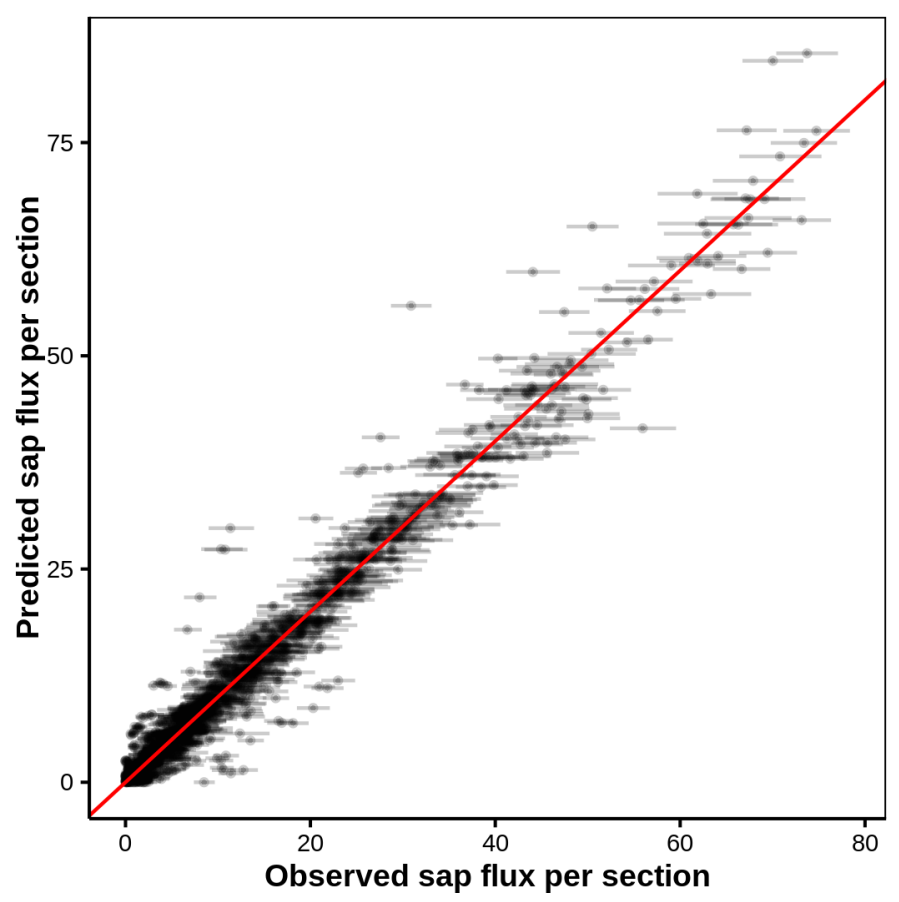

Figure B.1 Observed sap flow per section vs. daywise predictions of the full model including their $95 \%$ credible intervals (Bayesian pseudo- $\mathrm{R}^{2}: 0.960$ ). 

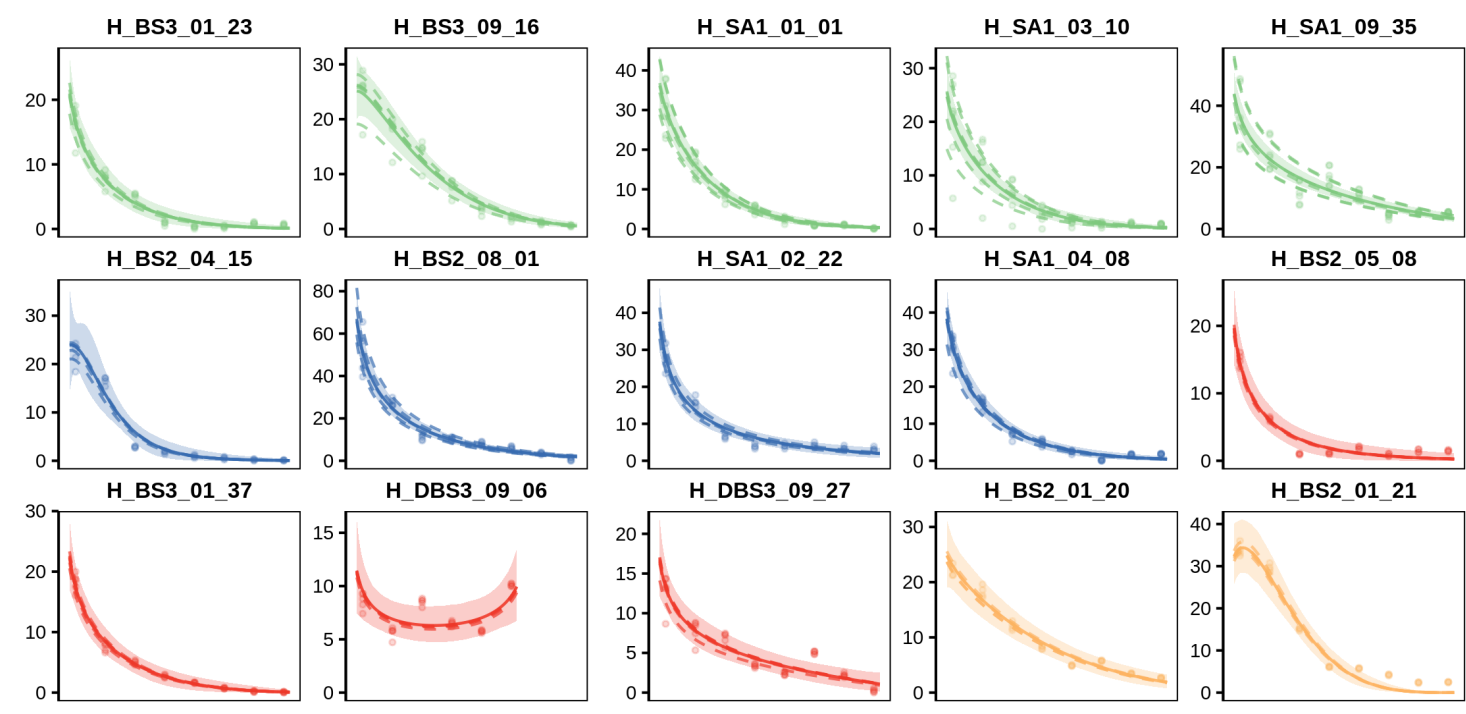

H BS2 0120

H_BS2_01_21
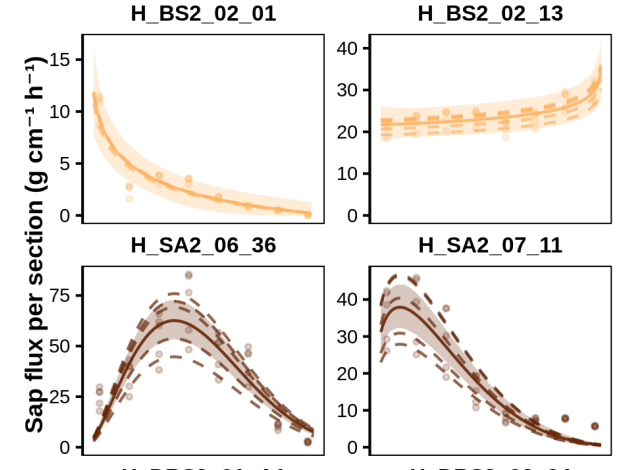

H DBS3 $02 \quad 08$
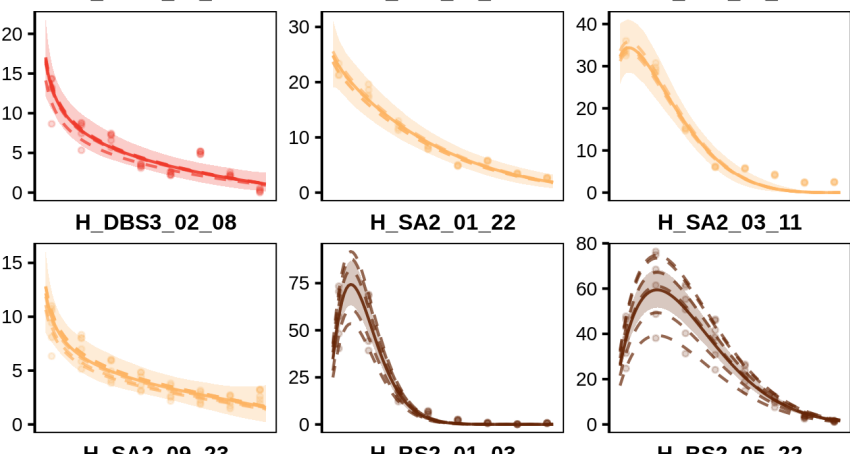

H_SA2_03_11
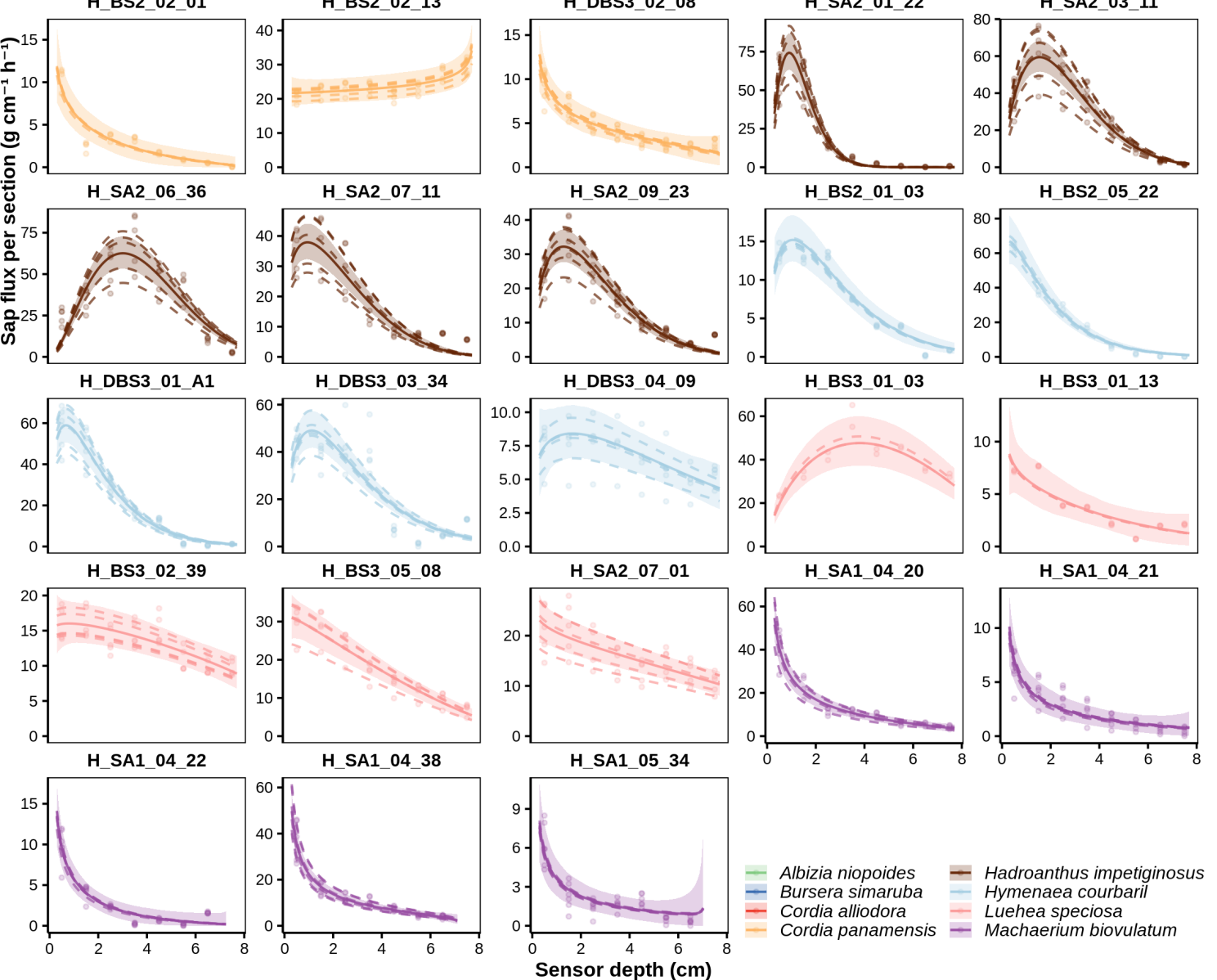

Figure B.2 Predicted radial sap flow profiles based on the full model. Shown are the observed daily averages of sap flow per section versus sensor depth overlayed with the day-level (dashed lines) and average day predictions (solid lines) for all stems with the $95 \%$ credible intervals for the average predictions. Colors indicate the different species. 

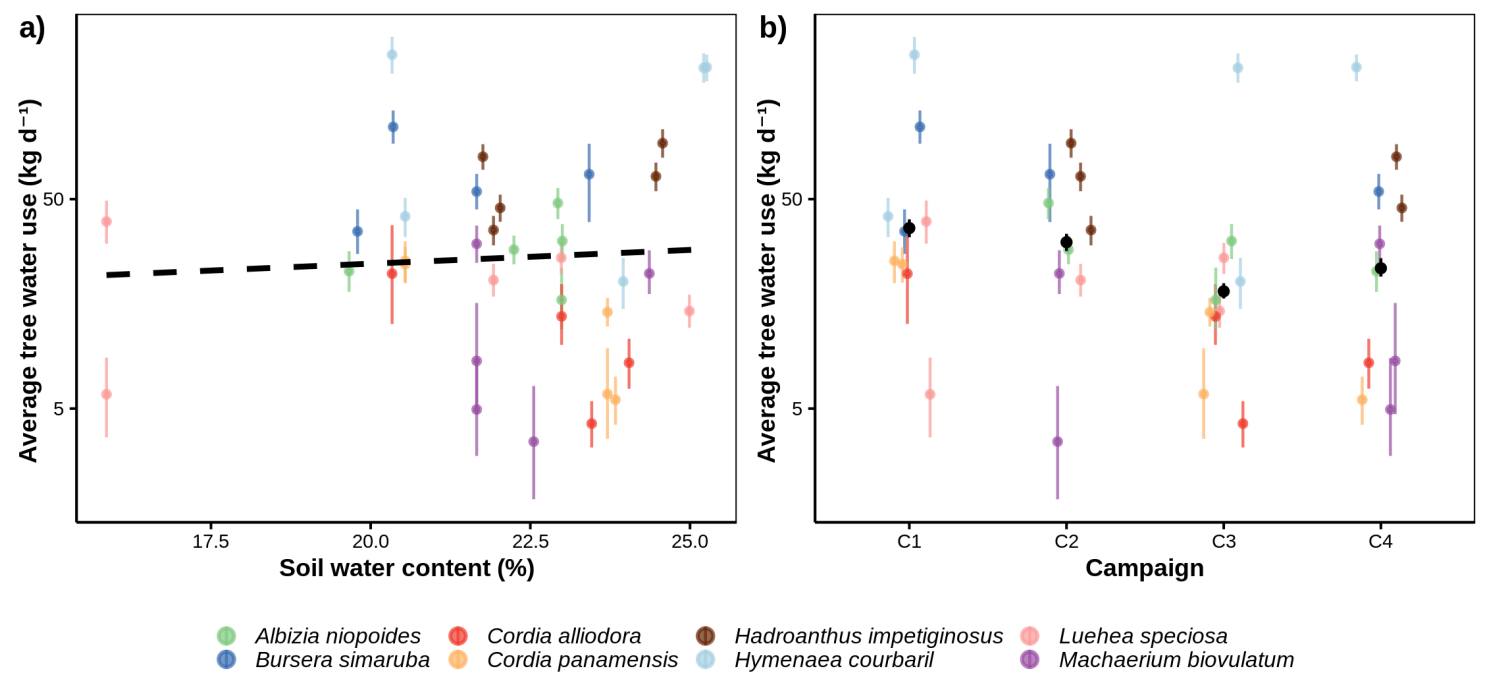

Figure B.3 Posterior mean $\pm 95 \%$ credible interval estimated sap flux density averaged over the estimated 'sap wood depth' (i.e. the outermost $90 \%$ quantile of the radial profile) on a $\log 10$ scale vs. a) soil water content and b) measurement campaign. Regression lines in a) from linear regression through the posterior mean predictions.

\section{Supplementary material C: Data package and model code on Github}

https://github.com/r-link/Link_et_al_2020_supplementary_material_C (repository kept in private mode until publication)

\section{References}

Alfaro, E. A., A. Alvarado, and A. Chaverri (2001). "Cambios edáficos asociados a tres etapas sucesionales de bosque tropical seco en Guanacaste, Costa Rica". In: Agronomía Costarricense 25.1, pp. 7-19.

Allen, R. G., L. S. Pereira, D. Raes, and M. Smith (1998). Crop Evapotranspiration: Guidelines for Computing Crop Water Requirements. Tech. rep. Rome: FAO, p. 300.

Bates, D., M. Mächler, B. Bolker, and S. Walker (2015). "Fitting Linear Mixed-Effects Models Using lme4". In: Journal of Statistical Software 67.1, pp. 1-48.

Berdanier, A. B., C. F. Miniat, and J. S. Clark (2016). "Predictive models for radial sap flux variation in coniferous, diffuse-porous and ring-porous temperate trees". In: Tree Physiology 36.8. Ed. by N. Phillips, pp. 932-941. URL: https://academic.oup.com/ treephys/article-lookup/doi/10.1093/treephys/tpw027. 
Betancourt, M. and M. Girolami (2015). "Hamiltonian Monte Carlo for hierarchical models". In: Current Trends in Bayesian Methodology with Applications. Ed. by S. Kumar Upadhyay, U. Singh, D. K. Dey, and A. Loganathan. Vol. 79. Boca Raton, FL: Chapman and Hall/CRC Press, p. 30.

Burgess, S. S. O., M. A. Adams, N. C. Turner, C. R. Beverly, C. K. Ong, A. A. H. Khan, and T. M. Bleby (2001). "An improved heat pulse method to measure low and reverse rates of sap flow in woody plants". In: Tree Physiology 21.9, pp. 589-598. URL: https://academic.oup.com/treephys/article-lookup/doi/10.1093/treephys/21.9.589.

Carpenter, B., A. Gelman, M. D. Hoffman, D. Lee, B. Goodrich, et al. (2017). "Stan : A Probabilistic Programming Language". In: Journal of Statistical Software 76.1. URL: http://www.jstatsoft.org/v76/i01/.

Caylor, K. K. and D. Dragoni (2009). "Decoupling structural and environmental determinants of sap velocity: Part I. Methodological development". In: Agricultural and Forest Meteorology 149.3-4, pp. 559-569. URL: https://linkinghub.elsevier.com/retrieve/pii/ S0168192308002803.

Čermák, J., E. Cienciala, J. Kucera, and J.-E. Hallgren (1992). "Radial velocity profiles of water flow in trunks of Norway spruce and oak and the response of spruce to severing". In: Tree Physiology 10.4, pp. 367-380. URL: https://academic.oup.com/treephys/articlelookup/doi/10.1093/treephys/10.4.367.

Čermák, J. and N. Nadezhdina (1998). "Sapwood as the scaling parameter- defining according to xylem water content or radial pattern of sap flow?" In: Annales des Sciences Forestières 55.5, pp. 509-521. URL: http:// www . afs-journal. org / 10 .1051/forest: 19980501.

Chiu, C.-W., T. Kume, H. Komatsu, H. Tseng, T.-H. Wey, and K. Otsuki (2016). "Seasonal changes of azimuthal, radial, and tree-to-tree variations in sap flux affect stand transpiration estimates in a Cryptomeria japonica forest, central Taiwan". In: Journal of Forest Research 21.4, pp. 151-160. URL: https://www.tandfonline.com/doi/full/10. 1007/s10310-016-0525-6.

Delzon, S., M. Sartore, A. Granier, and D. Loustau (2004). "Radial profiles of sap flow with increasing tree size in maritime pine". In: Tree Physiology 24.11, pp. 1285-1293. URL: https://academic.oup.com/treephys/article-lookup/doi/10.1093/treephys/24.11.1285.

Edwards, W. R. N. and R. E. Booker (1984). "Radial Variation in the Axial Conductivity of Populus and its Significance in Heat Pulse Velocity Measurement". In: Journal of Experimental Botany 35.4, pp. 551-561. URL: https://academic.oup.com/jxb/articlelookup/doi/10.1093/jxb/35.4.551.

Enquist, B. J. (2002). "Universal scaling in tree and vascular plant allometry: toward a general quantitative theory linking plant form and function from cells to ecosystems". In: Tree Physiology 22.15-16, pp. 1045-1064. URL: https://academic.oup.com/treephys/ article-lookup/doi/10.1093/treephys/22.15-16.1045.

Fan, J., A. Guyot, K. T. Ostergaard, and D. A. Lockington (2018). "Effects of earlywood and latewood on sap flux density-based transpiration estimates in conifers". In: Agricultural and Forest Meteorology 249, pp. 264-274. URL: https://linkinghub.elsevier.com/ retrieve/pii/S0168192317303799.

Ferrari, S. and F. Cribari-Neto (2004). "Beta Regression for Modelling Rates and Proportions". In: Journal of Applied Statistics 31.7, pp. 799-815. URL: http://www.tandfonline. com/doi/abs/10.1080/0266476042000214501.

Fiora, A. and A. Cescatti (2006). "Diurnal and seasonal variability in radial distribution of sap flux density: implications for estimating stand transpiration". In: Tree Physiology 
26.9, pp. 1217-1225. URL: https://academic.oup.com/treephys/article-lookup/doi/10. 1093/treephys/26.9.1217.

Ford, C. R., C. E. Goranson, R. J. Mitchell, R. E. Will, and R. O. Teskey (2004a). "Diurnal and seasonal variability in the radial distribution of sap flow: predicting total stem flow in Pinus taeda trees". In: Tree Physiology 24.9, pp. 951-960. URL: https://academic. oup.com/treephys/article-lookup/doi/10.1093/treephys/24.9.951.

Ford, C. R., M. A. McGuire, R. J. Mitchell, and R. O. Teskey (2004b). "Assessing variation in the radial profile of sap flux density in Pinus species and its effect on daily water use". In: Tree Physiology 24.3, pp. 241-249. URL: https://academic.oup.com/treephys/articlelookup/doi/10.1093/treephys/24.3.241.

Fuchs, S., C. Leuschner, R. M. Link, H. Coners, and B. Schuldt (2017). "Calibration and comparison of thermal dissipation, heat ratio and heat field deformation sap flow probes for diffuse-porous trees". In: Agricultural and Forest Meteorology 244-245, pp. 151-161. URL: https://linkinghub.elsevier.com/retrieve/pii/S0168192317301314.

Gebauer, T., V. Horna, and C. Leuschner (2008). "Variability in radial sap flux density patterns and sapwood area among seven co-occurring temperate broad-leaved tree species". In: Tree Physiology 28.12, pp. 1821-1830. URL: https://academic.oup.com/treephys/ article-lookup/doi/10.1093/treephys/28.12.1821.

Gelman, A. (2006). "Prior distributions for variance parameters in hierarchical models (comment on article by Browne and Draper)". In: Bayesian Analysis 1.3, pp. 515-534. URL: http://projecteuclid.org/euclid.ba/1340371048.

Gelman, A., J. B. Carlin, H. S. Stern, D. B. Dunson, A. Vehtari, and D. B. Rubin (2014). Bayesian data analysis. 3rd ed. Boca Raton, FL: Chapman \& Hall.

Gelman, A., B. Goodrich, J. Gabry, and A. Vehtari (2018). "R-squared for Bayesian regression models". In: The American Statistician, pp. 1-6. URL: https://www.tandfonline. com/doi/full/10.1080/00031305.2018.1549100.

Gelman, A., A. Jakulin, M. G. Pittau, and Y.-S. Su (2008). "A weakly informative default prior distribution for logistic and other regression models". In: The Annals of Applied Statistics 2.4, pp. 1360-1383. URL: http://projecteuclid.org/euclid.aoas/1231424214.

Gelman, A. and C. R. Shalizi (2013). "Philosophy and the practice of Bayesian statistics". In: British Journal of Mathematical and Statistical Psychology 66.1, pp. 8-38. URL: http://doi.wiley.com/10.1111/j.2044-8317.2011.02037.x.

Granier, A. (1985). "Une nouvelle méthode pour la mesure du flux de sève brute dans le tronc des arbres". In: Annales des Sciences Forestières 42.2, pp. 193-200. URL: http: //www.afs-journal.org/10.1051/forest:19850204.

Guyot, A., K. T. Ostergaard, J. Fan, N. S. Santini, and D. A. Lockington (2015). "Xylem hydraulic properties in subtropical coniferous trees influence radial patterns of sap flow: implications for whole tree transpiration estimates using sap flow sensors". In: Trees 29.4, pp. 961-972. URL: http://link.springer.com/10.1007/s00468-014-1144-5.

Hatton, T. J., S. J. Moore, and P. H. Reece (1995). "Estimating stand transpiration in a Eucalyptus populnea woodland with the heat pulse method: measurement errors and sampling strategies". In: Tree Physiology 15.4, pp. 219-227. URL: https://academic.oup. com/treephys/article-lookup/doi/10.1093/treephys/15.4.219.

Hernandez-Santana, V., J. Fernández, C. Rodriguez-Dominguez, R. Romero, and A. DiazEspejo (2016). "The dynamics of radial sap flux density reflects changes in stomatal conductance in response to soil and air water deficit". In: Agricultural and Forest Meteorology 218-219, pp. 92-101. URL: https:/ / linkinghub. elsevier.com/retrieve / pii / S0168192315007649. 
Hoffman, M. D. and A. Gelman (2014). "The No-U-Turn Sampler: Adaptively Setting Path Lengths in Hamiltonian Monte Carlo". In: Journal of Machine Learning Research 15.1 , pp. $1593-1623$.

Horna, V., B. Schuldt, S. Brix, and C. Leuschner (2011). "Environment and tree size controlling stem sap flux in a perhumid tropical forest of Central Sulawesi, Indonesia". In: Annals of Forest Science 68.5, pp. 1027-1038. URL: http://link.springer.com/10. 1007/s13595-011-0110-2.

Instituto Meteorológico de Costa Rica (2015). Boletin Del ENOS No. 82. URL: https: //www.imn.ac.cr/documents/10179/28160/\%5C\%23\%5C\%2082.

Kuznetsova, A., P. B. Brockhoff, and R. H. B. Christensen (2017). "lmerTest Package: Tests in Linear Mixed Effects Models". In: Journal of Statistical Software 82.13, pp. 126.

Lewandowski, D., D. Kurowicka, and H. Joe (2009). "Generating random correlation matrices based on vines and extended onion method". In: Journal of Multivariate Analysis 100.9, pp. 1989-2001.

Marshall, D. C. (1958). "Measurement of Sap Flow in Conifers by Heat Transport". In: Plant Physiology 33.6, pp. 385-396. URL: https://www.ncbi.nlm.nih.gov/pmc/articles/ PMC541111/.

Meinzer, F. C., B. J. Bond, J. M. Warren, and D. R. Woodruff (2005). "Does water transport scale universally with tree size?" In: Functional Ecology 19.4, pp. 558-565. URL: http://doi.wiley.com/10.1111/j.1365-2435.2005.01017.x.

Meinzer, F. C., M. J. Clearwater, and G. Goldstein (2001b). "Water transport in trees: current perspectives, new insights and some controversies". In: Environmental and Experimental Botany 45.3, pp. 239-262. URL: https://linkinghub.elsevier.com/retrieve/ pii/S0098847201000740.

Miller, D. R., C. A. Vavrina, and T. W. Christensen (1980). "Measurement of Sap Flow and Transpiration in Ring-porous Oaks Using a Heat Puise Velocity Technique". In: Forest Science 26.3, pp. 485-494. URL: https://academic.oup.com/forestscience/article/ 26/3/485/4788710.

Molina, A. J., X. Aranda, G. Carta, P. Llorens, R. Romero, R. Savé, and C. Biel (2016). "Effect of irrigation on sap flux density variability and water use estimate in cherry (Prunus avium) for timber production: Azimuthal profile, radial profile and sapwood estimation". In: Agricultural Water Management. Enhancing plant water use efficiency to meet future food production 164, pp. 118-126. URL: http://www.sciencedirect.com/ science/article/pii/S0378377415300834.

Nadezhdina, N. (2018). "Revisiting the Heat Field Deformation (HFD) method for measuring sap flow". In: iForest - Biogeosciences and Forestry 11.1, pp. 118-130. URL: http: //www.sisef.it/iforest/?doi=ifor2381-011.

Nadezhdina, N., J. Čermák, and R. Ceulemans (2002). "Radial patterns of sap flow in woody stems of dominant and understory species: scaling errors associated with positioning of sensors". In: Tree Physiology 22.13, pp. 907-918. URL: https://academic.oup. com/treephys/article-lookup/doi/10.1093/treephys/22.13.907.

Nadezhdina, N., J. Čermák, and V. Nadezhdin (1998). "Heat field deformation method for sap flow measurements". In: Measuring sap flow in intact plants. Proceedings of 4th International Workshop, Židlochovice, Czech Republic, IUFRO Publ. Brno, Czech Republic: Mendel University, pp. 72-92.

Nadezhdina, N., V. Nadezhdin, M. I. Ferreira, and A. Pitacco (2007). "Variability with xylem depth in sap flow in trunks and branches of mature olive trees". In: Tree Physiology 
27.1, pp. 105-113. URL: https://academic.oup.com/treephys/article-lookup/doi/10. 1093/treephys/27.1.105.

Nadezhdina, N., A. Al-Okaishi, and P. Madera (2018). "Sap Flow Measurements in a Socotra Dragon's Blood Tree (Dracaena cinnabari) in its Area of Origin". In: Tropical Plant Biology 11.3-4, pp. 107-118. URL: http://link.springer.com/10.1007/s12042-0189204-4.

Nadezhdina, N., M. W. Vandegehuchte, and K. Steppe (2012). "Sap flux density measurements based on the heat field deformation method". In: Trees 26.5, pp. 1439-1448. URL: http://link.springer.com/10.1007/s00468-012-0718-3.

Nakagawa, S. and H. Schielzeth (2013). "A general and simple method for obtaining $R^{2}$ from generalized linear mixed-effects models". In: Methods in Ecology and Evolution 4.2. Ed. by R. B. O'Hara, pp. 133-142. URL: http://doi.wiley.com/10.1111/j.2041210x.2012.00261.x.

Oishi, A. C., R. Oren, and P. C. Stoy (2008). "Estimating components of forest evapotranspiration: A footprint approach for scaling sap flux measurements". In: Agricultural and Forest Meteorology 148.11, pp. 1719-1732. URL: https://linkinghub.elsevier.com/ retrieve/pii/S0168192308001810.

Olson, M. E., D. Soriano, J. A. Rosell, T. Anfodillo, M. J. Donoghue, et al. (2018). "Plant height and hydraulic vulnerability to drought and cold". In: Proceedings of the National Academy of Sciences 115.29, pp. 7551-7556. URL: http://www.pnas.org/lookup/doi/ $10.1073 /$ pnas.1721728115.

Pinheiro, J., D. Bates, S. DebRoy, D. Sarkar, and R Core Team (2017). nlme: Linear and nonlinear mixed effects models. URL: https://CRAN.R-project.org/package=nlme.

Pinto, C. A., N. Nadezhdina, J. S. David, C. Kurz-Besson, M. C. Caldeira, et al. (2014). "Transpiration in Quercus suber trees under shallow water table conditions: the role of soil and groundwater". In: Hydrological Processes 28.25, pp. 6067-6079. URL: http: //doi.wiley.com/10.1002/hyp.10097.

Poyatos, R., J. Cermak, and P. Llorens (2007). "Variation in the radial patterns of sap flux density in pubescent oak (Quercus pubescens) and its implications for tree and stand transpiration measurements". In: Tree Physiology 27.4, pp. 537-548. uRL: https: //academic.oup.com/treephys/article-lookup/doi/10.1093/treephys/27.4.537.

R Core Team (2018). R: A Language and Environment for Statistical Computing. Vienna, Austria: R Foundation for Statistical Computing. URL: https://www.R-project.org/.

- (2019). R: A Language and Environment for Statistical Computing. Vienna, Austria: R Foundation for Statistical Computing. URL: https://www.R-project.org/.

Reyes Cordero, D. (2012). "Análisis de los procesos de restauración pasiva para un bosque seco tropical en la Estación Experimental Forestal Horizontes, Guanacaste, Costa Rica". Thesis. URL: http://copa.acguanacaste.ac.cr:8080/handle/11606/887.

Reyes-Acosta, J. L. and M. W. Lubczynski (2013). "Mapping dry-season tree transpiration of an oak woodland at the catchment scale, using object-attributes derived from satellite imagery and sap flow measurements". In: Agricultural and Forest Meteorology 174-175, pp. 184-201. URL: https://linkinghub.elsevier.com/retrieve/pii/S0168192313000403.

- (2014). "Optimization of dry-season sap flow measurements in an oak semi-arid open woodland in Spain". In: Ecohydrology 7.2, pp. 258-277. URL: http://doi.wiley.com/10. 1002/eco.1339.

Reyes-García, C., J. L. Andrade, J. L. Simá, R. Us-Santamaría, and P. C. Jackson (2012). "Sapwood to heartwood ratio affects whole-tree water use in dry forest legume and nonlegume trees". In: Trees 26.4, pp. 1317-1330. URL: http://link.springer.com/10.1007/ s00468-012-0708-5. 
Ryan, M. G., N. Phillips, and B. J. Bond (2006). "The hydraulic limitation hypothesis revisited". In: Plant, Cell and Environment 29.3, pp. 367-381. URL: http://doi.wiley. com/10.1111/j.1365-3040.2005.01478.x.

Ryan, M. G. and B. J. Yoder (1997). "Hydraulic Limits to Tree Height and Tree Growth". In: BioScience 47.4, pp. 235-242. URL: https://www.jstor.org/stable/1313077.

Schlesinger, W. H. and S. Jasechko (2014). "Transpiration in the global water cycle". In: Agricultural and Forest Meteorology 189-190, pp. 115-117. URL: https://linkinghub. elsevier.com/retrieve/pii/S0168192314000203.

Schuldt, B., C. Leuschner, V. Horna, G. Moser, M. Köhler, O. van Straaten, and H. Barus (2011). "Change in hydraulic properties and leaf traits in a tall rainforest tree species subjected to long-term throughfall exclusion in the perhumid tropics". In: Biogeosciences 8.8, pp. 2179-2194. URL: http://www.biogeosciences.net/8/2179/2011/.

Spicer, R. and B. Gartner (2001). "The effects of cambial age and position within the stem on specific conductivity in Douglas-fir (Pseudotsuga menziesii) sapwood". In: Trees 15.4, pp. 222-229. URL: http://link.springer.com/10.1007/s004680100093.

Stan Development Team (2017). Stan modeling language users guide and reference manual, version 2.17.0. URL: http://mc-stan.org.

- (2018). "RStan: the R interface to Stan". In: URL: http://mc-stan.org/.

Steppe, K., D. J. De Pauw, T. M. Doody, and R. O. Teskey (2010). "A comparison of sap flux density using thermal dissipation, heat pulse velocity and heat field deformation methods". In: Agricultural and Forest Meteorology 150.7-8, pp. 1046-1056. URL: https: //linkinghub.elsevier.com/retrieve/pii/S0168192310001000.

Vandegehuchte, M. W. and K. Steppe (2012c). "Interpreting the Heat Field Deformation method: Erroneous use of thermal diffusivity and improved correlation between temperature ratio and sap flux density". In: Agricultural and Forest Meteorology 162-163, pp. 91-97. URL: https://linkinghub.elsevier.com/retrieve/pii/S0168192312001438.

Wang, K. and R. E. Dickinson (2012). "A review of global terrestrial evapotranspiration: Observation, modeling, climatology, and climatic variability". In: Reviews of Geophysics 50.2. URL: http://doi.wiley.com/10.1029/2011RG000373.

Werden, L. K., B. G. Waring, C. M. Smith-Martin, and J. S. Powers (2018b). "Tropical dry forest trees and lianas differ in leaf economic spectrum traits but have overlapping water-use strategies". In: Tree Physiology 38.4, pp. 517-530. URL: https://academic.oup. com/treephys/article/38/4/517/4566185.

West, G. B., J. H. Brown, and B. J. Enquist (1999). "A general model for the structure and allometry of plant vascular systems". In: Nature 400.6745, pp. 664-667. URL: http: //www.nature.com/articles/23251.

Wilson, K. B., P. J. Hanson, P. J. Mulholland, D. D. Baldocchi, and S. D. Wullschleger (2001). "A comparison of methods for determining forest evapotranspiration and its components: sap-flow, soil water budget, eddy covariance and catchment water balance". In: Agricultural and Forest Meteorology 106.2, pp. 153-168. URL: https://linkinghub. elsevier.com/retrieve/pii/S0168192300001994.

Zhang, J.-G., Q.-Y. He, W.-Y. Shi, K. Otsuki, N. Yamanaka, and S. Du (2015). "Radial variations in xylem sap flow and their effect on whole-tree water use estimates". In: Hydrological Processes 29.24, pp. 4993-5002. URL: http://doi.wiley.com/10.1002/hyp. 10465.

Zhang, Z., P. Zhao, X. Zhao, J. Zhou, P. Zhao, X. Zeng, Y. Hu, and L. Ouyang (2018). "The tree height-related spatial variances of tree sap flux density and its scale-up to stand transpiration in a subtropical evergreen broadleaf forest: spatial variances of tree 
sap flux density and its scale-up". In: Ecohydrology 11.7, e1979. URL: http://doi.wiley. com/10.1002/eco.1979.

Zhao, H., S. Yang, X. Guo, C. Peng, X. Gu, C. Deng, and L. Chen (2018). "Anatomical explanations for acute depressions in radial pattern of axial sap flow in two diffuseporous mangrove species: implications for water use". In: Tree Physiology 38.2, pp. 276286. URL: https://academic.oup.com/treephys/article/38/2/276/4811927. 

Part II: Effect of functional and structural traits on growth and water relations 



\title{
5 Disentangling the functional drivers of water use and productivity in tropical rainforest trees
}

\author{
Martyna M. Kotowska ${ }^{1, *}$, Roman M. Link ${ }^{1,2,{ }^{*}}$, Alexander Röll ${ }^{3}$, Dietrich \\ Hertel $^{1}$, Dirk Hölscher ${ }^{3}$, Pierre-André Waite ${ }^{1}$, Gerald Moser ${ }^{4}$, Aiyen Tjoa ${ }^{5}$, \\ Christoph Leuschner ${ }^{1}$, Bernhard Schuldt ${ }^{1,2}$ \\ ${ }^{1}$ Plant Ecology and Ecosystems Research, Albrecht von Haller Institute for Plant Sciences, \\ University of Goettingen, Untere Karspüle 2, 37073 Göttingen, Germany \\ ${ }^{2}$ Chair of Ecophysiology and Vegetation Ecology, Julius-von-Sachs-Institute of Biological \\ Sciences, University of Würzburg, Julius-von-Sachs-Platz 3, 97082 Würzburg, Germany \\ 3 Tropical Silviculture and Forest Ecology, University of Goettingen, Büsgenweg 1, 37077 \\ Göttingen, Germany \\ 4 Plant Ecology, Justus Liebig University of Giessen, Heinrich-Buff-Ring 26, 35392 \\ Giessen, Germany \\ 5 Department of Agrotechnology, Faculty of Agricultural Sciences, Tadulako University, \\ Palu, Sulawesi Tengah, Indonesia \\ * First and second author contributed equally to this work
}

\subsection{Abstract}

1. The efficiency of the water transport system in plants sets physical limits to their productivity and water use. Although the coordination of carbon accumulation and hydraulic functions has long been documented, the mutual interrelationships between wood anatomy, tree water use, stem growth and tree size have to date not been jointly addressed in comprehensive field studies.

2. Based on observational data from 99 Indonesian rainforest tree species belonging to 37 families, we analysed how wood anatomy and sap flux density relate to tree size and wood density $(W D)$, and tested their combined influence on aboveground net primary productivity $(N P P)$ and daily water use $(D W U)$. Results from simple pairwise correlations were compared to the outcome of a structural equation model (SEM).

3. Across species, we found a strong positive correlation between $N P P$ and $D W U$. In addition, wood anatomical traits were more closely related to plant performance than $W D$, with positive associations between vessel diameter and $N P P, D W U$ and sap flux density. According to our SEM, the correlation between growth and water use was fully explained by their common relationship with tree size and sap flux density: tree species grew faster and had a higher $D W U$ if they were larger and able 
to achieve higher sap flux densities. Sap flux density, in turn, was higher for species with light and hydraulically efficient wood. Notably, after controlling for tree size only a relatively small indirect effect of wood properties on growth and water use remained that was mediated by sap flux density.

4. Synthesis: While we confirm that wood hydraulic traits are mechanistically linked to water use and productivity via their influence on sap flow, large parts of these commonly observed positive relationships can be attributed to confounding tree size effects. This emphasizes the importance of accounting for size effects to avoid erroneous interpretations of the relationship between plant traits. Our results further highlight the need to preserve tall tree species due to their fundamental role for carbon sequestration and the water cycle of tropical forests.

Keywords: functional traits, growth rate, hydraulic efficiency, net primary production, sap flux density, structural equation modelling, wood anatomy

Manuscript submitted to Functional Ecology

\subsection{Introduction}

Water availability is probably the single most important determant of tree size and productivity on a global scale (Moles et al. 2009; Šímová et al. 2019). Evolving an efficient vascular system designed for long-distance water transport allows trees to place their carbon assimilating foliage high above the ground (Sperry 2003), thereby gaining a competitive advantage over shorter neighbours in the competition for light. The absence of frost and extended dry periods in tropical rainforest climates with their usually ample water supply has spurred the race to reach advantageous canopy positions. The reduced selection for a 'safe' xylem in perennially wet climates allowed for the development of highly conductive vascular systems (Maherali et al. 2004; Mencuccini et al. 2015). To enable a sufficiently high water supply to the canopy, the stem wood of tall and productive tropical trees is commonly composed of wide xylem vessels that provide the necessary high flow rates (Poorter et al. 2010; Schuldt et al. 2013; Hietz et al. 2016). Nonetheless, trees cannot escape the inevitable link between carbon assimilation and transpirative water loss (Brodribb et al. 2002; Santiago et al. 2004; Brodribb 2009) Sufficient water supply needs to be secured over the entire length of the flow path, which ultimately limits the height growth potential (Koch et al. 2004; Liu et al. 2019). Although the coordination of productivity and hydraulic functioning has long been recognized, the precise role of xylem vascular anatomy for the efficiency of the water transport system, tree water use and stem growth rate is hard to express in quantitative terms and the underlying causal links remain often unresolved (Hoeber et al. 2014). Nevertheless, the approach to use easy-to measure plant functional traits for characterizing the hydraulic architecture of tropical trees and for understanding the coexistence and performance of tree species communities is increasingly popular (Poorter et al. 2018; McDowell et al. 2019).

In ecosystems with ample soil water supply and low atmospheric evaporative demand, the capacity to transport water efficiently to the canopy is most likely a key factor limiting plant growth performance. Consequently, physiological traits related to soil water access and water transport correlate positively with productivity (Tyree 2003; Hajek et al. 2014; Smith and Sperry 2014; Kotowska et al. 2015). Next to wood properties that determine hydraulic efficiency, wood density $(W D)$ is another widely used property that might be indicative of the growth performance of trees (King et al. 2006; Chave et al. 2009; Poorter 
et al. 2010; Hoeber et al. 2014) and of water use dynamics (Bucci et al. 2004). Fast-growing pioneer tree species tend to have lower wood densities than slower-growing species from later successional stages, with consequences for their wood anatomical structure and water transport properties (Apgaua et al. 2015; Eller et al. 2018). However, in evergreen tropical rainforests, several studies found wood density to vary largely independently of hydraulic traits (Baraloto et al. 2010; McCulloh et al. 2010; Fan et al. 2012; Schuldt et al. 2013; Kotowska et al. 2015), putting into question the predictive value of wood density.

Wood density, vessel diameter and hydraulic conductivity are increasingly used traits in dynamic vegetation models aiming to predict plant growth as well as demographic rates across a broad range of environments (Powell et al. 2013; Anderegg 2015; Maréchaux et al. 2015; Rowland et al. 2015b; Powell et al. 2017; Griffin-Nolan et al. 2018). Yet, it is still a matter of debate as to whether and to what extent hydraulic traits and wood properties represent suitable proxies for characterizing carbon and water fluxes in trees in the absence of water limitation (Zanne et al. 2010; Fortunel et al. 2014). Studies that simultaneously measured wood density, hydraulic anatomy, tree water use, and aboveground productivity in species-rich tropical rainforests trees are virtually absent, but are essential to achieve a more functional understanding of carbon assimilation and growth in trees.

Based on a dataset of 99 tropical tree species from lowland and pre-montane rainforests in Sumatra and Sulawesi (Indonesia), we studied important tree structural and functional properties (tree height, stem diameter, wood density), aboveground net primary productivity, wood anatomical and derived hydraulic traits, sap flux density, and daily water use on a tree basis. We chose a structural equation modelling approach to analyse a multivariate dataset of species-level trait aggregates of traits related to wood properties, tree size, productivity, and water use (cf. Figure 5.1). We tested the hypotheses that (i) wood anatomical traits are more closely related to tree productivity and water use than is wood density, (ii) faster growing tree species have a higher water use, and (iii) a more efficient xylem allows for higher sap flux rates and thus higher water use and productivity at a given average tree size.

\subsection{Materials and methods}

\subsubsection{Study sites}

This study investigates stem sap flux, wood anatomy and stem radial growth rates of 99 tropical tree species from 37 families using measurements from 265 tree individual trees (Table S1), combining data from two long-term studies in plot networks on th Indonesian islands Sumatra and Sulawesi. Structural variables (wood density, tree diameter, tree height) were recorded from every tree individual, while wood anatomy was measured on 238, sap flux density on 178, and biomass increment on 152 tree individuals, respectively (see Table 5.1 for details). All individuals were mature trees with $\mathrm{DBH} 10 \mathrm{~cm}$. On Sumatra, sampled trees were randomly chosen in equal proportions from dominant and co-dominant trees grouped in three tree size classes: larger $(\mathrm{DBH}>50 \mathrm{~cm})$, medium $(50-25 \mathrm{~cm})$ and smaller diameter $(10-25 \mathrm{~cm})$. On Sulawesi, measurements were performed on 15 species from dominant families chosen to represent slow-growing mid-story species as well as fast-growing upper canopy species, both from late stages of forest succession.

On the island of Sumatra, the field measurements were conducted in sixteen lowland rainforest sites in Jambi province $\left(01^{\circ} 47^{\prime}-02^{\circ} 09^{\prime} \mathrm{S}, 102^{\circ} 34^{\prime}-103^{\circ} 20^{\prime} \mathrm{E}\right.$; $80 \mathrm{~m}$ a.s.l.), 

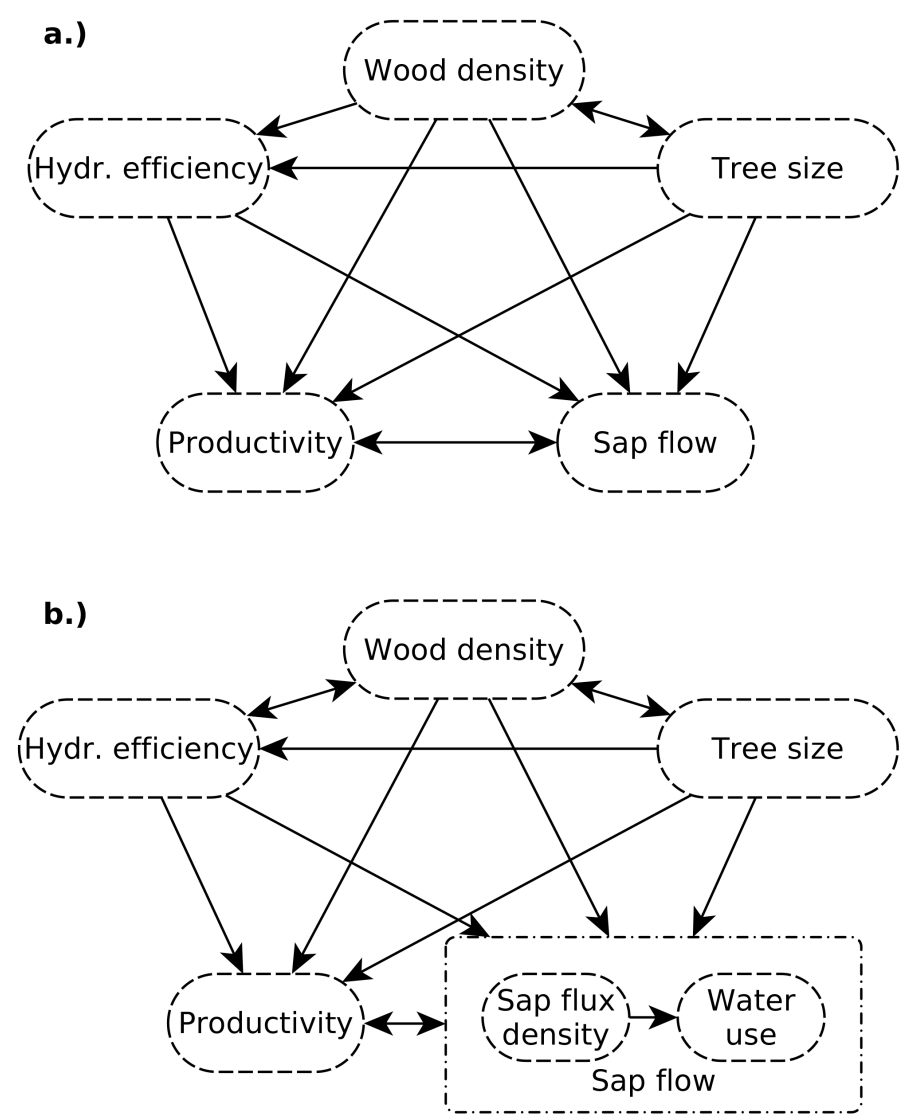

Figure 5.1: a) Initial and b) revised meta-model of the causal relations amongst structural characteristics and hydraulic traits, water use and productivity. Correlative relationships are indicated by double-headed arrows, while functional relationships are indicated by single-headed arrows.

Table 5.1: List of selected tree traits for the Sumatra and Sulawesi samples. Given are the acronyms used in the text, measurement units, averages \pm standard deviations of the traits, observation counts $\left(\mathrm{n}_{\mathrm{ob}}\right)$ and species numbers $\left(\mathrm{n}_{\mathrm{sp}}\right)$.

\begin{tabular}{|c|c|c|c|c|c|c|c|c|c|}
\hline \multirow[b]{2}{*}{ Variable } & \multirow[b]{2}{*}{ Acr. } & \multirow[b]{2}{*}{ Unit } & \multicolumn{2}{|c|}{ Sumatra } & \multicolumn{2}{|c|}{ Sulawesi } & \multicolumn{3}{|l|}{ Total } \\
\hline & & & mean \pm SD & $\mathbf{n}_{\mathrm{ob}} \mathbf{n}_{\mathrm{sp}}$ & mean \pm SD & $\mathbf{n}_{\mathrm{ob}} \mathbf{n}_{\mathrm{sp}}$ & mean \pm SD & $\mathbf{n}_{\mathbf{o b}}$ & $\mathbf{n}_{\mathrm{sp}}$ \\
\hline $\begin{array}{l}\text { Diameter at breast } \\
\text { height }\end{array}$ & $d b h$ & $\mathrm{~cm}$ & $36.82 \pm 19.77$ & 15184 & $29.22 \pm 18.61$ & 11415 & $33.55 \pm 19.61$ & 265 & 99 \\
\hline Tree height & $h$ & $\mathrm{~m}$ & $24.96 \pm 9.02$ & 15184 & $25.20 \pm 9.26$ & 11415 & $25.06 \pm 9.10$ & 265 & 99 \\
\hline Wood density & $W D$ & $\mathrm{~g} \mathrm{~cm}^{-3}$ & $0.54 \pm 0.11$ & 15184 & $0.45 \pm 0.10$ & 11315 & $0.50 \pm 0.12$ & 264 & 99 \\
\hline $\begin{array}{l}\text { Aboveground net } \\
\text { primary productivity }\end{array}$ & $N P P$ & $\mathrm{~kg} \mathrm{a}^{-1}$ & $26.24 \pm 22.68$ & 11971 & $50.37 \pm 60.85$ & 338 & $31.48 \pm 35.86$ & 152 & 79 \\
\hline Tree daily water use & $D W U$ & $\mathrm{~kg} \mathrm{~d}^{-1}$ & $30.90 \pm 53.78$ & 8857 & $26.94 \pm 45.13$ & 9015 & $28.90 \pm 49.49$ & 178 & 72 \\
\hline $\begin{array}{l}\text { Average sap flux } \\
\text { density }\end{array}$ & $J_{\mathrm{s}}$ & $\mathrm{g} \mathrm{cm}^{-2} \mathrm{~d}^{-1}$ & $9.17 \pm 4.42$ & 8857 & $9.92 \pm 5.93$ & 9015 & $9.55 \pm 5.24$ & 178 & 72 \\
\hline $\begin{array}{l}\text { Hydraulically } \\
\text { weighted vessel } \\
\text { diameter }\end{array}$ & $d h$ & $\mu \mathrm{m}$ & $181.4 \pm 56.1$ & 13477 & $147.9 \pm 64.7$ & 10215 & $166.9 \pm 62.1$ & 236 & 92 \\
\hline Vessel density & $V D$ & $\mathrm{n} \mathrm{mm}^{-2}$ & $7.75 \pm 7.37$ & 13477 & $10.35 \pm 7.25$ & 10415 & $8.89 \pm 7.41$ & 238 & 92 \\
\hline $\begin{array}{l}\text { Potential specific } \\
\text { conductivity }\end{array}$ & $K_{\mathrm{p}}$ & $\begin{array}{l}\mathrm{kg} \mathrm{m}^{-1} \\
\mathrm{MPa}^{-1} \mathrm{~s}^{-1}\end{array}$ & $132.9 \pm 181.2$ & 13477 & $76.8 \pm 92.4$ & 10415 & $108.4 \pm 151.4$ & 238 & 92 \\
\hline
\end{tabular}


which were in a close-to-natural state but subject to logging activities in the past, or secondary forest comprising a mixture of regrown native species. In the region, average annual temperature is $27.4 \pm 1.0^{\circ} \mathrm{C}$ (data from 1991 to 2011 ; mean $\pm \mathrm{SD}$ ), and annual precipitation is $2235 \pm 385 \mathrm{~mm}$ (Drescher et al. 2016). From June to September, the occurrence of a somewhat drier season $(<120 \mathrm{~mm}$ monthly precipitation) is possible. Soil types in the region are sandy or clayey Acrisols (Allen et al. 2015). These study sites were part of EFForTS, a large collaborative research project on the ecological and socioeconomic consequences of rainforest transformation (Drescher et al. 2016). On the island of Sulawesi, we used data from six study plots established in the frame of the STORMA project (see Hertel et al. 2009; Moser et al. 2014), situated in largely undisturbed old-growth rainforest at pre-montane elevation in the Pono Valley on the western boundary of Lore Lindu National Park close to Palu, Central Sulawesi province (01²9.6' S, $120^{\circ} 03.4^{\prime}$ E; $1050 \mathrm{~m}$ a.s.l.). The soils of this forest are Acrisols over metamorphic rocks. The climate is wet all around the year, with mean annual precipitation of $2700 \mathrm{~mm}$ and mean annual air temperature of $20.8{ }^{\circ} \mathrm{C}$ (Moser et al. 2014).

\subsubsection{Tree morphological characteristics}

Tree height was measured with a Vertex III height meter (Haglöf, Långsele, Sweden) and tree diameter was recorded with a diametric measuring tape at breast height $(130 \mathrm{~cm})$ or $10 \mathrm{~cm}$ above obstacles such as buttress roots. Stem increment cores with a diameter of $5.15 \mathrm{~mm}$ and a length between 4 and $7 \mathrm{~cm}$ were taken of each tree with an increment corer (Haglöf, Långsele, Sweden). Wood density $\left(W D, \mathrm{~g} \mathrm{~cm}^{-3}\right)$, defined as oven-dry weight over wet volume, was calculated for each core. The fresh volume of each sample was determined by Archimedes' principle or by using the length and diameter of the core assuming a cylindrical shape (Schüller et al. 2013). Subsequently, samples were oven-dried for $48 \mathrm{~h}$ at $105^{\circ} \mathrm{C}$ before determining their dry weight.

\subsubsection{Aboveground biomass and productivity}

Aboveground biomass was calculated with the R package BIOMASS (Réjou-Méchain et al. 2017) using the allometric equation of Chave et al. (2014) for tropical wet forests: $A G B=$ $0.0673 \times\left(W D \times D B H^{2} \times H\right)^{0.976}$, where $A G B$ is the estimated aboveground biomass $(\mathrm{kg}), D B H$ the diameter at breast height $(\mathrm{cm}), H$ total tree height $(\mathrm{m})$, and $W D$ stem wood density $\left(\mathrm{g} \mathrm{cm}^{-3}\right)$. We measured diameter increment using dendrometer tapes (UMS GmbH, München, Germany) or conducted repeated measurements with measuring tapes at marked positions on the stem. To estimate plant growth performance, we calculated aboveground woody biomass productivity (NPP; $\left.\mathrm{Mg}_{\text {tree }}{ }^{-1} \mathrm{yr}^{-1}\right)$ as the difference in tree biomass estimates (based on allometric regression models) over the measurement interval divided by the length of the measurement interval in years. Stem radial growth was monitored from 2007-2009 in Sulawesi, and from 2012-2016 in Sumatra. Additionally, all trees in the Sumatra dataset were re-measured at the previously marked position in 2017. Tree height was measured only at the beginning of the study, as we expected the measurement error to be larger than height growth in the investigation period. The most extreme $2 \%$ of values recorded for $A G B$ increment were excluded from further analysis, as they were most likely affected by measurement errors due to shifts in measurement positions on the stem. 


\subsubsection{Wood anatomical and derived hydraulic traits}

For the xylem anatomical analysis, we used the outermost $4 \mathrm{~cm}$ of the sapwood from the increment cores extracted for wood density determination. In total, 134 samples from Sumatra belonging to 80 species and 104 samples from Sulawesi belonging to 15 species were analysed. The samples were stored in $70 \%$ ethanol and stained with safranin $(1 \%$ in 50\% ethanol, Merck, Darmstadt, Germany) before sectioning. Subsequently, 10-20 $\mu \mathrm{m}$ semi-thin cross-sections were cut with a sliding microtome (G.S.L.1, WSL, Birmensdorf, Switzerland). Photographs of the sections were taken with a stereo-microscope with an automatic stage equipped with a digital camera (SteREOV20, Carl Zeiss MicroImaging GmbH, Göttingen, Gemany) at 100x magnification. Image processing was done with Adobe Photoshop CS6 (version 13.0.1, Adobe Systems Incorporated, USA) and the particle analysis-function of ImageJ v. 1.50e (Schneider et al. 2012). All vessels of a section (mean \pm SD: $64.22 \pm 25.03 \mathrm{~mm}^{2}$ ) were analysed, yielding 100 to 500 measured vessels per sample. The hydraulically weighted average vessel diameter $\left(D_{h}, \mu \mathrm{m}\right)$ was calculated from the measured vessel diameters $D_{i}$ as $D_{h}=\sum D_{i}^{5} / \sum D_{i}^{4}$ (Sperry et al. 1994). The potential hydraulic conductivity $\left(K p, \mathrm{~kg} \mathrm{~m}^{-1} \mathrm{MPa}^{-1} \mathrm{~s}^{-1}\right)$ of a wood segment was calculated based on Hagen-Poiseuille's law as $K_{p}=\left(\left(\pi \times \rho \times \sum D_{i}^{4}\right) /(128 \eta)\right) / A_{x y l e m}$, where $D_{i}$ is the diameter of each single vessel $i, \eta$ the water viscosity $(1.002 \times 10-9 \mathrm{MPa}$ s $)$ and the density of water (99), both at $20{ }^{\circ} \mathrm{C}$, and $A_{x y l e m}\left(\mathrm{~m}^{2}\right)$ the analysed sapwood area.

\subsubsection{Sap flux measurements and water use}

To derive daily tree water use rates, xylem sap flux density $\left(J_{s}, \mathrm{~g} \mathrm{~cm}^{-2} \mathrm{~h}^{-1}\right)$ was recorded with the thermal dissipation probe (TPD; Granier (1985)) technique (see Horna et al. 2011; Röll et al. 2019). Pairs of 20-mm long and 2-mm wide heating probes were inserted in northern and southern orientation into the sapwood at breast height $(1.30 \mathrm{~m})$ or above buttress roots; the upper probe was heated with a constant power of $0.2 \mathrm{~W}$ resulting in a current of $120 \mathrm{~mA}$. Subsequently, sensors were covered with reflective aluminium foil attached to isolative material and covered by plastic foil to minimize temperature gradients caused by radiation. The sensors were read by AM16/32 multiplexers connected to a CR1000 data logger (Campbell Scientific Inc., Logan, USA), and the data collected every $30 \mathrm{sec}$, averaged and logged at $10 \mathrm{~min}$ (Sumatra) or 30 min intervals (Sulawesi). Sap flux density was calculated according to the original empirical calibration coefficients given by Granier (1985) as $J_{s}=119 \times K^{1.231}$, where $K$ is a temperature constant determined as $K=\left(\Delta T_{0}-\Delta T\right) / \Delta T$, where $\Delta T_{0}$ is the maximum temperature difference at zero flux night-time conditions, and $\Delta T$ is the actual temperature difference between heated and reference probe. Although recent studies showed that the original equation parameters given by Granier (1985) might cause an underestimation of real flow (Steppe et al. 2010; Fuchs et al. 2017), they can be used to compare species with similar wood properties in relative terms.

On Sumatra, sap flux density was measured for a minimum of three weeks on eight dominant and co-dominant tree individuals, which account for the major part of stand water use on each of the 16 plots, yielding 88 stems from 58 species in total. On Sulawesi, measurements were performed on up to 14 stems of each species on the six plots, which were continuously measured from July 2007 until April 2009, yielding 90 trees in total. We standardized sap flux density by calculating the average of three representative days under similar weather conditions. Sunny conditions with a daily average vapour pressure deficit $(V P D)$ between 0.64 and $0.82 \mathrm{kPa}$ (mean $\pm \mathrm{SD}: 0.71 \pm 0.09 \mathrm{kPa}$ ) were chosen to 
obtain consistent estimates of daily mean sap flux density $\left(J_{s}, \mathrm{~g} \mathrm{~cm}^{-2} \mathrm{~d}^{-1}\right)$ for day-time hours ( 6 am to $7 \mathrm{pm})$. We chose this range for reasons of comparability because most trees had already reached their maximum flux at a $V P D$ of $0.7 \mathrm{kPa}$ (Figure S1, S2). For details on microclimatic measurements in the respective study regions (i.e. air temperature and relative air humidity), see Drescher et al. (2016) for Sumatra and Horna et al. (2011) for Sulawesi.

To calculate daily water use per tree $\left(D W U, \mathrm{~kg} \mathrm{~d}^{-1}\right), J_{s}$ was multiplied with the corresponding sapwood area $\left(A_{s}, \mathrm{~cm}^{2}\right)$. We used a subsample of 66 tree individuals belonging to 13 species covering a large range of tree height $(9.5$ to $81.0 \mathrm{~m})$ and wood density values ( 0.340 to $0.682 \mathrm{~g} \mathrm{~cm}^{-3}$ ) for estimating $A_{s}$ with dye injection to determine the maximum depth of hydraulically active xylem (Meinzer et al. 2001a). During the morning hours and before the onset of high transpiration rates, a hole was drilled with an increment corer (Haglöf, Långsele, Sweden) and a plastic tube filled with a $0.1 \%$ indigocarmin dye solution attached to the stem and sealed with modelling clay (Terostat IX, Henkel, Düsseldorf, Germany). The tube was fixed to the stem in horizontal orientation but with a slight inclination in order to avoid a pressure gradient that might actively force the dye into the sapwood, and refilled if necessary. In the afternoon, a second core was extracted $5 \mathrm{~cm}$ above the first hole, and sapwood depth measured with a calliper. The resulting measurements of sap wood depth were used to establish a relationship between the conductive sapwood area and diameter at breast height $\left(P<0.0001, r^{2}=0.75\right)$, which was used to predict the $A_{s}$ of all trees equipped with sap flux sensors according to $A_{s}=3.4794 \times \exp (0.7801 \times \exp (0.4689 \times \ln (D B H)))($ Figure S3 $)$.

\subsubsection{Statistical analyses}

All statistical analyses were performed in R v. 3.6.1 (R Core Team 2018) in the framework of the tidyverse (Wickham et al. 2019). The relationship between $D_{h}, W D$ and a series of growth-, water use and size-related traits as well as the relationship between $D W U$ and NPP were analysed using standardized major axis (SMA) regressions of species averages of those variables using $R$ package smatr v. 3.4-8 (Warton et al. 2012). As most of the variables in the dataset were strongly right-skewed, all traits except wood density were natural log-transformed prior to analysis.

The causal relationships between tree size and various plant functional traits were analysed with a structural equation modelling (SEM) approach based on the R package lavaan v. 0.6-3 (Rosseel 2012). Following Grace et al. (2012), we first developed a meta-model that reflected our a priori theoretical expectations about the relationships between wood density, wood anatomical traits and tree size, and the way these variables affect productivity and sap flow (Figure 5.1a). Initial data inspection suggested that the dataset was more accurately characterized by separating between the (area-specific) sap flux density and the (tree-specific) overall daily water use and replacing the causal link between wood density and wood anatomical properties by a correlative relationship (Figure 5.1b). We described 'hydraulic efficiency' by a latent variable measured through vessel diameter $D_{h}$, vessel density $V D$ and potential hydraulic conductivity $K_{p}$, and 'tree size' by a latent variable linked to tree height and diameter. Tree productivity, water use and sap flux density were represented by the associated variables $N P P, D W U$ and $J_{s}$, respectively, resulting in the causal diagram displayed in Figure S4.

A summary of the structural variables used in the model and wood density (average values of each trait and number of replicates per species) is given in Table S1. Before model fitting, 
all variables except wood density were natural log-transformed. Subsequently, all variables were centred and scaled to aid convergence. As the number of observations varied between species and the number of species was unevenly distributed between Sumatra and Sulawesi (Table 5.1)), we decided to work with species-level averages of the observed variables to circumvent problems related to the nested data structure and to reduce the impact of missing data. The dataset used for model fitting included species-level averages of all available data of the 265 individuals from 99 species.

The model was fit with a robust estimator with Huber-White standard errors to accommodate deviations from multivariate normality, and using full information maximum likelihood to account for pairwise missing data. We started by fitting the model described in Figure S4. Model adequacy was then evaluated by the inspection of modification indices (cf. Rosseel 2012). Model fit was assessed by the scaled $\chi^{2}$-value and its corresponding $P$-value, Root Mean Square Error of Approximation (RMSEA) and Comparative Fit Index (CFI). Subsequent inspection of modification indices suggested that an important path was missing in the initial model based on Figure S4, as this model did not account for the significant residual covariance between $V D$ and $K_{p}$. After allowing for a correlation between these variables, there was no indication for missing paths and the model no longer showed significant deviations from the observed data (model $\chi^{2}=15.65$, $d f=15$, $P=0.46)$ and achieved a high goodness of fit $(\mathrm{CFI}=0.999$, RMSEA $=0.021)$.

\subsection{Results}

\subsubsection{Unadjusted relationships with wood anatomy and wood density}

Species averages of wood anatomical and size related variables were highly correlated with sap flux density, growth and water use (Figure 5.2). Wood density $(W D)$, on the other hand, was only weakly associated with most other variables in the dataset (Figure 5.2). This is reflected in the results of the SMA regressions (Figure 5.3), which revealed a significant positive scaling relationship between hydraulically weighted vessel diameter and biomass increment $(N P P ; r=0.38, P<0.001)$, daily water use $(D W U ; r=0.56$, $P<0.001)$, sap flux density $\left(J_{s} ; r=0.38, P<0.001\right)$ and tree height $(H ; r=0.39$, $P<0.001$ ), while their relationship to $W D$ was insignificant with the exception of sap flux density $(r=-0.30, P=0.011$; cf. Figure 5.3, Table S2).

\subsubsection{Relationship between productivity and daily water use}

$N P P$ had a highly significant positive relationship with $D W U(r=0.63, P<0.001$; cf. Figure 5.2, 5.4), with a scaling coefficient of 1.271 (95\% CI 1.028 - 1.572; cf. Table S2). However, our structural equation model indicated that the strong correlation between the two variables was largely driven by their shared positive relationship with $J_{s}$ and average tree size (cf. Figure 5.2, 5.4). After accounting for the influence of these variables, no significant residual correlation remained between NPP and $D W U(r=0.145, z=1.09$, $P=0.28$; Table 5.2, Figure 5.5). 


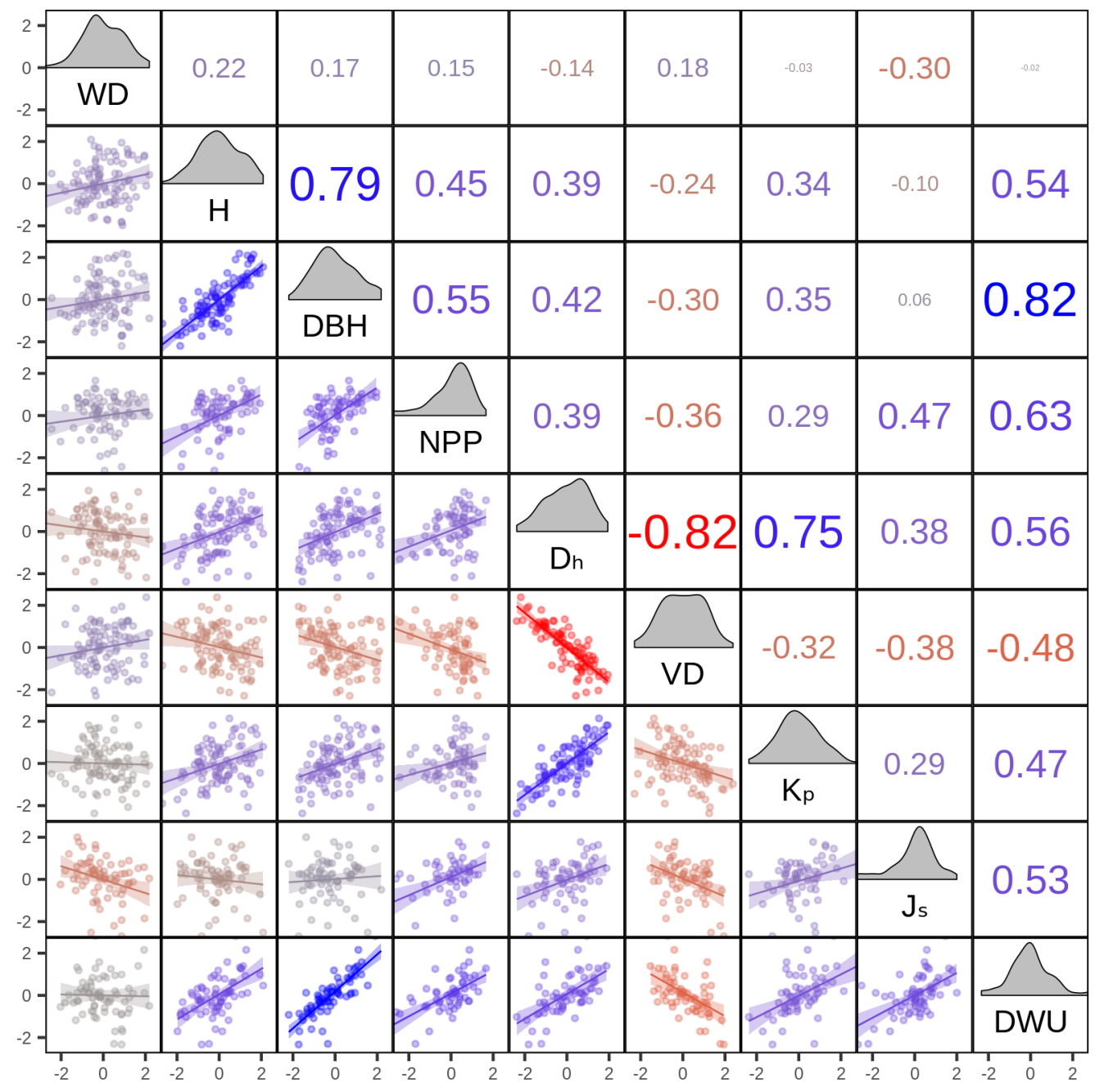

Figure 5.2: Pair-wise Pearson correlation table (upper triangle), scatterplots (lower triangle) and density plots (diagonal panels) for the transformed variables used for model fitting. Shown are the species means of the ln-transformed (with the exception of WD), scaled and centred structural characteristics and hydraulic traits for $\mathrm{n}=99$ species, including trend lines from linear regression with $95 \%$ confidence intervals. Colour and size indicate direction and strength of the correlation.

\subsubsection{Determinants of sap flux density and water use}

We found $J_{s}$ to be significantly higher for species with higher hydraulic efficiency (standardized path coefficient $0.42, z=3.21, P=0.001$; Table 5.2, Figure 5.5), and lower for species with a lower wood density $(-0.22, z=-2.08, P=0.038$; Table 5.2, Figure 5.5). While average tree size did not have a direct effect on $J_{s}$ contrary to our expectation, we found an indirect size effect mediated by hydraulic efficiency $(0.43, z=3.817, P<0.001$; Table 5.2, Figure 5.5), indicating that larger tree species had higher sap flux rates because of their significantly higher hydraulic efficiency. In either case, the low fraction of $23.8 \%$ of explained variance in $J_{s}$ (Table 5.2, Figure 5.5) shows that differences in tree size, $W D$ and wood anatomical variables only explained a small fraction of the interspecific differences in $J_{s}$.

In total, the model explained $91.9 \%$ of the variance in $D W U$ (Table 5.2, Figure 5.5). As 

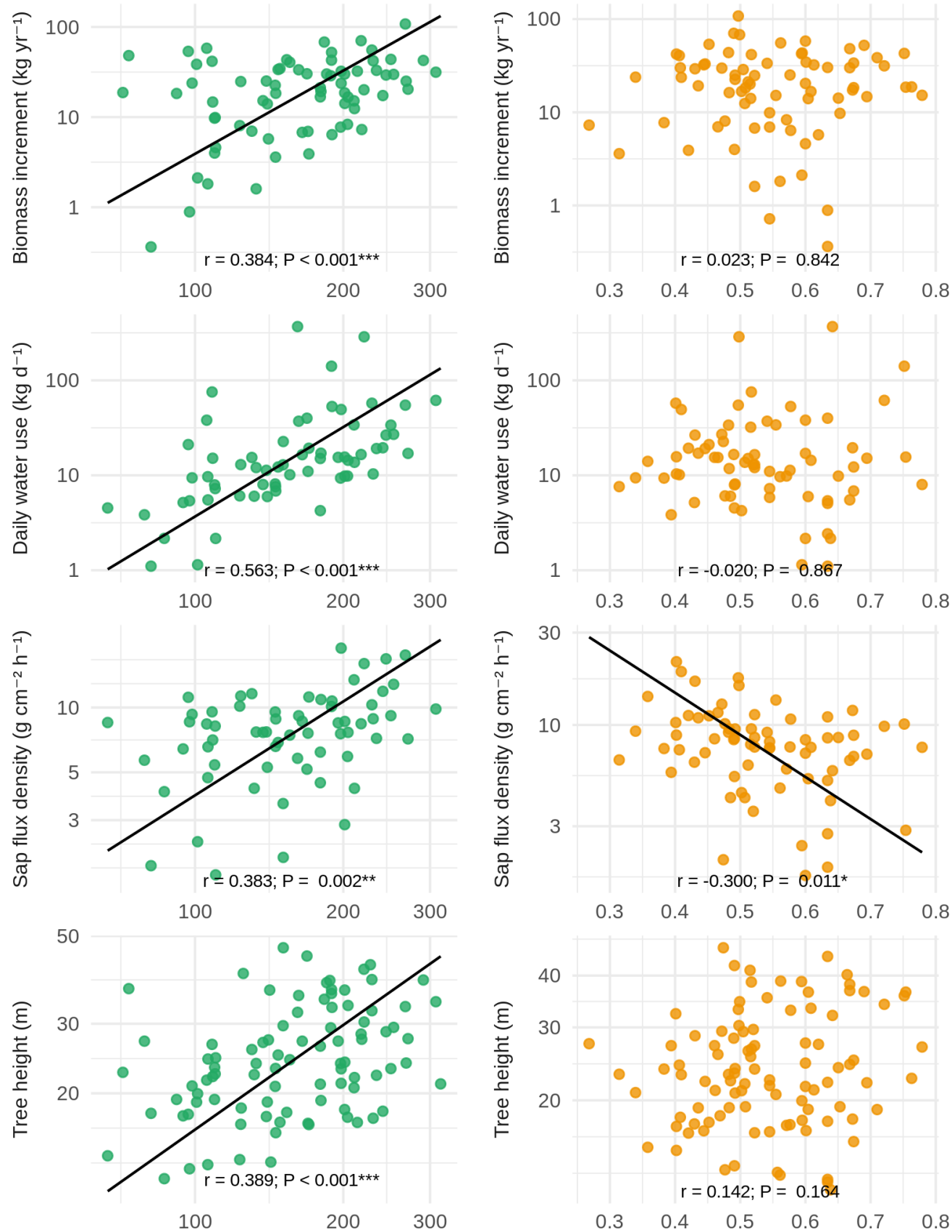

Hydraulically weighted vessel diameter $(\mu \mathrm{m})$

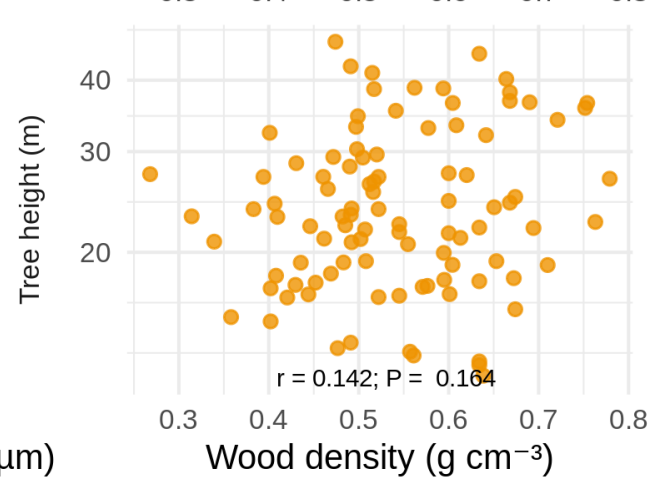

Figure 5.3: Results of standardized major axis regressions of species-level averages of biomass increment, daily water use, sap flux density, and tree height against hydraulically weighted vessel diameter and wood density.

expected, $D W U$ increased highly significantly with tree size $(0.85, z=12.64, P<0.001$; Table 5.2, Figure 5.5) and $J_{s}(0.51, z=9.943, P<0.001$; Table 5.2, Figure 5.5). After accounting for the effect of these two factors, no significant direct effect of hydraulic efficiency on $D W U$ remained, indicating that the positive association between $D W U$ and wood anatomical traits (cf. Figure 5.2, 5.4) was fully explained by their effect on $J_{s}$. However, there was a small but significant positive effect of $W D$ on $D W U(0.09, z=2.37$, $P=0.018$; Table 5.2, Figure 5.5), i.e. given the same values of $J_{s}$ and tree size, trees with 


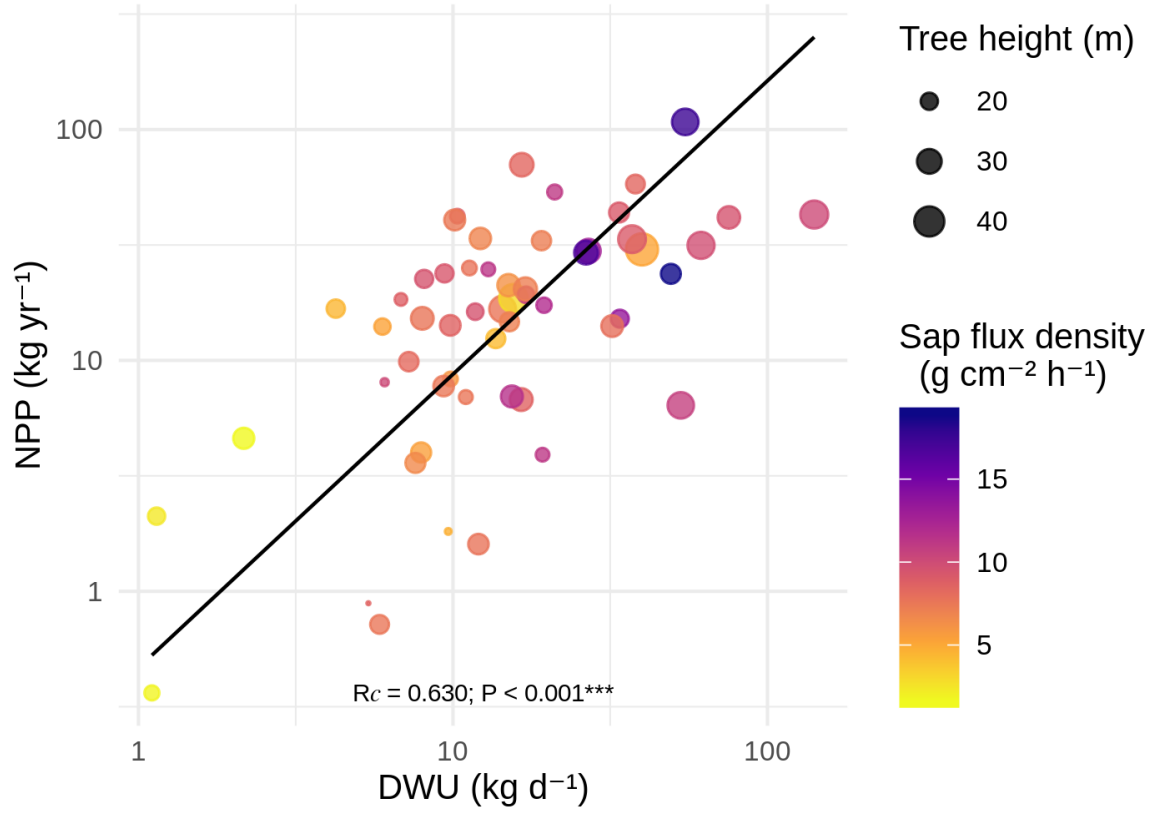

Figure 5.4: Results of standardized major axis regressions of species-level averages of biomass increment versus daily water use. Colour: average sap flux density; size: average tree height.

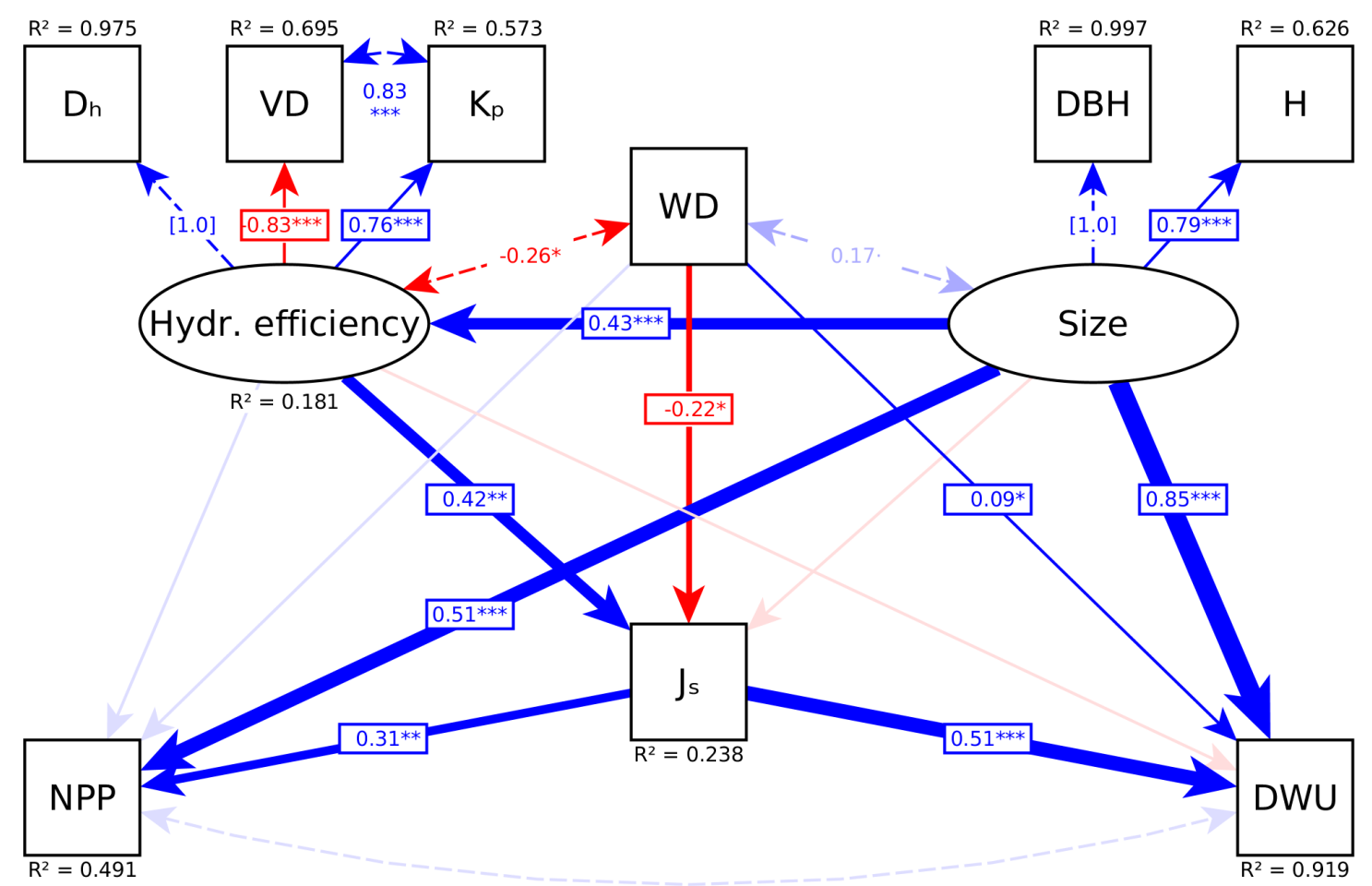

Figure 5.5: Path diagram of the final model (model $\chi^{2}=15.39, d f=15, P=0.442 ; \mathrm{CFI}=0.999$, RMSEA $=0.016)$. Shown are causal relationships with scaled path coefficients and explained variances. Positive links are displayed in blue, negative links in red and insignificant links in transparent colour. See Table 5.1) for abbreviations. 
Table 5.2: Estimated coefficients for the final structural equation model. Given are the standardized and unscaled estimates for path coefficients and variance parameters with the corresponding $z$-statistics and $P$-values for the hypothesis that the estimated coefficients are different from zero (note that one path coefficient for the coefficients of each latent variable is fixed to 1 by default to avoid identifiability issues).

\begin{tabular}{|c|c|c|c|c|c|c|}
\hline & Term & & $\begin{array}{r}\text { Standardized } \\
\text { coefficient } \\
\end{array}$ & $\begin{array}{r}\text { Unscaled } \\
\text { coefficient } \\
\end{array}$ & z value & $\mathrm{P}(>|\mathrm{z}|)$ \\
\hline \multirow[t]{12}{*}{ Path coefficients } & Hydr.Eff. & $\sim$ Size & 0.425 & 0.423 & 3.817 & $<0.001$ *** \\
\hline & $\overline{J s}$ & $\sim \mathrm{WD}$ & -0.220 & -0.220 & -2.075 & $0.038 *$ \\
\hline & & $\sim$ Size & -0.149 & -0.149 & -0.933 & 0.351 \\
\hline & & $\sim$ Hydr.Eff. & 0.424 & 0.427 & 3.211 & $0.001 * *$ \\
\hline & DWU & $\sim \mathrm{WD}$ & 0.087 & 0.089 & 2.369 & $0.018 *$ \\
\hline & & $\sim$ Size & 0.846 & 0.870 & 12.640 & $<0.001 * * *$ \\
\hline & & Hydr.Eff. & -0.054 & -0.056 & -1.408 & 0.159 \\
\hline & & $\sim \mathrm{J}_{\mathrm{S}}$ & 0.509 & 0.523 & 9.943 & $<0.001 * * *$ \\
\hline & NPP & $\sim \mathrm{WD}$ & 0.158 & 0.166 & 1.545 & 0.122 \\
\hline & & $\sim$ Size & 0.506 & 0.534 & 4.298 & $<0.001 * * *$ \\
\hline & & Hydr.Eff. & 0.150 & 0.159 & 1.485 & 0.138 \\
\hline & & $\sim$ Js & 0.314 & 0.331 & 3.009 & $0.003 * *$ \\
\hline \multirow[t]{5}{*}{ Indicator variables } & Hydr.Eff. & $=\sim \mathrm{Dh}$ & 0.988 & 1.000 & & \\
\hline & & $=\sim \mathrm{Kp}$ & 0.757 & 0.765 & 11.349 & $<0.001 * * *$ \\
\hline & & $=\sim \mathrm{VD}$ & -0.833 & -0.842 & -13.354 & $<0.001 * * *$ \\
\hline & Size & $=\sim \mathrm{DBH}$ & 0.999 & 1.000 & & \\
\hline & & $=\sim \mathrm{H}$ & 0.791 & 0.792 & 10.780 & $<0.001 * * *$ \\
\hline \multirow[t]{4}{*}{ Residual covariances } & DWU & $\sim \sim \mathrm{NPP}$ & 0.145 & 0.032 & 1.092 & 0.275 \\
\hline & $\mathrm{Kp}$ & $\sim$ VD & 0.833 & 0.300 & 5.009 & $<0.001 * * *$ \\
\hline & Hydr.Eff. & $\sim$ WD & -0.258 & -0.230 & -2.557 & $0.011 *$ \\
\hline & Size & $\sim$ WD & 0.173 & 0.171 & 1.793 & 0.073 \\
\hline \multirow[t]{10}{*}{ Variance parameters } & $\mathrm{Dh}$ & & 0.025 & 0.025 & 0.678 & 0.498 \\
\hline & $\mathrm{Kp}$ & & 0.427 & 0.426 & 4.910 & $<0.001 * * *$ \\
\hline & VD & & 0.305 & 0.305 & 4.765 & $<0.001 * * *$ \\
\hline & $\mathrm{DBH}$ & & 0.003 & 0.002 & 0.074 & 0.941 \\
\hline & $\mathrm{H}$ & & 0.374 & 0.371 & 6.815 & $<0.001 * * *$ \\
\hline & Js & & 0.762 & 0.753 & 5.845 & $<0.001 * * *$ \\
\hline & DWU & & 0.081 & 0.085 & 2.345 & $0.036 *$ \\
\hline & NPP & & 0.509 & 0.559 & 6.178 & $<0.001 * * *$ \\
\hline & Hydr.Eff. & & 0.819 & 0.801 & 6.744 & $<0.001 * * *$ \\
\hline & Size & & 1.000 & 0.987 & 7.569 & $<0.001 * * *$ \\
\hline
\end{tabular}

harder wood had a slightly higher water use.

\subsubsection{Determinants of plant productivity}

As anticipated, average tree size had a highly significant positive effect on the rate of aboveground biomass accumulation $(0.51, z=4.30, P<0.001$; Table 5.2, Figure 5.5). After accounting for this size effect, there was no evidence for direct effects of hydraulic efficiency and $W D$ on NPP. However, species of a given average size had a significantly higher NPP when they had higher sap flux densities $(0.31, z=3.01, P=0.003$; Table 5.2 , Figure 5.5), indicating that the effect of both $W D$ and wood hydraulic properties on $N P P$ was entirely mediated through their effect on $J_{s}$. Together, the predictor variables explained $49.1 \%$ of the variance in NPP (Table 5.2, Figure 5.5). 


\subsection{Discussion}

\subsubsection{Drivers of productivity-water use-relationships}

In line with our assumptions, we found aboveground productivity to be tightly positively associated with water use across a wide range of tropical tree species in this sample of Southeast Asian trees. We further show that differences in average tree size and sap flux density are sufficient to fully explain the relationship between productivity and water use: at a given average size, tree species that can achieve higher sap flux rates use more water and grow faster. In turn, sap flux density was confirmed to be significantly higher in trees that possess lighter sapwood with a higher hydraulic efficiency. This confirms the importance of an efficient vascular system as a prerequisite for high productivity and water use (cf. Tyree 2003; Brodribb 2009). Although these findings are merely supportive of previously discussed concepts, to our knowledge we are the first to demonstrate this complete pathway in a comprehensive observational dataset of both wood anatomical and empirically determined hydraulic traits of tropical rainforest species, and to combine it with growth measurements conducted for the same species.

The single most important predictor for the biomass production and water use of a tree species was its average size. This is not surprising as both carbon assimilation and transpiration directly depend on foliage area, which scales with tree mass (cf. Enquist et al. 1999; West 1999; Brown et al. 2004). In consequence, growth and water turnover are highly coordinated (Smith and Sperry 2014), as larger trees assimilate more carbon (Stephenson et al. 2014) and use more water (Wullschleger et al. 1998; Meinzer et al. 2005; Horna et al. 2011; Kunert et al. 2017; Link et al. in press). The strong size dependence of important aspects of tree carbon and water relations has the potential to mask or confound relationships between other variables in studies focusing of functional traits. In correspondence, many recent studies have highlighted the great importance of including plant size as a covariate when studying relationships between tree functional traits (e.g. Hietz et al. 2016; Gleason et al. 2018; Lechthaler et al. 2019; Š́mová et al. 2019). Indeed, we observed a meaningful influence of average tree size on wood anatomical properties related to hydraulic efficiency. These observations are in agreement with other studies showing that larger tropical trees possess wider vessels and higher potential conductivity, both at the stem base and in distal twigs (Poorter et al. 2010; Zach et al. 2010; Schuldt et al. 2013; Hietz et al. 2016). Tree height in particular has been singled out as the putative main driver of conduit dimensions (Coomes et al. 2007; Rosell et al. 2017; Olson et al. 2018; Fajardo et al. 2020).

The magnitude of the observed size effects was sufficient to explain large parts of the highly significant association of wood anatomical properties with both aboveground net primary productivity $(N P P)$ and daily water use $(D W U)$ (cf. Figure 5.3, 5.5). After controlling for tree size, the remaining effect of hydraulic efficiency on $N P P$ and $D W U$ was completely mediated through the effect of these variables on sap flux density. This demonstrates that the cause for the frequently reported relationship between productivity and wood properties is in fact the limiting effect of these anatomical features on plant hydraulic conductance and water transport (Brodribb 2009). This seems valid across all investigated tree species irrespective of their functional type and canopy positions.

In a stratified rainforest canopy, tall and emergent trees are exposed to a higher evaporative demand than their shorter understorey neighbours, which increases from the forest floor to the uppermost canopy (e.g. Schuldt et al. 2011). If the size of the evaporative demand 
is limiting sap flow rates as observed by Horna et al. (2011) in the pre-montane forests of Sulawesi, one could therefore expect a direct effect of average tree size on sap flux rates. However, our data do not provide evidence for direct size effects on sap flux density; rather, all observed size effects on sap flux density $\left(J_{s}\right)$ were mediated by size-related differences in wood anatomy. This indicates that for the present dataset, differences in evaporative demand were mirrored by corresponding adjustments in hydraulic architecture.

\subsubsection{Wood anatomical traits outperform wood density as predictors of plant growth and water use}

In accordance with previous findings, our observations show that growth and water use are more closely related to the water transport capacity in the vascular system - mainly driven by larger average vessel diameters - than to wood density (Russo et al. 2010; Hoeber et al. 2014; Eller et al. 2018).

In principle, natural selection should favour the development of higher hydraulic efficiency per sapwood area to save xylem construction and maintenance costs (McCulloh and Sperry 2005; Gleason et al. 2016). However, the advantage of large vessels and an efficient vascular network likely trades off with the vulnerability of conduits to embolize, which puts a practical limit on vessel dimensions (Tyree et al. 1994; Wheeler et al. 2005; Hajek et al. 2014). As trees in humid tropical forests are neither constrained by freeze-thaw embolism nor prolonged periods of soil desiccation, their maximum xylem hydraulic efficiency is expected to be high (Schuldt et al. 2013; Gleason et al. 2016; Liu et al. 2019). According to the energy minimization principle, a tree should aim at reducing xylem resistance to the lowest possible value for a given investment in vascular tissue (cf. McCulloh and Sperry 2005). Two ways to achieve this goal are a) improving conductivity by increasing vessel diameter, density and or/length, and b) reducing construction costs, which is reflected in reduced wood density. As denser wood tends to possess a higher proportion of fibres that restrict the area available for water conducting cells and thus influence conductivity (Roderick and Berry 2001; Barbour and Whitehead 2003), both adjustments are interdependent.

A positive influence of vessel size and thus larger potential hydraulic conductivity on growth rates has repeatedly been demonstrated (Poorter et al. 2010; Hietz et al. 2016; Gleason et al. 2018). Wood density, on the other hand, is known to be associated with most structural and functional wood properties (Chave et al. 2009). However, it ultimately constitutes an emergent property of wood structure rather than an unambiguous functional trait, with a large range of combinations of wood anatomical features resulting in the same wood density (Ziemińska et al. 2013, 2015). Thus, wood density is at least partially decoupled from wood anatomical traits (Zanne et al. 2010; Fan et al. 2012; Schuldt et al. 2013).

In tropical trees, harder wood tends to be associated with lower growth rates (e.g. MullerLandau 2004; King et al. 2006; Poorter et al. 2010; Rüger et al. 2012; Hoeber et al. 2014). Our results indicate that this relationship is a consequence of the negative relationship of wood density with both hydraulic efficiency and sap flux density, while wood density had no direct causal effect on NPP and only a minor effect on $D W U$. Due to the much closer mechanistic link of wood anatomical traits to $J_{s}$, their larger effect size on $J_{s}$ compared to wood density $(W D)$ is not surprising. As $W D$ does not have a direct mechanistic link to water transport, the observed effect on $J_{s}$ most likely results from a correlation with wood anatomical attributes that were not covered by our latent variable 
for hydraulic efficiency, e.g. pit membrane characteristics (Choat et al. 2008; Jansen et al. 2009; $\mathrm{Li}$ et al. 2016). It is further notable that in agreement with the null model by Francis et al. (2017), no direct $W D$ effects on biomass productivity could be identified. The lack of $W D$ effects on productivity may be a consequence of assessing it on a biomass increment basis, which implicitly accounts for construction costs. It is worth noting that $W D$ and hydraulic efficiency together only explain a comparatively low fraction of variance in sap flux density in our dataset $\left(r^{2}=0.24\right.$, cf. Figure 5.5), which puts a limit on the magnitude of their indirect effect on growth and water use. If, as our data suggest, a large part of the correlation between growth, water use and wood properties results from their common dependence on tree size, the question arises whether their importance for parameterizing dynamic vegetation and earth system models and for understanding responses to environmental change (Griffin-Nolan et al. 2018; Olson et al. 2018) may be overstated.

\subsubsection{The way forward from analyses of pairwise correlations}

The present study illustrates that focusing on simple pairwise relationships between plant traits without accounting for the complex, multivariate nature of ecological datasets can result in fundamentally different and potentially flawed interpretations. Our approach highlights that many commonly observed plant performance-hydraulic trait relationships may be attributed to a confounding effect of tree size (Poorter et al. 2010; Fan et al. 2012; Hietz et al. 2016; Gleason et al. 2018). The latter influences the hydraulic efficiency of the vascular system through its effects on a species' wood anatomical properties, while simultaneously being strongly associated with productivity and water use. To be able to interpret functional plant trait relationships in the context of plant performance, it is therefore necessary to account for the effects of tree size, which has been reportedly neglected in the past.

A common strategy to avoid confounding size effects is to compare species under 'optimal' growth conditions and at maturity, when species are more likely to express their full trait potential (Poorter and Bongers 2006; Pérez-Harguindeguy et al. 2013). However, the definition of both 'mature' trees and 'optimal' growth conditions across various ecosystems remains disputable, especially since observed hydraulic adaptations are inevitably interlinked with climate and the maximum potential height a tree can reach (Medeiros et al. 2019; Liu et al. 2019; Š́mová et al. 2019). Given the intrinsic complexity of ecological datasets, where tree size is only one of many potential confounders, it may often be preferable to explicitly account for the network of relationships between variables. Adopting a structural equation modelling approach did not only enable us to account for the aforementioned size effects, but also permitted to differentiate between direct and indirect effects and to test the hypothesis that our model as a whole is consistent with the observed data.

\subsubsection{Conclusions}

Our study provides evidence that the growth and water use of tropical trees are highly coordinated. We show that for tree species of a given average size, differences in growth and water use are explained by hydraulic adjustments resulting from differences in wood structure. While we find wood anatomical traits to be better predictors of growth and water use than wood density, their explanatory power is dwarfed by the magnitude of 
size effects, highlighting the importance of tree size as a driver of forest productivity (cf. Śímová et al. 2019). In consequence, the additional value of the inclusion of anatomical traits in dynamic vegetation models may often be overstated. As tropical regions are expected to be on the forefront of accelerating pressure from chronically-increasing stressors in near future, functional and taxonomic diversity will be massively lost with unknown consequences. Our results confirm the exceptional importance of large trees for the carbon stocks and biomass production of tropical forests (cf. Slik et al. 2013; Stephenson et al. 2014; Bastin et al. 2015; Bastin et al. 2018; Lutz et al. 2018) and point towards their central role for ecosystem transpiration. For these reasons, the disproportionate rates of loss of large trees that are observed worldwide (Lindenmayer et al. 2012; Bennett et al. 2015; Ryan 2015; Grote et al. 2016), either through selective logging or drought-stress induced mortality, have the potential to severely alter forest water cycles and the carbon sequestration potential.

\section{Acknowledgments}

This study was financed by the German Research Foundation (DFG) in the framework of the research projects EFForTS (CRC990) and STORMA (CRC552). Roman Link was funded by DFG grant number SCHU 2935/1-1. We thank village leaders, local plot owners, PT REKI, authorities of the Bukit Duabelas National Park and the Lore Lindu National Park for granting access and the Indonesian Research Foundation (LIPI) for research permissions. We further thank our counterparts and local assistants for support with fieldwork and administration, and Katja Rembold, Fabian Brambach and Heike Culmsee for species identification. This study was conducted with research permits No. 2704/IPH.1/KS.02/X1/2012, No. 15/EXT/SIP/FRP/SM/II/2013 and No. 251/SIP/FRP/E5/Dit.KI/VII/2016 issued by the FRP-Kemenristek.

\section{Author contribution}

BS, DHe, DHö and CL developed the original research questions. MK, PW and GM carried out the biomass and productivity measurements, MK, BS and RL the wood anatomical analyses, and AR and BS collected the sap flow data. RL performed the data analysis and statistical interpretation in close collaboration with MK and BS. MK and RL wrote the first version of the manuscript, which was discussed and revised by all authors. MK and RL contributed equally. 


\section{Supplementary material}

Table S1 (1/4): List of selected tree traits for the sampled tree species. Given are average values of the traits and observation counts in brackets for Sulawesi (Sul), Sumatra (Sum) and the full dataset (Tot). Shown are diameter at breast height $(D B H)$, tree height and wood density $(W D)$. The complete dataset including aboveground net primary production $(N P P)$, hydraulically weighted vessel diameter $\left(D_{h}\right)$, vessel density $(V D)$, potential hydraulic conductivity $\left(K_{p}\right)$, sap flux density $\left(J_{s}\right)$ and daily water use per tree $(D W U)$ will be uploaded to the TRY database (Kattge et al. 2011).

\begin{tabular}{|c|c|c|c|c|c|c|c|}
\hline Family & Species & Sul & Sum & Tot & $\begin{array}{r}\text { DBH } \\
(\mathrm{cm})\end{array}$ & $\begin{array}{l}\text { Height } \\
\text { (m) }\end{array}$ & $\begin{array}{c}\text { WD } \\
\left(\mathrm{g} \mathrm{cm}^{-3}\right)\end{array}$ \\
\hline Anacardiaceae & $\begin{array}{l}\text { Campnosperma } \\
\text { auriculatum }\end{array}$ & 0 & 1 & 1 & $20.95(n=1)$ & $17.30(\mathrm{n}=1)$ & $0.40(n=1)$ \\
\hline Anacardiaceae & Mangifera caesia & 0 & 1 & 1 & $55.98(\mathrm{n}=1)$ & $36.60(n=1)$ & $0.69(\mathrm{n}=1)$ \\
\hline Anacardiaceae & Mangifera foetida & 0 & 2 & 2 & $33.16(n=2)$ & $25.75(n=2)$ & $0.61(n=2)$ \\
\hline Anacardiaceae & Mangifera torquenda & 0 & 1 & 1 & $79.50(n=1)$ & $38.80(n=1)$ & $0.56(n=1)$ \\
\hline Anacardiaceae & Melanochyla beccariana & 0 & 1 & 1 & $28.35(n=1)$ & $27.10(n=1)$ & $0.52(\mathrm{n}=1)$ \\
\hline Annonaceae & $\begin{array}{l}\text { Drepananthus } \\
\text { biovulatus }\end{array}$ & 0 & 1 & 1 & $21.78(n=1)$ & $23.80(n=1)$ & $0.38(\mathrm{n}=1)$ \\
\hline Annonaceae & $\begin{array}{l}\text { Drepananthus } \\
\text { ramuliflorus }\end{array}$ & 0 & 1 & 1 & $15.64(n=1)$ & $21.70(n=1)$ & $0.55(\mathrm{n}=1)$ \\
\hline Annonaceae & Maasia glauca & 0 & 1 & 1 & $17.32(\mathrm{n}=1)$ & $22.10(n=1)$ & $0.63(n=1)$ \\
\hline Annonaceae & Mezzettia parviflora & 0 & 1 & 1 & $55.75(\mathrm{n}=1)$ & $44.50(n=1)$ & $0.63(n=1)$ \\
\hline Annonaceae & Polyalthia lateriflora & 1 & 0 & 1 & $25.20(\mathrm{n}=1)$ & $22.30(n=1)$ & $0.48(\mathrm{n}=1)$ \\
\hline Apocynaceae & Alstonia angustifolia & 0 & 2 & 2 & $28.65(n=2)$ & $18.50(n=2)$ & $0.47(n=2)$ \\
\hline Apocynaceae & Alstonia pneumatophora & 0 & 1 & 1 & $17.20(\mathrm{n}=1)$ & $7.50(\mathrm{n}=1)$ & $0.19(n=1)$ \\
\hline Burseraceae & Burseraceae sp. 27 & 0 & 1 & 1 & $22.43(n=1)$ & $24.60(n=1)$ & $0.60(n=1)$ \\
\hline Burseraceae & Burseraceae sp. 28 & 0 & 1 & 1 & $86.60(n=1)$ & $40.20(n=1)$ & $0.66(n=1)$ \\
\hline Burseraceae & Canarium megalanthum & 0 & 1 & 1 & $30.16(n=1)$ & $27.30(\mathrm{n}=1)$ & $0.62(\mathrm{n}=1)$ \\
\hline Burseraceae & Santiria apiculata & 13 & 0 & 13 & $29.20(n=13)$ & $23.52(n=13)$ & $0.49(n=13)$ \\
\hline Burseraceae & Santiria griffithii & 0 & 3 & 3 & $21.48(n=3)$ & $18.43(n=3)$ & $0.58(n=3)$ \\
\hline Burseraceae & Santiria laevigata & 0 & 2 & 2 & $47.23(n=2)$ & $26.35(n=2)$ & $0.52(\mathrm{n}=2)$ \\
\hline Cannabaceae & Gironniera nervosa & 0 & 2 & 2 & $32.30(n=2)$ & $26.40(n=2)$ & $0.51(n=2)$ \\
\hline Combretaceae & $\begin{array}{l}\text { Terminalia } \\
\text { subspathulata }\end{array}$ & 0 & 1 & 1 & $28.16(n=1)$ & $17.70(n=1)$ & $0.45(n=1)$ \\
\hline Compositae & Strobocalyx arboreus & 10 & 0 & 10 & $23.25(\mathrm{n}=10)$ & $23.29(\mathrm{n}=10)$ & $0.31(n=10)$ \\
\hline Dilleniaceae & Dillenia eximia & 0 & 1 & 1 & $18.22(\mathrm{n}=1)$ & $21.10(\mathrm{n}=1)$ & $0.50(n=1)$ \\
\hline Dipterocarpaceae & Hopea sangal & 0 & 1 & 1 & $25.32(n=1)$ & $25.00(n=1)$ & $0.45(n=1)$ \\
\hline Dipterocarpaceae & Shorea acuminata & 0 & 1 & 1 & $55.45(\mathrm{n}=1)$ & $42.30(n=1)$ & $0.49(\mathrm{n}=1)$ \\
\hline Dipterocarpaceae & Shorea bracteolata & 0 & 1 & 1 & $21.75(n=1)$ & $19.20(\mathrm{n}=1)$ & $0.48(\mathrm{n}=1)$ \\
\hline Dipterocarpaceae & Shorea ovalis & 0 & 6 & 6 & $44.52(n=6)$ & $30.47(n=6)$ & $0.47(n=6)$ \\
\hline Dipterocarpaceae & Shorea parvifolia & 0 & 4 & 4 & $49.86(n=4)$ & $34.72(n=4)$ & $0.43(n=4)$ \\
\hline Dipterocarpaceae & Shorea singkawang & 0 & 2 & 2 & $48.95(n=2)$ & $28.25(n=2)$ & $0.46(n=2)$ \\
\hline Ebenaceae & Diospyros coriacea & 0 & 1 & 1 & $19.45(n=1)$ & $26.90(n=1)$ & $0.78(n=1)$ \\
\hline
\end{tabular}


Table S1 (2/4): List of selected tree traits for the sampled tree species. Given are average values of the traits and observation counts in brackets. Shown are diameter at breast height $(D B H)$, tree height and wood density $(W D)$.

\begin{tabular}{|c|c|c|c|c|c|c|c|}
\hline Family & Species & Sul & Sum & Tot & $\begin{array}{r}\text { DBH } \\
(\mathbf{c m})\end{array}$ & $\begin{array}{l}\text { Height } \\
\text { (m) }\end{array}$ & $\begin{array}{c}\text { WD } \\
\left(\mathrm{g} \mathrm{cm}^{-3}\right)\end{array}$ \\
\hline Escalloniaceae & Polyosma integrifolia & 1 & 0 & 1 & $14.20(\mathrm{n}=1)$ & $27.10(n=1)$ & $0.39(\mathrm{n}=1)$ \\
\hline Euphorbiaceae & $\begin{array}{l}\text { Endospermum } \\
\text { diadenum }\end{array}$ & 0 & 7 & 7 & $35.90(n=7)$ & $22.79(n=7)$ & $0.45(n=7)$ \\
\hline Euphorbiaceae & Macaranga gigantea & 0 & 2 & 2 & $15.30(n=2)$ & $15.15(n=2)$ & $0.40(n=2)$ \\
\hline Euphorbiaceae & Macaranga hosei & 0 & 3 & 3 & $20.25(n=3)$ & $15.60(n=3)$ & $0.36(n=3)$ \\
\hline Euphorbiaceae & Macaranga hypoleuca & 0 & 2 & 2 & $27.02(n=2)$ & $16.70(n=2)$ & $0.42(n=2)$ \\
\hline Euphorbiaceae & Macaranga sumatrana & 0 & 4 & 4 & $25.42(n=4)$ & $19.38(n=4)$ & $0.44(n=4)$ \\
\hline Euphorbiaceae & Neoscortechinia kingii & 0 & 1 & 1 & $12.85(\mathrm{n}=1)$ & $17.80(\mathrm{n}=1)$ & $0.63(n=1)$ \\
\hline Fabaceae & Archidendron fagifolium & 0 & 1 & 1 & $22.89(n=1)$ & $18.20(n=1)$ & $0.41(n=1)$ \\
\hline Fabaceae & Callerya atropurpurea & 0 & 3 & 3 & $23.75(n=3)$ & $18.57(\mathrm{n}=3)$ & $0.67(n=3)$ \\
\hline Fabaceae & $\begin{array}{l}\text { Koompassia } \\
\text { malaccensis }\end{array}$ & 0 & 3 & 3 & $56.64(\mathrm{n}=3)$ & $37.40(n=3)$ & $0.75(n=3)$ \\
\hline Fabaceae & Parkia speciosa & 0 & 2 & 2 & $50.50(n=2)$ & $29.70(n=2)$ & $0.50(\mathrm{n}=2)$ \\
\hline Fabaceae & Parkia timoriana & 0 & 1 & 1 & $40.01(\mathrm{n}=1)$ & $23.10(n=1)$ & $0.48(\mathrm{n}=1)$ \\
\hline Fabaceae & $\begin{array}{l}\text { Peltophorum } \\
\text { pterocarpum }\end{array}$ & 0 & 1 & 1 & $19.52(n=1)$ & $17.90(n=1)$ & $0.59(\mathrm{n}=1)$ \\
\hline Fagaceae & Castanopsis buruana & 21 & 0 & 21 & $47.20(n=21)$ & $34.62(n=21)$ & $0.50(n=21)$ \\
\hline Fagaceae & Castanopsis inermis & 0 & 2 & 2 & $37.73(n=2)$ & $21.35(\mathrm{n}=2)$ & $0.46(n=2)$ \\
\hline Fagaceae & Castanopsis javanica & 0 & 1 & 1 & $79.30(n=1)$ & $38.70(n=1)$ & $0.59(n=1)$ \\
\hline Hypericaceae & $\begin{array}{l}\text { Cratoxylum } \\
\text { sumatranum }\end{array}$ & 0 & 2 & 2 & $13.05(n=2)$ & $12.90(n=2)$ & $0.63(n=2)$ \\
\hline Icacinaceae & Platea excelsa & 14 & 0 & 14 & $25.13(n=14)$ & $22.26(n=14)$ & $0.34(\mathrm{n}=14)$ \\
\hline Ixonanthaceae & Ixonanthes petiolaris & 0 & 2 & 2 & $27.39(\mathrm{n}=2)$ & $28.25(\mathrm{n}=2)$ & $0.49(n=2)$ \\
\hline Lauraceae & $\begin{array}{l}\text { Cinnamomum } \\
\text { porrectum }\end{array}$ & 0 & 1 & 1 & $20.72(n=1)$ & $16.70(n=1)$ & $0.52(n=1)$ \\
\hline Lauraceae & Cryptocarya laevigata & 13 & 0 & 13 & $18.02(n=13)$ & $18.03(n=13)$ & $0.43(n=13)$ \\
\hline Lauraceae & Dehaasia incrassata & 0 & 1 & 1 & $56.28(\mathrm{n}=1)$ & $26.60(n=1)$ & $0.52(\mathrm{n}=1)$ \\
\hline Lauraceae & Litsea firma & 0 & 1 & 1 & $64.82(n=1)$ & $46.70(\mathrm{n}=1)$ & $0.47(n=1)$ \\
\hline Lauraceae & Persea rimosa & 0 & 2 & 2 & $23.02(n=2)$ & $16.80(n=2)$ & $0.55(\mathrm{n}=2)$ \\
\hline Malvaceae & Durio zibethinus & 0 & 2 & 2 & $34.01(n=2)$ & $23.95(n=2)$ & $0.49(n=2)$ \\
\hline Malvaceae & $\begin{array}{l}\text { Pterocymbium } \\
\text { tubulatum }\end{array}$ & 0 & 1 & 1 & $42.50(\mathrm{n}=1)$ & $34.60(\mathrm{n}=1)$ & $0.50(\mathrm{n}=1)$ \\
\hline Malvaceae & Scaphium affine & 0 & 3 & 3 & $49.08(n=3)$ & $34.10(n=3)$ & $0.58(n=3)$ \\
\hline Melastomataceae & Pternandra caerulescens & 0 & 1 & 1 & $41.85(n=1)$ & $25.50(n=1)$ & $0.52(n=1)$ \\
\hline
\end{tabular}


Table S1 (3/4) List of selected tree traits for the sampled tree species. Given are average values of the traits and observation counts in brackets. Shown are diameter at breast height $(D B H)$, tree height and wood density $(W D)$.

\begin{tabular}{|c|c|c|c|c|c|c|c|}
\hline Family & Species & Sul & Sum & Tot & $\begin{array}{l}\text { DBH } \\
(\mathrm{cm})\end{array}$ & $\begin{array}{l}\text { Height } \\
\text { (m) }\end{array}$ & $\begin{array}{c}\text { WD } \\
\left(\mathrm{g} \mathrm{cm}^{-3}\right)\end{array}$ \\
\hline Meliaceae & Aglaia malaccensis & 0 & 2 & 2 & $47.19(n=2)$ & $33.80(n=2)$ & $0.61(n=2)$ \\
\hline Meliaceae & Dysoxylum densiflorum & 0 & 1 & 1 & $36.21(\mathrm{n}=1)$ & $16.90(n=1)$ & $0.60(n=1)$ \\
\hline Moraceae & Artocarpus elasticus & 0 & 5 & 5 & $27.07(\mathrm{n}=5)$ & $17.68(n=5)$ & $0.44(n=5)$ \\
\hline Moraceae & Artocarpus integer & 0 & 3 & 3 & $34.11(n=3)$ & $21.33(n=3)$ & $0.55(n=3)$ \\
\hline Moraceae & Artocarpus nitidus & 0 & 1 & 1 & $26.11(n=1)$ & $17.40(\mathrm{n}=1)$ & $0.57(n=1)$ \\
\hline Moraceae & Artocarpus rigidus & 0 & 1 & 1 & $35.21(\mathrm{n}=1)$ & $21.20(\mathrm{n}=1)$ & $0.61(n=1)$ \\
\hline Moraceae & Ficus variegata & 0 & 1 & 1 & $31.30(n=1)$ & $27.40(n=1)$ & $0.27(n=1)$ \\
\hline Myristicaceae & $\begin{array}{l}\text { Gymnacranthera } \\
\text { farquhariana }\end{array}$ & 0 & 2 & 2 & $39.75(n=2)$ & $29.70(n=2)$ & $0.52(\mathrm{n}=2)$ \\
\hline Myrtaceae & Myrtaceae sp. 10 & 2 & 0 & 2 & $17.80(n=2)$ & $29.20(n=2)$ & $0.68(n=2)$ \\
\hline Myrtaceae & Myrtaceae sp. 2 & 1 & 0 & 1 & $14.00(n=1)$ & $17.40(n=1)$ & 0.64 \\
\hline Myrtaceae & Myrtaceae sp. 3 & 2 & 0 & 2 & $17.80(n=2)$ & $21.10(n=2)$ & $0.49(n=2)$ \\
\hline Myrtaceae & Myrtaceae sp. 5 & 5 & 0 & 5 & $23.92(\mathrm{n}=5)$ & $20.42(\mathrm{n}=5)$ & $0.60(\mathrm{n}=5)$ \\
\hline Myrtaceae & Myrtaceae sp. 8 & 2 & 0 & 2 & $13.30(n=2)$ & $12.20(n=2)$ & $0.64(n=2)$ \\
\hline Myrtaceae & Syzygium cf. borneense & 0 & 1 & 1 & $68.05(n=1)$ & $26.63(n=1)$ & $0.69(n=1)$ \\
\hline Myrtaceae & Syzygium sp. 02 & 0 & 1 & 1 & $115.93(n=1)$ & 38.60 & \\
\hline Myrtaceae & Syzygium sp. 03 & 0 & 1 & 1 & $69.35(n=1)$ & $36.80(n=1)$ & $0.67(n=1)$ \\
\hline Myrtaceae & Syzygium sp. 08 & 0 & 1 & 1 & $27.19(\mathrm{n}=1)$ & $25.00(n=1)$ & $0.67(\mathrm{n}=1)$ \\
\hline Olacaceae & $\begin{array}{l}\text { Ochanostachys } \\
\text { amentacea }\end{array}$ & 0 & 8 & 8 & $35.25(\mathrm{n}=8)$ & $22.96(n=8)$ & $0.69(\mathrm{n}=8)$ \\
\hline Olacaceae & Strombosia ceylanica & 0 & 1 & 1 & $31.82(\mathrm{n}=1)$ & $22.60(n=1)$ & $0.76(n=1)$ \\
\hline Oxalidaceae & Sarcotheca diversifolia & 0 & 2 & 2 & $88.46(n=2)$ & $36.50(n=2)$ & $0.60(n=2)$ \\
\hline Pandaceae & Galearia maingayi & 0 & 2 & 2 & $35.93(n=2)$ & $22.10(n=2)$ & $0.59(\mathrm{n}=2)$ \\
\hline Passifloraceae & Paropsia varecifomis & 0 & 1 & 1 & $23.49(n=1)$ & $19.30(n=1)$ & $0.65(n=1)$ \\
\hline Phyllantaceae & Baccaurea macrocarpa & 0 & 2 & 2 & $18.68(n=2)$ & $13.70(n=2)$ & $0.48(n=2)$ \\
\hline Phyllanthaceae & Aporosa nervosa & 0 & 1 & 1 & $25.24(\mathrm{n}=1)$ & $23.80(n=1)$ & $0.52(\mathrm{n}=1)$ \\
\hline Phyllanthaceae & Baccaurea dulcis & 0 & 2 & 2 & $29.71(n=2)$ & $13.20(n=2)$ & $0.56(n=2)$ \\
\hline Poly galaceae & $\begin{array}{l}\text { Xanthophyllum } \\
\text { eurhynchum }\end{array}$ & 0 & 1 & 1 & $32.00(n=1)$ & $27.50(n=1)$ & $0.60(\mathrm{n}=1)$ \\
\hline Poly galaceae & $\begin{array}{l}\text { Xanthophyllum } \\
\text { stipitatum }\end{array}$ & 0 & 1 & 1 & $50.97(n=1)$ & $34.10(n=1)$ & $0.72(n=1)$ \\
\hline Putranjivaceae & Drypetes longifolia & 0 & 1 & 1 & $47.97(n=1)$ & $36.50(n=1)$ & $0.75(n=1)$ \\
\hline Rosaceae & Prunus polystachya & 0 & 2 & 2 & $29.64(n=2)$ & $23.30(n=2)$ & $0.41(n=2)$ \\
\hline
\end{tabular}


Table S1 (4/4) List of selected tree traits for the sampled tree species. Given are average values of the traits and observation counts in brackets. Shown are diameter at breast height $(D B H)$, tree height and wood density $(W D)$.

\begin{tabular}{|c|c|c|c|c|c|c|c|}
\hline Family & Species & Sul & Sum & Tot & $\begin{array}{r}\text { DBH } \\
(\mathrm{cm})\end{array}$ & $\begin{array}{c}\text { Height } \\
\text { (m) }\end{array}$ & $\begin{array}{c}\text { WD } \\
\left(\mathrm{g} \mathrm{cm}^{-3}\right)\end{array}$ \\
\hline Rubiaceae & Porterandia anisophylla & 0 & 1 & 1 & $10.20(\mathrm{n}=1)$ & $12.70(n=1)$ & $0.63(\mathrm{n}=1)$ \\
\hline Rubiaceae & Timonius wallichianus & 0 & 1 & 1 & $15.70(\mathrm{n}=1)$ & $15.90(\mathrm{n}=1)$ & $0.67(\mathrm{n}=1)$ \\
\hline Rutaceae & Acronychia pedunculata & 1 & 0 & 1 & $14.00(n=1)$ & $13.90(n=1)$ & $0.49(n=1)$ \\
\hline Rutaceae & Tetractomia tetrandra & 0 & 1 & 1 & $29.46(n=1)$ & $19.30(n=1)$ & $0.51(n=1)$ \\
\hline Sapindaceae & Pometia pinnata & 0 & 2 & 2 & $23.60(n=2)$ & $24.40(n=2)$ & $0.65(n=2)$ \\
\hline Sapindaceae & $\begin{array}{l}\text { Xerospermum } \\
\text { laevigatum }\end{array}$ & 0 & 1 & 1 & $44.17(n=1)$ & $21.60(\mathrm{n}=1)$ & $0.60(n=1)$ \\
\hline Sapindaceae & $\begin{array}{l}\text { Xerospermum } \\
\text { noronhianum }\end{array}$ & 0 & 1 & 1 & $33.08(\mathrm{n}=1)$ & $19.00(\mathrm{n}=1)$ & $0.71(\mathrm{n}=1)$ \\
\hline Sapotaceae & Palaquium gutta & 0 & 5 & 5 & $48.94(n=5)$ & $36.02(n=5)$ & $0.54(n=5)$ \\
\hline Sapotaceae & Palaquium hexandrum & 0 & 1 & 1 & $76.18(n=1)$ & $38.60(n=1)$ & $0.52(\mathrm{n}=1)$ \\
\hline Sapotaceae & Palaquium luzoniense & 11 & 0 & 11 & $32.05(n=11)$ & $25.55(\mathrm{n}=11)$ & $0.40(n=11)$ \\
\hline Sapotaceae & Palaquium obovatum & 0 & 1 & 1 & $33.36(n=1)$ & $25.80(\mathrm{n}=1)$ & $0.41(n=1)$ \\
\hline Sapotaceae & Pleioluma firma & 17 & 0 & 17 & $29.66(n=17)$ & $27.75(n=17)$ & $0.47(n=16)$ \\
\hline Simaroubaceae & Ailanthus integrifolia & 0 & 3 & 3 & $38.55(n=3)$ & $24.00(n=3)$ & $0.51(n=3)$ \\
\hline
\end{tabular}


Table S2: Results of the SMA regressions. Given are the estimates and $95 \%$ confidence intervals of the elevation and slope parameters of the common relationship, as well as the $P$ - value for the null hypothesis that there is no association and the proportion of variance explained by the relationship $\left(r^{2}\right)$.

\begin{tabular}{|c|c|c|c|c|c|c|c|c|c|}
\hline \multirow[b]{2}{*}{ Response } & \multirow[b]{2}{*}{ Predictor } & \multicolumn{3}{|c|}{ Elevation } & \multicolumn{3}{|c|}{ Slope } & \multirow[b]{2}{*}{ p-Value } & \multirow[b]{2}{*}{$\mathbf{R}^{2}$} \\
\hline & & Estimate & lower CI & upper CI & Estimate & lower CI & upper CI & & \\
\hline $\log (\mathrm{DWU})$ & WD & 8.164 & 6.784 & 9.544 & -10.382 & -13.170 & -8.184 & 0.867 & 0.000 \\
\hline $\log (\mathrm{Js})$ & WD & 4.689 & 4.059 & 5.320 & -5.008 & -6.285 & -3.991 & 0.011 & 0.090 \\
\hline $\log (\mathrm{NPP})$ & WD & -2.887 & -4.256 & -1.517 & 10.321 & 8.191 & 13.004 & 0.842 & 0.001 \\
\hline $\log ($ Height $)$ & WD & 1.511 & 1.170 & 1.853 & 3.048 & 2.498 & 3.720 & 0.164 & 0.020 \\
\hline $\log (\mathrm{DWU})$ & $\log (\mathrm{dh})$ & -13.120 & -16.440 & -9.799 & 3.131 & 2.543 & 3.857 & $<0.001$ & 0.317 \\
\hline $\log (\mathrm{Js})$ & $\log (\mathrm{dh})$ & -5.307 & -7.025 & -3.589 & 1.449 & 1.148 & 1.828 & 0.002 & 0.146 \\
\hline $\log (\mathrm{NPP})$ & $\log (\mathrm{dh})$ & -12.761 & -16.203 & -9.320 & 3.067 & 2.466 & 3.816 & $<0.001$ & 0.148 \\
\hline $\log ($ Height $)$ & $\log (\mathrm{dh})$ & -1.265 & -2.131 & -0.399 & 0.879 & 0.725 & 1.066 & $<0.001$ & 0.151 \\
\hline $\log (\mathrm{NPP})$ & $\log (\mathrm{DWU})$ & -0.762 & -1.531 & 0.006 & 1.271 & 1.028 & 1.572 & $<0.001$ & 0.397 \\
\hline
\end{tabular}




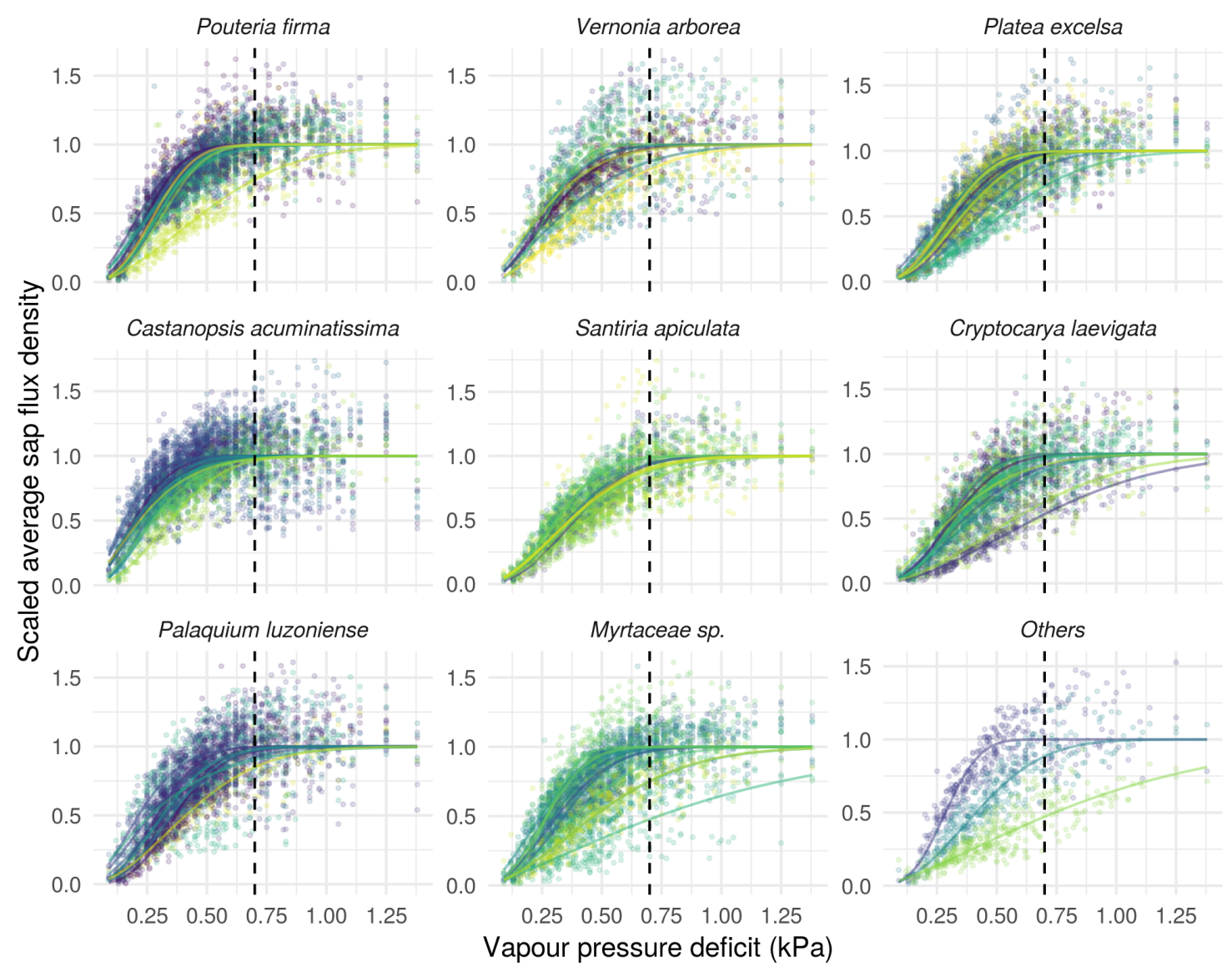

Figure S1: Normalized daily mean sap flux density $\left(J_{s}\right)$ in relation to daily mean vapour pressure deficit $(V P D)$ for all trees from Sulawesi for 2008. The dashed line indicates a $V P D$ of $0.7 \mathrm{kPa}$. To model the relationship between $J_{s}$ and $V P D$, a cumulative distribution function of a Weibull function has been used separately for each tree. 


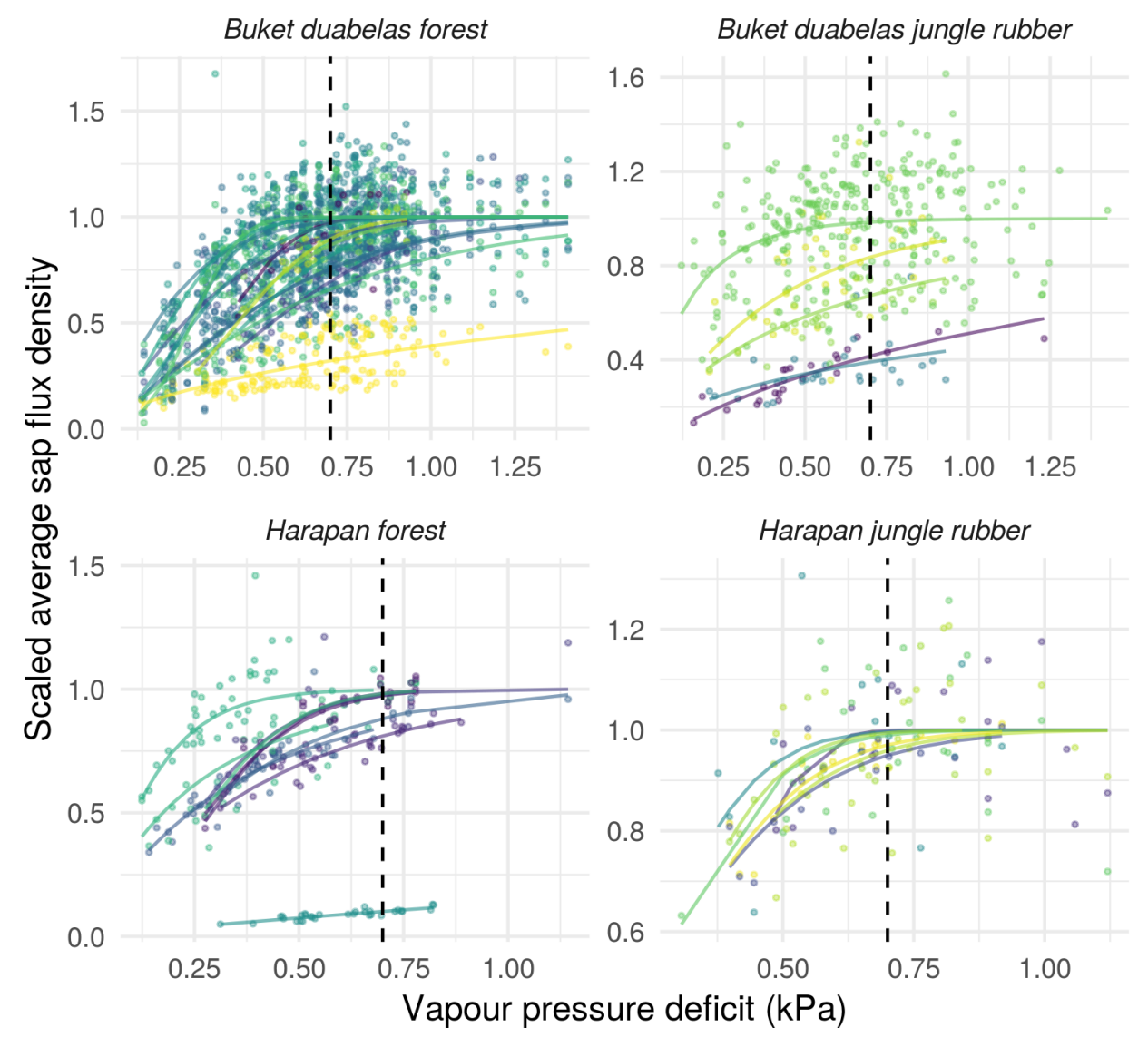

Figure S2: Figure S2: Normalized daily mean sap flux density $\left(J_{s}\right)$ in relation to daily mean vapour pressure deficit $(V P D)$ for all trees from Sumatra. The dashed line indicates a $V P D$ of $0.7 \mathrm{kPa}$. To model the relationship between $J_{s}$ and $V P D$, a cumulative distribution function of a Weibull function has been used separately for each tree.

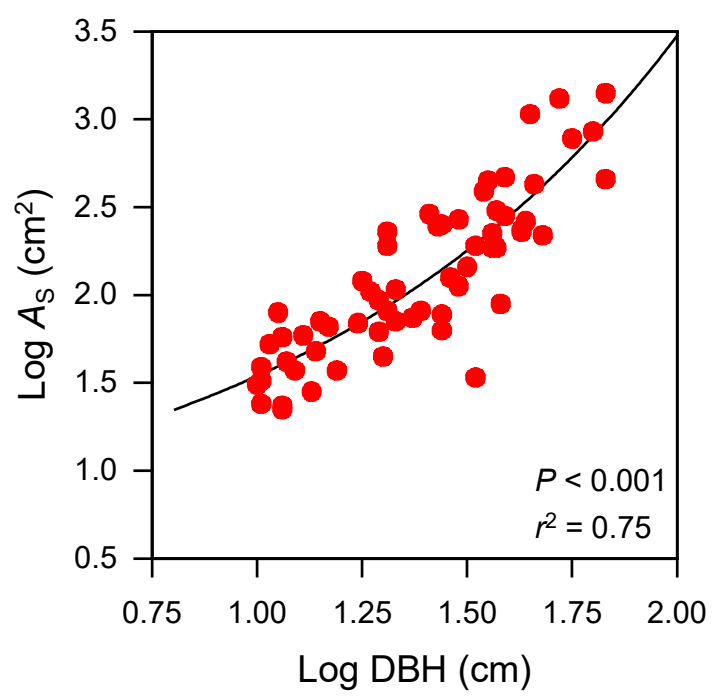

Figure S3: Logarithmized sapwood area $\left(A_{s}\right)$ identified by dye injection in relationship to logarithmized diameter at breast height $(D B H)$ for 13 tropical tree species from Indonesia ( $n=66$ mature trees). 


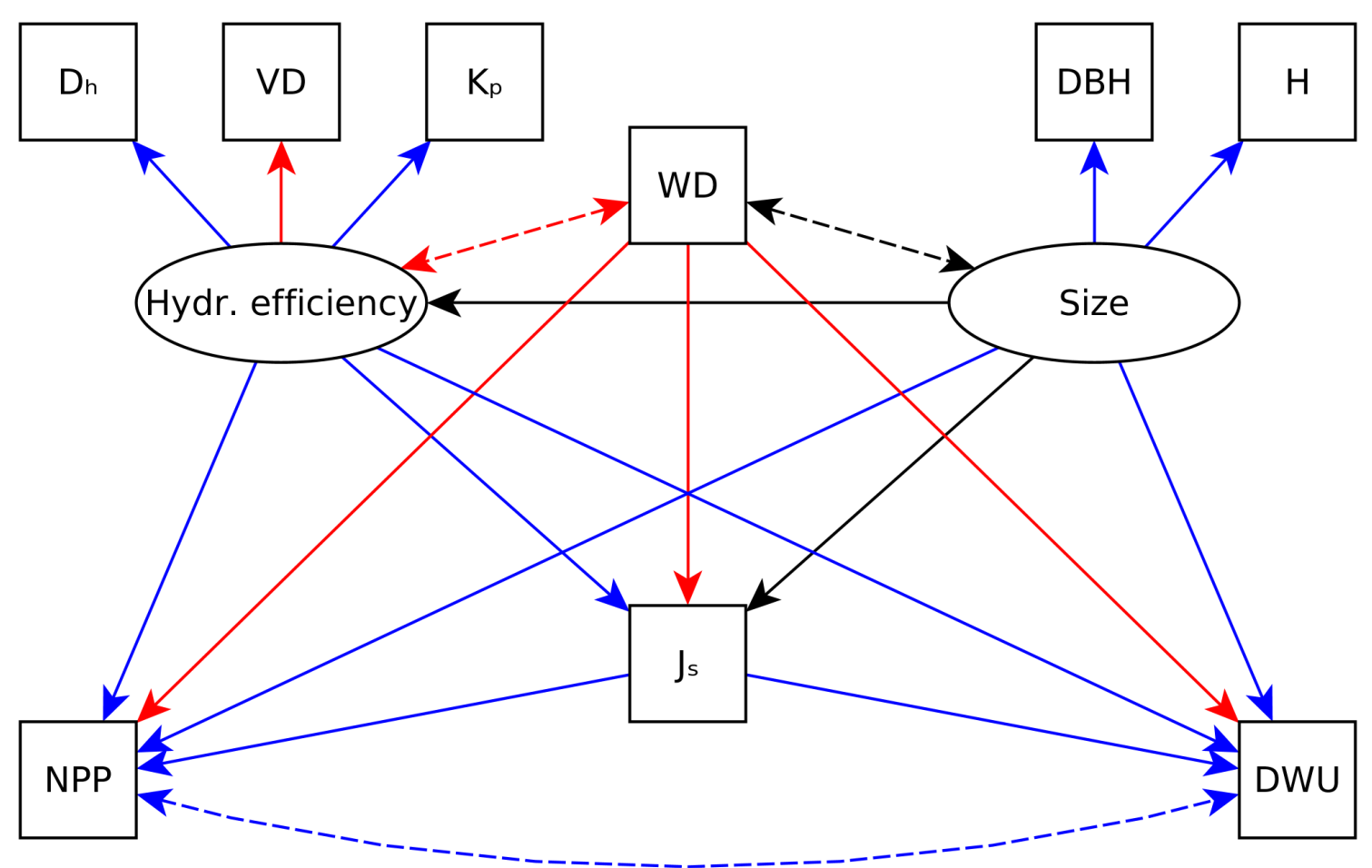

Figure S4: Causal diagram of the measured variables. Assumed positive links are displayed in blue, negative links in red, and links of unclear direction as dashed black arrows. See Table 5.1 for abbreviations.

\section{References}

Allen, K., M. D. Corre, A. Tjoa, and E. Veldkamp (2015). "Soil Nitrogen-Cycling Responses to Conversion of Lowland Forests to Oil Palm and Rubber Plantations in Sumatra, Indonesia". In: PLOS ONE 10.7. URL: https://www.ncbi.nlm.nih.gov/pmc/articles/ PMC4519237/.

Anderegg, W. R. L. (2015). "Spatial and temporal variation in plant hydraulic traits and their relevance for climate change impacts on vegetation". In: New Phytologist 205.3, pp. 1008-1014. URL: http://doi.wiley.com/10.1111/nph.12907.

Apgaua, D. M. G., F. Y. Ishida, D. Y. P. Tng, M. J. Laidlaw, R. M. Santos, et al. (2015). "Functional Traits and Water Transport Strategies in Lowland Tropical Rainforest Trees". In: PLoS ONE 10.6. URL: https://www.ncbi.nlm.nih.gov/pmc/articles/ PMC4472991/.

Baraloto, C., C. E. T. Paine, L. Poorter, J. Beauchene, D. Bonal, et al. (2010). "Decoupled leaf and stem economics in rain forest trees". In: Ecology Letters 13.11, pp. 1338-1347. URL: https://onlinelibrary.wiley.com/doi/abs/10.1111/j.1461-0248.2010.01517.x.

Barbour, M. M. and D. Whitehead (2003). "A Demonstration of the Theoretical Prediction That Sap Velocity Is Related to Wood Density in the Conifer Dacrydium cupressinum". In: New Phytologist 158.3, pp. 477-488. URL: https://www.jstor.org/stable/1514108.

Bastin, J.-F., N. Barbier, M. Réjou-Méchain, A. Fayolle, S. Gourlet-Fleury, et al. (2015). "Seeing Central African forests through their largest trees". In: Scientific Reports 5.1, p. 13156. URL: http://www.nature.com/articles/srep13156. 
Bastin, J.-F., E. Rutishauser, J. R. Kellner, S. Saatchi, R. Pélissier, et al. (2018). "Pantropical prediction of forest structure from the largest trees". In: Global Ecology and Biogeography 27.11, pp. 1366-1383. URL: http://doi.wiley.com/10.1111/geb.12803.

Bennett, A. C., N. G. McDowell, C. D. Allen, and K. J. Anderson-Teixeira (2015). "Larger trees suffer most during drought in forests worldwide". In: Nature Plants 1.10, p. 15139. URL: https://www.nature.com/articles/nplants2015139.

Brodribb, T. J., N. M. Holbrook, and M. V. Gutierrez (2002). "Hydraulic and photosynthetic co-ordination in seasonally dry tropical forest trees". In: Plant, Cell and Environment 25.11, pp. 1435-1444. URL: http://doi.wiley.com/10.1046/j.1365-3040.2002. 00919.x.

Brodribb, T. J. (2009). "Xylem hydraulic physiology: The functional backbone of terrestrial plant productivity". In: Plant Science 177.4, pp. 245-251. URL: https://linkinghub. elsevier.com/retrieve/pii/S0168945209001599.

Brown, J. H., J. F. Gillooly, A. P. Allen, V. M. Savage, and G. B. West (2004). "Toward a metabolic theory of ecology". In: Ecology 85, pp. 1771-1789. URL: https://esajournals. onlinelibrary.wiley.com/doi / full / 10.1890/03-9000\%5C \% 4010.1002/\%5C\% 28ISSN \% 5C\%291939-9170.MacArthurAward.

Bucci, S. J., G. Goldstein, F. C. Meinzer, F. G. Scholz, A. C. Franco, and M. Bustamante (2004). "Functional convergence in hydraulic architecture and water relations of tropical savanna trees: from leaf to whole plant". In: Tree Physiology 24.8, pp. 891-899. URL: https://academic.oup.com/treephys/article-lookup/doi/10.1093/treephys/24.8.891.

Chave, J., D. Coomes, S. Jansen, S. L. Lewis, N. G. Swenson, and A. E. Zanne (2009). "Towards a worldwide wood economics spectrum". In: Ecology Letters 12.4, pp. 351-366. URL: http://doi.wiley.com/10.1111/j.1461-0248.2009.01285.x.

Chave, J., M. Réjou-Méchain, A. Búrquez, E. Chidumayo, M. S. Colgan, et al. (2014). "Improved allometric models to estimate the aboveground biomass of tropical trees". In: Global Change Biology 20.10, pp. 3177-3190. URL: https://onlinelibrary.wiley.com/ doi/abs/10.1111/gcb.12629.

Choat, B., A. R. Cobb, and S. Jansen (2008). "Structure and function of bordered pits: new discoveries and impacts on whole-plant hydraulic function". In: New Phytologist 177.3, pp. 608-626. URL: http://doi.wiley.com/10.1111/j.1469-8137.2007.02317.x.

Coomes, D. A., K. L. Jenkins, and L. E. Cole (2007). "Scaling of tree vascular transport systems along gradients of nutrient supply and altitude". In: Biology Letters 3.1, pp. 8790. URL: http://www.royalsocietypublishing.org/doi/10.1098/rsbl.2006.0551.

Drescher, J., K. Rembold, K. Allen, P. Beckschäfer, D. Buchori, et al. (2016). "Ecological and socio-economic functions across tropical land use systems after rainforest conversion". In: Philosophical Transactions of the Royal Society B: Biological Sciences 371.1694, p. 20150275. URL: https://royalsocietypublishing.org/doi/full/10.1098/rstb.2015.0275.

Eller, C. B., F. d. V. Barros, P. R. L. Bittencourt, L. Rowland, M. Mencuccini, and R. S. Oliveira (2018). "Xylem hydraulic safety and construction costs determine tropical tree growth". In: Plant, Cell $\mathscr{E}$ Environment 41.3, pp. 548-562. URL: https://onlinelibrary. wiley.com/doi/abs/10.1111/pce.13106.

Enquist, B. J., G. B. West, E. L. Charnov, and J. H. Brown (1999). "Allometric scaling of production and life-history variation in vascular plants". In: Nature 401.6756, pp. 907911. URL: http://www.nature.com/articles/44819.

Fajardo, A., C. Martínez-Pérez, M. A. Cervantes-Alcayde, and M. E. Olson (2020). "Stem length, not climate, controls vessel diameter in two trees species across a sharp precipitation gradient". In: New Phytologist n/a.n/a. URL: https://nph.onlinelibrary.wiley. com/doi/abs/10.1111/nph.16287. 
Fan, Z.-X., S.-B. Zhang, G.-Y. Hao, J. Ferry Slik, and K.-F. Cao (2012). "Hydraulic conductivity traits predict growth rates and adult stature of 40 Asian tropical tree species better than wood density: Xylem traits and tree growth". In: Journal of Ecology 100.3, pp. 732-741. URL: http://doi.wiley.com/10.1111/j.1365-2745.2011.01939.x.

Fortunel, C., J. Ruelle, J. Beauchêne, P. V. A. Fine, and C. Baraloto (2014). "Wood specific gravity and anatomy of branches and roots in 113 Amazonian rainforest tree species across environmental gradients". In: New Phytologist 202.1, pp. 79-94. URL: http://doi.wiley.com/10.1111/nph.12632.

Francis, E. J., H. C. Muller-Landau, S. J. Wright, M. D. Visser, Y. Iida, C. Fletcher, S. P. Hubbell, and A. R. Kassim (2017). "Quantifying the role of wood density in explaining interspecific variation in growth of tropical trees". In: Global Ecology and Biogeography 26.10, pp. 1078-1087. URL: http://doi.wiley.com/10.1111/geb.12604.

Fuchs, S., C. Leuschner, R. M. Link, H. Coners, and B. Schuldt (2017). "Calibration and comparison of thermal dissipation, heat ratio and heat field deformation sap flow probes for diffuse-porous trees". In: Agricultural and Forest Meteorology 244-245, pp. 151-161. URL: https://linkinghub.elsevier.com/retrieve/pii/S0168192317301314.

Gleason, S. M., A. E. A. Stephens, W. C. Tozer, C. J. Blackman, D. W. Butler, et al. (2018). "Shoot growth of woody trees and shrubs is predicted by maximum plant height and associated traits". In: Functional Ecology 32.2. Ed. by M. Tjoelker, pp. 247-259. URL: http://doi.wiley.com/10.1111/1365-2435.12972.

Gleason, S. M., M. Westoby, S. Jansen, B. Choat, U. G. Hacke, et al. (2016). "Weak tradeoff between xylem safety and xylem-specific hydraulic efficiency across the world's woody plant species". In: New Phytologist 209.1, pp. 123-136. URL: https://nph.onlinelibrary. wiley.com/doi/abs/10.1111/nph.13646.

Grace, J. B., D. R. Schoolmaster, G. R. Guntenspergen, A. M. Little, B. R. Mitchell, K. M. Miller, and E. W. Schweiger (2012). "Guidelines for a graph-theoretic implementation of structural equation modeling". In: Ecosphere 3.8, pp. 1-44. URL: http://doi.wiley. com/10.1890/ES12-00048.1.

Granier, A. (1985). "Une nouvelle méthode pour la mesure du flux de sève brute dans le tronc des arbres". In: Annales des Sciences Forestières 42.2, pp. 193-200. URL: http: //www.afs-journal.org/10.1051/forest:19850204.

Griffin-Nolan, R. J., J. A. Bushey, C. J. W. Carroll, A. Challis, J. Chieppa, et al. (2018). "Trait selection and community weighting are key to understanding ecosystem responses to changing precipitation regimes". In: Functional Ecology 32.7. Ed. by C. Fox, pp. 17461756. URL: http://doi.wiley.com/10.1111/1365-2435.13135.

Grote, R., A. Gessler, R. Hommel, W. Poschenrieder, and E. Priesack (2016). "Importance of tree height and social position for drought-related stress on tree growth and mortality". In: Trees 30.5, pp. 1467-1482. URL: https://doi.org/10.1007/s00468-016-1446-x.

Hajek, P., C. Leuschner, D. Hertel, S. Delzon, and B. Schuldt (2014). "Trade-offs between xylem hydraulic properties, wood anatomy and yield in Populus". In: Tree Physiology 34.7, pp. 744-756. URL: https://academic.oup.com/treephys/article-lookup/doi/10. 1093/treephys/tpu048.

Hertel, D., G. Moser, H. Culmsee, S. Erasmi, V. Horna, B. Schuldt, and C. Leuschner (2009). "Below- and above-ground biomass and net primary production in a paleotropical natural forest (Sulawesi, Indonesia) as compared to neotropical forests". In: Forest Ecology and Management 258.9, pp. 1904-1912. URL: https://linkinghub.elsevier.com/ retrieve/pii/S0378112709004940. 
Hietz, P., S. Rosner, U. Hietz-Seifert, and S. J. Wright (2016). "Wood traits related to size and life history of trees in a Panamanian rainforest". In: New Phytologist 213.1, pp. 170-180. URL: http://doi.wiley.com/10.1111/nph.14123.

Hoeber, S., C. Leuschner, L. Köhler, D. Arias-Aguilar, and B. Schuldt (2014). "The importance of hydraulic conductivity and wood density to growth performance in eight tree species from a tropical semi-dry climate". In: Forest Ecology and Management 330, pp. 126-136. URL: https://linkinghub.elsevier.com/retrieve/pii/S037811271400406X.

Horna, V., B. Schuldt, S. Brix, and C. Leuschner (2011). "Environment and tree size controlling stem sap flux in a perhumid tropical forest of Central Sulawesi, Indonesia". In: Annals of Forest Science 68.5, pp. 1027-1038. URL: http://link.springer.com/10. 1007/s13595-011-0110-2.

Jansen, S., B. Choat, and A. Pletsers (2009). "Morphological variation of intervessel pit membranes and implications to xylem function in angiosperms". In: American Journal of Botany 96.2, pp. 409-419. URL: https://bsapubs.onlinelibrary.wiley.com/doi/abs/ 10.3732/ajb.0800248.

Kattge, J., S. Díaz, S. Lavorel, I. C. Prentice, P. Leadley, et al. (2011). "TRY - a global database of plant traits". In: Global Change Biology 17.9, pp. 2905-2935. URL: https: //onlinelibrary.wiley.com/doi/abs/10.1111/j.1365-2486.2011.02451.x.

King, D. A., S. J. Davies, S. Tan, and N. S. M. Noor (2006). "The role of wood density and stem support costs in the growth and mortality of tropical trees". In: Journal of Ecology 94.3, pp. 670-680. URL: http://doi.wiley.com/10.1111/j.1365-2745.2006.01112.x.

Koch, G. W., S. C. Sillett, G. M. Jennings, and S. D. Davis (2004). "The limits to tree height". In: Nature 428.6985 , p. 851 . URL: https: / / www . nature.com / articles / nature02417.

Kotowska, M. M., D. Hertel, Y. A. Rajab, H. Barus, and B. Schuldt (2015). "Patterns in hydraulic architecture from roots to branches in six tropical tree species from cacao agroforestry and their relation to wood density and stem growth". In: Frontiers in Plant Science 6. URL: https://www.frontiersin.org/articles/10.3389/fpls.2015.00191/full.

Kunert, N., L. M. T. Aparecido, S. Wolff, N. Higuchi, J. dos Santos, A. C. de Araujo, and S. Trumbore (2017). "A revised hydrological model for the Central Amazon: The importance of emergent canopy trees in the forest water budget". In: Agricultural and Forest Meteorology 239, pp. 47-57. URL: http://www.sciencedirect.com/science/article/ pii/S0168192317300825.

Lechthaler, S., T. L. Turnbull, Y. Gelmini, F. Pirotti, T. Anfodillo, M. A. Adams, and G. Petit (2019). "A standardization method to disentangle environmental information from axial trends of xylem anatomical traits". In: Tree Physiology 39.3, pp. 495-502. URL: https://academic.oup.com/treephys/article/39/3/495/5123810.

Li, S., F. Lens, S. Espino, Z. Karimi, M. Klepsch, et al. (2016). "Intervessel pit membrane thickness as a key determinant of embolism resistance in angiosperm xylem". In: IAWA Journal 37.2, pp. 152-171. URL: https://brill.com/view/journals/iawa/37/2/articlep152_4.xml.

Lindenmayer, D. B., W. F. Laurance, and J. F. Franklin (2012). "Global Decline in Large Old Trees". In: Science 338.6112, pp. 1305-1306. URL: http://www.sciencemag.org/cgi/ doi/10.1126/science.1231070.

Link, R. M., S. Fuchs, D. Arias Aguilar, C. Leuschner, M. Castillo Ugalde, J. C. Valverde Otarola, and B. Schuldt (in press). "Tree height predicts the shape of radial sap flow profiles of Costa-Rican tropical dry forest tree species". In: Agricultural and Forest Meteorology. 
Liu, H., S. M. Gleason, G. Hao, L. Hua, P. He, G. Goldstein, and Q. Ye (2019). "Hydraulic traits are coordinated with maximum plant height at the global scale". In: Science Advances 5.2, eaav1332. URL: http://advances.sciencemag.org/lookup/doi/10.1126/ sciadv.aav1332.

Lutz, J. A., T. J. Furniss, D. J. Johnson, S. J. Davies, D. Allen, et al. (2018). "Global importance of large-diameter trees". In: Global Ecology and Biogeography 27.7, pp. 849864. URL: http://doi.wiley.com/10.1111/geb.12747.

Maherali, H., W. T. Pockman, and R. B. Jackson (2004). "Adaptive variation in the vulnerability of woody plants to xylem cavitation". In: Ecology 85.8, pp. 2184-2199. URL: http://doi.wiley.com/10.1890/02-0538.

Maréchaux, I., M. K. Bartlett, L. Sack, C. Baraloto, J. Engel, E. Joetzjer, and J. Chave (2015). "Drought tolerance as predicted by leaf water potential at turgor loss point varies strongly across species within an Amazonian forest". In: Functional Ecology 29.10. Ed. by K. Kitajima, pp. 1268-1277. URL: http://doi.wiley.com/10.1111/1365-2435.12452.

McCulloh, K. A. and J. S. Sperry (2005). "Patterns in hydraulic architecture and their implications for transport efficiency". In: Tree Physiology 25.3, pp. 257-267. uRL: https: //academic.oup.com/treephys/article-lookup/doi/10.1093/treephys/25.3.257.

McCulloh, K., J. S. Sperry, B. Lachenbruch, F. C. Meinzer, P. B. Reich, and S. Voelker (2010). "Moving water well: comparing hydraulic efficiency in twigs and trunks of coniferous, ring-porous, and diffuse-porous saplings from temperate and tropical forests". In: New Phytologist 186.2, pp. 439-450. URL: http://doi.wiley.com/10.1111/j.14698137.2010.03181.x.

McDowell, N. G., T. J. Brodribb, and A. Nardini (2019). "Hydraulics in the $21^{\text {st }}$ century". In: New Phytologist 224.2, pp. 537-542. URL: https://onlinelibrary.wiley.com/doi/abs/ 10.1111/nph.16151.

Medeiros, J. S., F. Lens, H. Maherali, and S. Jansen (2019). "Vestured pits and scalariform perforation plate morphology modify the relationships between angiosperm vessel diameter, climate and maximum plant height". In: New Phytologist 221.4, pp. 18021813.

Meinzer, F. C., B. J. Bond, J. M. Warren, and D. R. Woodruff (2005). "Does water transport scale universally with tree size?" In: Functional Ecology 19.4, pp. 558-565. URL: http://doi.wiley.com/10.1111/j.1365-2435.2005.01017.x.

Meinzer, F. C., G. Goldstein, and J. L. Andrade (2001a). "Regulation of water flux through tropical forest canopy trees: Do universal rules apply?" In: Tree Physiology 21.1, pp. 19 26. URL: https://academic.oup.com/treephys/article-lookup/doi/10.1093/treephys/21. 1.19 .

Mencuccini, M., F. Minunno, Y. Salmon, J. Martínez-Vilalta, and T. Hölttä (2015). "Coordination of physiological traits involved in drought-induced mortality of woody plants". In: New Phytologist 208.2, pp. 396-409. URL: http://doi.wiley.com/10.1111/nph.13461.

Moles, A. T., D. I. Warton, L. Warman, N. G. Swenson, S. W. Laffan, et al. (2009). "Global patterns in plant height". In: Journal of Ecology 97, pp. 923-932. URL: https: // besjournals.onlinelibrary.wiley.com/doi/abs/10.1111/j.1365-2745.2009.01526.x\% 5C\%4010.1111/\%5C\%28ISSN\%5C\%291365-2745.GLOBWA.

Moser, G., B. Schuldt, D. Hertel, V. Horna, H. Coners, H. Barus, and C. Leuschner (2014). "Replicated throughfall exclusion experiment in an Indonesian perhumid rainforest: wood production, litter fall and fine root growth under simulated drought". In: Global Change Biology 20.5, pp. 1481-1497. URL: http://doi.wiley.com/10.1111/gcb.12424. 
Muller-Landau, H. C. (2004). "Interspecific and Inter-site Variation in Wood Specific Gravity of Tropical Trees". In: BIOTROPICA 36.1, p. 20. URL: http://www.bioone.org/ perlserv/?request $=$ get-abstract $\% 5 \mathrm{C} \&$ doi $=10.1646 \% 5 \mathrm{C} \% 2 \mathrm{~F} 02119$.

Olson, M. E., D. Soriano, J. A. Rosell, T. Anfodillo, M. J. Donoghue, et al. (2018). "Plant height and hydraulic vulnerability to drought and cold". In: Proceedings of the National Academy of Sciences 115.29, pp. 7551-7556. URL: http://www.pnas.org/lookup/doi/ $10.1073 /$ pnas. 1721728115.

Pérez-Harguindeguy, N., S. Díaz, E. Garnier, S. Lavorel, H. Poorter, et al. (2013). "New handbook for standardised measurement of plant functional traits worldwide". In: Australian Journal of Botany 61.3, p. 167. URL: http://www.publish.csiro.au/?paper= BT12225.

Poorter, L. and F. Bongers (2006). "Leaf Traits Are Good Predictors of Plant Performance Across 53 Rain Forest Species". In: Ecology 87.7, pp. 1733-1743. URL: https: //esajournals.onlinelibrary.wiley.com/doi/abs/10.1890/0012-9658\%5C\%282006\%5C\% $2987 \% 5 \mathrm{C} \% 5 \mathrm{~B} 1733 \% 5 \mathrm{C} \% 3 \mathrm{ALTAGPO} \% 5 \mathrm{C} \% 5 \mathrm{D} 2.0 . \mathrm{CO} \% 5 \mathrm{C} \% 3 \mathrm{~B} 2$.

Poorter, L., C. V. Castilho, J. Schietti, R. S. Oliveira, and F. R. C. Costa (2018). "Can traits predict individual growth performance? A test in a hyperdiverse tropical forest". In: New Phytologist 219.1, pp. 109-121. URL: http://doi.wiley.com/10.1111/nph.15206.

Poorter, L., I. McDonald, A. Alarcón, E. Fichtler, J.-C. Licona, et al. (2010). "The importance of wood traits and hydraulic conductance for the performance and life history strategies of 42 rainforest tree species". In: New Phytologist 185.2, pp. 481-492. URL: http://doi.wiley.com/10.1111/j.1469-8137.2009.03092.x.

Powell, T. L., D. R. Galbraith, B. O. Christoffersen, A. Harper, H. M. A. Imbuzeiro, et al. (2013). "Confronting model predictions of carbon fluxes with measurements of Amazon forests subjected to experimental drought". In: New Phytologist 200.2, pp. 350-365. URL: http://doi.wiley.com/10.1111/nph.12390.

Powell, T. L., J. K. Wheeler, A. A. R. de Oliveira, A. C. L. da Costa, S. R. Saleska, P. Meir, and P. R. Moorcroft (2017). "Differences in xylem and leaf hydraulic traits explain differences in drought tolerance among mature Amazon rainforest trees". In: Global Change Biology 23.10, pp. 4280-4293. URL: https://onlinelibrary.wiley.com/doi/ abs/10.1111/gcb.13731.

R Core Team (2018). R: A Language and Environment for Statistical Computing. Vienna, Austria: R Foundation for Statistical Computing. URL: https://www.R-project.org/.

Réjou-Méchain, M., A. Tanguy, C. Piponiot, J. Chave, and B. Hérault (2017). "BIOMASS: an $\mathrm{R}$ package for estimating above-ground biomass and its uncertainty in tropical forests". In: Methods in Ecology and Evolution 8.9. Ed. by S. Goslee, pp. 1163-1167. URL: http://doi.wiley.com/10.1111/2041-210X.12753.

Roderick, M. L. and S. L. Berry (2001). "Linking wood density with tree growth and environment: a theoretical analysis based on the motion of water". In: New Phytologist 149.3, pp. 473-485. URL: http://doi.wiley.com/10.1046/j.1469-8137.2001.00054.x.

Röll, A., F. Niu, A. Meijide, J. Ahongshangbam, M. Ehbrecht, et al. (2019). "Transpiration on the rebound in lowland Sumatra". In: Agricultural and Forest Meteorology 274, pp. 160-171. URL: http:/ / www . sciencedirect.com / science/article/pii / S0168192319301637.

Rosell, J. A., M. E. Olson, and T. Anfodillo (2017). "Scaling of Xylem Vessel Diameter with Plant Size: Causes, Predictions, and Outstanding Questions". In: Current Forestry Reports 3.1, pp. 46-59. URL: http://link.springer.com/10.1007/s40725-017-0049-0.

Rosseel, Y. (2012). "lavaan : An R Package for Structural Equation Modeling". In: Journal of Statistical Software 48.2. URL: http://www.jstatsoft.org/v48/i02/. 
Rowland, L., R. L. Lobo-do-Vale, B. O. Christoffersen, E. A. Melém, B. Kruijt, et al. (2015b). "After more than a decade of soil moisture deficit, tropical rainforest trees maintain photosynthetic capacity, despite increased leaf respiration". In: Global Change Biology 21.12, pp. 4662-4672. URL: https://www.onlinelibrary.wiley.com/doi/abs/10. $1111 /$ gcb.13035.

Rüger, N., C. Wirth, S. J. Wright, and R. Condit (2012). "Functional traits explain light and size response of growth rates in tropical tree species". In: Ecology 93.12, pp. 26262636. URL: http://doi.wiley.com/10.1890/12-0622.1.

Russo, S. E., K. L. Jenkins, S. K. Wiser, M. Uriarte, R. P. Duncan, and D. A. Coomes (2010). "Interspecific relationships among growth, mortality and xylem traits of woody species from New Zealand: Tree growth, mortality and woody traits". In: Functional Ecology 24.2, pp. 253-262. URL: http://doi.wiley.com/10.1111/j.1365-2435.2009.01670. $\mathrm{x}$.

Ryan, M. G. (2015). "Tree mortality: Large trees losing out to drought". In: Nature Plants 1.10, p. 15150. URL: http://www.nature.com/articles/nplants2015150.

Santiago, L. S., G. Goldstein, F. C. Meinzer, J. B. Fisher, K. Machado, D. Woodruff, and T. Jones (2004). "Leaf photosynthetic traits scale with hydraulic conductivity and wood density in Panamanian forest canopy trees". In: Oecologia 140.4, pp. 543-550. URL: http://link.springer.com/10.1007/s00442-004-1624-1.

Schneider, C. A., W. S. Rasband, and K. W. Eliceiri (2012). "NIH Image to ImageJ: 25 years of image analysis". In: Nature Methods 9, pp. 671-675. URL: https://www.nature. com/articles/nmeth.2089.

Schuldt, B., C. Leuschner, N. Brock, and V. Horna (2013). "Changes in wood density, wood anatomy and hydraulic properties of the xylem along the root-to-shoot flow path in tropical rainforest trees". In: Tree Physiology 33.2, pp. 161-174. URL: https://academic. oup.com/treephys/article-lookup/doi/10.1093/treephys/tps122.

Schuldt, B., C. Leuschner, V. Horna, G. Moser, M. Köhler, O. van Straaten, and H. Barus (2011). "Change in hydraulic properties and leaf traits in a tall rainforest tree species subjected to long-term throughfall exclusion in the perhumid tropics". In: Biogeosciences 8.8, pp. 2179-2194. URL: http://www.biogeosciences.net/8/2179/2011/.

Schüller, E., M. Martínez-Ramos, and P. Hietz (2013). "Radial Gradients in Wood Specific Gravity, Water and Gas Content in Trees of a Mexican Tropical Rain Forest". In: Biotropica 45.3, pp. 280-287. URL: http://doi.wiley.com/10.1111/btp.12016.

Šímová, I., B. Sandel, B. J. Enquist, S. T. Michaletz, J. Kattge, et al. (2019). "The relationship of woody plant size and leaf nutrient content to large-scale productivity for forests across the Americas". In: Journal of Ecology. Ed. by A. Hector, pp. 1365-2745.13163. URL: https://onlinelibrary.wiley.com/doi/abs/10.1111/1365-2745.13163.

Slik, J. W. F., G. Paoli, K. McGuire, I. Amaral, J. Barroso, et al. (2013). "Large trees drive forest aboveground biomass variation in moist lowland forests across the tropics: Large trees and tropical forest biomass". In: Global Ecology and Biogeography 22.12, pp. 1261-1271. URL: http://doi.wiley.com/10.1111/geb.12092.

Smith, D. D. and J. S. Sperry (2014). "Coordination between water transport capacity, biomass growth, metabolic scaling and species stature in co-occurring shrub and tree species". In: Plant, Cell \& Environment 37.12, pp. 2679-2690. URL: https:// onlinelibrary.wiley.com/doi/abs/10.1111/pce.12408.

Sperry, J. S. (2003). "Evolution of Water Transport and Xylem Structure". In: International Journal of Plant Sciences 164.S3, S115-S127. URL: http://www.journals.uchicago. edu/doi/10.1086/368398. 
Sperry, J. S., K. L. Nichols, J. E. M. Sullivan, and S. E. Eastlack (1994). "Xylem Embolism in Ring-Porous, Diffuse-Porous, and Coniferous Trees of Northern Utah and Interior Alaska”. In: Ecology 75.6, pp. 1736-1752. URL: http://doi.wiley.com/10.2307/1939633.

Stephenson, N. L., A. J. Das, R. Condit, S. E. Russo, P. J. Baker, et al. (2014). "Rate of tree carbon accumulation increases continuously with tree size". In: Nature 507.7490, pp. 90-93. URL: https://www.nature.com/articles/nature12914.

Steppe, K., D. J. De Pauw, T. M. Doody, and R. O. Teskey (2010). "A comparison of sap flux density using thermal dissipation, heat pulse velocity and heat field deformation methods". In: Agricultural and Forest Meteorology 150.7-8, pp. 1046-1056. URL: https: //linkinghub.elsevier.com/retrieve/pii/S0168192310001000.

Tyree, M. T. (2003). "Hydraulic limits on tree performance: transpiration, carbon gain and growth of trees". In: Trees 17, pp. 95-100.

Tyree, M. T., S. D. Davis, and H. Cochard (1994). "Biophysical Perspectives of Xylem Evolution: is there a Tradeoff of Hydraulic Efficiency for Vulnerability to Dysfunction?" In: IAWA Journal 15.4, pp. 335-360. URL: https://brill.com/view/journals/iawa/15/ 4/article-p335_2.xml.

Warton, D. I., R. A. Duursma, D. S. Falster, and S. Taskinen (2012). "smatr 3- an R package for estimation and inference about allometric lines". In: Methods in Ecology and Evolution 3.2, pp. 257-259. URL: https://besjournals.onlinelibrary.wiley.com/doi/ abs/10.1111/j.2041-210X.2011.00153.x.

West, G. B. (1999). "The Fourth Dimension of Life: Fractal Geometry and Allometric Scaling of Organisms". In: Science 284.5420, pp. 1677-1679. URL: http://www.sciencemag. org/cgi/doi/10.1126/science.284.5420.1677.

Wheeler, J. K., J. S. Sperry, U. G. Hacke, and N. Hoang (2005). "Inter-vessel pitting and cavitation in woody Rosaceae and other vesselled plants: a basis for a safety versus efficiency trade-off in xylem transport". In: Plant, Cell and Environment 28.6, pp. 800812. URL: http://doi.wiley.com/10.1111/j.1365-3040.2005.01330.x.

Wickham, H., M. Averick, J. Bryan, W. Chang, L. D. McGowan, et al. (2019). "Welcome to the tidyverse". In: Journal of Open Source Software 4.43, p. 1686.

Wullschleger, S. D., F. C. Meinzer, and R. A. Vertessy (1998). "A review of whole-plant water use studies in trees". In: Tree Physiology 18.8-9, pp. 499-512. URL: https:// academic.oup.com/treephys/article/18/8-9/499/1632547.

Zach, A., B. Schuldt, S. Brix, V. Horna, H. Culmsee, and C. Leuschner (2010). "Vessel diameter and xylem hydraulic conductivity increase with tree height in tropical rainforest trees in Sulawesi, Indonesia". In: Flora - Morphology, Distribution, Functional Ecology of Plants 205.8, pp. 506-512. URL: https://linkinghub.elsevier.com/retrieve/ pii/S0367253009001418.

Zanne, A. E., M. Westoby, D. S. Falster, D. D. Ackerly, S. R. Loarie, S. E. J. Arnold, and D. A. Coomes (2010). "Angiosperm wood structure: Global patterns in vessel anatomy and their relation to wood density and potential conductivity". In: American Journal of Botany 97.2, pp. 207-215. URL: http://doi.wiley.com/10.3732/ajb.0900178. 



\title{
6 Do wood anatomical traits predict the productivity of Costa Rican tropical forest trees?
}

\author{
Roman M. Link ${ }^{1,2}$, Henrik Hartmann ${ }^{3}$, Dagoberto Arias Aguilar ${ }^{4}$, Juan Carlos \\ Valverde Otarola ${ }^{4}$, Marvin Castillo Ugalde ${ }^{4}$, Bernhard Schuldt ${ }^{1,2}$ \\ ${ }^{1}$ Plant Ecology and Ecosystems Research, Albrecht von Haller Institute for Plant Sciences, \\ University of Goettingen, Untere Karspüle 2, 37073 Göttingen, Germany \\ ${ }^{2}$ University of Würzburg, Julius-von-Sachs-Institute of Biological Sciences, Chair of Eco- \\ physiology and Vegetation Ecology, Julius-von-Sachs-Platz 3, 97082 Würzburg, Germany \\ 3 Department of Biogeochemical Processes, Max Planck Institute for Biogeochemistry, \\ 07745 Jena, Germany \\ ${ }^{4}$ Instituto Tecnológico de Costa Rica, Escuela de Ingeniería Forestal, Apartado Postal 159 \\ 7050, Cartago, Costa Rica
}

\subsection{Abstract}

- Tree productivity is strongly associated with wood anatomical correlates of hydraulic efficiency, which in turn both change with tree size and annual precipitation. While these relationships are conceptually well established, their analysis often relies on pairwise correlations between species aggregates, which can obscure true relationships.

- Based on a dataset of 201 trees belonging to 40 tropical tree species from 5 sites along a rainfall gradient in western Costa Rica, we analyzed the relationship between drought intensity, growth, tree size, wood properties, sapwood nonstructural carbohydrate $(N S C)$ storage and drought affiliation in a piecewise structural equation modelling framework.

- While we found a strong relationship between potential conductivity $\left(K_{\mathrm{p}}\right)$ and aboveground biomass increment, our model attributed this correlation to a common positive size dependence. Instead, canopy exposure and tree diameter were the most important predictors of growth. After accounting for their influence no significant effect of $K_{\mathrm{p}}$ and wood density on growth remained. NSC concentrations increased with wood density and canopy exposure. Drought-affiliated species were more common in drier sites and upper canopy levels, but unexpectedly had lower NSC storage.

- Our results imply a much lower effect of wood traits on tree growth than previously anticipated, while canopy exposure emerges as a major driver of growth rates and potentially drought responses.

Keywords: Growth rate, hydraulic conductivity, functional traits, structural equation modelling, wood anatomy 


\subsection{Introduction}

Tropical forests are among the most productive terrestrial ecosystems worldwide, and are estimated to account for around one-third of the total metabolic activity of the Earth's land surface (Field et al. 1998; Roy et al. 2001; Malhi 2012). A central tenet of xylem ecophysiology is that high productivity in trees requires an efficient hydraulic pathway (Tyree 2003), whose properties are tightly coordinated with photosynthesis rates (Brodribb 2009). In tropical forests, productivity is tied to water availability, which limits the growth rates of trees both directly and indirectly via its effect on the maximum size of the corresponding species (Š́mová et al. 2019). In the xylem of tall trees, water faces a higher flow resistance than in smaller trees because of the longer flow path, which has to be overcome by steeper water potential gradients and in consequence pushes them closer to their hydraulic limits (Ryan and Yoder 1997; Koch et al. 2004; Ryan et al. 2006). The increase of flow resistance with tree height is thought to be counteracted by an increase in vessel size from the apex to the stem base (Anfodillo et al. 2006; Olson et al. 2014; Rosell et al. 2017), leading to a coordination between maximum plant height and hydraulic traits (Liu et al. 2019). The coupling of hydraulic limitation and path length not only results in a positive association between tree height and precipitation on a global scale (Moles et al. 2009), but also locally puts taller trees at a disproportionately larger risk of drought-induced mortality (Lindenmayer et al. 2012; Bennett et al. 2015; Ryan 2015; Grote et al. 2016; Olson et al. 2018). The higher risk of hydraulic failure in taller trees is specifically relevant for the global carbon and water budget because they have higher absolute rates of carbon accumulation (Stephenson et al. 2014) and harbor a major fraction of the total aboveground biomass (AGB) of tropical forests (Bastin et al. 2015; Bastin et al. 2018; Fauset et al. 2015), making their conservation a priority to maintain full ecosystem functioning (Lutz et al. 2018).

Besides tree height, wood density is one of the tree traits most often linked to tree growth and mortality. Traditionally, it is assumed that low wood density is indicative of life history strategies that prioritize fast growth and resource acquisition over long-term stability (Muller-Landau 2004). This is in line with studies finding light-wooded trees to both have higher overall mortality rates (Chao et al. 2008; Wright et al. 2010; McDowell et al. 2018) and an increased susceptibility for drought-induced mortality (Phillips et al. 2010a; O'Brien et al. 2017). In addition, low wood density is often associated with higher growth rates (King et al. 2006; Rüger et al. 2012; Gibert et al. 2016; Francis et al. 2017; Falster et al. 2018; Fauset et al. 2019) related to lower investment in construction costs (King et al. 2006; van Gelder et al. 2006). Moreover, at least for seasonally dry tropical forests there is evidence for a relationship between wood density and a variety of wood-anatomical traits such as vessel density and the fraction of xylem area occupied by vessels (Hoeber et al. 2014; Hietz et al. 2016) that might themselves be related to growth rates. In either case, evidence regarding the link between growth rates and wood density is ambiguous, with some authors reporting it to hold only for trees below a certain diameter threshold (Francis et al. 2017), and others not finding a significant trend at all (Zhang and Cao 2009; Russo et al. 2010; Fan et al. 2012; Schuldt et al. 2013; Kotowska et al. 2015). Another factor that may be decisive for tree death under drought, at least in isohydric trees that close their stomata well before reaching critical levels of loss of hydraulic function, is the successive depletion of nonstructural carbohydrate (NSC) stores, eventually leading to a 
process referred to as 'carbon starvation' (McDowell et al. 2008; McDowell et al. 2011). However, while some authors provide evidence for a link between NSC storage and plant drought responses (Sevanto et al. 2014; O'Brien et al. 2014), it could not be established in all studies (Rowland et al. 2015a). The role of the depletion of NSC stores for droughtinduced mortality of trees is therefore still debated (Körner 2015; Hartmann 2015), and its analysis is complicated by methodological (Quentin et al. 2015) as well as epistemological difficulties (Hartmann and Trumbore 2016).

The composition of plant communities along rainfall gradients is likely to reflect adaptations to different degrees of drought intensity (Engelbrecht et al. 2007), and thus may permit to identify trait combinations that allow plants to survive in an increasingly drier climate. Given that under the projected changes in rainfall patterns and temperatures both wet and dry forest ecosystems are equally at risk of drought induced forest decline (Choat et al. 2012), an improved understanding the factors contributing to differences in plant growth and drought response is crucial.

In this study, we use a dataset of 201 trees belonging to 40 Costa Rican tropical forest species to assess how tree size and wood density affect wood anatomical traits along a gradient of seasonal drought intensity, and to investigate their joint effect on tree aboveground biomass increment as an indicator of productivity. We further study the relationship of wood density and tree size with sapwood nonstructural carbohydrate storage along the gradient, and its implication for species drought adaptations. Based on a piecewise structural equation modelling approach, we test the hypotheses that (i) after accounting for size effects and random species differences, biomass increment significantly increases with sapwood potential hydraulic conductivity, is lower for hard-wooded trees, and higher for more sun-exposed trees; (ii) the effect of rainfall on tree growth is fully explained by changes in wood properties, tree size and canopy position; (iii) sapwood potential conductivity is higher for taller trees, in more humid environments and for soft-wooded trees, while tree diameter has no explanatory value after accounting for the height effect; (iv) trees in drier environments and in more exposed canopy positions have to invest more sapwood NSC storage, while the smaller parenchyma fraction in hard-wooded species leads to lower NSC contents; (v) a higher wood density and higher investment into sapwood NSC storage are indicative of more drought-affiliated species, while understory species tend to be less drought-resistant. In addition, we compare the outcome of our structural equation model to the analysis of simple bivariate relationships between species averages of wood anatomical traits and tree properties to illustrate how the choice of methods affects the interpretation of results in trait-based ecological studies.

\subsection{Material and methods}

\subsubsection{Research sites and species selection}

The study was conducted on five research sites situated along a rainfall gradient at the western shoreline of Costa Rica (cf. Figure 6.1). The vegetation is constituted by seasonally dry secondary forest in the two northernmost sites and evergreen tropical rainforest with a varying degree of past land-use intensity in the remaining sites.

The studied trees are situated on permanent sample plots on research sites managed by the School of Forestry Engineering of the Instituto Tecnológico de Costa Rica (TEC). At each site, eight local tree species were selected to represent a gradient in wood density and 


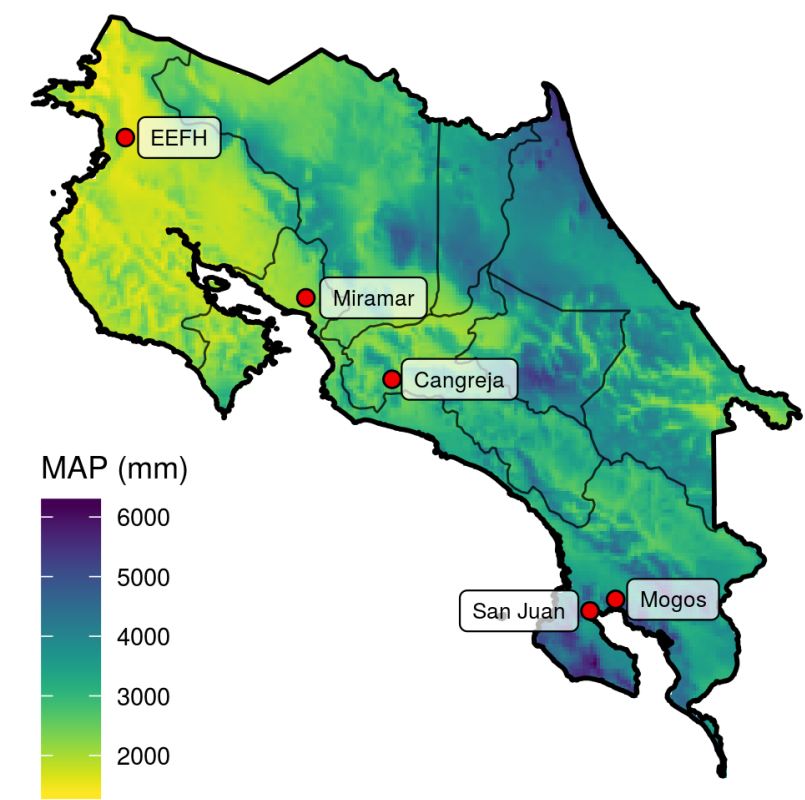

Figure 6.1: Map of the research area showing the gradient in long term mean annual precipitation based on datafrom the CHELSA climatologies (Karger et al. 2017).

tree height (cf. supplementary figure Figure S1). This was achieved by stratifying the 30 most common species at the site by wood density and average tree diameter (as a proxy for tree height, which was not available at all sites) and choosing eight species representing a broad range in both traits. In addition, additional species-specific information was taken into account such as the presence of large amounts of latex, which would have interfered with the hydraulic measurements performed at a subset of the sites. For each of the selected eight species per site, five experimental trees were selected from the 50th to 100th percentile of the diameter distribution to ensure selecting mature individuals.

For the northernmost site, high resolution climate data from a field climate station and precipitation data from daily rain gauge readings performed by the staff of the Estación Experimental Forestal Horizontes were available for the research interval from late2015 to early 2018 (Table 6.1). For the other four research sites, air temperature at breast height and relative humidity were hourly logged (iButton HygrochronTM, Dallas Semiconductor, Dallas, TX), while precipitation data were recorded based on weekly rain gauge readings over the study interval from mid 2015 to early 2018 (cf. Figure S2). Subsequently, temperature and relative humidity readings were used to calculate the air vapor pressure deficit $(V P D)$ based on Equation (11) in Allen et al. (1998).

\subsubsection{Measurements of wood density, tree size and growth rates}

All trees were equipped with dendrometer bands (UMS GmbH, München, Germany) between May and August 2015 to measure diameter at breast height $(D B H)$ and growth rates bimonthly until March/April 2018. The height of the experimental trees was determined during the initial measurement campaign in 2015 using a Vertex IV Hypsometer with Transponder T3 (Haglöf, Längsele, Sweden). Sapwood density (WD) was measured in the same interval on 5-7 cm long stem core samples taken at $1 \mathrm{~m}$ height with a $5 \mathrm{~mm}$ increment borer (Mora, Sweden). WD was calculated as the oven dry weight (dried at 105 
Table 6.1: Stand conditions and average climate conditions during the study interval. Given are coordinates, elevation, average stem density and basal area at the time of the last census, approximate canopy height (80th percentile of tree heights), mean annual precipitation, mean annual temperature, average relative humidity, and daytime (6:00 - 18:00) vapour pressure deficit including standard deviations.

\begin{tabular}{|c|c|c|c|c|c|c|c|c|c|}
\hline Site & Coordinates & $\begin{array}{c}\text { Elevation } \\
\text { (m a.s.l) }\end{array}$ & $\begin{array}{l}\text { Stem density } \\
\left(\mathrm{n} \mathrm{ha}^{-1}\right)\end{array}$ & $\begin{array}{c}\text { Basal area } \\
\left(\mathrm{m}^{2} \mathrm{ha}^{-1}\right)\end{array}$ & $\begin{array}{l}\text { Canopy hgt } \\
\text { (m) }\end{array}$ & $\begin{array}{l}\text { MAP } \\
(\mathrm{mm})\end{array}$ & $\begin{array}{l}\text { MAT } \\
\left({ }^{\circ} \mathrm{C}\right)\end{array}$ & $\begin{array}{c}\text { Rel. humidity } \\
(\%)\end{array}$ & $\begin{array}{c}\text { daily VPD } \\
\text { (kPa) }\end{array}$ \\
\hline EEFH & $10.711837^{\circ} \mathrm{N}$ & 97 & 493.9 & 20.9 & 16.4 & 987 & $26.9 \pm 3.9$ & $78.0 \pm 16.1$ & $1.31 \pm 0.94$ \\
\hline Miramar & $\begin{array}{l}85.550981^{\circ} \mathrm{E} \\
10.040557^{\circ} \mathrm{N}\end{array}$ & 58 & 365.3 & 30.0 & 20.4 & 2455 & $28.0 \pm 4.9$ & $83.7 \pm 17.9$ & $1.47 \pm 1.13$ \\
\hline & $84.748973^{\circ} \mathrm{E}$ & & & & & & & & \\
\hline Cangreja & $\begin{array}{r}9.699548^{\circ} \mathrm{N} \\
84.366278^{\circ} \mathrm{E}\end{array}$ & 468 & 552.2 & 40.1 & 34.1 & 5384 & $26.0 \pm 4.1$ & $91.4 \pm 17.0$ & $0.89 \pm 0.88$ \\
\hline Mogos & $\begin{array}{r}8.778120^{\circ} \mathrm{N} \\
83.373702^{\circ} \mathrm{E}\end{array}$ & 55 & 570.4 & 26.2 & 31.7 & 4208 & $27.5 \pm 4.3$ & $83.6 \pm 15.5$ & $1.25 \pm 1.09$ \\
\hline San Juan & $\begin{array}{r}8.729797^{\circ} \mathrm{N} \\
83.487431^{\circ} \mathrm{E}\end{array}$ & 219 & 524.5 & 28.4 & 34.7 & 4627 & $26.7 \pm 3.8$ & $88.2 \pm 11.4$ & $0.84 \pm 0.71$ \\
\hline
\end{tabular}

${ }^{\circ} \mathrm{C}$ ) divided by the wet volume (calculated from length and diameter measurements with a caliper). The tree diameter, height and wood density measurements were used to calculate aboveground biomass (AGB) estimates based on the improved pantropical equations from Chave et al. (2014) using R package BIOMASS (Réjou-Méchain et al. 2017). Average aboveground biomass increment $(A G B I)$ was estimated as the slope of the relationship between tree $\mathrm{AGB}$ and time. Analogously, relative diameter growth rates $(R G R)$ were estimated as the slope of relationship of natural log-transformed $D B H$ and time.

\subsubsection{Wood anatomical analyses}

Sapwood anatomy was analyzed on 5-7 $\mathrm{cm}$ long wood samples taken with a $5 \mathrm{~mm}$ increment corer that were collected in 2015 together with the samples used for wood density measurements. After sample collection, the samples were immediately stored in alcohol until processing at the University of Göttingen, Germany. Transverse sections were cut with a sliding microtome (G.S.L.1; Schenkung Dapples, Zurich, Switzerland) and digitalized at $100 \times$ magnification using a stereo-microscope with an automatic stage and an integrated digital camera (SteREOV20; Carl Zeiss MicroImaging GmbH, Göttingen, Germany). The analyzed cross-sections had an area of $145.5 \pm 54.1 \mathrm{~mm}^{2}$ (mean \pm standard deviation) and contained an average of 1386.4 vessels (range: 173-7557). The microscopic images were processed with Adobe Photoshop CS6 (v.13.0.1; Adobe Systems Inc., San Jose, CA, USA) and ImageJ (Schneider et al. 2012), using the particle analysis function to estimate vessel lumen area $\left(A_{\text {lumen }} ; \mu^{2}\right)$, vessel density $\left(\mathrm{VD} ; \mathrm{n} \mathrm{mm^{-2 }}\right)$ and equivalent vessel diameter $(D ; \mu \mathrm{m})$ calculated from the major and minor vessel radius (a and b) according to White (1991) as $D=\left(\left(32(a b)^{3}\right) /\left(a^{2}+b^{2}\right)\right)^{1 / 4}$. Based on $\mathrm{D}$, the hydraulically weighted average vessel diameter $\left(D_{h} ; \mu \mathrm{m}\right)$ was then calculated as $D_{h}=\Sigma D^{5} / \Sigma D^{4}$ (Sperry et al. 1994). Relative vessel lumen area $\left(\% A_{\text {lumen }} ; \%\right)$ was calculated as the sum of the areas of all vessels in a cross-section divided by the corresponding sapwood area $A_{x y l e m}$ according to $\% A_{\text {lumen }}=100\left(\Sigma A_{\text {lumen }}\right) / A_{\text {xylem }}$. Potential conductivity $\left(K_{p} ; \mathrm{kg} \mathrm{m}^{-1} \mathrm{MPa}^{-1} \mathrm{~s}^{-1}\right)$ was calculated according to the Hagen-Poiseuille equation as $K_{p}=\pi \cdot \rho \cdot\left(\Sigma D^{4}\right) /\left(128 \cdot \eta \cdot A_{x y l e m}\right)$, where $\eta$ is the viscosity and $\rho$ the density of water $\left(\eta=1.002 \cdot 10^{-9} \mathrm{MPa} \mathrm{s}\right.$ and $\rho=998.2 \mathrm{~kg} \mathrm{~m}^{-3}$ at $20^{\circ} \mathrm{C}$, respectively). 


\subsubsection{Measurement of non-structural carbohydrates}

NSC concentrations were analyzed from sapwood cores of a length of 5-7 cm and $5 \mathrm{~mm}$ diameter that were taken from all experimental trees during the initial sampling campaign in 2015. The samples were oven-dried at $105{ }^{\circ} \mathrm{C}$ within 48 hours after collection, and subsequently processed at the Max Planck Institute for Biogeochemistry in Jena to analyze glucose, fructose, sucrose and starch concentrations.

Soluble sugars were extracted from ground wood samples in an $80 \%$ ethanol solution heated at $90^{\circ} \mathrm{C}$ for $10 \mathrm{~min}$. After cool-down the extraction was centrifuged at 13,000 g for $1 \mathrm{~min}$ and the supernatant pipetted for quantification of glucose, fructose and sucrose concentrations. The remaining pellet was incubated for $30 \mathrm{~min}$ in an -amylase (SigmaAldrich) solution at $85^{\circ} \mathrm{C}$. After cool-down the extraction was also centrifuged at 13,000 $\mathrm{g}$ for 1 minute and then incubated for $30 \mathrm{~min}$ in an amyloglucosidase (Sigma-Aldrich) solution at $55^{\circ} \mathrm{C}$. Both the soluble sugar extracts and the hydrolyzed starch extracts were analyzed with High Performance Liquid Chromatography-Pulsed Amperometric Detection (HPLC-PAD, for more details see Landhäusser et al. 2018). The concentration of glucose hydrolysate was multiplied by 0.9 to account for mass gain during hydrolysation (Sullivan 1935).

\subsubsection{Water deficit affiliation}

To quantify plant drought adaptations, we adopted the approach of Esquivel-Muelbert et al. (2019). These authors defined a metric called 'water deficit affiliation' (WDA, mm) based on a large dataset of seasonal drought responses of trees in the western neotropics (Esquivel-Muelbert et al. 2017). The latter used the maximum cumulative water deficit (MCWD; cf. Aragão et al. 2007) dataset from Chave et al. (2014) to determine the preferences of Neotropical tree species in terms of dry season severity. The $M C W D$ quantifies the sum of the differences between monthly rainfall and evapotranspiration for all months in which evapotranspiration exceeds rainfall (Chave et al. 2014) and hence becomes increasingly more negative for sites more strongly affected by seasonal drought. Esquivel-Muelbert et al. $(2017 ; 2019)$ defined the $W D A$ of a species as the weighted average of $M C W D$ over 513 inventory plots in the Neotropics weighted by the species' abundance in each plot. Analogously, the authors calculated the abundance-weighted average of mean annual precipitation across a species' range $M A P_{\mathrm{sp}}$ based on precipitation data from WORLDCLIM (Hijmans et al. 2005). Of the 40 species used in this dataset, species-specific $W D A$ and $M A P_{\mathrm{sp}}$ were available for 26 species, genus-level data for 12 and family-level data for the remaining two species.

\subsubsection{Data analysis}

All statistical analyses were performed in R v. 3.6.0 (R Core Team 2019). To be able to analyze the causal network between wood properties, tree size, growth rates and plant drought responses while accounting for random variability between species, we used piecewise structural equation modelling (PSEM) in a multilevel framework (Shipley 2009), as implemented in R package piecewiseSEM v. 2.0.2 (Lefcheck 2016). Following the guidelines described in Grace et al. (2012), we first defined a meta-model based on theoretical knowledge and a-priori specified hypotheses about relations hips between theoretical constructs of interest (Figure 6.2a). This conceptual model was based on the assumption that 

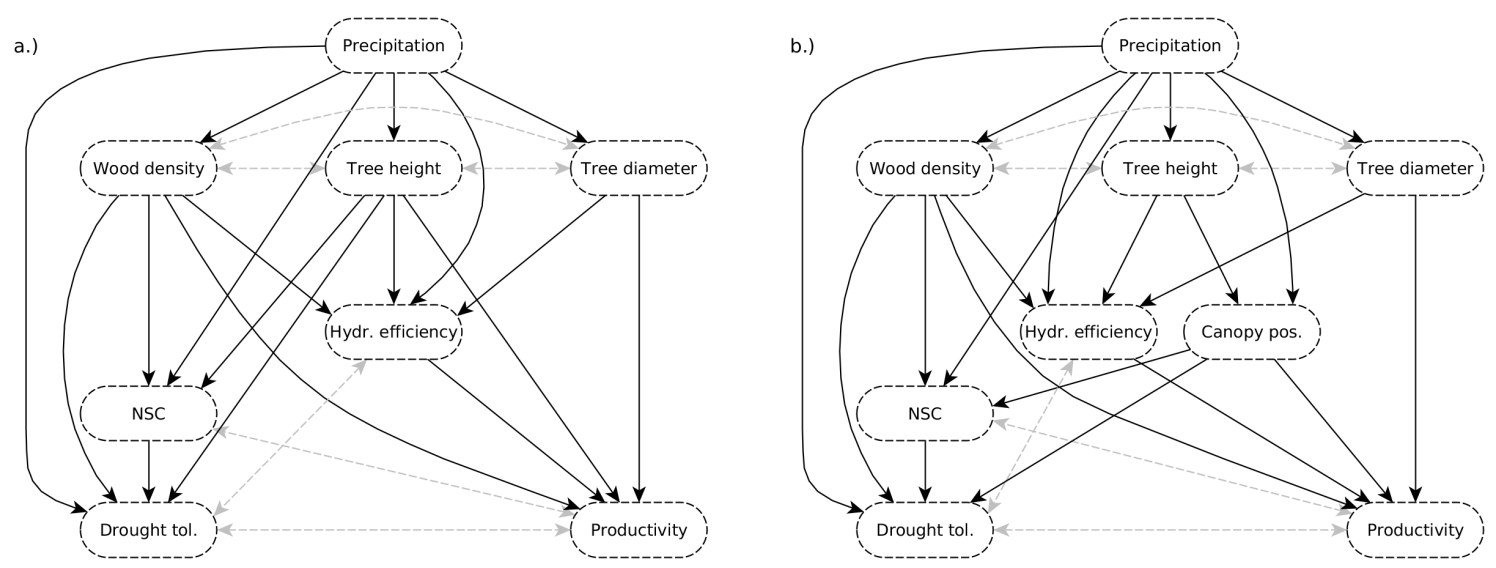

Figure 6.2: Meta-model for the assumed relationships between variables. Solid arrows represent directed causal links, dashed grey arrows indicate residual correlations.

differences in mean annual precipitation drive differences in tree size, wood density and wood anatomical traits, which in turn affect the nonstructural carbohydrate stocks and biomass productivity of trees. As tall trees experience a different microclimate than small trees independent of their diameter (e.g. Schuldt et al. 2011), we decided to treat diameter and height separately. Further, we assumed that after accounting for precipitation effects, the drought response of a tree is at least in part predicted by its investment in NSC, size and wood properties.

A summary table of all analyzed tree- and species-level variables, their averages, standard deviation, measurement units and the acronyms used for their representation is given in Table 2. Additionally, species-level averages of all variables are available in Table S1 in the supplementary material.

In order to minimize the effect of different measurement scales and skewed distributions on the subsequent analyses, the dataset was pre-processed with a series of transformations. All tree size, growth and anatomy-related traits were natural log-transformed to accommodate their strongly right-skewed distributions. The $N S C$-related variables were similarly right-skewed, but contained large number of zeroes related to observations near the detection threshold (especially in the case of the soluble sugars) and were therefore square-root transformed. $W D A$ - as a left-skewed variable with values strictly equal to or lower than to zero - was normalized by a $-\sqrt{-x}$-transformation, and $M A P_{s p}$ and $M A P_{\text {site }}$ were left untransformed. After the abovementioned transformations, all numeric variables were centered and scaled by their standard deviation to improve model convergence and ease the comparison of parameter estimates.

As there was a number of trees with incomplete observations (1 missing observation for $\mathrm{Hgt}$ and $W D, 4-5$ for growth rates and wood anatomy, and 11 for $N S C$ ), which currently cannot reliably be dealt with in a piecewise structural equation modelling context, missing data were imputed with a randomForest (Liaw and Wiener 2002) based imputation algorithm using R package missForest (Stekhoven and Buehlmann 2012). To improve the robustness of the imputation, species-level averages of all individual-level traits were appended to the matrix used for model training. Since model-fitting with the reduced dataset (i.e. without incomplete observations) essentially yielded the same results while decreasing the sample size, only the results for the imputed dataset are reported. A correlation matrix of the full dataset including all transformed variables is given in Figure 6.3. 
Table 6.2: Analyzed variables with the acronyms used for their representation, measurement units, mean and standard deviation.

\begin{tabular}{lllr}
\hline Acronym & Variable & Unit & Mean \pm SD \\
\hline$D B H$ & Diameter at breast height & $\mathrm{cm}$ & $340.9 \pm 176$ \\
$H g t$ & Tree height & $\mathrm{m}$ & $22 \pm 8.8$ \\
$C P$ & Canopy position & - & $0.815 \pm 0.26$ \\
$A G B$ & Aboveground biomass & $\mathrm{kg}$ & $1291 \pm 2287$ \\
$A G B I$ & Aboveground biomass increment & $\mathrm{kg} \mathrm{yr}^{-1}$ & $15.9 \pm 25.5$ \\
$R G R$ & Relative growth rate & - & $0.01 \pm 0.01$ \\
$W D$ & Wood density & $\mathrm{g} \mathrm{cm}^{-3}$ & $0.551 \pm 0.15$ \\
$\% A_{\text {lumen }}$ & \% lumen area & $\%$ & $12.3 \pm 12$ \\
$d_{h}$ & Hydr. weighted vessel diameter & $\mu \mathrm{m}^{2}$ & $153.3 \pm 56.1$ \\
$V D$ & Vessel density & $\mathrm{n} \mathrm{mm}{ }^{2}$ & $18 \pm 37.7$ \\
$K_{\mathrm{p}}$ & Potential conductivity & $\mathrm{kg} \mathrm{m}^{-1} \mathrm{MPa}^{-1} \mathrm{~s}^{-1}$ & $78.8 \pm 94.3$ \\
$N S C$ & Total NSC content & $\mathrm{mg} \mathrm{g}^{-1}$ & $35.8 \pm 33.7$ \\
SolSug & Sol. sugar content & $\mathrm{mg} \mathrm{g}^{-1}$ & $2.1 \pm 2.5$ \\
Starch & Starch content & $\mathrm{mg} \mathrm{g}^{-1}$ & $33.7 \pm 33.3$ \\
$M A P_{s p}$ & Sp. range MAP & $\mathrm{mm} \mathrm{yr}^{-1}$ & $2297 \pm 465$ \\
WDA & Sp. range mean $C W D$ & $\mathrm{~mm} \mathrm{yr}^{-1}$ & $-224 \pm 155$ \\
\hline
\end{tabular}

In order to identify common axes of variation between the observed traits and to single out the most relevant traits for later use in the PSEM, in a first, exploratory step of our analysis, we performed a principal component analysis (PCA) using R function prcomp() based on the full imputed and transformed dataset used for model fitting. In addition, we performed a set of bivariate standardized major axis (SMA) regressions of species averages of anatomical traits against averages of annual growth rates, tree heights and wood density using R package smatr v. 3.4-8 (Warton et al. 2012) to enable the comparison of our results with scaling coefficients found in similar studies (cf. Poorter et al. 2010; Fan et al. 2012).

Initial model implementations suggested that due to the pronounced change in canopy height along the transect (cf. Figure 6.3, Table 1), crown position relative to the canopy was a much more sensible predictor for height-related effects than tree height itself (see discussion). For this reason, we developed a revised meta-model that included canopy position $\left(C P\right.$; arbitrarily defined as the height of a tree relative to the $80^{\text {th }}$ percentile of height at the site) as an additional variable (cf. Figure S3), which we assumed to mediate the height effects on all variables besides wood anatomy (cf. Figure 6.2b). As the different wood anatomical traits were highly correlated and $K_{\mathrm{p}}$ - which effectly combines the information about vessel density and the vessel diameter distribution - showed the strongest correlations with most structural and growth-related traits (cf. Figure 6.3), we chose $K_{\mathrm{p}}$ as the sole representation of wood anatomical traits in our model. Analogously, we used the total $N S C$ concentration as an integrator of the different types of analyzed $N S C$ components, and represented the drought tolerance of a species by the WDA.

All submodels except for the model for WDA were fitted with linear mixed effects models (LMM) using R package lme4 v. 1.1-21 (Bates et al. 2015), using fixed effects as indicated in Figure $6.2 \mathrm{~b}$, and allowing the intercept to vary randomly between species. The inclusion of a higher nesting level for site was not possible as the low number of 5 replicates (cf. Bolker et al. 2009) led to boundary problems and convergence issues for most models. 


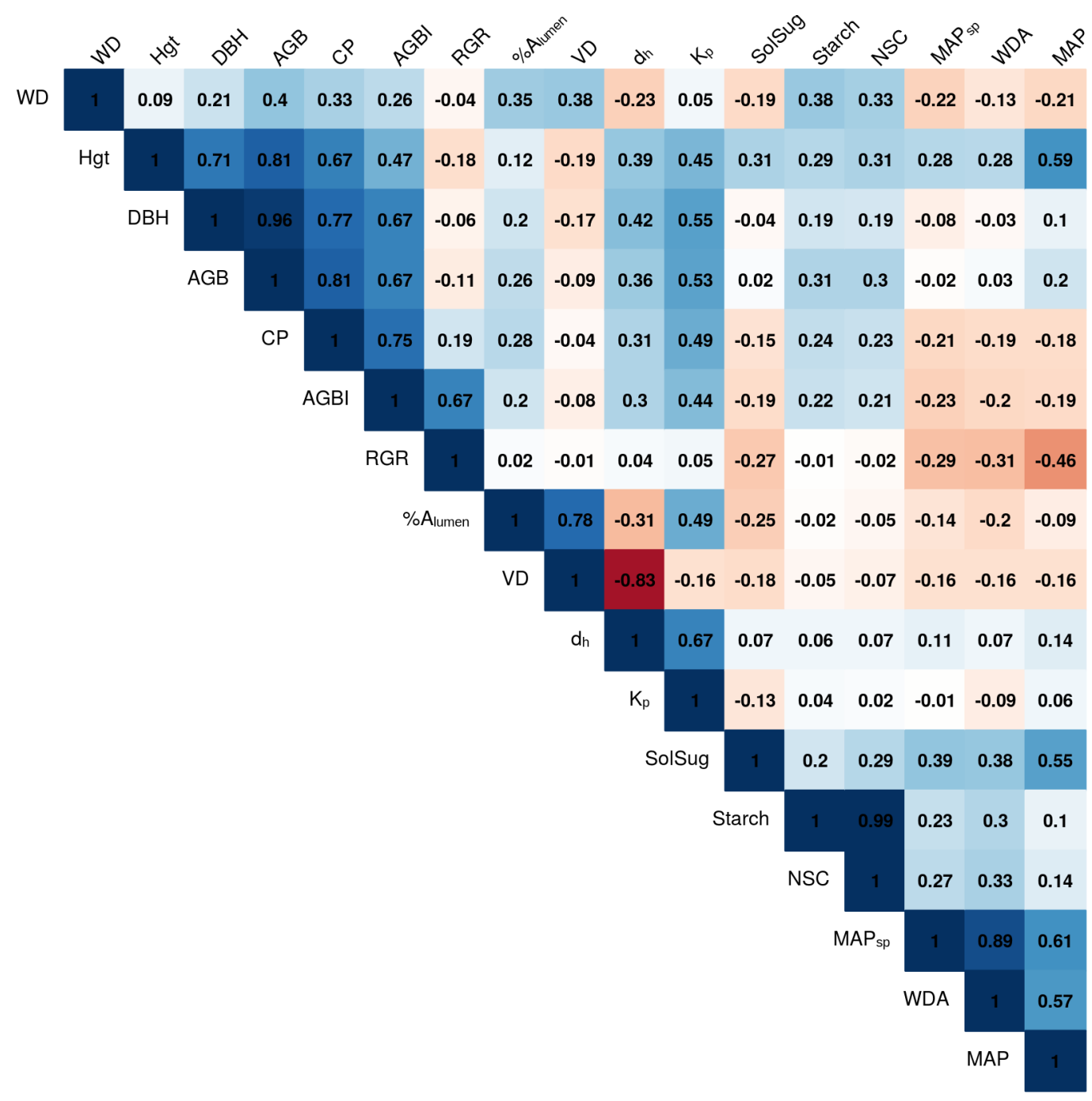

Figure 6.3: Correlation heat map of the transformed dataset used for modeling.

However, in all models with a site effect that did converge, the estimated standard deviation of the site effect was near zero, indicating that existing site differences in the response were well accommodated by the effect of MAP. All LMM were fitted with Restricted Maximum Likelihood. Inference was based on Wald $t$-tests with degrees of freedom based on Satterthwaite's correction using R package lmerTest v. 3.1-0 (Kuznetsova et al. 2017). As the $W D A$ values were identical for all individuals of a species, it was not possible to include species-level random effects. To account for the nesting in site in this model, we fitted the corresponding submodel with a generalized least squares (GLS) model based on R package nlme v. 2.1-139 (Pinheiro et al. 2019) using a compound-symmetric correlation structure (Pinheiro and Bates 2000) with site as a nesting variable. To test whether the data quality of the WDA data affected the model outcome, we fitted a second model that additionally included a constant variance function allowing for differences in error variances between the species-level and the genus/family-level values of $W D A$, and compared it against the model with a single error variance using a likelihood ratio test. The reported scaled path coefficients, marginal and conditional $R^{2}$ (Nakagawa et al. 2017) and reports of model p-values based on Shipley's d-separation test (Shipley 2000) are based on the piecewiseSEM model output (Lefcheck 2016). 


\subsection{Results}

\subsubsection{Associations between wood anatomical traits and tree properties}

Standardized major axis regressions of species means of wood anatomical traits against averages of tree properties suggested a positive relationship between hydraulically weighted vessel diameter and both tree height and aboveground biomass increment, while it did not differ between trees with different wood density (Figure 6.4). Average vessel density, on the other hand, did not change with tree size and growth, but had a significant positive relationship with wood density (Figure 6.4). The behavior of species-level averages of potential hydraulic conductivity mirrored the changes in vessel diameter, with significant changes both with tree height and AGBI, but no change with WD (Figure 6.4). The Pearson correlation between the analyzed variables (Figure 6.3) suggest species-level relationships between the variables largely mirrored the behavior on individual level.

\subsubsection{Principal component analysis}

A biplot of the first two axes of the PCA based on the transformed values of tree properties is shown in Figure 6.5. The first axis, which explained $31.03 \%$ of the variance, was highly positively related to tree size and directly size-related traits such as absolute biomass growth rates and canopy position. In addition, it was positively associated with potential conductivity. The second axis explained $20.5 \%$ of the variance and was highly negatively associated with the WDA and the average MAP in the range of the analyzed species, and separated the dry forest sites (EEFH and Miramar) from the humid evergreen rainforest sites (La Cangreja, Mogos and San Juan), especially in the range of lower scores on the first axis (i.e. for smaller trees). In addition, the second axis was negatively related to the concentration of soluble sugars, indicating that soluble sugar stores were larger for tree species associated with lower levels of seasonal drought. Additionally, the second axis was positively associated with wood anatomical traits (vessel density and percent lumen area) as well as relative growth rates. Notably, wood density was not strongly associated with neither of the two axes.

\subsubsection{Piecewise structural equation model}

Figure 6.6 shows a path diagram for the final piecewise structural equation model. Partial residual plots illustrating the effects of all predictors in all submodels when controlling for the effect of all other predictors are given in Figure 6.7. A test of directed separation indicated that the final path model was consistent with the data (Fischer's $C=15.368$, df $=20, \mathrm{P}=0.755)$. The fixed effects explained between $0.8 \%$ and $96.3 \%$ of the variance in the dependent variables in the different submodels $(33.9 \%$ on average, compare marginal $\mathrm{R}^{2}$ column in Table 3). Including random species differences increased the proportion of explained variance to over $70 \%$ in all submodels, with the exception of the submodel for $W D A$ where the inclusion of species-level random effects was not possible (see Figure 6.6, conditional $R^{2}$ column in Table 3). This indicates that while there was a considerable amount of unexplained between-species variance, most of the observed variables were relative consistent within species.

While aboveground biomass increment responded strongly positively to tree diameter $(t$ $=2.885$, eff. $\mathrm{df}=172.6, \mathrm{p}<0.001)$ and crown position relative to the canopy height $(t$ 

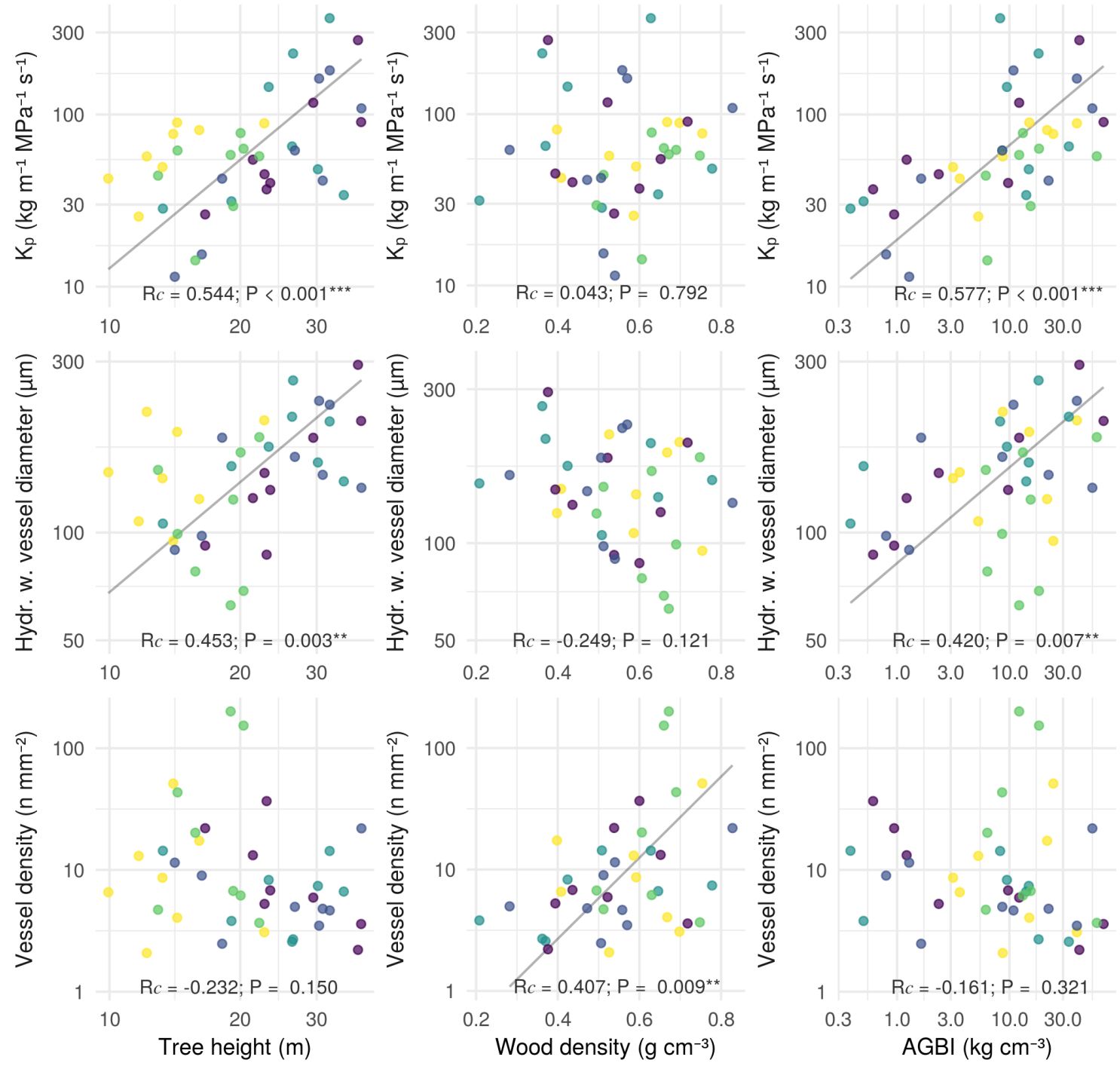

- Cangreja - San Juan - Mogos - Miramar

EEFH

Figure 6.4: Results of species-level standardized major axis regressions of the relationship of wood anatomical variables with tree height, wood density and aboveground biomass increment. Shown are species averages of the analyzed variables (points, colored by site) and the regression predictions of the significant relationships. 
Table 6.3: Estimated coefficients of the piecewise structural equation model (cf. Figure 6.6). Shown are the standardized and the unscaled parameter estimate with the corresponding standard error for the latter, $t$-statistic, effective degrees of freedom, p-value for the null hypothesis that a parameter is equal to zero, the estimated standard deviation for the random intercept for species $\left(S D_{s p}\right)$ and the marginal and conditional $R^{2}$ (explained variance by the fixed effects and variance explained in total by both fixed effects and random species effects). Residual correlations between variables are indicated by double tildes.

\begin{tabular}{|c|c|c|c|c|c|c|c|c|c|c|}
\hline Resp. & Pred. & Std.Est. & Unsc.Est. & Std.Err. & t-val. & df & $\operatorname{Pr}(>|t|)$ & $\mathrm{SD}_{\mathrm{sp}}$ & Marg. $\mathrm{R}^{2}$ & Cond. $\mathrm{R}^{2}$ \\
\hline \multirow[t]{4}{*}{$\overline{W D A}$} & $C P$ & -0.149 & -0.146 & 0.059 & -2.481 & 201.0 & $0.014 *$ & - & 0.42 & - \\
\hline & NSC & 0.335 & 0.319 & 0.059 & 5.388 & 201.0 & $<0.001 * * *$ & & & \\
\hline & $W D$ & -0.090 & -0.093 & 0.061 & -1.513 & 201.0 & 0.132 & & & \\
\hline & $M A P$ & 0.496 & 0.483 & 0.053 & 9.167 & 201.0 & $<0.001 * * *$ & & & \\
\hline \multirow[t]{4}{*}{$A G B I$} & $D B H$ & 0.254 & 0.245 & 0.085 & 2.885 & 172.6 & $0.004 * *$ & 0.40 & 0.57 & 0.73 \\
\hline & $C P$ & 0.542 & 0.535 & 0.075 & 7.111 & 196.0 & $<0.001 * * *$ & & & \\
\hline & $W D$ & 0.034 & 0.035 & 0.067 & 0.530 & 80.7 & 0.597 & & & \\
\hline & $K_{p}$ & 0.027 & 0.027 & 0.065 & 0.414 & 159.4 & 0.68 & & & \\
\hline \multirow[t]{3}{*}{$N S C$} & $C P$ & 0.181 & 0.186 & 0.068 & 2.730 & 196.8 & $0.007 * *$ & 0.75 & 0.18 & 0.7 \\
\hline & $W D$ & 0.296 & 0.321 & 0.094 & 3.418 & 137.4 & $<0.001 * * *$ & & & \\
\hline & MAP & 0.240 & 0.245 & 0.127 & 1.931 & 38.9 & 0.061 & & & \\
\hline \multirow[t]{4}{*}{$K_{p}$} & $D B H$ & 0.471 & 0.454 & 0.087 & 5.221 & 192.7 & $<0.001 * * *$ & 0.71 & 0.18 & 0.73 \\
\hline & $H g t$ & -0.068 & -0.069 & 0.095 & -0.729 & 175.3 & 0.467 & & & \\
\hline & MAP & 0.054 & 0.053 & 0.131 & 0.407 & 50.6 & 0.686 & & & \\
\hline & $W D$ & -0.024 & -0.025 & 0.086 & -0.292 & 143.5 & 0.771 & & & \\
\hline \multirow[t]{2}{*}{$C P$} & $H g t$ & 1.193 & 1.224 & 0.008 & 161.675 & 168.9 & $<0.001 * * *$ & 0.66 & 0.96 & $>0.99$ \\
\hline & MAP & -0.908 & -0.904 & 0.031 & -29.350 & 39.5 & $<0.001 * * *$ & & & \\
\hline $\mathrm{Hgt}$ & $M A P$ & 0.602 & 0.585 & 0.110 & 5.315 & 38.0 & $<0.001 * * *$ & 0.19 & 0.34 & 0.77 \\
\hline$D B H$ & $M A P$ & 0.091 & 0.093 & 0.144 & 0.646 & 38.0 & 0.522 & 0.88 & 0.01 & 0.76 \\
\hline$W D$ & $M A P$ & -0.231 & -0.217 & 0.150 & -1.450 & 38.0 & 0.155 & 0.93 & 0.05 & 0.88 \\
\hline$\sim$ WDA & $\sim \sim K_{p}$ & -0.041 & -0.041 & & -0.574 & 201.0 & 0.283 & & & \\
\hline \multirow[t]{2}{*}{$\sim \sim A G B I$} & $\sim W D A$ & -0.042 & -0.042 & & -0.590 & 201.0 & 0.278 & & & \\
\hline & $\sim N S C$ & 0.073 & 0.073 & & 1.030 & 201.0 & 0.152 & & & \\
\hline \multirow[t]{2}{*}{$\sim \sim H g t$} & $\sim \sim D B H$ & 0.566 & 0.566 & & 9.657 & 201.0 & $<0.001 * * *$ & & & \\
\hline & $\sim \sim W D$ & 0.122 & 0.122 & & 1.727 & 201.0 & $0.043 *$ & & & \\
\hline$\sim \sim W D$ & $\sim \sim D B H$ & 0.138 & 0.138 & & 1.964 & 201.0 & $0.025 *$ & & & \\
\hline
\end{tabular}




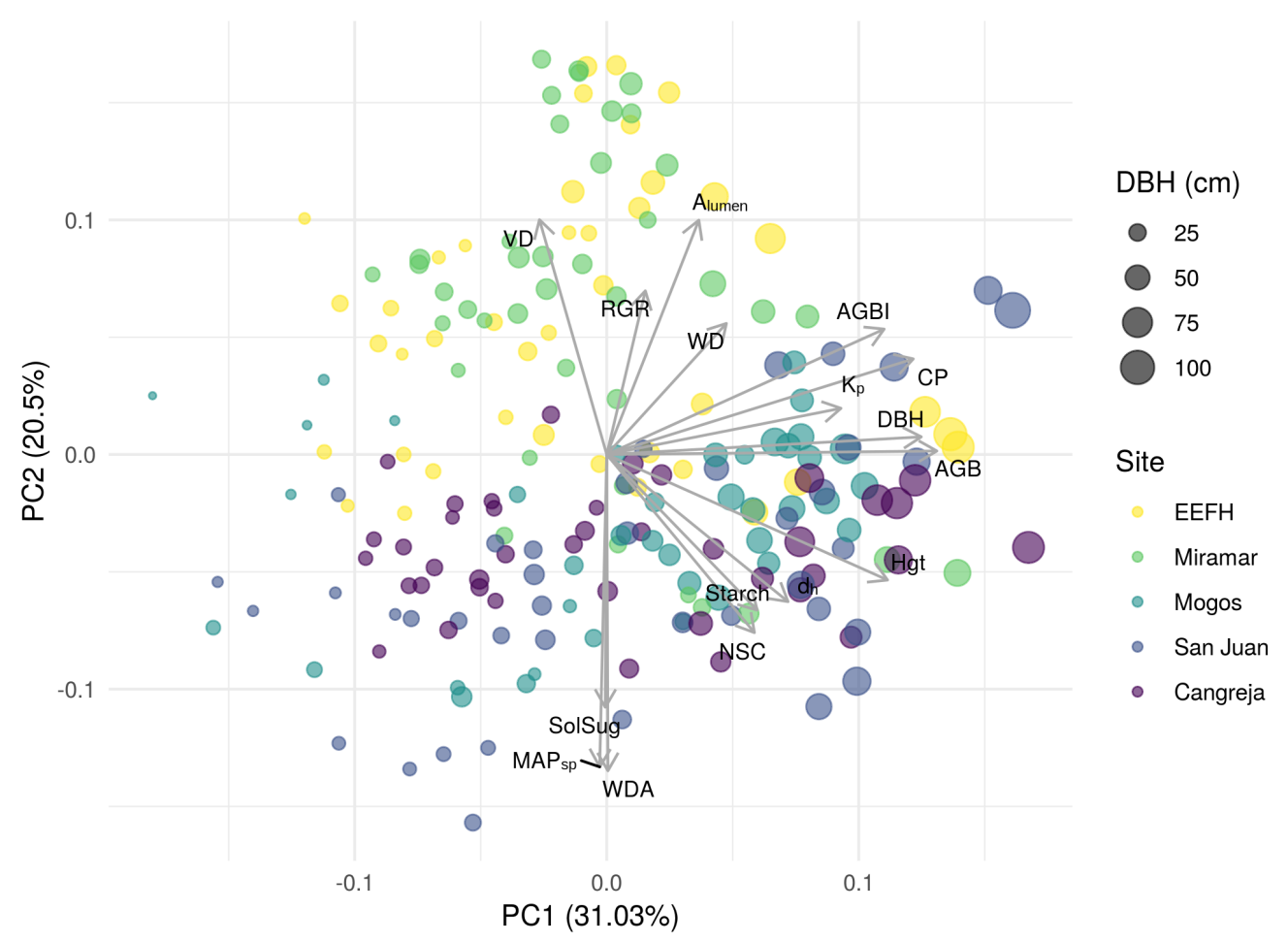

Figure 6.5: Biplot of the first two axes of the principal component analysis of the analyzed tree traits overlaid with the variable loadings. Explained variance of the first two PCA axes: 51.53 \%. Colors: research sites; size: tree diameter.

$=7.111$, eff. $\mathrm{df}=196, \mathrm{p}<0.001)$, it did not change significantly with wood properties (Figure 6.6, Table 3). Mean annual precipitation during the sampling interval had a highly significant positive effect on tree height $(t=5.32$, eff. $\mathrm{df}=38.0, \mathrm{p}<0.001)$, while it did neither significantly affect wood density nor tree diameter (Figure 6.6, Table 3). As expected, $H g t, D B H$ and $W D$ showed significant residual correlations that were not explained by precipitation and random species effects (Figure 6.6, Table 3). Together, $\mathrm{Hgt}$ and $M A P$ explained nearly the entire variance in $C P$ (marginal $R^{2}=0.963$, conditional $R^{2}$ $=0.998)$, which indicates that $M A P$ alone was sufficient to explain site-specific differences in average canopy height (Figure 6.6, Table 3). Notably, while $K_{\mathrm{p}}$ responded highly significantly positively to tree diameter, it was decoupled from $M A P, W D$ and tree height, and did not have a significant relationship with growth (Figure 6.6, Table 3). This implies that all observed correlations of $K_{\mathrm{p}}$ with other traits - most notably the strong positive association with $A G B I$ (cf. Figure 6.3) - resulted from a shared positive relationship with tree size.

The total NSC concentration in the sapwood was significantly higher both for trees with denser sapwood and for trees closer to the forest canopy, but only showed a marginally significant increase with MAP (Figure 6.6, Table 3). Interestingly, the NSC concentration in the sapwood had a significant effect on the $W D A$ - and hence drought response - of a tree, with tree species associated with sites that on average are subjected to higher drought intensity tending to have smaller NSC stores (Figure 6.6, Table 3). Additionally, WDA was significantly lower for trees in higher canopy positions, indicating that trees in more exposed positions tended to belong to more drought-adapted species (Figure 6.6, Table 3). The near-zero within-site correlation of $\rho=-0.005$ in the submodel for WDA 
indicates that the site differences in $W D A$ were fully accounted for by the differences in $M A P$. The inclusion of separate variances for species- and genus-/family-level WDA did not significantly improve the model $\left(\chi^{2}=1.417, \mathrm{df}=1, \mathrm{p}=0.234\right)$, which indicates that the WDA data quality did not have a significant influence on the results. For that reason, all reported results are based on the simpler model with homogeneous variances. Notably, after accounting for the effects of the other predictors in the model, no significant residual correlation remained neither between $A G B I$ and $N S C(t=1.030, \mathrm{df}=201, \mathrm{P}=0.152)$ nor between $A G B I$ and $W D A(t=-0.590, \mathrm{df}=201, \mathrm{P}=0.278)$. Accordingly, there neither was evidence for a tradeoff between growth and $N S C$ storage nor between growth and drought affiliation.

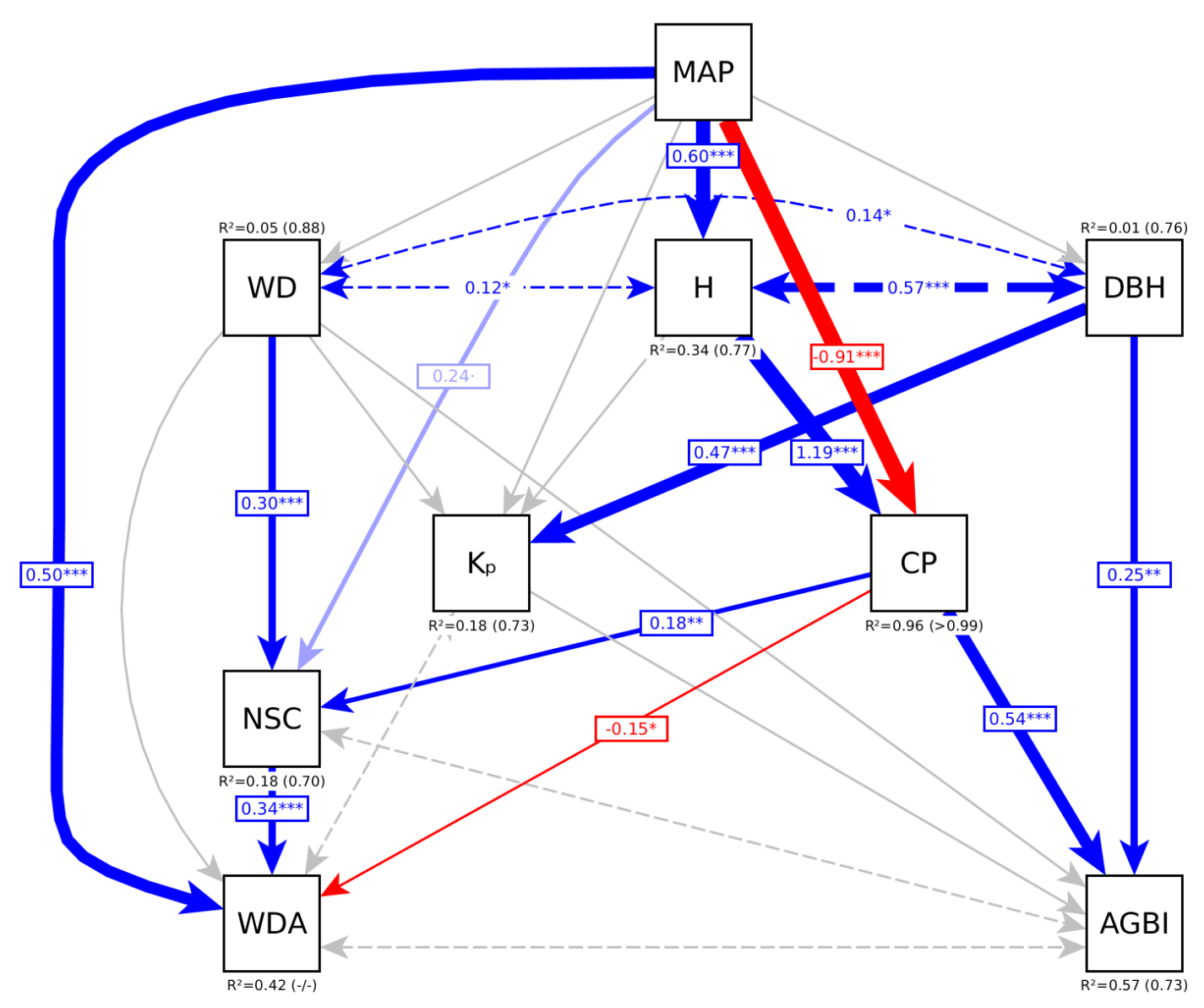

Figure 6.6: Path diagram of the fitted piecewise structural equation model (Fischer's $C=15.368$, $\mathrm{df}=20, \mathrm{P}=0.755)$. Positive relationships are displayed in blue, negative relationships in red, and insignificant relationships are displayed in grey. Solid arrows represent directed causal links, dashed arrows indicate residual correlations. The width of the arrows indicate the strength of the links. For each significant path, the scaled path coefficient with stars indicating the corresponding $\mathrm{p}$ value is displayed $\left({ }^{* * *} \mathrm{p}<0.001,{ }^{* *}-\mathrm{p}<0.01{ }^{*}-\mathrm{p}<0.05\right.$; cf. Table 3). $R^{2}$-values next to the endogenous variables refer to the marginal and (in brackets) conditional $R^{2}$ (where applicable). 

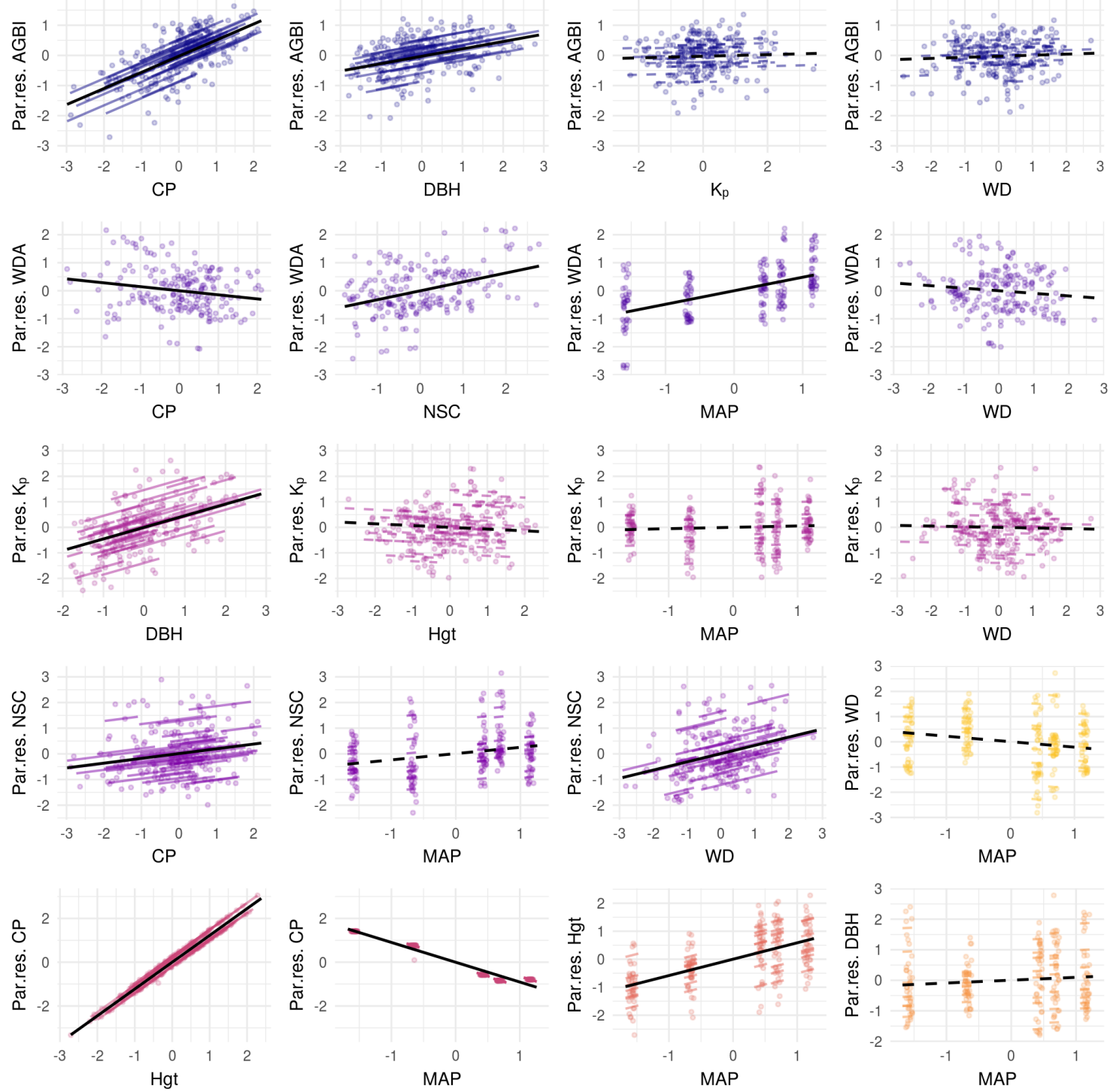

Figure 6.7: Partial residual plots for all links in the piecewise SEM shown in Figure 6.6 on the transformed, scaled and centered scale. Dots show partial residuals (hypothethical values of each observation when holding all other predictors at their average values), colored lines show conditional predictions (species-specific predictions assuming all other variables were at their average values) and black lines show marginal predictions (overall predictions when holding all other variables at their average values). Significant relationships are indicated by solid lines, colors show different responses. 


\subsection{Discussion}

\subsubsection{Determinants of plant growth}

Our piecewise structural equation model indicates that the relationship between precipitation and aboveground biomass increment can be fully explained by changes in functional and structural traits along the studied rainfall gradient. As expected, biomass growth rates were strongly size dependent: trees with larger diameters grew significantly faster, especially when they had access to the canopy level, with canopy position being the single most influential predictor in the submodel for biomass increment.

After accounting for size and canopy position effects, causal links could be identified neither between wood density nor potential conductivity and $A G B I$. A lack of relationship between WD and AGBI has repeatedly been reported in other studies (Zhang and Cao 2009; Russo et al. 2010; Fan et al. 2012; Schuldt et al. 2013; Kotowska et al. 2015), and is already apparent in the relatively low bivariate correlation between the two variables $(r=$ 0.26; cf. Figure 6.3). It is however surprising that the PSEM did not provide evidence for a positive effect of potential hydraulic conductivity on biomass increment, either. In this context, it is important to underline that when focusing on bivariate relationships at the species level, we found a highly significant positive association between AGBI and $K_{\mathrm{p}}$ that was comparable in magnitude to previously reported findings for growth- $K_{\mathrm{p}}$ relationships (Poorter et al. 2010; Fan et al. 2012; Hoeber et al. 2014). While $A G B I$ and $K_{\mathrm{p}}$ were relatively highly correlated at the species level (cf. Figure 6.4), our model showed this correlation to result from a common dependence on $D B H$, with larger trees having both higher $K_{\mathrm{p}}$ and larger productivity. The missing causal link between the two variables may be related to the fact that xylem potential hydraulic conductivity is an imperfect proxy for true xylem efficiency. First, due to the tapering of vessel dimensions along the flow path (Olson et al. 2014; Rosell et al. 2017), the potential conductivity measured at breast height is not necessarily representative of its value in the canopy. Second, $K_{\mathrm{p}}$ does not incorporate information about the hydraulic resistivity water is facing when passing through pit membranes (Sperry et al. 2005; Wheeler et al. 2005), which depends on pit membrane diameter and thickness, pit frequency, vessel connectivity and the distribution of vessel lengths (Choat et al. 2006; Choat et al. 2008; Link et al. 2018). Furthermore, there is substantive evidence that trees rarely use the full extent of their hydraulic potential (cf. Dietrich et al. 2018; Körner 2019), which decouples theoretical values of potential conductivity from actually realized sap flow rates, hence limiting its effect on growth.

In general, while both species level SMA models and bivariate correlations indicated relationships between anatomical traits and tree properties that were in line with previously reported results (Poorter et al. 2010; Fan et al. 2012; Hoeber et al. 2014; Hietz et al. 2016), the remaining effects in our model after accounting for confounding covariates and species effects were remarkably low. Potential hydraulic conductivity did not only have no direct effect on $A G B I$, but was also unrelated to wood density, and practically independent from precipitation and $W D A$. A link between wood density and $K_{\mathrm{p}}$ is not apparent neither at tree nor species level, indicating that our data are not consistent with a hypothesized trade-off between water transport and mechanical support (cf. Hietz et al. 2016). Surprisingly, we found both $K_{\mathrm{p}}$ and vessel diameter to be much closer related to DBH than to tree height. This suggests that size-dependent changes in vessel dimensions might be influenced by variables that change with increasing tree diameter, such as cambial age (cf. Spicer and Gartner 2001), instead of invariably scaling with the length of the flow path 
and hence tree height (cf. Anfodillo et al. 2006; Olson et al. 2014; Rosell et al. 2017). In either case, our results indicate the relationship between $K_{\mathrm{p}}$ and productivity to be a mere by-product of a scaling of both variables with tree size, which contrasts with previous reports of wood anatomical traits as close predictors of growth performance (Poorter et al. 2010; Fan et al. 2012). This underlines the importance of controlling for tree size when analyzing relationships between variables that carry an ontogenetic signal (Hietz et al. 2016). While the significantly higher absolute growth rates for larger trees are in line with theoretical assumptions (Stephenson et al. 2014), our results underline that in addition to mere size, the position of a tree relative to the height of the canopy and thus light availability plays a highly important role. It is well known that tree size - and hence average canopy height - is closely related to annual precipitation (Moles et al. 2009), though the implications of this relationship for the link between tree size and biomass increment have rarely been studied. The high importance of canopy position in our dataset is in line with recent SEM-based studies of functional determinants of plant growth (Gleason et al. 2018; Š́mová et al. 2019) as well as findings from studies that explicitly incorporated light availability data from canopy density measurements into growth models of tropical trees (Rüger et al. 2011; Rüger et al. 2012), and suggests that light effects were comparatively well covered by our simple percentile-based proxy for canopy position. It is noteworthy that in an earlier iteration of our model that omitted canopy position and incorporated a direct height effect on $A G B I$ (cf. Figure 6.2a), tests of directed separation indicated the presence of a strong negative effect of annual precipitation on biomass increment (results not shown). This counterintuitive effect resulted from differences in canopy height between sites, which caused trees of a given height to be directly canopy exposed in a dry forest environment and shaded in a humid environment (cf. Figure S3). All direct effects of precipitation on growth completely diminished when accounting for crown position relative to the canopy level. This indicates that the link between tree height and growth rates is not merely a result of a scaling of productivity with size, but at least partially related to a tree's position in the light environment. In consequence, accounting for light effects is necessary when comparing size-growth relationships between forest ecosystems with different canopy heights.

\subsubsection{NSC, drought responses and wood anatomical traits along the rainfall gradient}

According to our model, nonstructural carbohydrate stocks were higher in trees that occupied more sun-exposed positions within the canopy. However, we unexpectedly found trees with a higher wood density to have significantly higher NSC stocks, indicating that the sapwood NSC content was not driven by a trade-off between parenchyma and fibers. Remarkably, these trends were only driven by starch content, ewhile soluble sugars instead were weakly negatively correlated with the same traits (Figure 6.3). As anticipated, our model identified a clear positive relationship of WDA (Esquivel-Muelbert et al. 2017; Esquivel-Muelbert et al. 2019) with mean annual precipitation, suggesting that the trees present at wetter sites belong to species that on average occupy wetter habitats. The near-zero within-site correlation in the model for WDA indicated that MAP was sufficient to fully explain the site-specific differences in drought affiliation. In accordance with our assumptions, tree species occurring closer to the canopy level tended to be adapted to drier habitats, which is likely a reflection of environmental filtering driven by the stronger drought exposure and higher drought-induced mortality risk of large canopy trees (Rowland et al. 2015a; Olson et al. 2018). In contrast to our hypotheses, more drought adapted 
tree species tended to have significantly lower $N S C$ storage pools after accounting for the effect of rainfall and canopy position. This pattern was more pronounced for soluble sugars, which also were more closely correlated with precipitation than the starch content and more strongly associated with the axis of variation describing differences in drought adaptation and anatomical traits than starch, which was more closely tied to the axis associated with size-related variables (Figure 6.3, 6.5). While in theory it is possible that the observed higher drought resistance for species with lower NSC storage is indicative of a general pattern, it is more likely that it is affected by the time of sampling in the early-to-mid vegetation period after an extreme dry season driven by an ENSO event that caused a delayed onset of the rainy season. It has often been shown that $N S C$ storage is not a conserved property of tree species, but often subject to large seasonal variations (Hartmann and Trumbore 2016; Martínez-Vilalta et al. 2016). The stronger depletion of the NSC stores of more drought-resistant species thus might well be a result of their ability to mobilize more of these stores during a drought event rather than a reflection of the store size at the onset of the dry season. It bears mention that we did not find evidence for a trade-off between growth rate and drought resistance in our study, as illustrated in the insignificant residual correlation of -0.04 between $A G B I$ and $W D A$. Indeed, the bivariate correlation between the two variables showed more drought resistant species to have slightly higher growth rates $(\mathrm{r}=0.20$, cf. Figure 6.3$)$ that were likely related to their higher abundance in upper canopy layers. Likewise, the missing correlation between $W D A$ and potential conductivity both for model residuals and raw values points at a weak or nonexistent tradeoff between drought resistance and hydraulic efficiency (cf. Gleason et al. 2016), though this result should be interpreted with care as no direct measurements of vulnerability to embolism were available. Notwithstanding the indirect nature of WDA, our proxy for drought resistance, our model was able to identify significant effects of both plant traits and environmental variables, and explained a total of $42 \%$ of the variance in $W D A$. Notably, a test for separate error variances between species- and genus-level WDA values did not provide evidence for significantly larger errors when species-specific information was not available. Together, this indicates that the approach of Esquivel-Muelbert et al. $(2017 ; 2019)$ indeed provides a valuable tool for studies of plant adaptations to seasonal drought. Studies focusing on the mechanisms of plant drought responses clearly benefit most of the use of more proximal variables, e.g. related to hydraulic functioning or $N S C$ usage (Hartmann et al. 2018), to elucidate the true nature of the processes leading to drought-induced plant death, an issue that still is the subject of lively debate. However, indirect approaches like the WDA can be advantageous for ecological studies focusing on drought responses of large numbers of plants, since they are readily available for many species without an overhead for complicated measurements. Moreover, they are derived from the actual spatial distribution of a species and therefore guaranteed to be related to its drought response no matter what mechanisms govern it.

\subsubsection{Influence of model choice}

The interpretation of relationships between plant properties and environmental variables depends strongly on decisions regarding the statistical methods used to analyze them. Our case illustrates how shifting the focus on a different level of aggregation and accounting for important covariates instead of focusing on bivariate relationships led to vastly different conclusions about the influence of wood anatomy on biomass increment. As recently pointed out by Poorter et al. (2018), the level of aggregation in studies of trait-growth relationships has important repercussions for the interpretation of its outcome. The authors 
noted that counterintuitively, working on the individual level may lead to poor predictions of individual growth performance. However, working with individual level observations instead of using species-level aggregates likely reflects the underlying processes more accurately, as constraints on tree growth are likely to act on the individual and not the species level (cf. Clark et al. 2011). Inferring individual growth performance from species-level aggregates entails the risk of succumbing to ecological fallacies (i.e. erroneously inferring individual behavior from population level aggregates; cf. Robinson 1950). Relationships that hold on species level may not be relevant at the level of individual trees - for instance, the same processes that cause taller tree individuals to be at higher drought mortality risk compared to smaller trees of the same species may result in a selection for drought resistance in canopy species. Accordingly, the outcome of trait-based studies can only be meaningfully interpreted on the correct level of aggregation. The other - and potentially more important - reason for the differences between SMA and PSEM-based results was the shift of focus away from bivariate associations to an approach that more accurately reflects complex interrelationships between multiple variables of interest. Only by this shift in perspective were we able to detect the confounding effect of tree diameter on the link between $K_{\mathrm{p}}$ and $A G B I$, and identify the need to account for the effect of precipitation on canopy height when analyzing size effects on growth. Working with a piecewise structural equation modelling approach (Shipley 2009; Lefcheck 2016) enables to benefit of many of the advantages of causal inference in an structural equation modelling, like the identification of indirect effects and tests of mediation (cf. Grace 2006; Grace et al. 2012) while permitting the use of flexible models that account for the invariably hierarchical nature of ecological datasets.

\subsubsection{Conclusions}

The large discrepancies in our results for the relationship between wood traits and biomass increment depending on the model choice highlight the vast importance of focusing on the correct scale of aggregation, and of investigating the response of the variables of interest to multiple predictors in a joint framework instead of trying to infer networks of relationships from the inspection of bivariate links. By focusing on the individual tree level and analyzing our dataset in a piecewise SEM framework, we were able to demonstrate that the observed highly significant correlation between wood hydraulic traits and growth rate arose merely as a consequence of their common positive relationship with tree size, indicating that the link between wood anatomical properties and productivity may be weaker than previously anticipated. Instead, our study implies size relative to the canopy level and hence light exposure as a central control variable for growth rates of tropical forest trees. In our case, differences in tree growth rates along the studied rainfall gradient were fully explained by the effect of rainfall on tree height and the resulting changes in the height of the canopy. Accordingly, analyses of size effects on demographic rates and tree properties may benefit greatly if they do not only consider the height of each individual tree, but also consider its size relative to the size of neighboring trees.

A further important outcome of our study is the finding that the water deficit affiliation sensu Esquivel-Muelbert et al. (2017; 2019)can serve as a useful proxy for plant drought responses, with a high enough information content to distinguish within-site differences in drought response both in dependence of canopy position and between plants with different $N S C$ storage strategies. This illustrates that indirect variables derived from species distributions may be valuable tools for the quantification of plant drought responses. 


\section{Acknowledgements}

This study was financed by the German Science Foundation (DFG, SCHU 2935/1-1). We gratefully acknowledge the logistic support of Milena Gutiérrez, the Área de Conservación Guanacaste and the staff of the Estación Experimental Forestal Horizontes. We further wish to extend our gratitude to Leland van Werden for providing climate data for the Horizontes region, and a large number of field assistants without whom this work would not have been possible.

\section{Author contributions}

R.M.L. performed field measurements, collected and analyzed the data and wrote a first version the manuscript, which was intensively discussed by all authors. B.S. planned and designed the research, H.H. performed measurements of NSC contents, D.A.A., J.C.V., and M.C.U assisted with logistics and field measurements, H.H., B.S., D.A.A., J.C.V., and M.C.U. discussed the results and provided comments. 


\section{Supplementary figures}
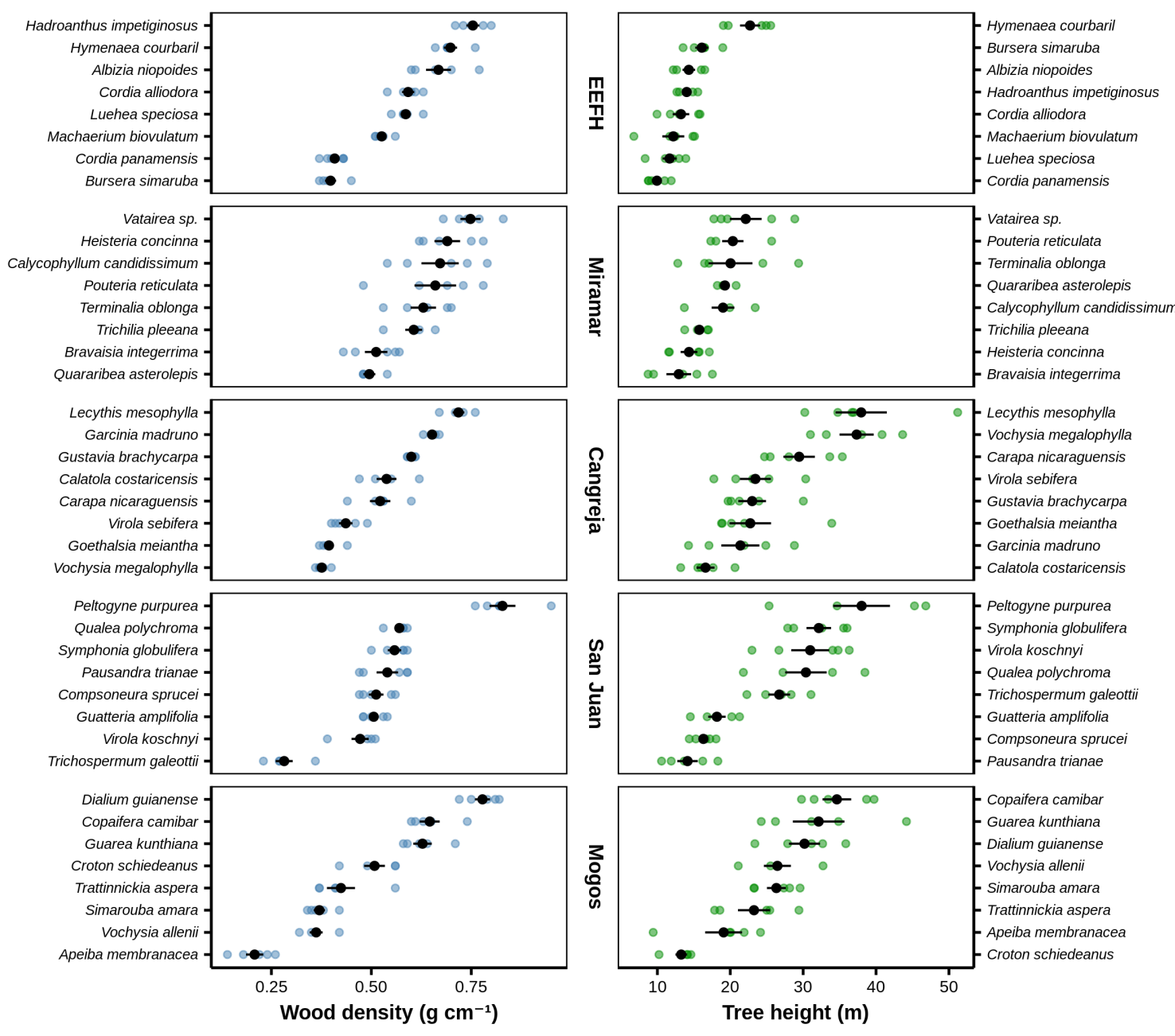

Figure S1 Species-wise wood density (left, blue) and tree height (right, green) at the five research sites. Colored points: observations for individual trees, black points and lines: means \pm standard errors. 


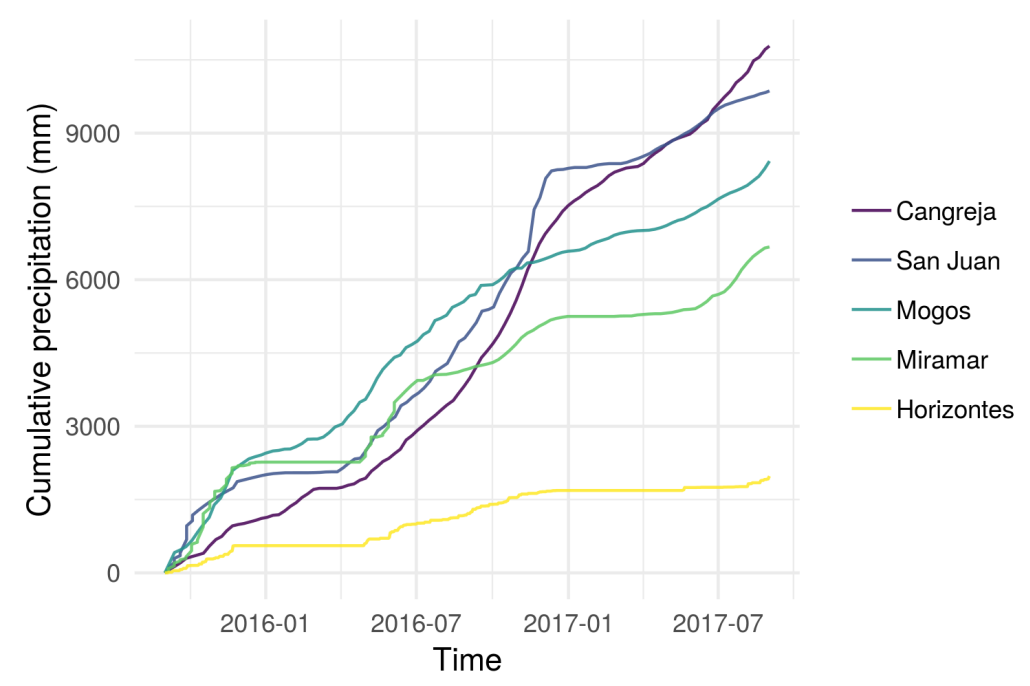

Figure S2 Cumulative precipitation $(\mathrm{mm})$ over the measurement interval.
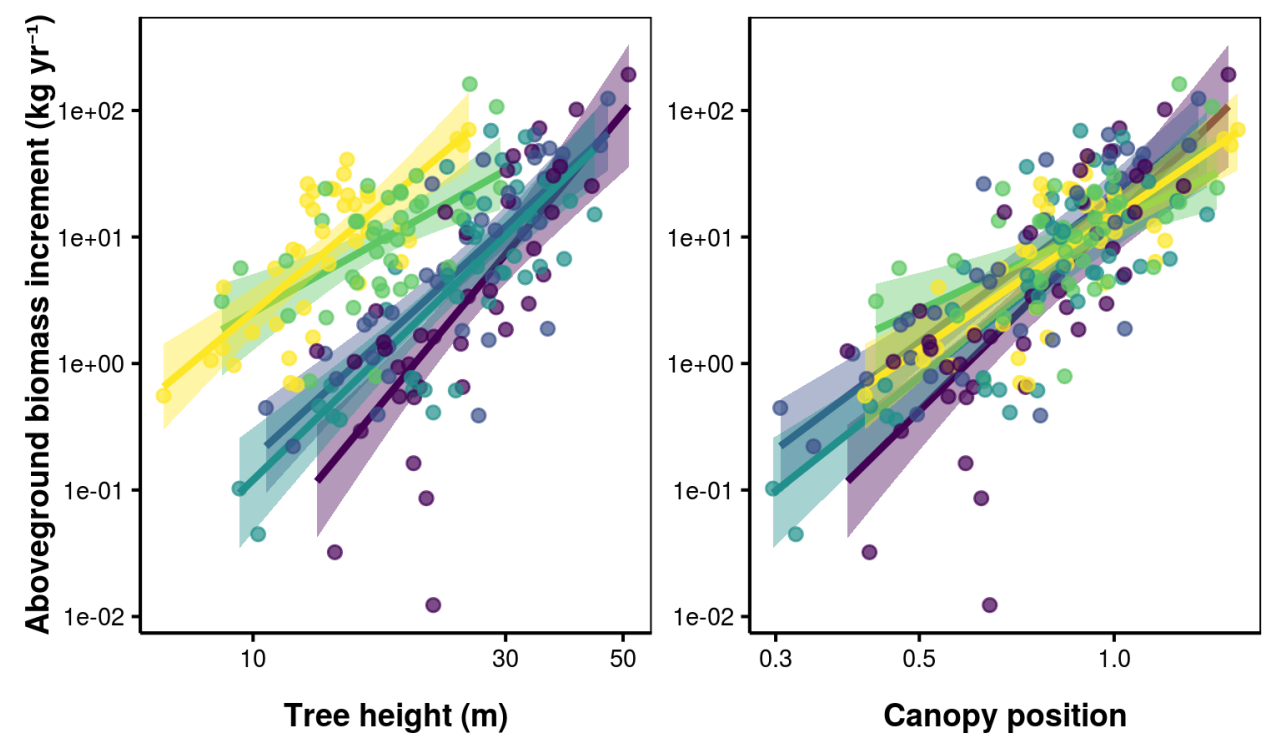

Cangreja $=$ San Juan - Mogos = Miramar EEFH

Figure S3 Aboveground biomass increment vs. tree height and canopy position (i.e. tree height relative to the 80th percentile of height at the corresponding site). Lines and shaded areas indicate predictions and confidence bounds of simple log-log-linear models based on ggplot 2: :geom_smooth() and are only meant for illustrative purposes. Note that the clear difference in intercepts disappears when correcting for the position relative to the canopy. 


\section{Supplementary tables}

Table S1 Species averages \pm standard deviations for diameter at breast height, tree height, canopy position, aboveground biomass, aboveground biomass increment and relative growth rate. Additionally given are the mean annual precipitation in the species range weighted by species abundance and water deficit affiliation based onEsquivel-Muelbert et al. $(2017 ; 2019)$. Table continued on next page.

\begin{tabular}{|c|c|c|c|c|c|c|c|c|c|}
\hline Site & Species & $\begin{array}{l}\text { DBH } \\
(\mathbf{m m})\end{array}$ & $\begin{array}{l}\text { Height } \\
\text { (m) }\end{array}$ & $\begin{array}{c}\mathbf{C P} \\
\text { (unitless) }\end{array}$ & $\begin{array}{c}\text { AGB } \\
(\mathrm{kg})\end{array}$ & $\begin{array}{c}\text { AGBI } \\
\left(\mathrm{kg} \mathrm{yr}^{-1}\right)\end{array}$ & $\begin{array}{c}\text { RGR } \\
\text { (unitless) }\end{array}$ & $\begin{array}{c}\mathbf{M A P}_{\mathrm{sp}} \\
\left(\mathrm{mm} \mathrm{yr}^{-1}\right)\end{array}$ & $\begin{array}{c}\text { WDA } \\
\left(\mathrm{mm} \mathrm{yr}^{-1}\right)\end{array}$ \\
\hline \multirow[t]{8}{*}{ EEFH } & Albizia niopoides & $290.1 \pm 54.4$ & $14.3 \pm 1.9$ & $0.870 \pm 0.118$ & $463 \pm 236$ & $15.0 \pm 6.5$ & $0.024 \pm 0.019$ & 2314 & -228 \\
\hline & Bursera simaruba & $506.2 \pm 163.0$ & $16.1 \pm 2.0$ & $0.978 \pm 0.123$ & $947 \pm 597$ & $21.6 \pm 12.0$ & $0.017 \pm 0.013$ & 1476 & -437 \\
\hline & Cordia alliodora & $208.4 \pm 53.5$ & $13.2 \pm 2.5$ & $0.805 \pm 0.154$ & $210 \pm 151$ & $3.1 \pm 3.8$ & $0.006 \pm 0.005$ & 1872 & -337 \\
\hline & Cordia panamensis & $210.7 \pm 66.2$ & $9.9 \pm 1.3$ & $0.604 \pm 0.078$ & $117 \pm 105$ & $3.6 \pm 2.8$ & $0.018 \pm 0.011$ & 2635 & -108 \\
\hline & Had. impetiginosus & $297.2 \pm 40.0$ & $14.0 \pm 1.2$ & $0.852 \pm 0.074$ & $512 \pm 155$ & $24.6 \pm 4.9$ & $0.029 \pm 0.012$ & 1471 & -467 \\
\hline & Hym. courbaril & $729.7 \pm 177.3$ & $22.7 \pm 3.1$ & $1.381 \pm 0.187$ & $4651 \pm 2405$ & $39.9 \pm 29.9$ & $0.004 \pm 0.002$ & 2001 & -269 \\
\hline & Luehea speciosa & $235.7 \pm 20.1$ & $11.7 \pm 2.1$ & $0.710 \pm 0.130$ & $215 \pm 71$ & $5.3 \pm 6.6$ & $0.012 \pm 0.015$ & 2056 & -261 \\
\hline & Mach. biovulatum & $171.4 \pm 22.5$ & $12.2 \pm 3.4$ & $0.741 \pm 0.205$ & $113 \pm 59$ & $8.7 \pm 10.0$ & $0.034 \pm 0.034$ & 919 & -838 \\
\hline \multirow[t]{8}{*}{ Mir. } & Brav. integerrima & $293.8 \pm 29.9$ & $12.9 \pm 3.8$ & $0.635 \pm 0.186$ & $317 \pm 128$ & $6.2 \pm 4.2$ & $0.010 \pm 0.005$ & 1473 & -427 \\
\hline & C. candidissimum & $277.7 \pm 39.7$ & $19.0 \pm 3.5$ & $0.933 \pm 0.171$ & $537 \pm 202$ & $12.2 \pm 10.3$ & $0.016 \pm 0.016$ & 1900 & -444 \\
\hline & Heisteria concinna & $219.2 \pm 48.8$ & $14.3 \pm 2.6$ & $0.704 \pm 0.126$ & $275 \pm 141$ & $8.6 \pm 4.7$ & $0.017 \pm 0.006$ & 2530 & -302 \\
\hline & Pouteria reticulata & $332.0 \pm 55.6$ & $20.4 \pm 3.3$ & $1.000 \pm 0.161$ & $861 \pm 471$ & $18.3 \pm 9.4$ & $0.013 \pm 0.008$ & 2043 & -245 \\
\hline & Quar. asterolepis & $244.6 \pm 35.4$ & $19.3 \pm 1.1$ & $0.946 \pm 0.053$ & $329 \pm 119$ & $15.5 \pm 6.8$ & $0.021 \pm 0.015$ & 2300 & -163 \\
\hline & Term. oblonga & $363.8 \pm 139.1$ & $20.0 \pm 6.7$ & $0.984 \pm 0.330$ & $1108 \pm 803$ & $13.2 \pm 12.1$ & $0.005 \pm 0.003$ & 1742 & -397 \\
\hline & Trichilia pleeana & $286.9 \pm 62.5$ & $15.8 \pm 1.3$ & $0.774 \pm 0.065$ & $462 \pm 225$ & $6.4 \pm 4.5$ & $0.007 \pm 0.002$ & 2105 & -288 \\
\hline & Vatairea sp. & $380.3 \pm 166.5$ & $22.1 \pm 4.9$ & $1.087 \pm 0.239$ & $1564 \pm 1414$ & $60.0 \pm 70.6$ & $0.016 \pm 0.010$ & 2581 & -80 \\
\hline \multirow[t]{8}{*}{ Can. } & Calat. costaricensis & $194.2 \pm 15.3$ & $16.6 \pm 2.8$ & $0.487 \pm 0.081$ & $189 \pm 58$ & $0.9 \pm 0.5$ & $0.003 \pm 0.002$ & 2373 & -111 \\
\hline & Car. nicaraguensis & $381.3 \pm 76.3$ & $29.4 \pm 4.8$ & $0.864 \pm 0.141$ & $1300 \pm 751$ & $12.2 \pm 19.7$ & $0.005 \pm 0.008$ & 2916 & -65 \\
\hline & Garcinia madruno & $213.4 \pm 34.5$ & $21.4 \pm 5.8$ & $0.627 \pm 0.171$ & $362 \pm 156$ & $1.2 \pm 1.4$ & $0.002 \pm 0.002$ & 2713 & -189 \\
\hline & Goeth. meiantha & $266.9 \pm 34.4$ & $22.7 \pm 6.4$ & $0.667 \pm 0.187$ & $355 \pm 134$ & $2.3 \pm 3.2$ & $0.003 \pm 0.003$ & 2446 & -152 \\
\hline & Gust. brachycarpa & $232.4 \pm 35.4$ & $23.0 \pm 4.3$ & $0.675 \pm 0.125$ & $429 \pm 215$ & $0.6 \pm 0.8$ & $0.001 \pm 0.001$ & 2956 & -31 \\
\hline & Lec. mesophylla & $528.5 \pm 214.2$ & $38.0 \pm 7.9$ & $1.114 \pm 0.231$ & $4762 \pm 4536$ & $68.9 \pm 72.0$ & $0.009 \pm 0.006$ & 2541 & -49 \\
\hline & Virola sebifera & $266.5 \pm 62.8$ & $23.4 \pm 4.8$ & $0.688 \pm 0.140$ & $435 \pm 268$ & $9.7 \pm 8.1$ & $0.012 \pm 0.011$ & 2420 & -166 \\
\hline & Voc. megalophylla & $763.6 \pm 61.5$ & $37.3 \pm 5.2$ & $1.095 \pm 0.154$ & $4279 \pm 1169$ & $41.9 \pm 36.8$ & $0.005 \pm 0.004$ & 2575 & -194 \\
\hline \multirow[t]{8}{*}{ S. J. } & Compson. sprucei & $193.1 \pm 23.0$ & $16.3 \pm 1.5$ & $0.470 \pm 0.043$ & $177 \pm 53$ & $0.8 \pm 0.9$ & $0.002 \pm 0.003$ & 2980 & 0 \\
\hline & Guatt. amplifolia & $255.5 \pm 40.0$ & $18.2 \pm 2.7$ & $0.524 \pm 0.077$ & $345 \pm 154$ & $1.6 \pm 1.9$ & $0.002 \pm 0.002$ & 2737 & -80 \\
\hline & Pausandra trianae & $155.0 \pm 14.3$ & $14.1 \pm 3.1$ & $0.408 \pm 0.091$ & $104 \pm 31$ & $1.3 \pm 1.0$ & $0.006 \pm 0.004$ & 2607 & -113 \\
\hline & Peltog. purpurea & $680.7 \pm 247.9$ & $38.0 \pm 8.7$ & $1.096 \pm 0.251$ & $8759 \pm 7861$ & $54.7 \pm 42.2$ & $0.004 \pm 0.004$ & 1808 & -294 \\
\hline & Qual. polychroma & $453.3 \pm 139.5$ & $30.4 \pm 6.4$ & $0.876 \pm 0.184$ & $2191 \pm 1435$ & $39.8 \pm 16.8$ & $0.016 \pm 0.014$ & 2333 & -213 \\
\hline & Symph. globulifera & $398.9 \pm 94.1$ & $32.1 \pm 3.8$ & $0.927 \pm 0.109$ & $1576 \pm 782$ & $10.9 \pm 11.1$ & $0.004 \pm 0.004$ & 2633 & -99 \\
\hline & Trichosp. galeottii & $346.3 \pm 96.9$ & $26.7 \pm 3.4$ & $0.770 \pm 0.097$ & $581 \pm 457$ & $8.6 \pm 7.1$ & $0.008 \pm 0.005$ & 2145 & -238 \\
\hline & Virola koschnyi & $478.8 \pm 167.3$ & $31.0 \pm 5.8$ & $0.893 \pm 0.168$ & $2157 \pm 1509$ & $22.3 \pm 22.5$ & $0.005 \pm 0.004$ & 2797 & -198 \\
\hline \multirow[t]{8}{*}{ Mogos } & Ap.. membranacea & $236.5 \pm 59.9$ & $19.1 \pm 5.7$ & $0.602 \pm 0.179$ & $138 \pm 96$ & $0.5 \pm 0.3$ & $0.002 \pm 0.002$ & 2714 & -96 \\
\hline & Copaifera camibar & $595.9 \pm 81.2$ & $34.6 \pm 4.4$ & $1.091 \pm 0.139$ & $4203 \pm 1631$ & $14.1 \pm 8.3$ & $0.002 \pm 0.001$ & 1784 & -288 \\
\hline & Crot. schiedeanus & $138.7 \pm 4.3$ & $13.3 \pm 1.8$ & $0.418 \pm 0.056$ & $75 \pm 19$ & $0.4 \pm 0.2$ & $0.002 \pm 0.001$ & 2091 & -352 \\
\hline & Dialium guianense & $439.8 \pm 41.8$ & $30.2 \pm 4.8$ & $0.951 \pm 0.150$ & $2376 \pm 563$ & $14.9 \pm 15.2$ & $0.003 \pm 0.003$ & 2406 & -166 \\
\hline & Guarea kunthiana & $480.4 \pm 73.3$ & $32.1 \pm 7.9$ & $1.012 \pm 0.249$ & $2537 \pm 1236$ & $8.3 \pm 4.5$ & $0.002 \pm 0.001$ & 2543 & -97 \\
\hline & Simarouba amara & $362.9 \pm 96.5$ & $26.3 \pm 2.9$ & $0.830 \pm 0.091$ & $768 \pm 549$ & $33.8 \pm 24.4$ & $0.024 \pm 0.012$ & 2406 & -207 \\
\hline & Tratt. aspera & $216.1 \pm 49.9$ & $23.3 \pm 4.9$ & $0.733 \pm 0.155$ & $275 \pm 185$ & $9.5 \pm 7.2$ & $0.018 \pm 0.007$ & 2907 & -116 \\
\hline & Vochysia allenii & $335.2 \pm 118.0$ & $26.5 \pm 4.1$ & $0.834 \pm 0.131$ & $640 \pm 451$ & $18.2 \pm 24.7$ & $0.012 \pm 0.010$ & 2575 & -194 \\
\hline
\end{tabular}


Table S1 (ctnd.) Species averages \pm standard deviations for wood density, \% lumen area, vessel diameter, vessel density, potential conductivity, total sapwood NSC concentration, sapwood soluble sugar concentration, and sapwood starch concentration.

\begin{tabular}{|c|c|c|c|c|c|c|c|c|c|}
\hline Site & Species & $\begin{array}{c}\text { WD } \\
\left(\mathrm{g} \mathrm{cm}^{-3}\right)\end{array}$ & $\begin{array}{c}A_{\text {lumen }} \\
(\%)\end{array}$ & $\begin{array}{c}d_{h} \\
(\mu \mathrm{m})\end{array}$ & $\begin{array}{c}\text { VD } \\
\left(\mathrm{n} \mathrm{mm}^{-1}\right)\end{array}$ & $\begin{array}{c}K_{p}\left(k_{g ~ ~ m^{-1}}\right. \\
\left.s^{-1} \mathrm{MPa}^{-1}\right)\end{array}$ & $\begin{array}{c}\mathrm{NSC} \\
\left(\mathrm{mg} \mathrm{g}^{-1}\right)\end{array}$ & $\begin{array}{c}\text { SolSug } \\
\left(\mathrm{mg} \mathrm{g}^{-1}\right)\end{array}$ & $\begin{array}{c}\text { Starch } \\
\left(\mathrm{mg} \mathrm{g}^{-1}\right)\end{array}$ \\
\hline \multirow[t]{8}{*}{ EEFH } & Albizia niopoides & $0.668 \pm 0.070$ & $8.6 \pm 2.0$ & $190.9 \pm 19.4$ & $4.0 \pm 0.5$ & $89.9 \pm 38.4$ & $46.5 \pm 16.5$ & $2.1 \pm 1.5$ & $44.5 \pm 16.1$ \\
\hline & Bursera simaruba & $0.398 \pm 0.031$ & $17.8 \pm 3.1$ & $124.0 \pm 16.0$ & $17.3 \pm 1.3$ & $81.3 \pm 33.7$ & $26.9 \pm 17.3$ & $0.0 \pm 0.1$ & $26.8 \pm 17.4$ \\
\hline & Cordia alliodora & $0.592 \pm 0.034$ & $9.3 \pm 1.8$ & $141.7 \pm 11.1$ & $8.6 \pm 2.4$ & $49.5 \pm 9.3$ & $24.3 \pm 32.3$ & $0.9 \pm 1.0$ & $23.4 \pm 31.4$ \\
\hline & Cordia panamensis & $0.408 \pm 0.026$ & $7.3 \pm 1.4$ & $147.3 \pm 11.9$ & $6.6 \pm 1.0$ & $42.5 \pm 14.0$ & $13.6 \pm 12.4$ & $0.5 \pm 0.8$ & $13.1 \pm 12.5$ \\
\hline & Had. impetiginosus & $0.754 \pm 0.036$ & $29.8 \pm 12.1$ & $94.7 \pm 2.0$ & $51.2 \pm 20.5$ & $77.1 \pm 32.6$ & $22.2 \pm 14.2$ & $0.1 \pm 0.1$ & $22.0 \pm 14.2$ \\
\hline & Hym. courbaril & $0.698 \pm 0.037$ & $7.4 \pm 2.4$ & $205.6 \pm 15.7$ & $3.1 \pm 0.6$ & $88.9 \pm 40.3$ & $67.0 \pm 15.0$ & $0.9 \pm 0.6$ & $66.1 \pm 14.9$ \\
\hline & Luehea speciosa & $0.586 \pm 0.029$ & $8.2 \pm 1.2$ & $107.4 \pm 11.8$ & $13.0 \pm 1.9$ & $25.5 \pm 7.9$ & $8.1 \pm 7.4$ & $0.8 \pm 0.5$ & $7.3 \pm 6.9$ \\
\hline & Mach. biovulatum & $0.526 \pm 0.021$ & $4.6 \pm 0.6$ & $217.3 \pm 10.0$ & $2.1 \pm 0.2$ & $57.1 \pm 10.4$ & $13.2 \pm 10.0$ & $0.4 \pm 0.5$ & $12.8 \pm 9.8$ \\
\hline \multirow[t]{8}{*}{ Mir. } & Brav. integerrima & $0.512 \pm 0.063$ & $6.7 \pm 2.5$ & $149.5 \pm 14.9$ & $4.7 \pm 1.0$ & $44.2 \pm 22.6$ & $2.7 \pm 2.3$ & $0.0 \pm 0.0$ & $2.7 \pm 2.3$ \\
\hline & C. candidissimum & $0.672 \pm 0.104$ & $49.9 \pm 17.0$ & $62.6 \pm 6.3$ & $200.4 \pm 40.4$ & $58.3 \pm 28.9$ & $19.1 \pm 3.9$ & $0.5 \pm 0.7$ & $18.6 \pm 3.2$ \\
\hline & Heisteria concinna & $0.690 \pm 0.072$ & $24.5 \pm 18.9$ & $99.1 \pm 9.8$ & $43.3 \pm 47.5$ & $61.8 \pm 31.7$ & $46.2 \pm 33.1$ & $0.0 \pm 0.1$ & $46.1 \pm 33.1$ \\
\hline & Pouteria reticulata & $0.660 \pm 0.116$ & $46.2 \pm 15.7$ & $68.7 \pm 6.2$ & $153.3 \pm 33.9$ & $63.3 \pm 29.1$ & $6.1 \pm 5.8$ & $0.1 \pm 0.2$ & $6.0 \pm 5.6$ \\
\hline & Quar. asterolepis & $0.495 \pm 0.030$ & $6.7 \pm 1.1$ & $123.6 \pm 11.9$ & $6.7 \pm 0.8$ & $29.4 \pm 11.6$ & $58.1 \pm 40.0$ & $2.0 \pm 3.4$ & $56.1 \pm 39.1$ \\
\hline & Term. oblonga & $0.630 \pm 0.071$ & $10.2 \pm 0.9$ & $167.3 \pm 6.8$ & $6.2 \pm 0.5$ & $78.1 \pm 13.0$ & $22.7 \pm 10.7$ & $0.1 \pm 0.1$ & $22.5 \pm 10.6$ \\
\hline & Trichilia pleeana & $0.606 \pm 0.047$ & $8.2 \pm 0.6$ & $77.9 \pm 5.1$ & $20.2 \pm 2.2$ & $14.2 \pm 2.7$ & $10.8 \pm 9.9$ & $0.0 \pm 0.0$ & $10.8 \pm 9.9$ \\
\hline & Vatairea sp. & $0.748 \pm 0.056$ & $6.1 \pm 1.0$ & $184.6 \pm 14.1$ & $3.7 \pm 0.3$ & $57.2 \pm 17.5$ & $147.3 \pm 23.0$ & $0.4 \pm 0.4$ & $146.9 \pm 23.4$ \\
\hline \multirow[t]{8}{*}{ Can. } & Calat. costaricensis & $0.538 \pm 0.055$ & $11.7 \pm 3.3$ & $91.9 \pm 20.3$ & $22.0 \pm 9.2$ & $26.3 \pm 3.8$ & $46.3 \pm 29.7$ & $7.4 \pm 3.7$ & $38.9 \pm 28.7$ \\
\hline & Car. nicaraguensis & $0.522 \pm 0.057$ & $11.2 \pm 3.4$ & $183.8 \pm 43.9$ & $5.9 \pm 1.9$ & $117.1 \pm 88.6$ & $52.8 \pm 11.4$ & $1.8 \pm 0.6$ & $51.0 \pm 11.0$ \\
\hline & Garcinia madruno & $0.652 \pm 0.015$ & $12.6 \pm 1.3$ & $124.8 \pm 6.4$ & $13.2 \pm 1.5$ & $54.7 \pm 10.6$ & $36.3 \pm 21.7$ & $4.7 \pm 0.5$ & $31.6 \pm 21.5$ \\
\hline & Goeth. meiantha & $0.394 \pm 0.027$ & $7.2 \pm 1.5$ & $146.6 \pm 14.6$ & $5.3 \pm 1.1$ & $45.0 \pm 14.7$ & $30.4 \pm 26.3$ & $2.3 \pm 1.1$ & $28.1 \pm 27.1$ \\
\hline & Gust. brachycarpa & $0.600 \pm 0.010$ & $17.1 \pm 2.5$ & $86.7 \pm 12.8$ & $36.7 \pm 4.7$ & $36.8 \pm 13.8$ & $11.1 \pm 4.3$ & $3.4 \pm 1.6$ & $7.8 \pm 3.1$ \\
\hline & Lec. mesophylla & $0.718 \pm 0.033$ & $7.8 \pm 2.2$ & $204.9 \pm 25.6$ & $3.6 \pm 0.3$ & $90.4 \pm 43.2$ & $49.1 \pm 24.1$ & $2.0 \pm 0.9$ & $47.1 \pm 23.9$ \\
\hline & Virola sebifera & $0.436 \pm 0.038$ & $8.1 \pm 0.7$ & $131.5 \pm 6.9$ & $6.8 \pm 1.0$ & $40.0 \pm 5.6$ & $24.7 \pm 9.0$ & $0.3 \pm 0.2$ & $24.4 \pm 8.9$ \\
\hline & Voc. megalophylla & $0.376 \pm 0.015$ & $11.2 \pm 1.5$ & $293.8 \pm 12.8$ & $2.2 \pm 0.5$ & $270.5 \pm 24.2$ & $3.9 \pm 1.7$ & $1.5 \pm 0.4$ & $2.4 \pm 1.4$ \\
\hline \multirow[t]{8}{*}{ S. J. } & Compson. sprucei & $0.512 \pm 0.041$ & $5.6 \pm 1.9$ & $97.9 \pm 8.6$ & $9.0 \pm 3.1$ & $15.4 \pm 6.4$ & $99.1 \pm 32.1$ & $2.9 \pm 0.8$ & $96.2 \pm 32.2$ \\
\hline & Guatt. amplifolia & $0.506 \pm 0.028$ & $4.4 \pm 0.6$ & $183.9 \pm 20.2$ & $2.5 \pm 0.7$ & $42.4 \pm 15.0$ & $16.3 \pm 6.4$ & $0.6 \pm 0.2$ & $15.7 \pm 6.6$ \\
\hline & Pausandra trianae & $0.540 \pm 0.060$ & $5.3 \pm 1.3$ & $89.4 \pm 2.8$ & $11.5 \pm 2.5$ & $11.4 \pm 3.3$ & $23.9 \pm 15.3$ & $6.0 \pm 3.3$ & $17.8 \pm 13.1$ \\
\hline & Peltog. purpurea & $0.828 \pm 0.073$ & $22.4 \pm 7.5$ & $133.3 \pm 8.9$ & $21.9 \pm 12.6$ & $108.6 \pm 17.4$ & $60.1 \pm 10.9$ & $2.5 \pm 0.9$ & $57.6 \pm 11.5$ \\
\hline & Qual. polychroma & $0.570 \pm 0.023$ & $10.6 \pm 2.1$ & $233.1 \pm 15.3$ & $3.5 \pm 0.6$ & $161.9 \pm 45.7$ & $39.6 \pm 17.3$ & $1.0 \pm 0.5$ & $38.6 \pm 17.2$ \\
\hline & Symph. globulifera & $0.558 \pm 0.038$ & $12.4 \pm 2.5$ & $227.4 \pm 24.6$ & $4.6 \pm 0.5$ & $180.5 \pm 80.6$ & $52.6 \pm 15.9$ & $5.3 \pm 3.0$ & $47.3 \pm 14.1$ \\
\hline & Trichosp. galeottii & $0.282 \pm 0.048$ & $8.3 \pm 2.1$ & $162.6 \pm 7.4$ & $5.0 \pm 1.1$ & $61.8 \pm 19.1$ & $17.1 \pm 6.3$ & $5.9 \pm 1.8$ & $11.1 \pm 7.3$ \\
\hline & Virola koschnyi & $0.472 \pm 0.048$ & $6.7 \pm 1.8$ & $144.9 \pm 16.5$ & $4.8 \pm 1.3$ & $41.3 \pm 18.5$ & $98.2 \pm 59.1$ & $3.5 \pm 2.3$ & $94.7 \pm 57.9$ \\
\hline \multirow[t]{8}{*}{ Mogos } & Ap.. membranacea & $0.208 \pm 0.048$ & $4.7 \pm 2.3$ & $153.2 \pm 19.0$ & $3.8 \pm 1.5$ & $31.3 \pm 18.0$ & $21.4 \pm 24.5$ & $3.2 \pm 2.2$ & $18.2 \pm 24.3$ \\
\hline & Copaifera camibar & $0.646 \pm 0.056$ & $6.6 \pm 1.2$ & $138.9 \pm 5.9$ & $6.6 \pm 1.2$ & $34.0 \pm 7.6$ & $49.3 \pm 17.4$ & $3.2 \pm 1.8$ & $46.1 \pm 18.5$ \\
\hline & Crot. schiedeanus & $0.508 \pm 0.058$ & $8.4 \pm 1.9$ & $105.9 \pm 29.5$ & $14.4 \pm 5.3$ & $28.4 \pm 21.6$ & $14.8 \pm 9.3$ & $2.4 \pm 3.0$ & $12.4 \pm 7.6$ \\
\hline & Dialium guianense & $0.778 \pm 0.042$ & $8.1 \pm 4.4$ & $156.9 \pm 20.4$ & $7.4 \pm 5.1$ & $48.1 \pm 16.9$ & $67.2 \pm 13.7$ & $2.4 \pm 1.6$ & $64.8 \pm 14.7$ \\
\hline & Guarea kunthiana & $0.628 \pm 0.052$ & $31.5 \pm 31.3$ & $204.2 \pm 26.9$ & $14.3 \pm 13.0$ & $363.0 \pm 356.8$ & $28.5 \pm 9.1$ & $0.2 \pm 0.2$ & $28.4 \pm 9.2$ \\
\hline & Simarouba amara & $0.370 \pm 0.032$ & $5.4 \pm 0.9$ & $210.5 \pm 29.5$ & $2.6 \pm 0.5$ & $65.3 \pm 24.1$ & $12.2 \pm 3.6$ & $6.7 \pm 2.8$ & $5.5 \pm 1.8$ \\
\hline & Tratt. aspera & $0.424 \pm 0.079$ & $14.0 \pm 7.3$ & $173.6 \pm 47.7$ & $8.3 \pm 3.1$ & $144.7 \pm 140.6$ & $81.0 \pm 29.8$ & $3.1 \pm 2.0$ & $77.9 \pm 28.6$ \\
\hline & Vochysia allenii & $0.362 \pm 0.036$ & $11.0 \pm 2.1$ & $265.8 \pm 20.6$ & $2.7 \pm 0.2$ & $226.3 \pm 76.3$ & $2.1 \pm 2.5$ & $0.8 \pm 0.5$ & $1.4 \pm 2.2$ \\
\hline
\end{tabular}




\section{References}

Allen, R. G., L. S. Pereira, D. Raes, and M. Smith (1998). Crop Evapotranspiration: Guidelines for Computing Crop Water Requirements. Tech. rep. Rome: FAO, p. 300.

Anfodillo, T., V. Carraro, M. Carrer, C. Fior, and S. Rossi (2006). "Convergent tapering of xylem conduits in different woody species". In: New Phytologist 169.2, pp. 279-290. URL: http://doi.wiley.com/10.1111/j.1469-8137.2005.01587.x.

Aragão, L. E. O. C., Y. Malhi, R. M. Roman-Cuesta, S. Saatchi, L. O. Anderson, and Y. E. Shimabukuro (2007). "Spatial patterns and fire response of recent Amazonian droughts". In: Geophysical Research Letters 34.7. URL: https://agupubs.onlinelibrary. wiley.com/doi/abs/10.1029/2006GL028946.

Bastin, J.-F., N. Barbier, M. Réjou-Méchain, A. Fayolle, S. Gourlet-Fleury, et al. (2015). "Seeing Central African forests through their largest trees". In: Scientific Reports 5.1, p. 13156. URL: http://www.nature.com/articles/srep13156.

Bastin, J.-F., E. Rutishauser, J. R. Kellner, S. Saatchi, R. Pélissier, et al. (2018). "Pantropical prediction of forest structure from the largest trees". In: Global Ecology and Biogeography 27.11, pp. 1366-1383. URL: http://doi.wiley.com/10.1111/geb.12803.

Bates, D., M. Mächler, B. Bolker, and S. Walker (2015). "Fitting Linear Mixed-Effects Models Using lme4". In: Journal of Statistical Software 67.1, pp. 1-48.

Bennett, A. C., N. G. McDowell, C. D. Allen, and K. J. Anderson-Teixeira (2015). "Larger trees suffer most during drought in forests worldwide". In: Nature Plants 1.10, p. 15139. URL: https://www.nature.com/articles/nplants2015139.

Bolker, B. M., M. E. Brooks, C. J. Clark, S. W. Geange, J. R. Poulsen, M. H. H. Stevens, and J.-S. S. White (2009). "Generalized linear mixed models: a practical guide for ecology and evolution". In: Trends in Ecology 83 Evolution 24.3, pp. 127-135. URL: https: //linkinghub.elsevier.com/retrieve/pii/S0169534709000196.

Brodribb, T. J. (2009). "Xylem hydraulic physiology: The functional backbone of terrestrial plant productivity". In: Plant Science 177.4, pp. 245-251. URL: https://linkinghub. elsevier.com/retrieve/pii/S0168945209001599.

Chao, K.-J., O. L. Phillips, E. Gloor, A. Monteagudo, A. Torres-Lezama, and R. V. Martínez (2008). "Growth and wood density predict tree mortality in Amazon forests". In: Journal of Ecology 96.2, pp. 281-292. URL: http://doi.wiley.com/10.1111/j.13652745.2007.01343.x.

Chave, J., M. Réjou-Méchain, A. Búrquez, E. Chidumayo, M. S. Colgan, et al. (2014). "Improved allometric models to estimate the aboveground biomass of tropical trees". In: Global Change Biology 20.10, pp. 3177-3190. URL: https://onlinelibrary.wiley.com/ doi/abs/10.1111/gcb.12629.

Choat, B., T. W. Brodie, A. R. Cobb, M. A. Zwieniecki, and N. M. Holbrook (2006). "Direct measurements of intervessel pit membrane hydraulic resistance in two angiosperm tree species". In: American Journal of Botany 93.7, pp. 993-1000. URL: http://doi.wiley. com/10.3732/ajb.93.7.993.

Choat, B., A. R. Cobb, and S. Jansen (2008). "Structure and function of bordered pits: new discoveries and impacts on whole-plant hydraulic function". In: New Phytologist 177.3, pp. 608-626. URL: http://doi.wiley.com/10.1111/j.1469-8137.2007.02317.x.

Choat, B., S. Jansen, T. J. Brodribb, H. Cochard, S. Delzon, et al. (2012). "Global convergence in the vulnerability of forests to drought". In: Nature 491.7426, pp. 752-755. URL: https://www.nature.com/articles/nature11688.

Clark, J. S., D. M. Bell, M. H. Hersh, M. C. Kwit, E. Moran, et al. (2011). "Individualscale variation, species-scale differences: inference needed to understand diversity". In: 
Ecology Letters 14.12, pp. 1273-1287. URL: https://onlinelibrary.wiley.com/doi/abs/ 10.1111/j.1461-0248.2011.01685.x.

Dietrich, L., G. Hoch, A. Kahmen, and C. Körner (2018). "Losing half the conductive area hardly impacts the water status of mature trees". In: Scientific Reports 8.1, p. 15006. URL: http://www.nature.com/articles/s41598-018-33465-0.

Engelbrecht, B. M. J., L. S. Comita, R. Condit, T. A. Kursar, M. T. Tyree, B. L. Turner, and S. P. Hubbell (2007). "Drought sensitivity shapes species distribution patterns in tropical forests". In: Nature 447.7140, pp. 80-82. URL: https://www.nature.com/articles/ nature05747.

Esquivel-Muelbert, A., T. R. Baker, K. G. Dexter, S. L. Lewis, R. J. W. Brienen, et al. (2019). "Compositional response of Amazon forests to climate change". In: Global Change Biology 25.1, pp. 39-56. URL: https://onlinelibrary.wiley.com/doi/abs/10. 1111/gcb.14413.

Esquivel-Muelbert, A., T. R. Baker, K. G. Dexter, S. L. Lewis, H. ter Steege, et al. (2017). "Seasonal drought limits tree species across the Neotropics". In: Ecography 40.5, pp. 618629. URL: https://onlinelibrary.wiley.com/doi/full/10.1111/ecog.01904.

Falster, D. S., R. A. Duursma, and R. G. FitzJohn (2018). "How functional traits influence plant growth and shade tolerance across the life cycle". In: Proceedings of the National Academy of Sciences 115.29, E6789-E6798. URL: http://www.pnas.org/lookup/doi/10. 1073/pnas. 1714044115.

Fan, Z.-X., S.-B. Zhang, G.-Y. Hao, J. Ferry Slik, and K.-F. Cao (2012). "Hydraulic conductivity traits predict growth rates and adult stature of 40 Asian tropical tree species better than wood density: Xylem traits and tree growth". In: Journal of Ecology 100.3, pp. 732-741. URL: http://doi.wiley.com/10.1111/j.1365-2745.2011.01939.x.

Fauset, S., M. Gloor, N. M. Fyllas, O. L. Phillips, G. P. Asner, et al. (2019). "IndividualBased Modeling of Amazon Forests Suggests That Climate Controls Productivity While Traits Control Demography". In: Frontiers in Earth Science 7, p. 83. URL: https://www. frontiersin.org/article/10.3389/feart.2019.00083/full.

Fauset, S., M. O. Johnson, M. Gloor, T. R. Baker, A. Monteagudo M., et al. (2015). "Hyperdominance in Amazonian forest carbon cycling". In: Nature Communications 6.1, p. 6857. URL: http://www.nature.com/articles/ncomms7857.

Field, C. B., M. J. Behrenfeld, J. T. Randerson, and P. Falkowski (1998). "Primary Production of the Biosphere: Integrating Terrestrial and Oceanic Components". In: Science 281.5374, pp. 237-240. URL: https://science.sciencemag.org/content/281/5374/237.

Francis, E. J., H. C. Muller-Landau, S. J. Wright, M. D. Visser, Y. Iida, C. Fletcher, S. P. Hubbell, and A. R. Kassim (2017). "Quantifying the role of wood density in explaining interspecific variation in growth of tropical trees". In: Global Ecology and Biogeography 26.10, pp. 1078-1087. URL: http://doi.wiley.com/10.1111/geb.12604.

Gibert, A., E. F. Gray, M. Westoby, I. J. Wright, and D. S. Falster (2016). "On the link between functional traits and growth rate: meta-analysis shows effects change with plant size, as predicted". In: Journal of Ecology 104.5. Ed. by S. Wilson, pp. 1488-1503. URL: http://doi.wiley.com/10.1111/1365-2745.12594.

Gleason, S. M., A. E. A. Stephens, W. C. Tozer, C. J. Blackman, D. W. Butler, et al. (2018). "Shoot growth of woody trees and shrubs is predicted by maximum plant height and associated traits". In: Functional Ecology 32.2. Ed. by M. Tjoelker, pp. 247-259. URL: http://doi.wiley.com/10.1111/1365-2435.12972.

Gleason, S. M., M. Westoby, S. Jansen, B. Choat, U. G. Hacke, et al. (2016). "Weak tradeoff between xylem safety and xylem-specific hydraulic efficiency across the world's woody 
plant species". In: New Phytologist 209.1, pp. 123-136. URL: https://nph.onlinelibrary. wiley.com/doi/abs/10.1111/nph.13646.

Grace, J. B. (2006). Structural Equation Modeling and Natural Systems. New York: Cambridge University Press.

Grace, J. B., D. R. Schoolmaster, G. R. Guntenspergen, A. M. Little, B. R. Mitchell, K. M. Miller, and E. W. Schweiger (2012). "Guidelines for a graph-theoretic implementation of structural equation modeling". In: Ecosphere 3.8, pp. 1-44. URL: http:// doi.wiley. com/10.1890/ES12-00048.1.

Grote, R., A. Gessler, R. Hommel, W. Poschenrieder, and E. Priesack (2016). "Importance of tree height and social position for drought-related stress on tree growth and mortality". In: Trees 30.5, pp. 1467-1482. URL: https://doi.org/10.1007/s00468-016-1446-x.

Hartmann, H. (2015). "Carbon starvation during drought-induced tree mortality - are we chasing a myth?" In: Journal of Plant Hydraulics 2, e005. URL: https://hal.archivesouvertes.fr/hal-01230747.

Hartmann, H., C. F. Moura, W. R. L. Anderegg, N. K. Ruehr, Y. Salmon, et al. (2018). "Research frontiers for improving our understanding of drought-induced tree and forest mortality". In: New Phytologist 218.1, pp. 15-28. URL: http://doi.wiley.com/10.1111/ nph.15048.

Hartmann, H. and S. Trumbore (2016). "Understanding the roles of nonstructural carbohydrates in forest trees - from what we can measure to what we want to know". In: New Phytologist 211.2, pp. 386-403. URL: http://doi.wiley.com/10.1111/nph.13955.

Hietz, P., S. Rosner, U. Hietz-Seifert, and S. J. Wright (2016). "Wood traits related to size and life history of trees in a Panamanian rainforest". In: New Phytologist 213.1, pp. 170-180. URL: http://doi.wiley.com/10.1111/nph.14123.

Hijmans, R. J., S. E. Cameron, J. L. Parra, P. G. Jones, and A. Jarvis (2005). "Very high resolution interpolated climate surfaces for global land areas". In: International Journal of Climatology 25.15, pp. 1965-1978. URL: http://doi.wiley.com/10.1002/joc.1276.

Hoeber, S., C. Leuschner, L. Köhler, D. Arias-Aguilar, and B. Schuldt (2014). "The importance of hydraulic conductivity and wood density to growth performance in eight tree species from a tropical semi-dry climate". In: Forest Ecology and Management 330, pp. 126-136. URL: https://linkinghub.elsevier.com/retrieve/pii/S037811271400406X.

Karger, D. N., O. Conrad, J. Böhner, T. Kawohl, H. Kreft, et al. (2017). "Climatologies at high resolution for the earth's land surface areas". In: Scientific Data 4, p. 170122. URL: http://www.nature.com/articles/sdata2017122.

King, D. A., S. J. Davies, S. Tan, and N. S. M. Noor (2006). "The role of wood density and stem support costs in the growth and mortality of tropical trees". In: Journal of Ecology 94.3, pp. 670-680. URL: http://doi.wiley.com/10.1111/j.1365-2745.2006.01112.x.

Koch, G. W., S. C. Sillett, G. M. Jennings, and S. D. Davis (2004). "The limits to tree height". In: Nature 428.6985 , p. 851. URL: https: / / www . nature.com / articles / nature02417.

Körner, C. (2015). "Paradigm shift in plant growth control". In: Current Opinion in Plant Biology 25, pp. 107-114. URL: http:// www . sciencedirect.com/science/article/pii / S1369526615000540.

- (2019). "No need for pipes when the well is dry-a comment on hydraulic failure in trees". In: Tree Physiology 39.5, pp. 695-700.

Kotowska, M. M., D. Hertel, Y. A. Rajab, H. Barus, and B. Schuldt (2015). "Patterns in hydraulic architecture from roots to branches in six tropical tree species from cacao agroforestry and their relation to wood density and stem growth". In: Frontiers in Plant Science 6. URL: https://www.frontiersin.org/articles/10.3389/fpls.2015.00191/full. 
Kuznetsova, A., P. B. Brockhoff, and R. H. B. Christensen (2017). "lmerTest Package: Tests in Linear Mixed Effects Models". In: Journal of Statistical Software 82.13, pp. 126.

Landhäusser, S. M., P. S. Chow, L. T. Dickman, M. E. Furze, I. Kuhlman, et al. (2018). "Standardized protocols and procedures can precisely and accurately quantify nonstructural carbohydrates". In: Tree Physiology 38.12, pp. 1764-1778. URL: https:// academic.oup.com/treephys/article/38/12/1764/5146736.

Lefcheck, J. S. (2016). "PIECEWISESEM : Piecewise structural equation modelling in R for ecology, evolution, and systematics". In: Methods in Ecology and Evolution 7.5. Ed. by R. Freckleton, pp. 573-579. URL: http://doi.wiley.com/10.1111/2041-210X.12512.

Liaw, A. and M. Wiener (2002). "Classification and Regression by randomForest". In: $R$ News 2.3, pp. 18-22. URL: https://CRAN.R-project.org/doc/Rnews/.

Lindenmayer, D. B., W. F. Laurance, and J. F. Franklin (2012). "Global Decline in Large Old Trees". In: Science 338.6112, pp. 1305-1306. uRL: http://www.sciencemag.org/cgi/ doi/10.1126/science.1231070.

Link, R. M., B. Schuldt, B. Choat, S. Jansen, and A. R. Cobb (2018). "Maximum-likelihood estimation of xylem vessel length distributions". In: Journal of Theoretical Biology 455, pp. 329-341. URL: https://linkinghub.elsevier.com/retrieve/pii/S0022519318303679.

Liu, H., S. M. Gleason, G. Hao, L. Hua, P. He, G. Goldstein, and Q. Ye (2019). "Hydraulic traits are coordinated with maximum plant height at the global scale". In: Science Advances 5.2, eaav1332. URL: http://advances.sciencemag.org/lookup/doi/10.1126/ sciadv.aav1332.

Lutz, J. A., T. J. Furniss, D. J. Johnson, S. J. Davies, D. Allen, et al. (2018). "Global importance of large-diameter trees". In: Global Ecology and Biogeography 27.7, pp. 849864. URL: http://doi.wiley.com/10.1111/geb.12747.

Malhi, Y. (2012). "The productivity, metabolism and carbon cycle of tropical forest vegetation". In: Journal of Applied Ecology, pp. 65-75. URL: https://besjournals.onlinelibrary. wiley.com/doi/abs/10.1111/j.1365-2745.2011.01916.x\%5C\%4010.1111/\%5C\%28ISSN\% 5C\%291365-2664.NovelEcosystemsintheAnthropocene.

Martínez-Vilalta, J., A. Sala, D. Asensio, L. Galiano, G. Hoch, S. Palacio, F. I. Piper, and F. Lloret (2016). "Dynamics of non-structural carbohydrates in terrestrial plants: a global synthesis". In: Ecological Monographs 86.4, pp. 495-516. URL: http://doi.wiley. com/10.1002/ecm.1231.

McDowell, N. G., D. J. Beerling, D. D. Breshears, R. A. Fisher, K. F. Raffa, and M. Stitt (2011). "The interdependence of mechanisms underlying climate-driven vegetation mortality". In: Trends in Ecology \& Evolution 26.10, pp. 523-532. URL: https: //linkinghub.elsevier.com/retrieve/pii/S0169534711001698.

McDowell, N., C. D. Allen, K. Anderson-Teixeira, P. Brando, R. Brienen, et al. (2018). "Drivers and mechanisms of tree mortality in moist tropical forests". In: New Phytologist 219.3, pp. 851-869. URL: https://nph.onlinelibrary.wiley.com/doi/abs/10.1111/nph. 15027.

McDowell, N., W. T. Pockman, C. D. Allen, D. D. Breshears, N. Cobb, et al. (2008). "Mechanisms of plant survival and mortality during drought: why do some plants survive while others succumb to drought?" In: New Phytologist 178.4, pp. 719-739. URL: http: //doi.wiley.com/10.1111/j.1469-8137.2008.02436.x.

Moles, A. T., D. I. Warton, L. Warman, N. G. Swenson, S. W. Laffan, et al. (2009). "Global patterns in plant height". In: Journal of Ecology 97, pp. 923-932. URL: https: / / besjournals.onlinelibrary.wiley.com/doi/abs/10.1111/j.1365-2745.2009.01526.x\% 5C\%4010.1111/\%5C\%28ISSN\%5C\%291365-2745.GLOBWA. 
Muller-Landau, H. C. (2004). "Interspecific and Inter-site Variation in Wood Specific Gravity of Tropical Trees". In: BIOTROPICA 36.1, p. 20. URL: http://www.bioone.org/ perlserv/?request $=$ get-abstract $\% 5 \mathrm{C} \&$ doi $=10.1646 \% 5 \mathrm{C} \% 2 \mathrm{~F} 02119$.

Nakagawa, S., P. C. D. Johnson, and H. Schielzeth (2017). "The coefficient of determination $\mathrm{R}^{2}$ and intra-class correlation coefficient from generalized linear mixed-effects models revisited and expanded". In: Journal of the Royal Society, Interface 14.134.

O'Brien, M. J., B. M. J. Engelbrecht, J. Joswig, G. Pereyra, B. Schuldt, et al. (2017). "A synthesis of tree functional traits related to drought-induced mortality in forests across climatic zones". In: Journal of Applied Ecology 54.6. Ed. by J. Firn, pp. 1669-1686. URL: http://doi.wiley.com/10.1111/1365-2664.12874.

O'Brien, M. J., S. Leuzinger, C. D. Philipson, J. Tay, and A. Hector (2014). "Drought survival of tropical tree seedlings enhanced by non-structural carbohydrate levels". In: Nature Climate Change 4.8, pp. 710-714. URL: http:// www. nature.com/articles / nclimate2281.

Olson, M. E., T. Anfodillo, J. A. Rosell, G. Petit, A. Crivellaro, et al. (2014). "Universal hydraulics of the flowering plants: vessel diameter scales with stem length across angiosperm lineages, habits and climates". In: Ecology Letters 17.8. Ed. by B. Enquist, pp. 988-997. URL: http://doi.wiley.com/10.1111/ele.12302.

Olson, M. E., D. Soriano, J. A. Rosell, T. Anfodillo, M. J. Donoghue, et al. (2018). "Plant height and hydraulic vulnerability to drought and cold". In: Proceedings of the National Academy of Sciences 115.29, pp. 7551-7556. URL: http://www.pnas.org/lookup/doi/ $10.1073 /$ pnas. 1721728115.

Phillips, O. L., G. van der Heijden, S. L. Lewis, G. López-González, L. E. O. C. Aragão, et al. (2010a). "Drought-mortality relationships for tropical forests". In: New Phytologist, pp. 631-646. URL: https:/ / nph. onlinelibrary . wiley . com/doi / abs / 10.1111/j.14698137.2010.03359.x\%5C\%4010.1002/\%5C\%28ISSN\%5C\%291469-8137\%5C\%28CAT\% $5 \mathrm{C} \% 29$ FeatureIssues $\% 5 \mathrm{C} \% 28 \mathrm{VI} \% 5 \mathrm{C} \% 29$ Amazonianrainforestsanddrought.

Pinheiro, J. C. and D. M. Bates (2000). Mixed-effects models in S and S-Plus. New York: Springer.

Pinheiro, J., D. Bates, S. DebRoy, D. Sarkar, and R Core Team (2019). nlme: Linear and Nonlinear Mixed Effects Models. URL: https://CRAN.R-project.org/package=nlme.

Poorter, L., C. V. Castilho, J. Schietti, R. S. Oliveira, and F. R. C. Costa (2018). "Can traits predict individual growth performance? A test in a hyperdiverse tropical forest". In: New Phytologist 219.1, pp. 109-121. URL: http://doi.wiley.com/10.1111/nph.15206.

Poorter, L., I. McDonald, A. Alarcón, E. Fichtler, J.-C. Licona, et al. (2010). "The importance of wood traits and hydraulic conductance for the performance and life history strategies of 42 rainforest tree species". In: New Phytologist 185.2, pp. 481-492. URL: http://doi.wiley.com/10.1111/j.1469-8137.2009.03092.x.

Quentin, A. G., E. A. Pinkard, M. G. Ryan, D. T. Tissue, L. S. Baggett, et al. (2015). "Non-structural carbohydrates in woody plants compared among laboratories". In: Tree Physiology 35.11, pp. 1146-1165. URL: https://academic.oup.com/treephys/article/35/ 11/1146/2364599.

R Core Team (2019). R: A Language and Environment for Statistical Computing. Vienna, Austria: R Foundation for Statistical Computing. URL: https://www.R-project.org/.

Réjou-Méchain, M., A. Tanguy, C. Piponiot, J. Chave, and B. Hérault (2017). "BIOMASS: an $\mathrm{R}$ package for estimating above-ground biomass and its uncertainty in tropical forests". In: Methods in Ecology and Evolution 8.9. Ed. by S. Goslee, pp. 1163-1167. URL: http://doi.wiley.com/10.1111/2041-210X.12753. 
Robinson, W. S. (1950). "Ecological Correlations and the Behavior of Individuals". In: American Sociological Review 15, pp. 351-357.

Rosell, J. A., M. E. Olson, and T. Anfodillo (2017). "Scaling of Xylem Vessel Diameter with Plant Size: Causes, Predictions, and Outstanding Questions". In: Current Forestry Reports 3.1, pp. 46-59. URL: http://link.springer.com/10.1007/s40725-017-0049-0.

Rowland, L., A. C. L. da Costa, D. R. Galbraith, R. S. Oliveira, O. J. Binks, et al. (2015a). "Death from drought in tropical forests is triggered by hydraulics not carbon starvation". In: Nature 528.7580, pp. 119-122.

Roy, J., H. A. Mooney, and B. Saugier (2001). Terrestrial Global Productivity. Elsevier.

Rüger, N., U. Berger, S. P. Hubbell, G. Vieilledent, and R. Condit (2011). "Growth Strategies of Tropical Tree Species: Disentangling Light and Size Effects". In: PLoS ONE 6.9. Ed. by E. Scalas, e25330. URL: https://dx.plos.org/10.1371/journal.pone.0025330.

Rüger, N., C. Wirth, S. J. Wright, and R. Condit (2012). "Functional traits explain light and size response of growth rates in tropical tree species". In: Ecology 93.12, pp. 26262636. URL: http://doi.wiley.com/10.1890/12-0622.1.

Russo, S. E., K. L. Jenkins, S. K. Wiser, M. Uriarte, R. P. Duncan, and D. A. Coomes (2010). "Interspecific relationships among growth, mortality and xylem traits of woody species from New Zealand: Tree growth, mortality and woody traits". In: Functional Ecology 24.2, pp. 253-262. URL: http://doi.wiley.com/10.1111/j.1365-2435.2009.01670. $\mathrm{x}$.

Ryan, M. G. (2015). "Tree mortality: Large trees losing out to drought". In: Nature Plants 1.10, p. 15150. URL: http://www.nature.com/articles/nplants2015150.

Ryan, M. G., N. Phillips, and B. J. Bond (2006). "The hydraulic limitation hypothesis revisited". In: Plant, Cell and Environment 29.3, pp. 367-381. URL: http://doi.wiley. com/10.1111/j.1365-3040.2005.01478.x.

Ryan, M. G. and B. J. Yoder (1997). "Hydraulic Limits to Tree Height and Tree Growth". In: BioScience 47.4, pp. 235-242. URL: https://www.jstor.org/stable/1313077.

Schneider, C. A., W. S. Rasband, and K. W. Eliceiri (2012). "NIH Image to ImageJ: 25 years of image analysis". In: Nature Methods 9, pp. 671-675. URL: https://www.nature. com/articles/nmeth.2089.

Schuldt, B., C. Leuschner, N. Brock, and V. Horna (2013). "Changes in wood density, wood anatomy and hydraulic properties of the xylem along the root-to-shoot flow path in tropical rainforest trees". In: Tree Physiology 33.2, pp. 161-174. URL: https://academic. oup.com/treephys/article-lookup/doi/10.1093/treephys/tps122.

Schuldt, B., C. Leuschner, V. Horna, G. Moser, M. Köhler, O. van Straaten, and H. Barus (2011). "Change in hydraulic properties and leaf traits in a tall rainforest tree species subjected to long-term throughfall exclusion in the perhumid tropics". In: Biogeosciences 8.8, pp. 2179-2194. URL: http://www.biogeosciences.net/8/2179/2011/.

Sevanto, S., N. G. Mcdowell, L. T. Dickman, R. Pangle, and W. T. Pockman (2014). "How do trees die? A test of the hydraulic failure and carbon starvation hypotheses". In: Plant, Cell Ef Environment 37.1, pp. 153-161. URL: http://doi.wiley.com/10.1111/pce.12141.

Shipley, B. (2000). "A New Inferential Test for Path Models Based on Directed Acyclic Graphs". In: Structural Equation Modeling: A Multidisciplinary Journal 7.2, pp. 206218. URL: https://doi.org/10.1207/S15328007SEM0702_4.

- (2009). "Confirmatory path analysis in a generalized multilevel context". In: Ecology 90.2, pp. 363-368. URL: http://doi.wiley.com/10.1890/08-1034.1.

Šímová, I., B. Sandel, B. J. Enquist, S. T. Michaletz, J. Kattge, et al. (2019). "The relationship of woody plant size and leaf nutrient content to large-scale productivity for forests 
across the Americas". In: Journal of Ecology. Ed. by A. Hector, pp. 1365-2745.13163. URL: https://onlinelibrary.wiley.com/doi/abs/10.1111/1365-2745.13163.

Sperry, J. S., U. G. Hacke, and J. K. Wheeler (2005). "Comparative analysis of end wall resistivity in xylem conduits". In: Plant, Cell and Environment 28.4, pp. 456-465. URL: http://doi.wiley.com/10.1111/j.1365-3040.2005.01287.x.

Spicer, R. and B. Gartner (2001). "The effects of cambial age and position within the stem on specific conductivity in Douglas-fir (Pseudotsuga menziesii) sapwood". In: Trees 15.4, pp. 222-229. URL: http://link.springer.com/10.1007/s004680100093.

Stekhoven, D. J. and P. Buehlmann (2012). "MissForest - non-parametric missing value imputation for mixed-type data". In: Bioinformatics 28.1, pp. 112-118.

Stephenson, N. L., A. J. Das, R. Condit, S. E. Russo, P. J. Baker, et al. (2014). "Rate of tree carbon accumulation increases continuously with tree size". In: Nature 507.7490, pp. 90-93. URL: https://www.nature.com/articles/nature12914.

Sullivan, J. T. (1935). "The Estimation of Starch". In: Industrial \& Engineering Chemistry Analytical Edition 7.5, pp. 311-314. URL: https://pubs.acs.org/doi/abs /10.1021/ ac50097a010.

Tyree, M. T. (2003). "Hydraulic limits on tree performance: transpiration, carbon gain and growth of trees". In: Trees 17, pp. 95-100.

van Gelder, H. A., L. Poorter, and F. J. Sterck (2006). "Wood mechanics, allometry, and life-history variation in a tropical rain forest tree community". In: New Phytologist 171.2, pp. 367-378. URL: http://doi.wiley.com/10.1111/j.1469-8137.2006.01757.x.

Warton, D. I., R. A. Duursma, D. S. Falster, and S. Taskinen (2012). "smatr 3- an R package for estimation and inference about allometric lines". In: Methods in Ecology and Evolution 3.2, pp. 257-259. URL: https://besjournals.onlinelibrary.wiley.com/doi/ abs/10.1111/j.2041-210X.2011.00153.x.

Wheeler, J. K., J. S. Sperry, U. G. Hacke, and N. Hoang (2005). "Inter-vessel pitting and cavitation in woody Rosaceae and other vesselled plants: a basis for a safety versus efficiency trade-off in xylem transport". In: Plant, Cell and Environment 28.6, pp. 800812. URL: http://doi.wiley.com/10.1111/j.1365-3040.2005.01330.x.

Wright, S. J., K. Kitajima, N. J. B. Kraft, P. B. Reich, I. J. Wright, et al. (2010). "Functional traits and the growth-mortality trade-off in tropical trees". In: Ecology 91.12, pp. 3664-3674. URL: http://www.jstor.org/stable/29779549.

Zhang, J.-L. and K.-F. Cao (2009). "Stem hydraulics mediates leaf water status, carbon gain, nutrient use efficiencies and plant growth rates across dipterocarp species". In: Functional Ecology 23.4, pp. 658-667. URL: http:// doi.wiley.com/10.1111/j.13652435.2009.01552.x. 



\section{Synthesis}

In the following, I summarize the main findings from the four manuscripts presented in the framework of my dissertation, and discuss the outcome of my work in the light of the current state of knowledge regarding plant ecophysiology and water relations. In doing so, I put a special focus the research objectives and hypotheses that motivated the present work (cf Section 1.7), and demonstrate how my findings can contribute to a) an improved accuracy in sap flow measurements and b) a more nuanced understanding of trait interactions in tropical forests.

In order to be able to address the hypotheses regarding the drought response of tropical trees in sufficient detail, I additionally dedicate one Section of this Chapter to the presentation of preliminary results from tree hydraulic measurements from the Osa peninsula in Costa Rica (see Section 7.2).

\subsection{Using sap flow probes to estimate whole tree water use and transpiration rates}

\subsubsection{How reliable are different sensor systems?}

While plant transpiration is a key component of land evaporative fluxes, its accurate measurement to this day is complicated (Poyatos et al. 2016). The results of the calibration study (Chapter 3) demonstrate that commonly used sensor systems for sap flow measurements differ considerably in their performance, and that both species identity and differences between individual trees can result in differences in the relationship between observed flow rates and sensor readings.

Our results corroborate findings (Lundblad et al. 2001; Taneda and Sperry 2008; Bush et al. 2010; Pasqualotto et al. 2019) that the parameters of the "Granier equation" (Equation (3.1)) for thermal dissipation probes (TDP, cf. Granier 1985) do not universally generalize to new species, which is consistent with the assumption that heat dissipation depends on wood properties (Wullschleger et al. 2011). In addition, our study provides evidence for the assumption of Vandegehuchte and Steppe (2012c) that the heat field deformation (HFD) method strongly benefits from species-specific calibration. At low sap flux densities, the heat ratio method (HRM) showed the by far best performance of all assessed methods when applied without species-specific calibration, which we attributed to its direct derivation from physical principles. However, as reported by Bleby et al. (2008), the accuracy of HRM sensors deteriorated rapidly when it was used at flow rates exceeding the boundary conditions under which the approximation of sap velocity by Equation (3.4) (Marshall 1958) is valid.

As thermometric sap flow methods have become the most commonly applied approach to estimate tree-level transpiration (Poyatos et al. 2016), an accurate quantification of the different sources of uncertainty in sap flux density measurements becomes increasingly 
important. In a recent research synthesis building upon the data of 60 sap flow calibration studies (including the data from Chapter 3), Flo et al. (2019) compare the out-of-thebox accuracy of seven different sap flow measurement methods using the original authors' calibration equations. In agreement with our findings, these authors suggest that empirical calibrations may be needed to guarantee correct absolute values of sap flow, even when using relatively robust Pulse methods. Further, their results confirm our notion that TDP sensors systematically underestimate sap flow while HRM sensors may achieve the highest level of accuracy when applied within their range of the validity.

\subsubsection{Components of measurement uncertainty in sap flux density estimates}

While the work of Flo et al. (2019) represents a truly commendable effort with regard to the identification of uncertainty and bias in different sap flow measurement methods, the focus of their work is put predominantly on the methods comparison. In the following, I will therefore discuss the different sources of uncertainty and variability in sap flow calibrations in a systematic fashion, and detail how the hierarchical modelling approach employed in Chapter 3 and 4 may contribute to a more detailed understanding of the uncertainty budget in sap flux density estimates.

On a conceptual level, the main sources of bias uncertainty when estimating sap flux density from thermometric sensor readings can be separated into errors that derive from $a$. measurement-method specific differences, $b$. installation effects, $c$. variability between species, $d$. variability between trees and $e$. variability within single stems.

With regard to $a$., the comparison of different sensor systems provided in Flo et al. (2019) provides the fullest and most complete method comparison available to date. However, their work discusses the accuracy, bias and precision of each method based on the original formulation of the calibration relationships proposed by its authors. Besides the question whether the original calibration relationship is unconditional valid under conditions that differ from the conditions under which the original calibrations were performed, an additional, hidden source of uncertainty in $a$. is entailed in the functional form of the relationship between sensor readings and 'true' flow rates. As an example for different functional forms for the same calibration relationship, see e.g. the polynomial models Vandegehuchte and Steppe (2012c) propose for the HFD method. An inappropriate functional form may result in non-linear sensor behavior (cf. Flo et al. 2019) even after a study-specific calibration experiment.

Installation-related effects on sap flux density estimates $(b$.) include wounding reactions (Clearwater et al. 1999; Burgess et al. 2001; Steppe et al. 2015; Wiedemann et al. 2016) and effects of improper sensor needle alignment (Burgess et al. 2001; Nadezhdina et al. 2012). While the adaption of well-defined installation protocols as well as mathematical corrections for wounding-reactions (e.g. Green et al. 2003; Wiedemann et al. 2016) may alleviate installation effects on the measurement of sap flow methods, a certain impact on the overall accuracy is ultimately not avoidable due to the physical nature of the installation process.

Especially for fully empirical measurement methods, variability of calibration relationships between species (c.) may play a central role in the uncertainty budget. As the heat transfer in sapwood crucially depends on its thermal diffusivity (Vandegehuchte and Steppe 2012a; Vandegehuchte and Steppe 2012b), the same sap flux densities can result in different sensor readings if tree species differ in wood properties related to thermal diffusivity, such 
as wood density and moisture content (cf. Vergeynst et al. 2014; Looker et al. 2016; Peters et al. 2018), as well as wood anatomical traits related to the anisotropy in heat transport (Vandegehuchte and Steppe 2012b). However, while some studies assume a remarked effect of wood density on calibration performance (e.g. Wullschleger et al. 2011), Flo et al. (2019) do not report evidence for an elevated role of wood properties. In either case, the pronounced species-specific differences in our re-calibrations indicates that significant species-specific variation was at play in our case.

Tree-specific $(d$.$) and within-tree (e.) differences in calibration relationships may result$ from intraspecific variability in the same wood traits that also are responsible for the observed species differences, and may be exacerbated by temporal trends such as longterm changes in sapwood water content. These sources of errors pose a real challenge for sap flux density measurements as they can not be accommodated by species-specific calibration. Under realistic field settings, they can therefore have a major impact on the measurement accuracy.

It is important to note that all of the aforementioned patterns refer to differences in the relationship between sensor readings and actual sap flux density. In realistic settings, these are generally overlaid by patterns in sap flux density itself, which is known to differ between species and individual trees, and to exhibit radial, azimuthal and temporal patterns within each tree (Steppe et al. 2015). As under these conditions it is usually not possible to distinguish between differences driven by biological signals and differences driven by inadequate sensor calibrations, care has to be taken to 1 . optimize the measurement methods to minimize the impact of the different sources of error and 2. use methods that allow for an appropriate propagation of uncertainty.

Our results in Chapter 3 suggest that in settings where a species-specific sensor calibration is feasible (e.g. in species-poor temperate or boreal forests, or for plantation trees), this may be the most effective way to avoid biased estimates. If this is not possible, it is advisable to use methods whose mode of operation has a strong physical basis (as for the HRM method within its validity range). In either case, intra-specific variability in calibration relationships was considerable in our study. As this component of the uncertainty budget cannot be accounted for by study-specific calibrations, it constitutes a major liability for the accuracy of sap flow studies. While the most prudent strategy to account for its effect is to measure sap flow on large numbers of trees to average it out, this will likely often times not be possible.

To more accurately propagate the measurement uncertainty in such cases, it may make sense to device calibration setups based on a hierarchical modelling approach and error propagation methods analogous to Chapter 4, ideally building upon large unified calibration datasets as in Flo et al. (2019). Without using a modelling approach that accurately reflects the hierarchy of different sources of uncertainty in the calibration relationship, it will hardly be possible to account for the uncertainty in sap flux density estimates when generalizing to new species. Simulating from probability models using Monte Carlo approaches enables to easily propagate inferential uncertainty in parameter estimates into predictions of new quantities (cf. Gelman and Hill 2006, Chapter 7). As demonstrated in Chapter 4, this approach blends in nicely with a hierarchical Bayesian modeling framework, as Markov Chain Monte Carlo (MCMC) samples from the posterior distribution provide a straightforward tool for uncertainty propagation (cf. Clark 2005; Ogle 2009). 


\subsubsection{Incorporating radial profiles into upscaled water use estimates}

Besides the impact of uncertainty in the measurement procedure itself (discussed Section 7.1.2), the accuracy of the upscaled water use and transpiration estimates on whole-tree level crucially depends on how well the information in the point measurements of sap flux density obtained at the sensor positions can be mapped onto the stem cross-sectional area.

As discussed in Chapter 4, sap flux density is known to vary considerably along the azimuthal and radial dimension of trees. While azimuthal variation can be assumed to average out over large enough sample sizes, assuming constant sap flux across the entire sapwood depth in the presence of radial gradients has been shown lead to extremely poor water use estimates, with a trend towards overestimating real flow (Čermák and Nadezhdina 1998; Ford et al. 2004b). In accordance with this, we found estimates based on the assumption of constant sap flow across the entire sapwood depth to overestimate water use by on average $26 \%$ with a range of $-42 \%$ to $+113 \%$ compared to estimates based on our model of radial profiles. Notably, we found the amount of bias in these estimates to differ credibly between species, which indicates that ignoring radial profiles may result in systematic errors in species comparisons.

Under realistic field settings, it will often not be possible to equip all trees with sap flow sensor systems capable of measuring radial sap flux profiles. By following the approach of Caylor and Dragoni (2009) to decompose sap flow signals into a stem conductivity signal and the radial profile, it is possible to combine measurements from simple single-point sensors with radial profile measurements (e.g. based on the HFD method) for a subset of trees. Building upon the work of Berdanier et al. (2016), in Chapter 4 we illustrate how to use a Bayesian hierarchical modelling framework to propagate uncertainty when making predictions for new trees and new species.

Further, our manuscript is a proof of concept that the shape of radial sap flux profiles can be predicted by structural and functional tree properties. However, while we found tree height to be a credible predictor of the shape of radial profiles, the explanatory power was low compared to the large inter- and intraspecific variability. In agreement with previous findings (Delzon et al. 2004; Reyes-Acosta and Lubczynski 2013; Zhang et al. 2015; Berdanier et al. 2016), our data indicate that variability in radial profiles may have a major effect on the accuracy of estimates of sap flow and tree water use, which indicates that future studies might benefit considerably from identifying variables that are more closely related to their shape. Berdanier et al. (2016) provide an example for a potentially useful predictor of radial profile shape by demonstrating credible differences between the shapes of radial profiles of conifers, ring-porous and diffuse-porous trees. Analogous comparisons between different plant functional types, major phylogenetic groups etc. might shed light on the determinants of the shapes of radial sap flux profiles, and have the potential to considerably improve the accuracy of transpiration estimates.

\subsection{Preliminary results of the hydraulic measurements on the Osa peninsula}

This section shows preliminary results of the vulnerability curve measurements performed in the rainy seasons 2016 and 2017 on the two research sites situated on the Osa Peninsula, Mogos and San Juan (see Section 2.1.6 for details). The results are part of a manuscript in preparation that is intended for publication in 2020. In this section, the results of 


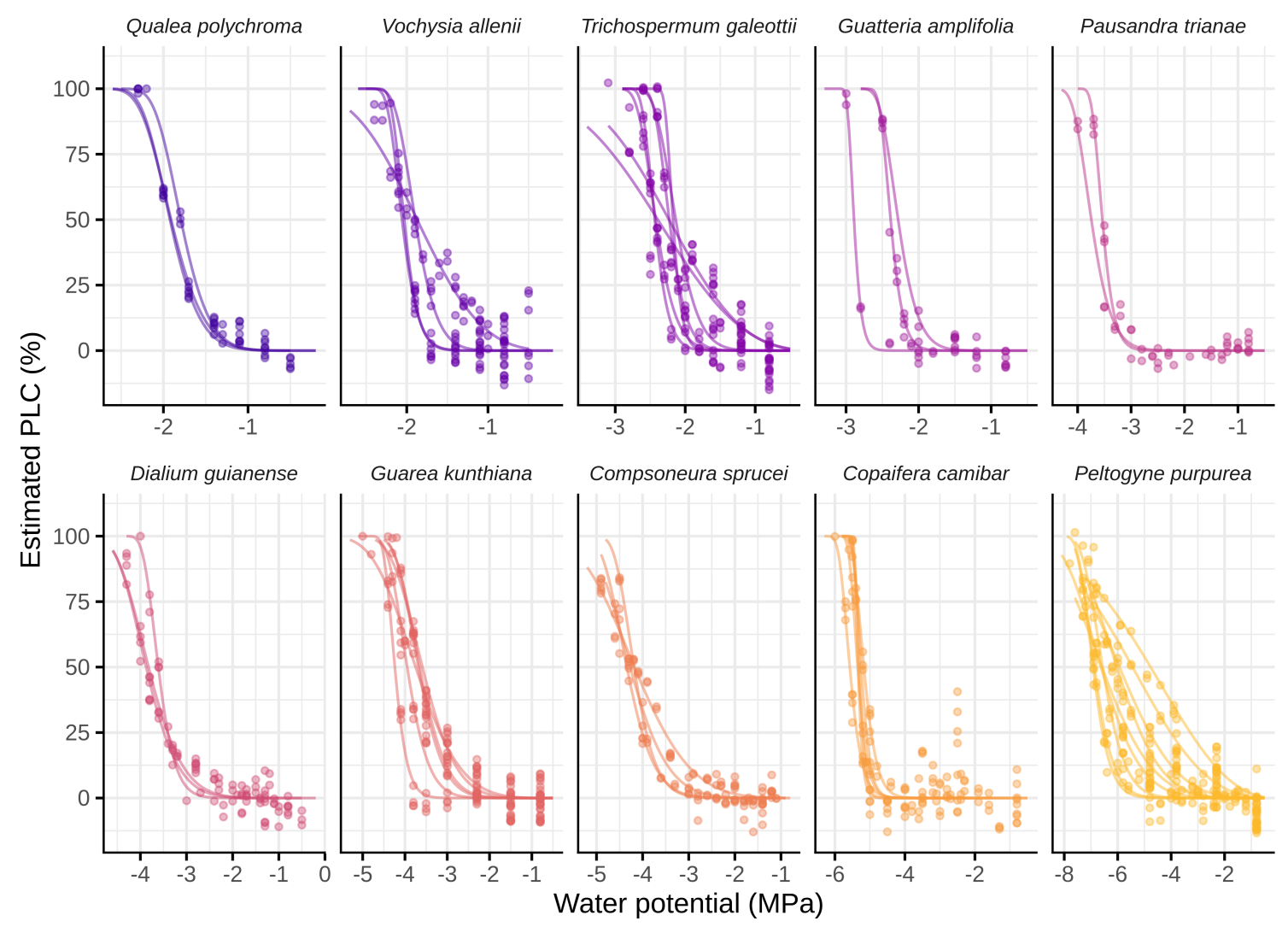

Figure 7.1: Predicted vulnerability curves for the 10 studied species (ordered by increasing embolism resistance). Curves were estimated with the model specified in Eq. (2.5) and subsequently rescaled to the PLC scale to ease the comparison between branches (points: observed PLC, lines: sample-level prediction). Note the negative PLC-values for individual measurements result from the model fitting on the conductivity scale, which assumes $K_{\max }$ to be measured with error.

the measurements are discussed briefly based on preliminary models focusing on simple linear associations between estimated vulnerability curve parameters and structural and functional traits. The final publication will be based on a hierarchical Bayesian approach that allows to propagate the uncertainty in the parameter estimates building upon the work of Ogle et al. (2009).

\subsubsection{Fitted vulnerability curves}

Preliminary vulnerability curves for the ten tree species studied on the Osa Peninsula based on model fits according to (2.5) are shown Figure 7.1. While the preliminary model predictions in these figures are based on simplistic branch-wise models that ignore the hierarchical nature of the dataset, it is notable that already these preliminary models in most cases were able to achieve a considerable goodness of fit (avg. pseudo- $\mathrm{R}^{2}$ : 0.946 , range: 0.626-0.997). In addition, with the exception of Peltogyne purpurea, Trichospermum galeotti and Vochysia allenii, the measured vulnerability curves were remarkably consistent within species.

This is also illustrated by the low within-species variability in the estimated parameters (Figure 7.2), which is especially evident in case of $\Psi_{50}$. The observed values of water 
Table 7.1: Average, minimum and maximum parameter estimates for the parameters of the fitted vulnerability curves (cf. Figure 7.2). K_max - maximum specific conductivity $\left(\mathrm{kg} \mathrm{m}^{-1} \mathrm{Mpa}^{-1}\right.$ $\left.\mathrm{s}^{-1}\right) ; P_{50}$ - water potential at $50 \%$ loss of conductivity (MPa); $k$ - shape parameter of the Weibull distribution (unitless, $>1$ if s-shaped).

\begin{tabular}{|c|c|c|c|c|c|c|c|c|c|c|}
\hline \multirow[b]{2}{*}{ Family } & \multirow[b]{2}{*}{ Species } & \multicolumn{3}{|c|}{$\Psi_{50}$} & \multicolumn{3}{|c|}{$k$} & \multicolumn{3}{|c|}{$K_{\max }$} \\
\hline & & Avg. & Min. & Max. & Avg. & Min. & Max. & Avg. & Min. & Max. \\
\hline Fabaceae & Peltogyne purpurea & -6.195 & -6.922 & -4.769 & 7.775 & 2.355 & 16.749 & 0.479 & 0.041 & 1.093 \\
\hline Fabaceae & Copaifera camibar & -5.329 & -5.574 & -5.171 & 35.745 & 21.222 & 58.739 & 0.119 & 0.024 & 0.261 \\
\hline Myristicaceae & Compsoneura sprucei & -4.243 & -4.341 & -4.176 & 9.384 & 5.112 & 13.448 & 0.299 & 0.080 & 0.497 \\
\hline Meliaceae & Guarea kunthiana & -3.809 & -4.239 & -3.586 & 10.616 & 5.240 & 21.859 & 0.255 & 0.037 & 0.430 \\
\hline Fabaceae & Dialium guianense & -3.769 & -3.874 & -3.611 & 10.352 & 7.705 & 14.941 & 0.116 & 0.088 & 0.131 \\
\hline Euphorbiaceae & Pausandra trianae & -3.640 & -3.743 & -3.537 & 19.457 & 14.962 & 23.951 & 1.013 & 0.633 & 1.392 \\
\hline Annonaceae & Guatteria amplifolia & -2.519 & -2.890 & -2.282 & 25.115 & 12.414 & 42.037 & 0.409 & 0.212 & 0.542 \\
\hline Malvaceae & Trichospermum galeottii & -2.288 & -2.436 & -2.135 & 12.234 & 2.912 & 25.208 & 0.834 & 0.390 & 1.858 \\
\hline Vochysiaceae & Vochysia allenii & -1.964 & -2.058 & -1.872 & 11.790 & 3.483 & 17.471 & 0.275 & 0.128 & 0.637 \\
\hline Vochysiaceae & Qualea polychroma & -1.875 & -1.922 & -1.794 & 7.821 & 7.305 & 8.134 & 0.390 & 0.291 & 0.507 \\
\hline
\end{tabular}

potentials at the $\Psi_{50}$ range from $-6.9 \mathrm{MPa}$ to $-1.8 \mathrm{MPa}$ (cf. Table 7.1), which suggest that the analyzed species represented a large range of hydraulic strategies. Notably, our estimates coincide well with the range of -7.63 MPa to -1.86 MPa reported for the average $\Psi_{50}$ estimates for 30 neotropical canopy tree species from French Guiana studied by Ziegler et al. (2019) using the same $1 \mathrm{~m}$ centrifuge (cf. Section 2.1.6).

The estimated shape parameter $k$ ranged from 2.4 for one sample from P. purpurea to 58.7 for a sample of $C$. camibar (cf. Table 7.1), indicating that while none of the samples had an r-shaped vulnerability curve $(k \leq 1)$, there was a large variability in curve shape. The by far highest average shape parameter was found for $C$. camibar, reflecting the sudden increase in PLC of that species close to the estimated average $P_{50}$ of around $-5.3 \mathrm{MPa}$.

While the large range of estimated values for $K_{\max }$ within species indicates a high variability in specific conductivity between branches belonging to the same species (cf. Figure 7.2, Table 7.1), these results have to be interpreted with caution as they refer to measurements performed on very long samples and with a Cavitron device without prior flushing of emboli and are therefore likely associated with a very low measurement accuracy.

The results for $P$. purpurea are remarkable in various regards: Besides being the most resistant species in the dataset, it had the highest variability in $\Psi_{50}$ of all species, combined with a relatively large range in $k$ (Figure 7.2, Table 7.1), resulting in a large range of possible curve shapes (Figure 7.1). In this context, it is notable that $P$. purpurea is a rare timber species whose wood has a high economic value due to its remarkable hardness, coloration and structure (cf. Lobo et al. 2007). In our dataset, P. purpurea ranked among the three species with the highest wood densities along the entire rainfall gradient, while simultaneously belonging to the tallest tree species in the dataset.

\subsubsection{Relationship between vulnerability to embolism and tree properties}

A correlation matrix for the estimated vulnerability curve parameters and a set of structural and functional traits is given in Figure 7.3. It is evident that while estimated pressure at $50 \%$ loss of conductivity $\Psi_{50}$ was closely related to a series of other tree traits, the other 

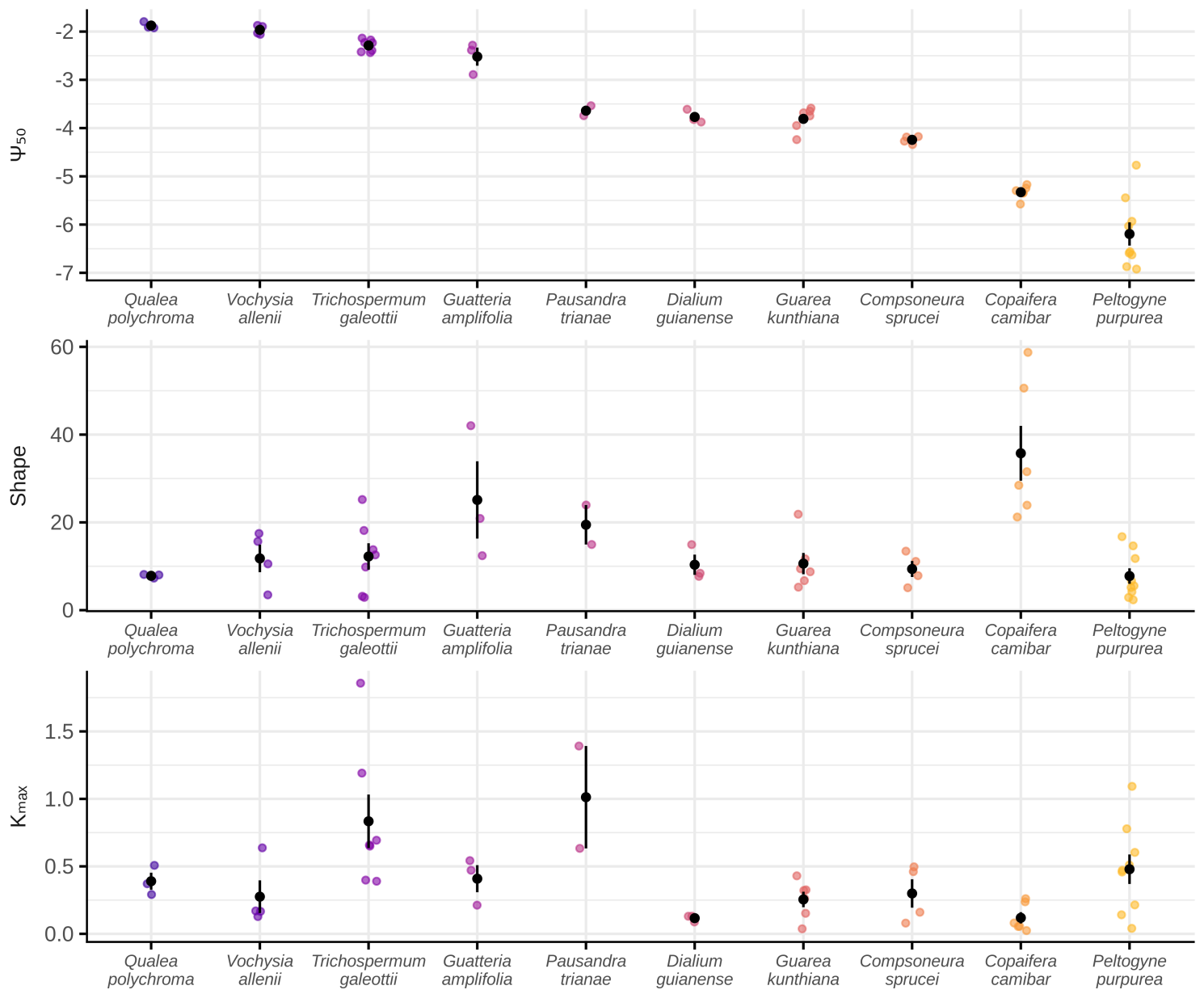

Figure 7.2: Parameter estimates of the vulnerability curves for the 10 studied species ordered by increasing embolism resistance (black: mean \pm standard error, colored: predictions for individual samples). $K_{\max }$ - maximum specific conductivity $\left(\mathrm{kg} \mathrm{m}^{-1} \mathrm{Mpa}^{-1} \mathrm{~s}^{-1}\right) ; P_{50}$ - water potential at $50 \%$ loss of conductivity (MPa); Shape - shape parameter $k$ of the Weibull distribution (unitless, $>1$ if s-shaped). 


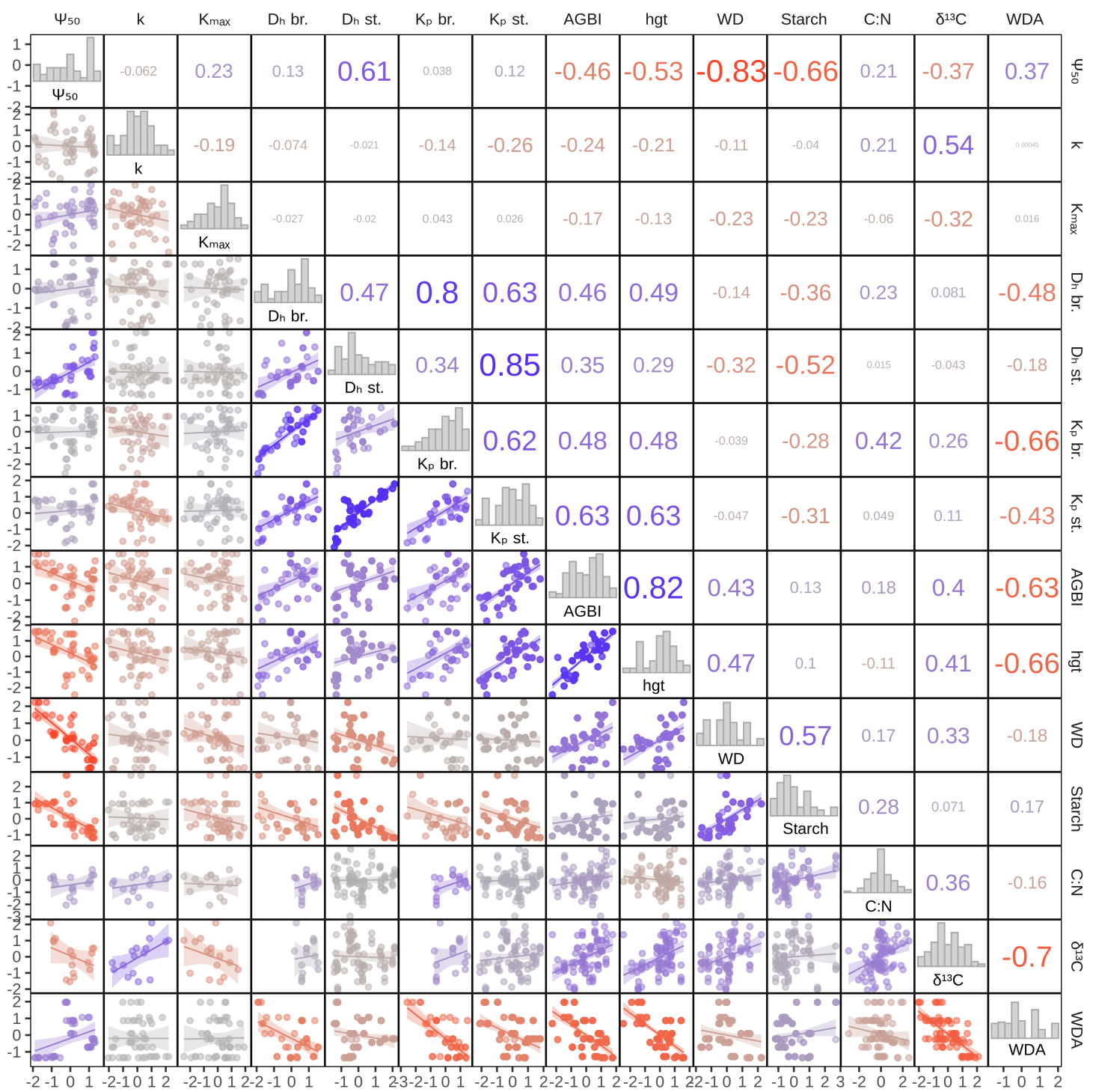

Figure 7.3: Pearson correlation table for the vulnerability curve parameters and a set of functional and structural traits. Figure created with R package corrmorant (Link 2020). Legend: $\Psi_{50}$ - water potential at $50 \%$ loss of conductivity, $k$ - shape parameter of the Weibull function (natural log-transformed), $K_{\max }$ - maximum specific conductivity (natural log-transformed), $D_{h}$ br./st. - hydraulically weighted vessel diameter in branch and stem, $K_{p}$ br./st. - potential hydraulic conductivity in branch and stem (natural log-transformed), AGBI - aboveground biomass increment (natural log-transformed), hgt - tree height (natural log-transformed), WD - wood density, Starch - branch sapwood starch content, C:N - leaf C:N content, $\delta^{13} \mathrm{C}$ - leaf $\delta^{13} \mathrm{C}$, WDA - water deficit affiliation. All variables scaled and centered for comparison. 


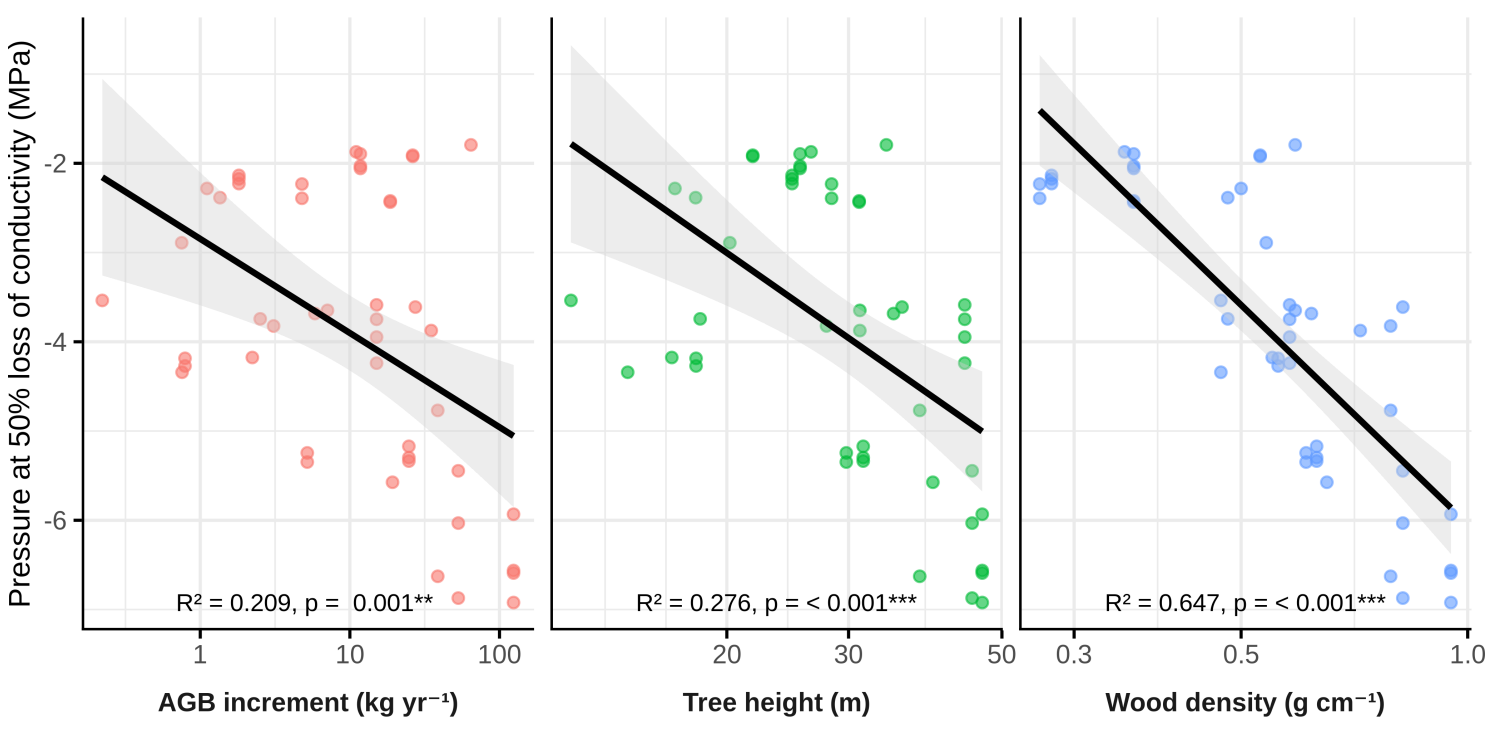

Figure 7.4: Predicted pressure at 50\% loss conductivity vs. (L-R) aboveground biomass increment, tree height and wood density. Shown are the observed values overlaid with the p-values and explained variance from bivariate linear regressions with the corresponding regression lines and $95 \%$ confidence intervals (only if $p \leq 0.05$ ).

vulnerability curve parameters were largely independent of tree properties, with the exception of a positive relationship between the shape parameter $k$ and $\delta^{13} \mathrm{C}$.

A striking finding is that the water deficit affiliation based on Esquivel-Muelbert et al. $(2017 ; 2019)$ (cf. Section 6.3 .5$)$ was significantly correlated with the estimated $\Psi_{50}$ $(\mathrm{r}=0.37, \mathrm{t}=2.66, \mathrm{df}=45, P=0.011)$, thus confirming a predictive value of this quantity for drought responses. Notably, WDA was more closely associated with wood anatomical parameters, tree size and growth rates than the estimated $\Psi_{50}$, while the latter was more closely associated with wood density and sapwood starch content (Fig. 7.3).

$\Psi_{50}$ decreased significantly with aboveground biomass increment, tree height and wood density (Figure 7.5), resulting in a higher embolism resistance for trees with denser wood as well as an unexpected higher embolism resistance for larger and faster growing trees. This finding runs counter the prediction that large trees should be more vulnerable (Rowland et al. 2015a; Olson et al. 2018), and may be indicative of a selection pressure on canopy trees to develop a wood structure that is able to withstand the extreme microclimatic conditions in the tropical forest canopy (cf. Schuldt et al. 2011; Eamus et al. 2013). Notably, this unexpexted pattern in $\Psi_{50}$ is in accordance with the stronger drought affiliation for taller species observed all along the Costa Rican rainfall gradient (Chapter 6). However, it should be noted that $\Psi_{50}$ could be measured for 10 species, which with $C$. camibar and $D$. guianense included two other emergent Fabaceae species besides $P$. purpurea with high heartwood densities and exceptional growth strategies. For that reason, inferences from this species sample are unlikely to generalize unconditionally to other species. In addition, it should be noted that the correlations of AGB increment and tree height with wood density are high enough to fully explain the significant relationships of these traits with $\Psi_{50}$ by confounding (cf. Figure 7.3).

$\Psi_{50}$ was found to increase significantly with hydraulically weighted vessel diameter in the stem, resulting in a higher vulnerability to embolism for species with larger vessel diameters in their stem wood, but was unrelated to branch vessel diameter and potential 


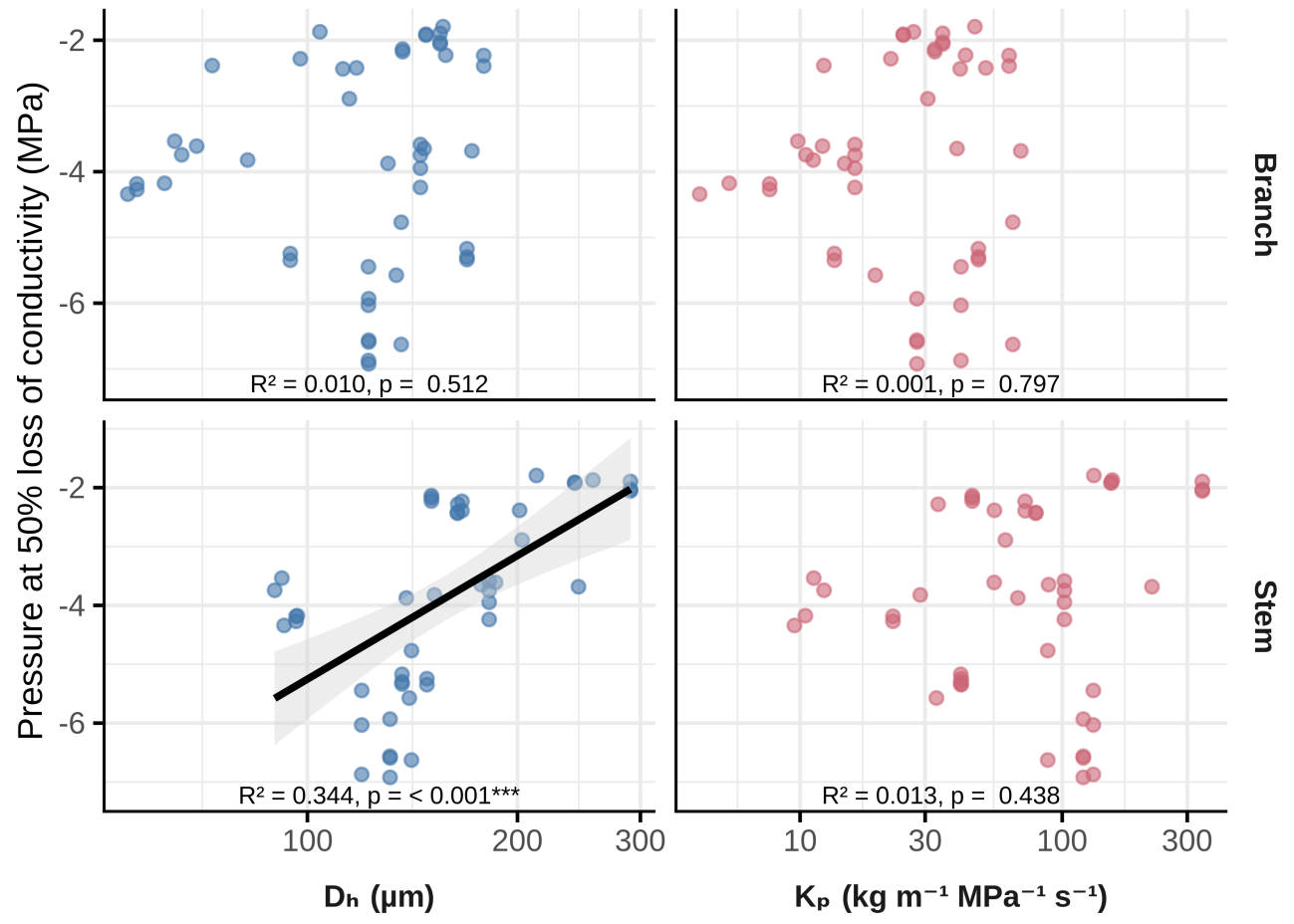

Figure 7.5: Predicted pressure at $50 \%$ loss conductivity vs. hydraulically weighted vessel diameter $d_{\mathrm{h}}$ (left) and potential hydraulic conductivity $K_{\mathrm{p}}$ (right) in branch (top) and stem (bottom). Shown are the observed values overlaid with the p-values and explained variance from bivariate linear regressions with the corresponding regression lines and $95 \%$ confidence intervals (only if $p \leq 0.05)$.

conductivity in stem and branch (Figure 7.5). A decrease of embolism resistance with vessel diameter agrees with well-established theoretical assumptions (cf. Hacke and Sperry 2001). However, since vessel diameter can be assumed to increase along the flow path to maintain flow resistance at a minimum (Anfodillo et al. 2006; Olson et al. 2014; Rosell et al. 2017), it is surprising that vessel diameters at the stem base were more closely associated to branch embolism resistance than branch vessel diameters. As vessel size simultaneously increased for species more affiliated to drought (Figure 7.3), it may well be possible that the observed patterns are driven by the peculiar species set.

$\Psi_{50}$ was not significantly related to leaf C:N ratio and leaf $\delta^{13} \mathrm{C}$, but decreased significantly with branch starch content. The higher vulnerability to embolism for trees with lower branch nonstructural carbohydrate storage is a remarkable finding as it is consistent with the controversial hypothesis that nonstructural carbohydrates stored as starch deposits in xylem parenchyma cells can be converted into soluble sugars to repair embolism (Salleo et al. 2009; Nardini et al. 2011). However, it is questionable whether this effect would be replicable in a larger species sample as NSC had an opposite effect on WDA in the piecewise SEM in Chapter 5. 

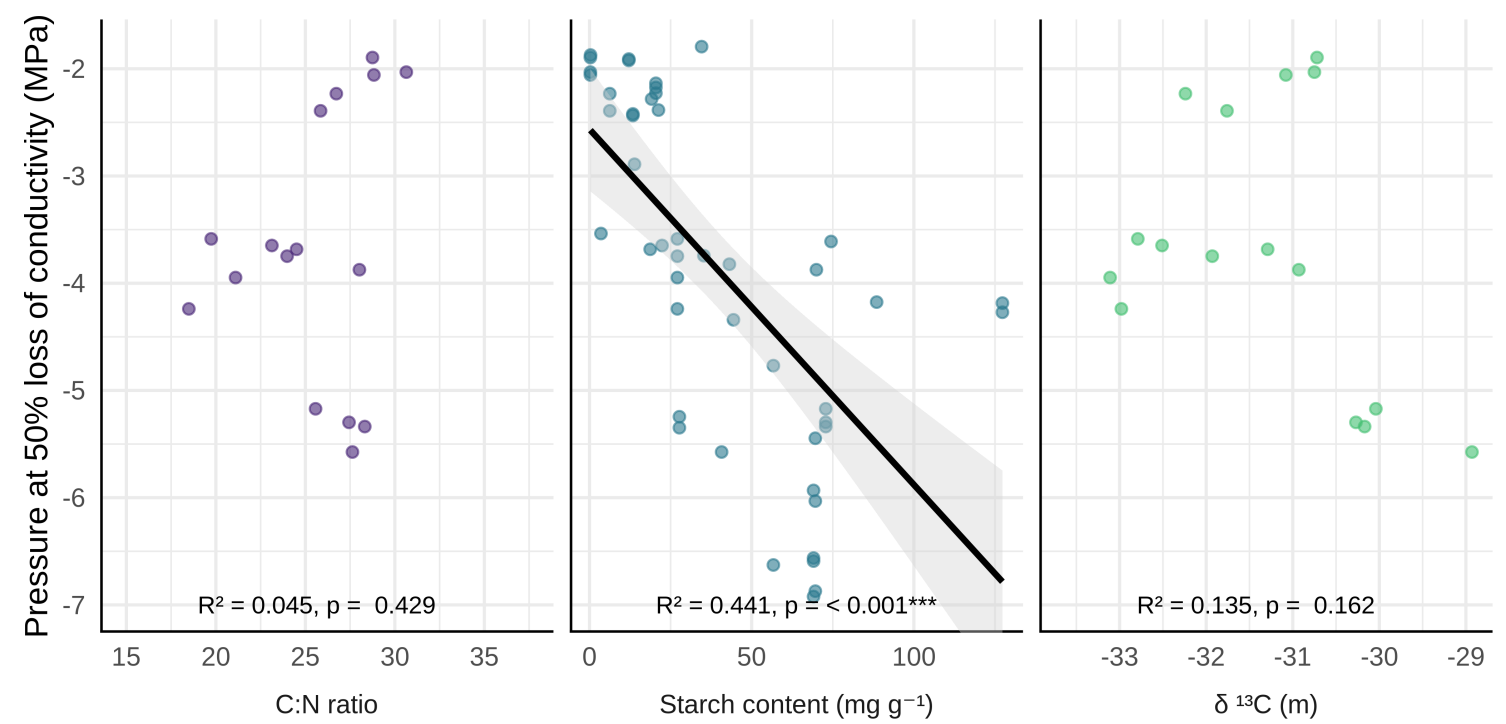

Figure 7.6: Predicted pressure at 50\% loss conductivity vs. leaf C:N ratio, branch starch content and leaf $\delta^{13} \mathrm{C}$. Shown are the observed values overlaid with the p-values and explained variance from bivariate linear regressions with the corresponding regression lines and $95 \%$ confidence intervals (only if $p \leq 0.05$ ).

\subsection{Drivers of plant productivity and water relations in tropical forests}

\subsubsection{Effects of tree size, wood density and wood anatomy}

In Section 1.7, a set of hypotheses was posited about the effects of tree size, wood density and wood anatomical traits for a set of variables related to tree productivity and water use. In the following, I will discuss these hypotheses in the light of the results presented in the frame of this work.

$i$. Larger trees have higher biomass productivity and water use resulting from their more conductive xylem both in stem and branch tissue which simultaneously makes them more prone to drought-induced embolism

In apparent support of this hypothesis, in Chapter 5 we found average tree height and diameter to be significantly associated with biomass increment, average plant water use and wood anatomical traits associated with hydraulic efficiency. Analogously, in Chapter 6 , tree height, diameter and canopy position were significantly positively associated with biomass increment, vessel diameter and potential conductivity. However, in both cases an analysis in a structural equation modelling context indicated that the correlation between growth and water use and hydraulic traits was in large parts driven by the confounding effect of tree size. Accordingly, while larger trees had both higher growth rates and a more efficient xylem, the faster growth in large parts resulted from a simple scaling with size rather than the effect of hydraulic efficiency. After controlling for size effects, only a weak indirect link of hydraulic efficiency with average biomass increment and water use could be identified in Chapter 5, while in Chapter 6 no causal link from potential conductivity on biomass increment could be identified at all after accounting for the effect of canopy height and tree diameter.

Taken together, these findings provide clear evidence that both on individual level and for 
species aggregates, the link between wood hydraulic traits and tree growth performance is much weaker than previously anticipated.

The ubiquity of allometric scaling relationships in biological systems can be traced back to simple rules (Enquist et al. 1999; West 1999; Brown et al. 2004) that have profound consequences for the size dependence of water use (Meinzer et al. 2005), biomass growth (Smith and Sperry 2014) and vessel dimensions (Anfodillo et al. 2006). As a result, many central plant properties are known to scale with size in scaling relationships with different exponents. The resulting need to account for size effects when studying functional trait relationships with growth rates and hydraulic traits is recognized in a growing number of recent studies (Hietz et al. 2016; Gleason et al. 2018; Lechthaler et al. 2019; Śímová et al. 2019).

With regard to embolism resistance, the results in Section 7.2.2 indicate that in contrast to our assumption, larger trees were less vulnerable than smaller trees. However, as discussed above, this result is most likely a consequence of the large proportion of hard-wooded late successional emergent Fabaceae species in the studied species sample.

ii. Trees with harder wood have slower biomass growth rates and lower hydraulic efficiency, but are more resistant against drought-induced embolism

In Chapter 5, we found a weak but significant negative association between wood density and hydraulic efficiency as well as a negative effect of wood density on sap flux density, which promoted a weak indirect effect on growth. In 6, no causal link between wood density and growth and no relationship with potential conductivity could be detected at all (though there was a weak positive bivariate relationship with biomass increment that was likely driven by large hard-wooded species like P. purpurea; see Section 7.2.1).

A low relationship between wood density and growth rates in humid tropical forests has been reported in a series of studies (Zhang and Cao 2009; Poorter et al. 2010; Fan et al. 2012; Schuldt et al. 2013; Kotowska et al. 2015). In part, this may result from the fact that wood density is an emergent property of wood anatomy rather than strictly causally linked to hydraulic efficiency, as large numbers of different wood structures with remarkably different conductivity can result in the same wood density (Ziemińska et al. 2015; Zanne et al. 2010; Fan et al. 2012). Another possible reason for the weak relationship is that all across this work, growth rates were analyzed in the form of biomass increment, which is arguably the most straightforward way of describing growth processes. However, Francis et al. (2017) find that aboveground biomass increment is independent of wood density, and relate this behavior to the adherence to simple null model for tree growth.

Interestingly, in our vulnerability curve measurements, wood density was the variable that was by far most closely related to $\Psi_{50}$ with a correlation of $r=-0.83$, which is in line with predictions that high wood density is associated with a lower risk of xylem implosion (Hacke et al. 2001).

iii. Wood anatomical traits are more closely related to productivity and water use than wood density

In agreement with this hypothesis, in the Indonesian dataset wood anatomical traits were much more strongly associated with nearly all variables in the dataset than wood density (Chapter 5). This is in accordance with theoretical expectations as due to the reasons described above wood anatomical traits are causally much more immediately related to growth than wood density. For the Costa Rican dataset, neither of the two had a significant impact on productivity (Chapter 6). 


\subsubsection{Water deficit affiliation as a predictor of drought resistance}

Our results indicate that the water deficit affiliation (WDA) based on Esquivel-Muelbert et al. $(2017 ; 2019)$ can serve as a useful indicator of plant drought responses. This indicator is calculated based on the distribution of the maximum cumulative water deficit (Aragão et al. 2007) over the range of a species and is based on freely accessible climate (Hijmans et al. 2005) and biological datasets (Chave et al. 2014) (cf. Section 6.3.5).

In Chapter 6, our structural equation model was able to explain $42 \%$ in the variance in WDA. In this model, WDA interestingly was not only clearly different between sites with different rainfall environments, but even contained enough information to respond to nonstructural carbohydrate storage and tree canopy position. In addition, the preliminary results of the vulnerability curve output in Section 7.2.2 indicate that WDA was significantly correlated with $P_{50}$ and more closely associated with wood anatomy, tree size, and growth rates than the latter.

In summary, these results indicate that WDA (and possibly other metrics derived from the climate niche of a species) may serve as a cost-effective alternative to complex, expensive and error-prone hydraulic measurements in settings were the focus is on predictions of drought performance rather than inference about the mechanisms governing plant drought responses.

\subsection{Concluding remarks}

The first part of the present work provides a methodological comparison of common thermometric sap flow measurement methods, as well as a framework that allows to minimize measurement errors and propagate uncertainty when scaling up from point measurements of sap flux density to whole-tree water using information about the radial sap flow profile. In conjunct, the two studies provide clear advice for future studies of tree transpiration based on sap flow measurements: Chapter 3 indicates that if possible, it is advisable to perform species-specific empirical sensor calibrations. If species-specific calibration is not feasible (as e.g. in species-rich tropical forests), it is advisable to use sensor systems with a physically justified working principle which is not sensitive to differences in sapwood thermal diffusivity. In agreement with other methods comparisons, our study suggests that in its range of validity, HRM sensors may achieve the best performance. Corrections for radial profiles are necessary for accurate sap flow estimates. If the measurement of speciesspecific radial profiles e.g. with HFD sensors is not possible, our model provides a starting point for predicting its shape from tree properties. Our results further point at important sources of variability in tree properties that cannot be controlled for, and thus limit the achievable accuracy. This finding is highly important for the correct understanding of the uncertainty budget of said methods. Based on the modelling framework proposed in Chapter 4, it is possible to account for the uncertainty associated with generalizing to new trees and species and to propagate it into water use estimates.

The second part of this dissertation presents two datasets from tropical field studies from Indonesia and Costa Rica, and aims to test a set of hypotheses related to the size, tree water use, productivity and hydraulic wood properties (cf. Section 1.7). In this regard, it is important to point out the special importance of Chapter 5 as the first example of a simultaneous study of field measurements of sap flow, hydraulic architecture and productivity on a larger sample of tropical tree species. As discussed in Section 7.3, 
when taken out of context, the results presented in Part II in large parts all but confirm the patterns of relationships between these traits that are most commonly reported in literature. However, the results of the structural equation models in Chapter 5 and 6 indicated that when analyzing these variables before the backdrop of a more complex network of relationships, the previously highly significant links between wood properties and growth- and water use-related traits shrunk to a small fraction of their initial size. In consequence, while our results do show that wood hydraulic traits are indeed linked to growth and water use - and more strongly so than wood density - a sizable fraction of the shared variance between these variables seems to be a mere consequence of a confounding size effect rather than a causal relationship. Accordingly, both when focusing on individual trees and on species-level trait aggregates, tree size emerges as a central control variable of plant productivity and water use that should routinely be accounted for.

\section{References}

Anfodillo, T., V. Carraro, M. Carrer, C. Fior, and S. Rossi (2006). "Convergent tapering of xylem conduits in different woody species". In: New Phytologist 169.2, pp. 279-290. URL: http://doi.wiley.com/10.1111/j.1469-8137.2005.01587.x.

Aragão, L. E. O. C., Y. Malhi, R. M. Roman-Cuesta, S. Saatchi, L. O. Anderson, and Y. E. Shimabukuro (2007). "Spatial patterns and fire response of recent Amazonian droughts". In: Geophysical Research Letters 34.7. URL: https://agupubs.onlinelibrary. wiley.com/doi/abs/10.1029/2006GL028946.

Berdanier, A. B., C. F. Miniat, and J. S. Clark (2016). "Predictive models for radial sap flux variation in coniferous, diffuse-porous and ring-porous temperate trees". In: Tree Physiology 36.8. Ed. by N. Phillips, pp. 932-941. URL: https://academic.oup.com/ treephys/article-lookup/doi/10.1093/treephys/tpw027.

Bleby, T., A. McElrone, and S. Burgess (2008). "Limitations of the HRM: great at low flow rates, but not yet up to speed". In: 7th International Workshop on Sap Flow: Book of Abstracts. Seville, Spain: International Society of Horticultural Sciences.

Brown, J. H., J. F. Gillooly, A. P. Allen, V. M. Savage, and G. B. West (2004). "Toward a metabolic theory of ecology". In: Ecology 85, pp. 1771-1789. URL: https://esajournals. onlinelibrary.wiley.com/doi / full/10.1890/03-9000\%5C\% 4010.1002/\%5C\% 28ISSN\% 5C\%291939-9170.MacArthurAward.

Burgess, S. S. O., M. A. Adams, N. C. Turner, C. R. Beverly, C. K. Ong, A. A. H. Khan, and T. M. Bleby (2001). "An improved heat pulse method to measure low and reverse rates of sap flow in woody plants". In: Tree Physiology 21.9, pp. 589-598. URL: https://academic.oup.com/treephys/article-lookup/doi/10.1093/treephys/21.9.589.

Bush, S. E., K. R. Hultine, J. S. Sperry, and J. R. Ehleringer (2010). "Calibration of thermal dissipation sap flow probes for ring- and diffuse-porous trees". In: Tree Physiology 30.12, pp. 1545-1554. URL: https://academic.oup.com/treephys/article-lookup/doi/10. 1093/treephys/tpq096.

Caylor, K. K. and D. Dragoni (2009). "Decoupling structural and environmental determinants of sap velocity: Part I. Methodological development". In: Agricultural and Forest Meteorology 149.3-4, pp. 559-569. URL: https://linkinghub.elsevier.com/retrieve/pii/ S0168192308002803.

Čermák, J. and N. Nadezhdina (1998). "Sapwood as the scaling parameter- defining according to xylem water content or radial pattern of sap flow?" In: Annales des Sciences 
Forestières 55.5, pp. 509-521. URL: http:/ / www . afs-journal .org/10.1051/forest: 19980501.

Chave, J., M. Réjou-Méchain, A. Búrquez, E. Chidumayo, M. S. Colgan, et al. (2014). "Improved allometric models to estimate the aboveground biomass of tropical trees". In: Global Change Biology 20.10, pp. 3177-3190. URL: https://onlinelibrary.wiley.com/ doi/abs/10.1111/gcb.12629.

Clark, J. S. (2005). "Why environmental scientists are becoming Bayesians". In: Ecology Letters 8.1, pp. 2-14. URL: http://doi.wiley.com/10.1111/j.1461-0248.2004.00702.x.

Clearwater, M. J., F. C. Meinzer, J. L. Andrade, G. Goldstein, and N. M. Holbrook (1999). "Potential errors in measurement of nonuniform sap flow using heat dissipation probes". In: Tree Physiology 19.10, pp. 681-687. URL: https:/ / academic.oup.com/treephys / article-lookup/doi/10.1093/treephys/19.10.681.

Delzon, S., M. Sartore, A. Granier, and D. Loustau (2004). "Radial profiles of sap flow with increasing tree size in maritime pine". In: Tree Physiology 24.11, pp. 1285-1293. URL: https://academic.oup.com/treephys/article-lookup/doi/10.1093/treephys/24.11.1285.

Eamus, D., N. Boulain, J. Cleverly, and D. D. Breshears (2013). "Global change-type drought-induced tree mortality: Vapor pressure deficit is more important than temperature per se in causing decline in tree health". In: Ecology and Evolution 3.8, pp. 27112729. URL: https://arizona.pure. elsevier.com/en/publications / global-change- typedrought-induced-tree-mortality-vapor-pressure- .

Enquist, B. J., G. B. West, E. L. Charnov, and J. H. Brown (1999). "Allometric scaling of production and life-history variation in vascular plants". In: Nature 401.6756, pp. 907911. URL: http://www.nature.com/articles/44819.

Esquivel-Muelbert, A., T. R. Baker, K. G. Dexter, S. L. Lewis, R. J. W. Brienen, et al. (2019). "Compositional response of Amazon forests to climate change". In: Global Change Biology 25.1, pp. 39-56. URL: https://onlinelibrary.wiley.com/doi/abs/10. $1111 /$ gcb.14413.

Esquivel-Muelbert, A., T. R. Baker, K. G. Dexter, S. L. Lewis, H. ter Steege, et al. (2017). "Seasonal drought limits tree species across the Neotropics". In: Ecography 40.5, pp. 618629. URL: https://onlinelibrary.wiley.com/doi/full/10.1111/ecog.01904.

Fan, Z.-X., S.-B. Zhang, G.-Y. Hao, J. Ferry Slik, and K.-F. Cao (2012). "Hydraulic conductivity traits predict growth rates and adult stature of 40 Asian tropical tree species better than wood density: Xylem traits and tree growth". In: Journal of Ecology 100.3, pp. 732-741. URL: http://doi.wiley.com/10.1111/j.1365-2745.2011.01939.x.

Flo, V., J. Martinez-Vilalta, K. Steppe, B. Schuldt, and R. Poyatos (2019). "A synthesis of bias and uncertainty in sap flow methods". In: Agricultural and Forest Meteorology 271, pp. 362-374. URL: http:/ / www . sciencedirect.com / science / article / pii / S0168192319301248.

Ford, C. R., M. A. McGuire, R. J. Mitchell, and R. O. Teskey (2004b). "Assessing variation in the radial profile of sap flux density in Pinus species and its effect on daily water use". In: Tree Physiology 24.3, pp. 241-249. URL: https://academic.oup.com/treephys/articlelookup/doi/10.1093/treephys/24.3.241.

Francis, E. J., H. C. Muller-Landau, S. J. Wright, M. D. Visser, Y. Iida, C. Fletcher, S. P. Hubbell, and A. R. Kassim (2017). "Quantifying the role of wood density in explaining interspecific variation in growth of tropical trees". In: Global Ecology and Biogeography 26.10, pp. 1078-1087. URL: http://doi.wiley.com/10.1111/geb.12604.

Gelman, A. and J. Hill (2006). Data analysis using regression and multilevel/hierarchical models. Cambridge, New York: Cambridge University Press. 
Gleason, S. M., A. E. A. Stephens, W. C. Tozer, C. J. Blackman, D. W. Butler, et al. (2018). "Shoot growth of woody trees and shrubs is predicted by maximum plant height and associated traits". In: Functional Ecology 32.2. Ed. by M. Tjoelker, pp. 247-259. URL: http://doi.wiley.com/10.1111/1365-2435.12972.

Granier, A. (1985). "Une nouvelle méthode pour la mesure du flux de sève brute dans le tronc des arbres". In: Annales des Sciences Forestières 42.2, pp. 193-200. URL: http: //www.afs-journal.org/10.1051/forest:19850204.

Green, S., B. Clothier, and B. Jardine (2003). "Theory and Practical Application of Heat Pulse to Measure Sap Flow". In: Agronomy Journal 95.6, p. 1371. URL: https://www. agronomy.org/publications/aj/abstracts/95/6/1371.

Hacke, U. G., J. S. Sperry, W. T. Pockman, S. D. Davis, and K. A. McCulloh (2001). "Trends in wood density and structure are linked to prevention of xylem implosion by negative pressure". In: Oecologia 126.4, pp. 457-461. uRL: http://link.springer.com/10. $1007 / \mathrm{s} 004420100628$.

Hacke, U. G. and J. S. Sperry (2001). "Functional and ecological xylem anatomy". In: Perspectives in Plant Ecology, Evolution and Systematics 4.2, pp. 97-115.

Hietz, P., S. Rosner, U. Hietz-Seifert, and S. J. Wright (2016). "Wood traits related to size and life history of trees in a Panamanian rainforest". In: New Phytologist 213.1, pp. 170-180. URL: http://doi.wiley.com/10.1111/nph.14123.

Hijmans, R. J., S. E. Cameron, J. L. Parra, P. G. Jones, and A. Jarvis (2005). "Very high resolution interpolated climate surfaces for global land areas". In: International Journal of Climatology 25.15, pp. 1965-1978. URL: http://doi.wiley.com/10.1002/joc.1276.

Kotowska, M. M., D. Hertel, Y. A. Rajab, H. Barus, and B. Schuldt (2015). "Patterns in hydraulic architecture from roots to branches in six tropical tree species from cacao agroforestry and their relation to wood density and stem growth". In: Frontiers in Plant Science 6. URL: https://www.frontiersin.org/articles/10.3389/fpls.2015.00191/full.

Lechthaler, S., T. L. Turnbull, Y. Gelmini, F. Pirotti, T. Anfodillo, M. A. Adams, and G. Petit (2019). "A standardization method to disentangle environmental information from axial trends of xylem anatomical traits". In: Tree Physiology 39.3, pp. 495-502. URL: https://academic.oup.com/treephys/article/39/3/495/5123810.

Link, R. M. (2020). corrmorant: Flexible Correlation Matrices Based on ggplot2. R package version 0.0.0.9002 (developmental version). URL: https://github.com/r-link/corrmorant.

Lobo, J., G. Barrantes, M. Castillo, R. Quesada, T. Maldonado, E. J. Fuchs, S. Solís, and M. Quesada (2007). "Effects of selective logging on the abundance, regeneration and short-term survival of Caryocar costaricense (Caryocaceae) and Peltogyne purpurea (Caesalpinaceae), two endemic timber species of southern Central America". In: Forest Ecology and Management 245.1, pp. 88-95. URL: http://www.sciencedirect.com/science/ article/pii/S037811270700309X.

Looker, N., J. Martin, K. Jencso, and J. Hu (2016). "Contribution of sapwood traits to uncertainty in conifer sap flow as estimated with the heat-ratio method". In: Agricultural and Forest Meteorology 223, pp. 60-71. URL: http://www.sciencedirect.com/science/ article/pii/S0168192316302040.

Lundblad, M., F. Lagergren, and A. Lindroth (2001). "Evaluation of heat balance and heat dissipation methods for sapflow measurements in pine and spruce". In: Annals of Forest Science 58.6, pp. 625-638. URL: http://dx.doi.org/10.1051/forest:2001150.

Marshall, D. C. (1958). "Measurement of Sap Flow in Conifers by Heat Transport". In: Plant Physiology 33.6, pp. 385-396. URL: https://www.ncbi.nlm.nih.gov/pmc/articles/ PMC541111/. 
Meinzer, F. C., B. J. Bond, J. M. Warren, and D. R. Woodruff (2005). "Does water transport scale universally with tree size?" In: Functional Ecology 19.4, pp. 558-565. URL: http://doi.wiley.com/10.1111/j.1365-2435.2005.01017.x.

Nadezhdina, N., M. W. Vandegehuchte, and K. Steppe (2012). "Sap flux density measurements based on the heat field deformation method". In: Trees 26.5, pp. 1439-1448. URL: http://link.springer.com/10.1007/s00468-012-0718-3.

Nardini, A., M. A. Lo Gullo, and S. Salleo (2011). "Refilling embolized xylem conduits: Is it a matter of phloem unloading?" In: Plant Science 180.4, pp. 604-611. URL: https: //linkinghub.elsevier.com/retrieve/pii/S0168945211000045.

Ogle, K. (2009). "Hierarchical Bayesian Statistics: Merging Experimental and Modeling Approaches in Ecology". In: Ecological Applications 19.3, pp. 577-581. URL: http:// www.jstor.org/stable/27645997.

Ogle, K., J. J. Barber, C. Willson, and B. Thompson (2009). "Hierarchical statistical modeling of xylem vulnerability to cavitation: Methods". In: New Phytologist 182.2, pp. 541-554. URL: http://doi.wiley.com/10.1111/j.1469-8137.2008.02760.x.

Olson, M. E., T. Anfodillo, J. A. Rosell, G. Petit, A. Crivellaro, et al. (2014). "Universal hydraulics of the flowering plants: vessel diameter scales with stem length across angiosperm lineages, habits and climates". In: Ecology Letters 17.8. Ed. by B. Enquist, pp. 988-997. URL: http://doi.wiley.com/10.1111/ele.12302.

Olson, M. E., D. Soriano, J. A. Rosell, T. Anfodillo, M. J. Donoghue, et al. (2018). "Plant height and hydraulic vulnerability to drought and cold". In: Proceedings of the National Academy of Sciences 115.29, pp. 7551-7556. URL: http://www.pnas.org/lookup/doi/ $10.1073 /$ pnas. 1721728115.

Pasqualotto, Carraro, Menardi, and Anfodillo (2019). "Calibration of Granier-Type (TDP) Sap Flow Probes by a High Precision Electronic Potometer". In: Sensors 19.10, p. 2419. URL: https://www.mdpi.com/1424-8220/19/10/2419.

Peters, R. L., P. Fonti, D. C. Frank, R. Poyatos, C. Pappas, et al. (2018). "Quantification of uncertainties in conifer sap flow measured with the thermal dissipation method". In: New Phytologist 219.4, pp. 1283-1299. URL: https://nph.onlinelibrary.wiley.com/doi/ abs/10.1111/nph.15241.

Poorter, L., I. McDonald, A. Alarcón, E. Fichtler, J.-C. Licona, et al. (2010). "The importance of wood traits and hydraulic conductance for the performance and life history strategies of 42 rainforest tree species". In: New Phytologist 185.2, pp. 481-492. URL: http://doi.wiley.com/10.1111/j.1469-8137.2009.03092.x.

Poyatos, R., V. Granda, R. Molowny-Horas, M. Mencuccini, K. Steppe, and J. MartínezVilalta (2016). "SAPFLUXNET: towards a global database of sap flow measurements". In: Tree Physiology 36.12, pp. 1449-1455. URL: https://academic.oup.com/treephys/ article/36/12/1449/2571314.

Reyes-Acosta, J. L. and M. W. Lubczynski (2013). "Mapping dry-season tree transpiration of an oak woodland at the catchment scale, using object-attributes derived from satellite imagery and sap flow measurements". In: Agricultural and Forest Meteorology 174-175, pp. 184-201. URL: https://linkinghub.elsevier.com/retrieve/pii/S0168192313000403.

Rosell, J. A., M. E. Olson, and T. Anfodillo (2017). "Scaling of Xylem Vessel Diameter with Plant Size: Causes, Predictions, and Outstanding Questions". In: Current Forestry Reports 3.1, pp. 46-59. URL: http://link.springer.com/10.1007/s40725-017-0049-0.

Rowland, L., A. C. L. da Costa, D. R. Galbraith, R. S. Oliveira, O. J. Binks, et al. (2015a). "Death from drought in tropical forests is triggered by hydraulics not carbon starvation". In: Nature 528.7580, pp. 119-122. 
Salleo, S., P. Trifilò, S. Esposito, A. Nardini, and M. A. L. Gullo (2009). "Starch-to-sugar conversion in wood parenchyma of field-growing Laurus nobilis plants: a component of the signal pathway for embolism repair?" In: Functional Plant Biology 36.9, pp. 815825. URL: https://www.publish.csiro.au/fp/FP09103.

Schuldt, B., C. Leuschner, N. Brock, and V. Horna (2013). "Changes in wood density, wood anatomy and hydraulic properties of the xylem along the root-to-shoot flow path in tropical rainforest trees". In: Tree Physiology 33.2, pp. 161-174. URL: https://academic. oup.com/treephys/article-lookup/doi/10.1093/treephys/tps122.

Schuldt, B., C. Leuschner, V. Horna, G. Moser, M. Köhler, O. van Straaten, and H. Barus (2011). "Change in hydraulic properties and leaf traits in a tall rainforest tree species subjected to long-term throughfall exclusion in the perhumid tropics". In: Biogeosciences 8.8, pp. 2179-2194. URL: http://www.biogeosciences.net/8/2179/2011/.

Šímová, I., B. Sandel, B. J. Enquist, S. T. Michaletz, J. Kattge, et al. (2019). "The relationship of woody plant size and leaf nutrient content to large-scale productivity for forests across the Americas". In: Journal of Ecology. Ed. by A. Hector, pp. 1365-2745.13163. URL: https://onlinelibrary.wiley.com/doi/abs/10.1111/1365-2745.13163.

Smith, D. D. and J. S. Sperry (2014). "Coordination between water transport capacity, biomass growth, metabolic scaling and species stature in co-occurring shrub and tree species". In: Plant, Cell \& Environment 37.12, pp. 2679-2690. URL: https:// onlinelibrary.wiley.com/doi/abs/10.1111/pce.12408.

Steppe, K., M. W. Vandegehuchte, R. Tognetti, and M. Mencuccini (2015). "Sap flow as a key trait in the understanding of plant hydraulic functioning". In: Tree Physiology 35.4, pp. 341-345. URL: https://academic.oup.com/treephys/article/35/4/341/1668298.

Taneda, H. and J. S. Sperry (2008). "A case-study of water transport in co-occurring ringversus diffuse-porous trees: contrasts in water-status, conducting capacity, cavitation and vessel refilling". In: Tree Physiology 28.11, pp. 1641-1651. URL: https://academic. oup.com/treephys/article-lookup/doi/10.1093/treephys/28.11.1641.

Vandegehuchte, M. W. and K. Steppe (2012a). "Improving sap flux density measurements by correctly determining thermal diffusivity, differentiating between bound and unbound water". In: Tree Physiology 32.7, pp. 930-942. uRL: https://academic.oup.com/treephys/ article/32/7/930/1643947.

- (2012b). "Use of the correct heat conduction-convection equation as basis for heatpulse sap flow methods in anisotropic wood". In: Journal of Experimental Botany 63.8, pp. 2833-2839. URL: https://academic.oup.com/jxb/article-lookup/doi/10.1093/jxb/ ers041.

- (2012c). "Interpreting the Heat Field Deformation method: Erroneous use of thermal diffusivity and improved correlation between temperature ratio and sap flux density". In: Agricultural and Forest Meteorology 162-163, pp. 91-97. URL: https://linkinghub. elsevier.com/retrieve/pii/S0168192312001438.

Vergeynst, L. L., M. W. Vandegehuchte, M. A. McGuire, R. O. Teskey, and K. Steppe (2014). "Changes in stem water content influence sap flux density measurements with thermal dissipation probes". In: Trees 28.3, pp. 949-955. URL: https://doi.org/10.1007/ s00468-014-0989-y.

West, G. B. (1999). "The Fourth Dimension of Life: Fractal Geometry and Allometric Scaling of Organisms". In: Science 284.5420, pp. 1677-1679. URL: http://www.sciencemag. org/cgi/doi/10.1126/science.284.5420.1677.

Wiedemann, A., S. Marañón-Jiménez, C. Rebmann, M. Herbst, and M. Cuntz (2016). "An empirical study of the wound effect on sap flux density measured with thermal 
dissipation probes". In: Tree Physiology 36.12. Ed. by R. Oren, pp. 1471-1484. URL: https://academic.oup.com/treephys/article-lookup/doi/10.1093/treephys/tpw071.

Wullschleger, S. D., K. W. Childs, A. W. King, and P. J. Hanson (2011). "A model of heat transfer in sapwood and implications for sap flux density measurements using thermal dissipation probes". In: Tree Physiology 31.6, pp. 669-679. URL: https://academic.oup. com/treephys/article-lookup/doi/10.1093/treephys/tpr051.

Zanne, A. E., M. Westoby, D. S. Falster, D. D. Ackerly, S. R. Loarie, S. E. J. Arnold, and D. A. Coomes (2010). "Angiosperm wood structure: Global patterns in vessel anatomy and their relation to wood density and potential conductivity". In: American Journal of Botany 97.2, pp. 207-215. URL: http://doi.wiley.com/10.3732/ajb.0900178.

Zhang, J.-G., Q.-Y. He, W.-Y. Shi, K. Otsuki, N. Yamanaka, and S. Du (2015). "Radial variations in xylem sap flow and their effect on whole-tree water use estimates". In: Hydrological Processes 29.24, pp. 4993-5002. URL: http://doi.wiley.com/10.1002/hyp. 10465.

Zhang, J.-L. and K.-F. Cao (2009). "Stem hydraulics mediates leaf water status, carbon gain, nutrient use efficiencies and plant growth rates across dipterocarp species". In: Functional Ecology 23.4, pp. 658-667. URL: http://doi.wiley.com/10.1111/j.13652435.2009.01552.x.

Ziegler, C., S. Coste, C. Stahl, S. Delzon, S. Levionnois, et al. (2019). "Large hydraulic safety margins protect Neotropical canopy rainforest tree species against hydraulic failure during drought". In: Annals of Forest Science 76.4, p. 115. URL: https://doi.org/10. 1007/s13595-019-0905-0.

Ziemińska, K., M. Westoby, and I. J. Wright (2015). "Broad Anatomical Variation within a Narrow Wood Density Range-A Study of Twig Wood across 69 Australian Angiosperms". In: PLOS ONE 10.4. Ed. by S. Delzon, e0124892. URL: https://x.plos.org/ 10.1371/journal.pone.0124892. 



\section{List of Figures}

2.1 Map of the research area . . . . . . . . . . . . . . . . 34

2.2 Gradients in wood density and tree height . . . . . . . . . . . 36

3.1 Plot of predicted versus gravimetrically determined sap flux density . . . 59

3.2 Typical progression of a flow experiment . . . . . . . . . . . . 60

3.3 Observed sap flux density versus sap flow index $\mathrm{K}$ for the $3 \mathrm{TDP}$ sensors . . 62

3.4 Observed sap flux density versus HFD ratio . . . . . . . . . . . . . . 63

4.1 Possible shapes of radial sap flux density profiles . . . . . . . . . . . . 84

4.2 Microclimatic and soil humidity measurments . . . . . . . . . . . . . . 90

4.3 Predicted radial sap flow profiles . . . . . . . . . . . . . . . . . 91

4.4 Partial residual plots for the stem-level regressions . . . . . . . . . . . . 93

4.5 Estimated daily water use . . . . . . . . . . . . . . . . . . 94

4.6 Estimated ratio of over-/underprediction . . . . . . . . . . . . . . 94

5.1 Meta-model for the SEM . . . . . . . . . . . . . . . . . . . . . . . . 120

5.2 Pair-wise Pearson correlation table . . . . . . . . . . . . . . . 125

5.3 Results of standardized major axis regressions . . . . . . . . . . . . . 126

5.4 SMA regressions of of growth vs. daily water use . . . . . . . . . . . 127

5.5 Path diagram of the final SEM . . . . . . . . . . . . . 127

6.1 Map of the research area . . . . . . . . . . . . . . . . . . . 152

6.2 PSEM meta-model . . . . . . . . . . . . . . . . . . . . . 155

6.3 Correlation heat map . . . . . . . . . . . . . . . . . . . . . 157

6.4 Results of SMA regressions . . . . . . . . . . . . . . . . 159

6.5 PCA biplot . . . . . . . . . . . . . . . . . . . 161

6.6 Path diagram of the PSEM . . . . . . . . . . . . . . . . . 162

6.7 Partial residual plots for all submodels . . . . . . . . . . . . . . . 163

7.1 Shape of the predicted vulnerability curves . . . . . . . . . . . . . 185

7.2 Estimated vulnerability curve parameters . . . . . . . . . . . . . 187

7.3 Correlation scatter plot matrix . . . . . . . . . . . . . . . . 188

7.4 Predicted $\Psi_{50}$ vs. stand parameters. . . . . . . . . . . . . . . . . 189

7.5 Predicted $\Psi_{50}$ vs. wood anatomical parameters. . . . . . . . . . . . . 190

7.6 Predicted $\Psi_{50}$ vs. NSC and leaf traits. . . . . . . . . . . . . . . . 191 



\section{List of Tables}

2.1 Stand characteristics and average climate conditions . . . . . . . . 35

3.1 Detailed specifications of the three compared TDP sensor designs. . . . . . 53

3.2 Accuracy of the five tested sensor systems . . . . . . . . . . . . . . 61

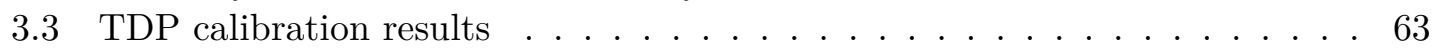

3.4 HFD calibration results . . . . . . . . . . . . . . . . . . . 64

4.1 List of species with their main characteristics . . . . . . . . . . . . . . 86

4.2 Predictive accuracy of models . . . . . . . . . . . . . . . . . 92

4.3 Summary of MCMC output . . . . . . . . . . . . . . . . . 95

5.1 List of selected tree traits for the Sumatra and Sulawesi samples . . . . . 120

5.2 Estimated SEM coefficients . . . . . . . . . . . . . . . . . . 128

6.1 Stand and climate conditions during the study interval . . . . . . . . . . 153

6.2 List of variables . . . . . . . . . . . . . . . . . . . . 156

6.3 Estimated PSEM coefficients . . . . . . . . . . . . . . 160

7.1 Estimated vulnerability curve parameters . . . . . . . . . . . . 186 

Curriculum vitae
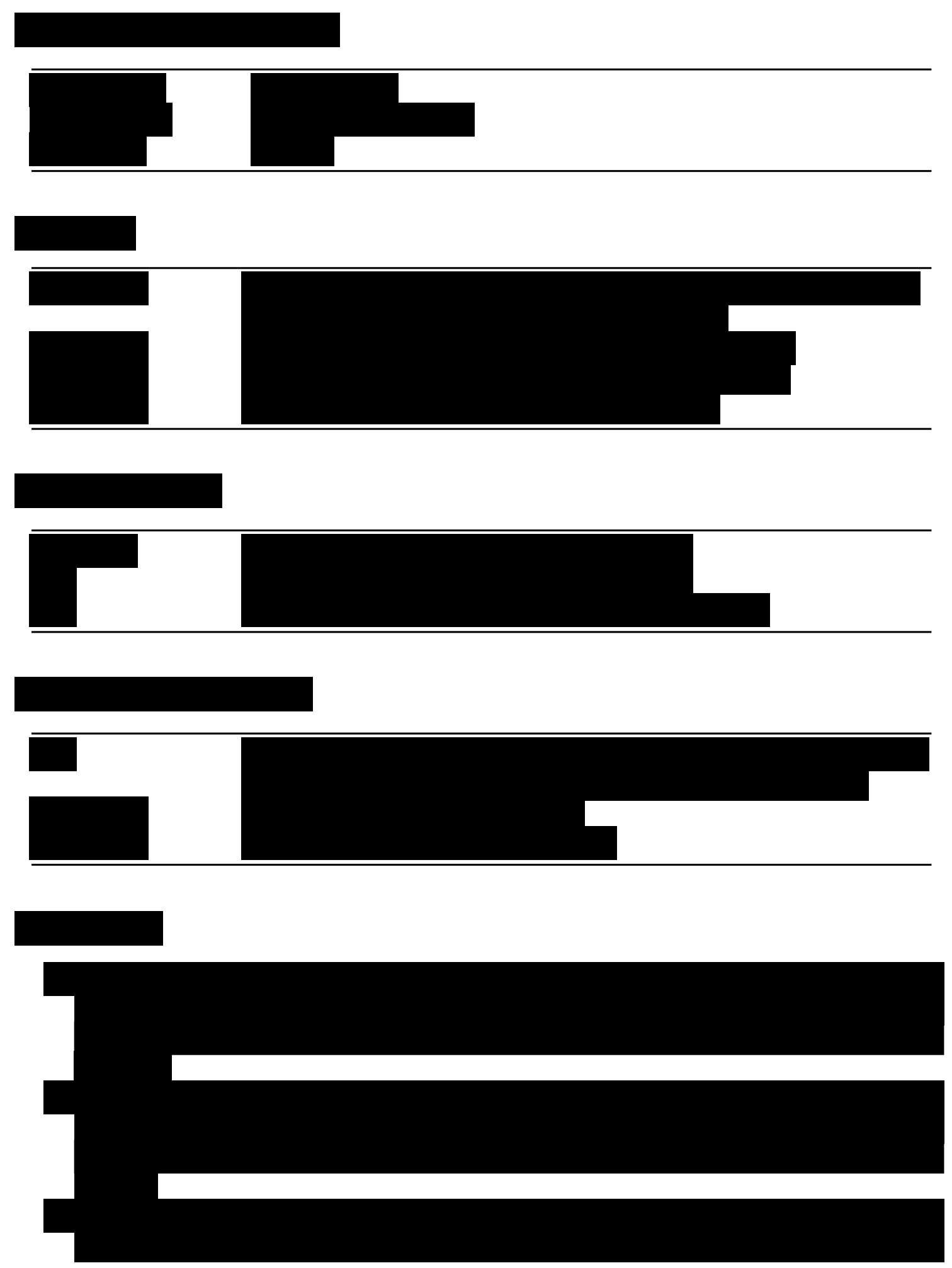


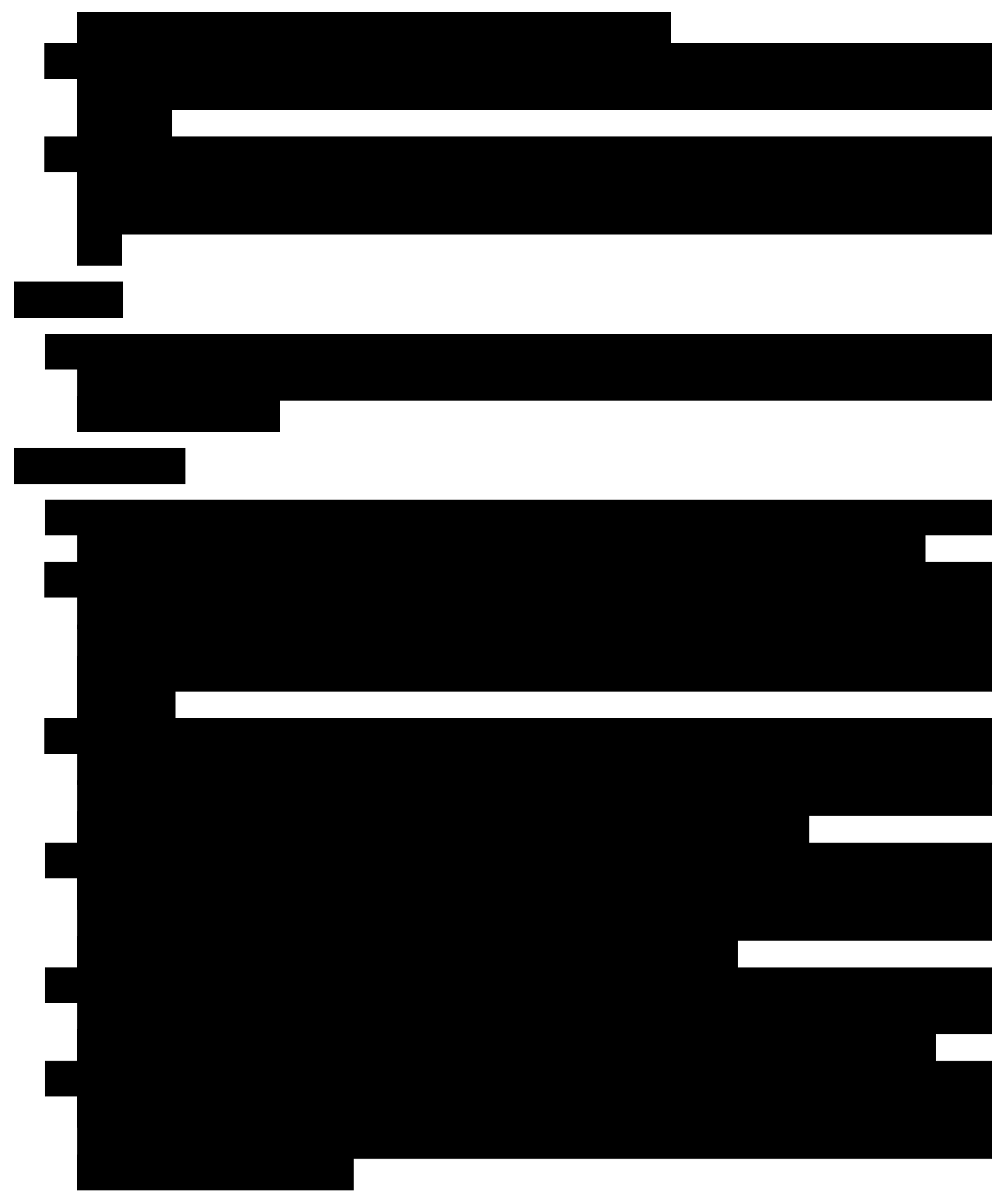




\section{Acknowledgements}

Without the invaluable help, advice and guidance of numerous friends and colleagues I would never have been able to finish this seemingly gigantic project. I am grateful for being able to be a part of this!

First and foremost I want to extend my gratitude to my advisors Prof. Dr. Christoph Leuschner and Prof. Dr. Bernhard Schuldt for offering me the opportunity to show my scientific aptitude in this fascinating and challenging $\mathrm{PhD}$ project. In particular I am greatly obliged to Bernhard for all the trust he put in me, his support, patience, advice and excellent mentoring. I am looking forward to working on our future projects in Würzburg!

I further wish to thank Prof. Dr. Steven Jansen for his support as a part of my advisory committee, as well as Prof. Dr. Dirk Hölscher, Prof. Dr. Holger Kreft, Prof. Dr. Hermann Behling and Prof. Dr. Erwin Bergmeier for their willingness to take part in my examination committee.

I am incredibly thankful for all the support by the German field assistants that accompanied me to Costa Rica, Sebastian Fuchs, Katja Steinhoff and Adrian Fröhlich - thanks for being with me in these often complicated times!

I further want to thank Sebastian Fuchs, Katja Steinhoff and Nathalie Rodenbach for proofreading part of this work.

Muchas gracias a mis colegas de Cartago, más que todo Dagoberto Arias, Marvin Castillo y Juan Carlos Valverde por la colaboración que hizo posible este proyecto, los demás colegas del Instituto Tecnológico de Costa Rica, Milena Gutierrez y el equipo de la Estación Experimental Forestal Horizontes por el apoyo práctico durante el trabajo del campo, y amis asistentes del campo Erick Naranjo, Mario Quesada, Pedro Rojas y Maynor Rodriguez.

Special thanks go to all my coauthors, particularly to Dr. Alexander Cobb, Dr. Martyna Kotowska and Dr. Henrik Hartmann. I am grateful for the opportunity to work with you!

Many thanks to my colleagues in Göttingen and Würzburg - there are too many of you to mention, you know who you are.

My sincere gratitude is extended to the $\mathrm{R}$ and open source software community, without whom scientific work in its present form would not be possible.

Finally, I want to thank my closest friends - Martin Bannenberg, Philipp Zug, Sebastian Zinke and Lana Heinrich - for being there; my family - Ulrike, Alex, and Leonhard Link and Sophia Kerber - for their unending support; and lastly and most importantly Kerstin Pierick for being the most amazing human being to ever walk this earth. 



\section{Declaration of originality and certificate of ownership}

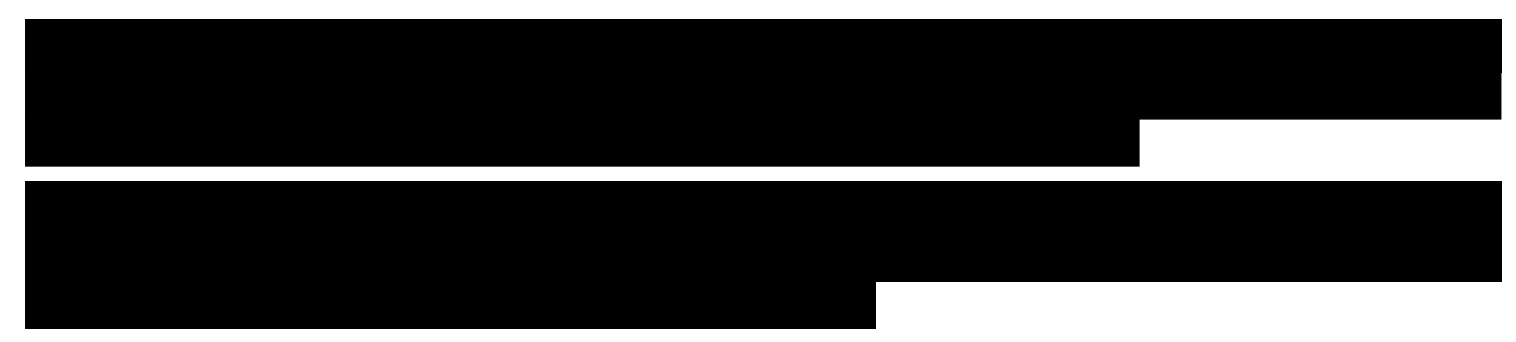

